Key Words:

In-Tank SCIX

Cs Separation

IX sRF resin

Batch Tests

Small Columns

Retention:

Permanent

\title{
REAL WASTE TESTING OF SPHERICAL RESORCINOL- FORMALDEHYDE ION EXCHANGE RESIN
}

\author{
Charles A. Nash \\ Mark R. Duignan
}

OCTOBER 30, 2009

Savannah River National Laboratory

Savannah River Nuclear Solutions

Aiken, SC 29808 


\section{DISCLAIMER}

This work was prepared under an agreement with and funded by the U.S. Government. Neither the U. S. Government or its employees, nor any of its contractors, subcontractors or their employees, makes any express or implied:

1. warranty or assumes any legal liability for the accuracy, completeness, or for the use or results of such use of any information, product, or process disclosed; or

2. representation that such use or results of such use would not infringe privately owned rights; or

3. endorsement or recommendation of any specifically identified commercial product, process, or service.

Any views and opinions of authors expressed in this work do not necessarily state or reflect those of the United States Government, or its contractors, or subcontractors.

Printed in the United States of America

Prepared for

U.S. Department of Energy 
Key Words:

In-Tank SCIX

Cs Separation

IX sRF resin

Batch Tests

Small Columns

Retention:

Permanent

\section{REAL WASTE TESTING OF SPHERICAL RESORCINOL- FORMALDEHYDE ION EXCHANGE RESIN}

Charles A. Nash

Mark R. Duignan

OCTOBER 30, 2009

Savannah River National Laboratory

Savannah River Nuclear Solutions

Savannah River Site

Aiken, SC 29808 


\section{REVIEWS AND APPROVALS}

Charles A. Nash, Author, SRNL/Separations Science Programs

Date

Mark R. Duignan. Author, SRNL/Engineering Development Laboratory

Date

Bill King, Technical Reviewer, SRNL/Advanced Characterization and Processing

Date

Samuel D. Fink, Manager, SRNL/Separations Science Programs

Date

B. J. Giddings, Manager, SRNL/Engineering Development Laboratory

Date

Frank M. Pennebaker, Manager, SRNL/ Advanced Characterization and Processing

Date

S. L. Marra, Manager, SRNL E\&CPT Research Programs

Date

Bill R. Wilmarth, Sector Manager, EM Technology Integration Office

Date 


\section{TABLE OF CONTENTS}

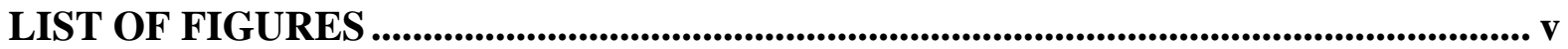

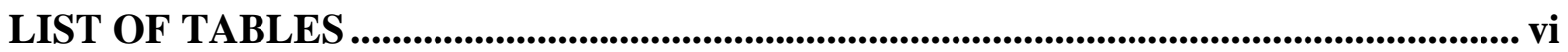

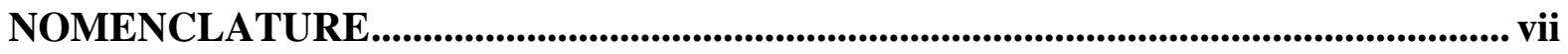

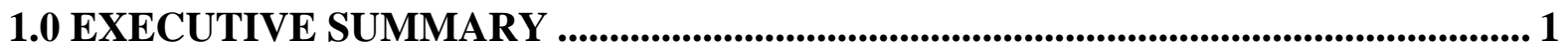

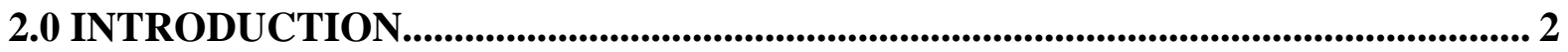

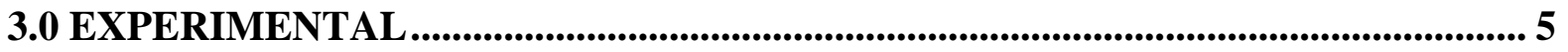

3.1 RESIN HISTORY AND HANDLING ........................................................... 5

3.2 SIMULANT SOLUTION ....................................................................................... 5

3.3 RADIOACTIVE DISSOLVED SALT SOLUTION ................................................... 6

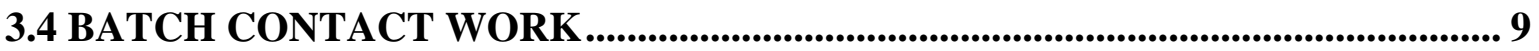

3.5 SIMULANT AND REAL-WASTE WITH SMALL SCALE IX COLUMNS ......... 9

3.5.1 Spherical Resorcinol Formaldehyde (SRF) ........................................................ 10

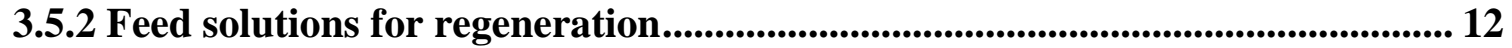

3.5.3 Test equipment .................................................................................................................... 12

3.5.4 Test Matrix............................................................................................................................ 23

3.5.5 Test Operation ............................................................................................................... 25

4.0 RESULTS AND DISCUSSION

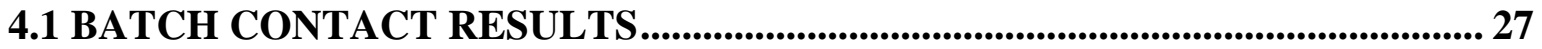

4.1.1 Batch contact Set 1: Effect of contact time ....................................................... 27

4.1.2 Batch contact Set 2: Effect of phase ration and initial Cs concentration......... 28

4.1.3 Batch contact Set 3 - Effect of high initial Cs concentration ............................. 29

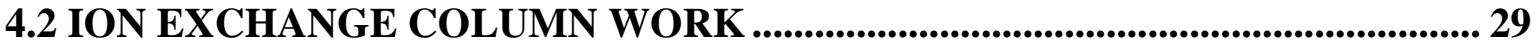

4.2.1 Cesium results with Tank 2F simulant....................................................... 29

4.2.2 Cesium results with SRS real waste.............................................................. 34

4.2.3 Comparison of cesium results: SRS simulant versus real-waste ...................... 40

4.2.4 Bed changes that occur during elution of sRF resin ....................................... 43

4.2.5 Miscellaneous analytes ..................................................................................................... 45

4.2.6 Analyses of composites of eluates during the real-waste test ........................... 47

4.3 TCLP RESULTS TO DISPOSE OF SRF RESIN ............................................... 49

5.0 CONCLUSTIONS......................................................................................... 50

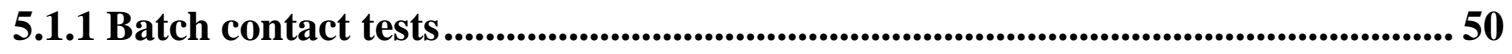

5.1.2 Ion exchange column tests ........................................................................................... 51

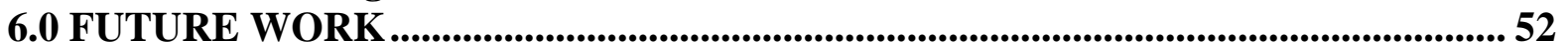

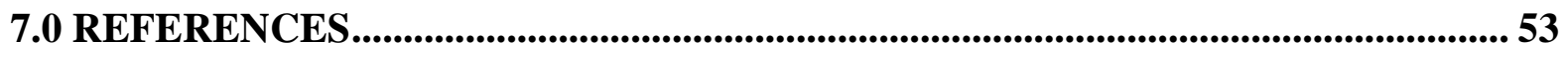

8.0 ACKNOWLEDGMENTS .................................................................................... 55

APPENDIX A. BATCH CONTACT DATA ........................................................................ 56

APPENDIX B. DATA SHEETS: SIMULANT \& REAL-WASTE TESTS.................. 58

APPENDIX C. R\&D DIRECTION FOR REAL-WASTE TEST ................................. 69 


\section{LIST OF FIGURES}

Figure 1. New Spherical Resorcinol Formaldehyde resin beads in H-form.... 10

Figure 2. Sample of sRF resin before pretreatment of approximately $80 \mathrm{~mL}$. It is shown in

$\mathrm{H}$-form and stored in deionized water. 11

Figure 3. Flow path schematic of two-column test rig in two-column operation.................. 13

Figure 4. Schematic of test rig with feed reservoirs, effluent reservoirs, tubing runs, valves,

strip heater, column thermocouples, and pump discharge pressure gauge ..................... 14

Figure 5. Test rig in ventilation hood demonstrating its size while taking a sample............. 18

Figure 6. Test rig setup for the simulant test phase. (The real-waste setup was similar.) ..... 19

Figure 7. Close-up of pumps, waste feed reservoir, and temperature monitors ................... 20

Figure 8. Close-up of the reservoirs for regeneration solutions, the two effluent containers,

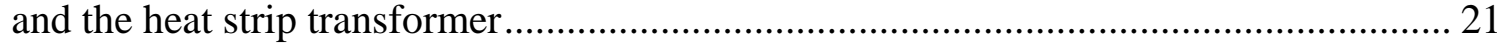

Figure 9. Picture contains the control panels for the feeds and valves, the discharge pump pressure and both IX columns. Note the color difference of the columns. The lighter colored resin to the right had been eluted (i.e., it was in H-form) while the left column

was just starting elution (i.e., it was still in Na-form) ............................................... 22

Figure 10. SCIX test equipment during radioactive waste processing .............................. 22

Figure 11. Lead column effluent Cs for Cycle 1 with simulant......................................... 30

Figure 12. Lead column effluent Cs for Cycles 1 and 2 with simulant .............................. 31

Figure 13. Lead column Cs adsorption for Cycle 1 with simulant [Note, the scale is

amplified to show the features near 5\% breakthrough.] .......................................... 32

Figure 14. Lead column Cs adsorption for Cycle 2 with simulant ..................................... 32

Figure 15. Lead column Cs elution during Cycles $1 \& 2$ of the simulant test phase............. 33

Figure 16. Lead column Cs elution during Cycles 1 of the simulant test phase................... 34

Figure 17. Lead column Cs elution during Cycle 2 of the simulant test phase .................... 34

Figure 18. Lead column effluent Cs for Cycle 1 with SRS radioactive waste ...................... 36

Figure 19. Lead column effluent Cs for Cycle 2 with SRS radioactive waste ..................... 36

Figure 20. Lead column Cs adsorption for Cycle 1 with SRS radioactive waste.................. 37

Figure 21. Lead column Cs elution during Cycle 1 of the real waste test phase ................... 38

Figure 22. Lead column Cs elution during Cycle 2 of the real waste test phase .................. 39

Figure 23. Lead column Cs elution during Cycles $1 \& 2$ of the real waste test phase .......... 40

Figure 24. Cs loading of the Lead column for both the simulated waste and real waste ...... 41

Figure 25. Cs loading of the Lag column for both the simulated waste and real waste ........ 42

Figure 26. Cs elution for both the simulant and real waste test phases ............................. 42

Figure 27. Cs elution for both the simulant and real waste test phases ............................. 43

Figure 28. Cs elution for both the simulant and real waste test phases .............................. 44

Figure 29. sRF resin color and height shrinkage during elution as it changes from $\mathrm{pH}=14$ to

$\mathrm{pH}=1$ [Approximate time progression from left to right: 0, 12, 45, $64 \mathrm{~min}$.] ................. 45

Figure 30. Effect of ${ }^{126} \mathrm{Sb}$ passing through the sRF resin during real-waste loading ............ 46

Figure 31. Select analyte concentrations in effluent stream during the elution of the Cycle 1

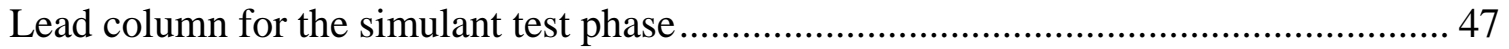

Figure 32. Plot of the Batch Contact Data and a Power Law Fit ...................................... 50 


\section{LIST OF TABLES}

Table 1. Characteristics of selected SRS stored waste considered for treatment ................... 3

Table 2. Waste simulant used for the SCIX test ............................................................... 6

Table 3. Chemical Components for "Old Feed" ................................................................ 7

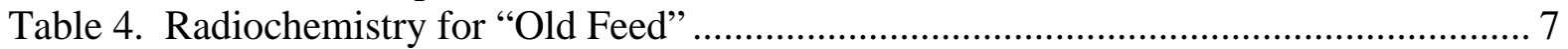

Table 5. Chemical Components for "New Feed" ............................................................... 8

Table 6. Radiochemistry for "New Feed"..................................................................... 8

Table 7. Internal volumes of flow paths throughout the SCIX test rig................................ 15

Table 8. Valve position for each of the 6 cycle steps, plus a "Internal Flush" step to remove

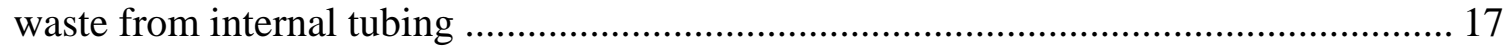

Table 9. Target test matrix for 2-Column SCIX test (see following table for X1-X4)......... 23

Table 10. Planned Feed Volumes and Times to Process (see preceding table).................... 24

Table 11. Set 1: Batch Contacts with Real Dissolved Saltcake......................................... 27

Table 12. Set 2: Batch contacts with a Mixture of Real waste and Simulant ....................... 28

Table 13. Set 3: Nonradioactive Batch Contacts ............................................................ 29

Table 14. Stable elements in eluate composites from the real-waste test phase.................. 48

Table 15. Radiochemistry of Eluate Composites.......................................................... 49

Table 16. F-Factor Data For Batch Contacts ................................................................ 56

Table 17. F-Factor Data for Resin used in the Columns................................................ 56

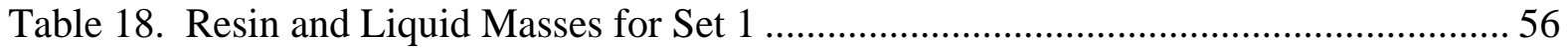

Table 19. Resin and Liquid Masses for Set 2 ............................................................. 57

Table 20. Part A - Cycle 1 Simulant Data Sheet............................................................. 58

Table 21. Part B - Cycle 1 Simulant Data Sheet.............................................................. 59

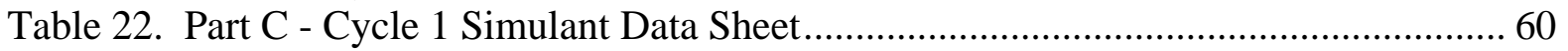

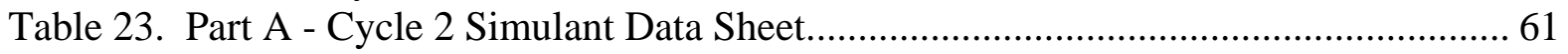

Table 24. Part B - Cycle 2 Simulant Data Sheet................................................................ 62

Table 25. Part C - Cycle 2 Simulant Data Sheet............................................................... 63

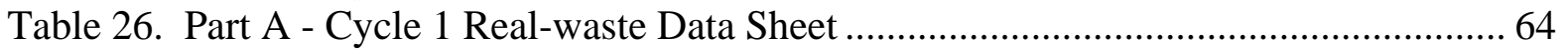

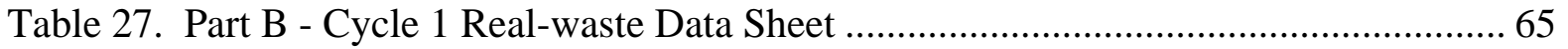

Table 28. Part C - Cycle 1 Real-waste Data Sheet ........................................................... 66

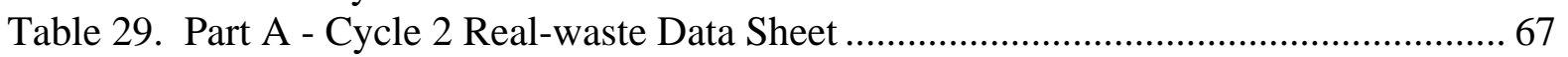

Table 30. Part B - Cycle 2 Real-waste Data Sheet .......................................................... 68 


\section{NOMENCLATURE}

ACTL Aiken County Technology Laboratory (helped with simulant development)

$\mathrm{AD}$

BV

$\mathrm{BH}$

$\mathrm{C} / \mathrm{C}_{0}$

$\mathrm{cm}$

$\mathrm{cP}$

$\mathrm{g}$

g/cC

$\mathrm{g} / \mathrm{mL}$

GEL

h

IX

ICP-ES

ICP-MS

eHAP

L

lpm

media

M\&TE

meq

mmol

ORNL

psi

QA

$Q_{\text {final }}$

resin

R\&D

RF

RPP

SCIX

SRF

SRNL

Std. Dev.

T1 or T2

TCLP

TTQAP

WTP
Analytical Development, Savannah River National Laboratory

resin bed volume

Bed Height (of IX resin)

column product concentration divided by feed concentration

Centimeter

centipoise

grams (mass)

gram/cubic centimeter

gram/milliliter

GEL Laboratories, LLC (supplied some of analyte results)

hour

ion exchange

Inductively Coupled Plasma -Emission Spectroscopy

Inductively Coupled Plasma - Mass Spectroscopy

electronic Hazards Assessment Package

Length

liters per minute

IX resin - or the material that is used to adsorb ions (cesium in this case)

Measurement and Test Equipment (calibrated per QA program)

milliequivalents

millimoles

Oak Ridge National Laboratory

pounds per square inch

Quality Assurance

batch contact resin loading after reaching equilibrium (Defined in Section 4.1)

IX media - or the material that is used to adsorb ion (cesium in this case)

Research and Development

Resorcinol-formaldehyde (ion exchange resin)

River Protection Project

Small Column Ion Exchange

Spherical Resorcinol-Formaldehyde resin

Savannah River National Laboratory

standard deviation

temperatures from thermocouples used on the test rig

Toxicity Characteristic Leaching Protocol (EPA SW-846 protocols)

Technical Task and Quality Assurance Plan

Waste Treatment and Immobilization Plant 


\subsection{EXECUTIVE SUMMARY}

This report presents data on batch contact and column testing tasks for spherical resorcinolformaldehyde (sRF) resin. The testing used a non-radioactive simulant of SRS Tank 2F dissolved salt, as well as an actual radioactive waste sample of similar composition, which are both notably high in sodium (6 M). The resin was Microbeads batch 5E-370/641 which had been made on the hundred gallon scale. Equilibrium batch contact work focused on cesium at a temperature of $25^{\circ} \mathrm{C}$ due to the lack of such data to better benchmark existing isotherm models. Two campaigns were performed with small-scale ion exchange columns, first with Tank 2F simulant, then with actual dissolved salt in the Shielded Cells.

An extrapolation of the batch contact results with radioactive waste over-predicted the cesium loaded onto the IX sRF resin bed by approximately $11 \%$. This difference is not unexpected considering uncertainties from measurement and extrapolation and because the ion exchange that occurs when waste flows through a resin bed probably cannot reach the same level of equilibrium as when waste and resin are joined in a long term batch contact. Resin was also characterized to better understand basic chemistry issues such as holdup of trace transition metals present in the waste feed streams.

The column tests involved using two beds of sRF resin in series, with the first bed referred to as the Lead column and the second bed as the Lag column. The test matrix included two complete IX cycles for both the simulant and actual waste phases. A cycle involves cesium adsorption, until the resin in the Lead column reaches saturation, and then regenerating the sRF resin, which includes eluting the cesium. Both the simulated and the actual wastes were treated with two cycles of operation, and the resin beds that were used in the Lead and Lag columns of simulant test phase were regenerated and reused in the actual waste test phase.

This task is the first to demonstrate the treatment of SRS waste with sRF resin and the tests clearly demonstrated cesium decontamination for actual waste. The results of the column tests were similar for both the simulated and the actual waste and demonstrated Cs removal with sRF from both wastes. For a flowrate of 1.4 bed volumes (BV)/hour at $25^{\circ} \mathrm{C}$ those results with sRF resin were:

- Simulant and actual waste results are equivalent

- Cs breakthrough began between 200 and 250 BV

- Cs breakthrough reached $100 \%$ at around $400 \mathrm{BV}$

- Cs breakthrough curve from $5 \%$ to $100 \%$ is approximately linear

- Cs elution with $0.5 \mathrm{M} \mathrm{HNO}_{3}$ starts at $2 \mathrm{BV}$ and ends at $6 \mathrm{BV}$

- Most, if not all, of Cs adsorbed during treatment is released during elution

- At $100 \%$ breakthrough of Cs the resin bed adsorbs approximately $85 \%$ of full capacity before detection in the effluent; the remaining $15 \%$ is adsorbed at saturation

- Approximately $90 \%$ of resin bed changes (color and volume) are complete by $6 \mathrm{BV}$

- During elution the resin shrinks to about $80 \%$ of its fully working (sodium form) BV 


\subsection{INTRODUCTION}

Removal of cesium from stored liquid waste at the Savannah River Site (SRS) will be performed on a large scale by solvent extraction at the Salt Waste Processing Facility. To support tank closure needs at SRS and Hanford there is a more immediate need to treat some of that salt waste. To address this potential, another separation technology is under investigation that would allow in situ treatment of stored waste called the Small Column Ion Exchange (SCIX). The word "small" is relative because a column may be as tall as 20 feet and 2 feet in diameter, but what is meant by "small column" is that a column will be small with respect to industrial sized columns so that it can completely fit inside SRS waste storage tanks that are approximately 35 feet deep.

Ion exchange is a mature technology to remove cesium from liquid wastes. The resin under study was designed by the Savannah River National Laboratory (Ebra and Wallace, 1983) to remove cesium from highly alkaline wastes, including the radioactive ${ }^{137} \mathrm{Cs}$, which makes up about $25 \%$ of the total cesium. The resin is a resorcinol $\left(\mathrm{C}_{6} \mathrm{H}_{6} \mathrm{O}_{2}\right)$ formaldehyde $\left(\mathrm{CH}_{2} \mathrm{O}\right)$ polymer and is referred to as RF. This resin has a strong preference for $\mathrm{H}^{+}$and can be eluted by using acid to remove $\mathrm{Cs}^{+}$and its competitors. Its relative affinities has been determined (Smith, 2007) to be $\mathrm{H}^{+}>\mathrm{Cs}^{+}>\mathrm{Rb}^{+}>\mathrm{K}^{+}>\mathrm{Na}^{+}$. As such, $\mathrm{RF}$ resin can withstand multiple cycles of loading and eluting before its usefulness is exhausted. However, the original form of RF resin contained ground shards with sharp-edged and irregular shapes, resulting in significant flow resistances and inconsistent results as shards cracked and broke down creating fines, as seen with CST resin (Welch et al., 2000) and SL-644 resin ${ }^{\dagger}$ (Adamson et al., 2006; Arm et al., 2006). Because of the poor hydraulic performance of the resin in shardform, the RF resin was improved during work for the Waste Treatment and Immobilization Plant (WTP) of the DOE River Protection Project (RPP) that is being built at the Hanford Site in the state of Washington. To address the hydrodynamic issues, RF resin was deposited on the surface of microspheres by Microbeads AS, in Skedsmokorset, Norway, leading to much better and consistent flow performance. (Duignan et al., 2008, Arm et al., 2006, Adamson et al., 2006). In its spherical form RF is referred to as sRF.

There has been considerable research both computationally and experimentally with sRF on radioactive alkaline wastes, both simulated and real; however, most of those studies have been limited to wastes stored at the Hanford Site (Adamson et al., 2006, Fiskum et al., 2006a, 2006b, Nash et al, 2006). At least one significant difference between some of those wastes is the concentration of potassium. As mentioned above, potassium is a competitor of cesium for sites on the sRF resin so its presence will affect loading performance. In general, SRS wastes have lower concentrations of potassium $<0.05 \mathrm{M}$ (see Table 1). Besides not having experimental data of SRF performance with SRS wastes, hitherto computational modeling has a need for benchmark data because of model discrepancies leading the modeler (Smith, 2007) to conclude that: "(Experimental) testing with SRS waste would be required to confirm the expected performance.”

\footnotetext{
${ }^{\dagger}$ CST and SL-644 are two cesium specific IX resins. CST is a Crystalline Silicotitanate resin trademarked as IONSIV IE-911 by UOP LLC, and SL-644 is trademarked as SupLig-644 by IBC Advanced Technologies Inc.
} 
To improve existing IX models this task chose a combination of experiments to develop the necessary database. The first important selection was the SRS waste to use among the current five tanks, Table 1, under consideration for closure. Tank 2F was chosen based on the low concentration of potassium and its availability as a simulant. The experiments performed involved batch and small column tests with "small," in this case, meaning a resin bed height of approximately $6.5 \mathrm{~cm}$ and diameter of approximately $1.5 \mathrm{~cm}$.

Table 1. Characteristics of selected SRS stored waste considered for treatment

\begin{tabular}{|c|c|c|c|c|c|c|}
\hline \multicolumn{7}{|c|}{ Dissolved Saltcake Compositions (1) } \\
\hline Species & Unit & Tank 1F & Tank 2F & Tank 3F & Tank $37 \mathrm{H}$ & Tank $41 \mathrm{H}$ \\
\hline $\mathrm{Na}^{+1}$ & M & 6 & 6 & 6 & 6 & 6 \\
\hline $\mathrm{NO}_{3}^{-1}$ & M & 3.07 & 4.19 & 4.60 & 2.26 & 2.42 \\
\hline $\mathrm{NO}_{2}^{-1}$ & M & 0.30 & 0.15 & 0.29 & 0.74 & 0.69 \\
\hline $\mathrm{OH}^{-1}$ & M & 1.41 & 0.76 & 0.55 & 1.97 & 1.81 \\
\hline $\mathrm{ALO}_{2}^{-1}$ & M & 0.30 & 0.29 & 0.06 & 0.35 & 0.34 \\
\hline $\mathrm{CO}_{3}^{-2}$ & M & 0.18 & 0.13 & 0.08 & 0.11 & 0.13 \\
\hline $\mathrm{SO}_{4}^{-2}$ & $\mathrm{M}$ & 0.25 & 0.03 & 0.10 & 0.15 & 0.15 \\
\hline $\mathrm{PO}_{4}^{-3}$ & M & 0.003 & 0.005 & 0.003 & 0.01 & 0.01 \\
\hline $\mathrm{CL}^{-1}$ & M & 0.03 & 0.003 & 0.01 & 0.03 & 0.03 \\
\hline $\mathrm{F}^{-1}$ & M & 0.06 & 0.003 & 0.025 & 0.03 & 0.03 \\
\hline $\mathrm{K}^{+1}$ & M & 0.02 & 0.007 & 0.002 & 0.01 & 0.01 \\
\hline $\mathrm{Cs}^{+1}$ & M & 181.0E-6 & $17.0 \mathrm{E}-6$ & $63.5 \mathrm{E}-6$ & 108.0E-6 & $7.5 \mathrm{E}-6$ \\
\hline $\mathrm{Sr}^{+1}$ & M & 308.0E-6 & 308.0E-6 & 164.0E-6 & 3.0E-6 & $3.0 \mathrm{E}-6$ \\
\hline $\mathrm{Rb}^{+1}$ & M & 21.9E-6 & 6.3E-6 & $21.9 \mathrm{E}-6$ & $11.8 \mathrm{E}-6$ & $2.6 \mathrm{E}-6$ \\
\hline \multicolumn{7}{|c|}{ Physical Properties at $25^{\circ} \mathrm{C}(2)$} \\
\hline Density & $\mathrm{g} / \mathrm{mL}$ & 1.240 & 1.246 & 1.245 & 1.232 & 1.234 \\
\hline Viscosity & $\mathrm{cP}$ & 2.39 & 2.14 & 1.83 & 2.59 & 2.54 \\
\hline \multicolumn{7}{|c|}{$\begin{array}{l}\text { (1) Values were taken from Tran, 2007: Table } 4 \\
\text { (2) Values were calculated with software by OLI Systems, Inc. as shown } \\
\text { in Smith, 2007: Table 6-3 }\end{array}$} \\
\hline
\end{tabular}

Batch tests contact IX resin, that starts at some known state, with a solution to treat until both come to equilibrium. These tests are used to study a large range of parameters (e.g., different temperatures, concentrations of $\mathrm{Cs}, \mathrm{Rb}$, and $\mathrm{K}$ ) which are fundamental to benchmark resin models. However, a solution processed through an IX facility generally never comes to an ionic equilibrium with the IX resin. Therefore, the fundamental approach is to measure adsorption at prototypic IX conditions to determine the actual treatment efficiency in IX columns and establish parameters for the IX model. Moreover, once the resin is fully loaded it needs to be eluted and regenerated for further use; therefore, that regeneration process needs to be understood before designing the full-scale unit. The regeneration process with 
sRF was perfected using Hanford Site wastes (Adamson et al., 2006) and was incorporated into the present tests. To evaluate flow through resin columns, Smith (2007) modeled the effect of temperatures (i.e., $25^{\circ} \mathrm{C}, 35^{\circ} \mathrm{C}$, and $45^{\circ} \mathrm{C}$ ) and found that as temperature increased cesium loading decreased; therefore, the lower temperature was selected for testing. The models further evaluated waste treatment at flowrates [in terms of (resin) bed volume (BV)] of $0.7 \mathrm{BV} / \mathrm{h}, 1.4 \mathrm{BV} / \mathrm{h}$, and $2.8 \mathrm{BV} / \mathrm{h}$. The resin was found to be more effective at the slower rates, but it takes longer to treat equivalent volumes. The middle treatment flowrate of 1.4 $\mathrm{BV} / \mathrm{h}$ was chosen for testing.

The other important feature selected for the column test was the intended Lead-Lag design where the Lead IX column does most of the cesium separation with the Lag column, connected in series, capturing cesium that leaves the Lead column once the Lead column approaches saturation. At some design level of saturation the waste treatment will be stopped, ending one cycle of operation. To begin the next cycle, the Lead column is regenerated, which is then moved to the Lag position. The partially loaded Lag column is moved to the Lead position and the process repeats.

After many cycles of treatment and regeneration the sRF will eventually lose its effectiveness and will need replacement. To properly handle the spent resin it must have a well defined path forward for disposal as a hazardous waste. To assist in the development of a disposition plan the column test finished by removing the spent resin after converting to H-form with acid and then grinding for testing. The resin was subjected to the Federal EPA TCLP (Toxicity Characteristic Leaching Procedure) method that evaluates it for organic and inorganic analytes; those data will be included in a second report.

This work was governed by a Task Technical and Quality Assurance Plan (Nash and Duignan, 2009). Safety was controlled by electronic Hazard Assessment Package (SRNLL3000-2009-00006, rev. 0). Data were recorded in a laboratory notebook (Nash, 2008). 
SRNL-STI-2009-00594, REVISION 0

\subsection{EXPERIMENAL}

\subsection{RESIN HISTORY AND HANDLING}

Batch 5E-370/641 of the spherical RF ion exchange resin was purchased from Microbeads AS in Skedsmokorset, Norway and shipped in acid form. As it was received by SRNL in 2005, the resin has been stored in hydrogen form under deionized (DI) water in sealed containers. Storage under such conditions maintains the resin stable. The specific material had not previously seen pretreatment or use and was procured for large-scale column work (Adamson et al., 2006). Random samples of resin were taken from one of the sealed containers (Drum \#3) and combined to provide about $150 \mathrm{~mL}$ of resin for this work. This sub-sample was stored in a wide-mouth polyethylene bottle in a metal paint can so that the resin would not be exposed to light.

Protocol P1 part B (Nash, 2004) was performed initially for the resin to be used in batch and column work. Thus, resin was converted to sodium form and back to hydrogen form to swell and clean it. The resin was returned to DI water storage in a polyethylene bottle/paint can.

\subsection{SIMULANT SOLUTION}

Before subjecting the IX test rig to radioactive waste a considerable amount of information can be obtained by testing with a non-radioactive simulant. A simulant test is useful to perfect the test matrix, understand and refine the operation of the test equipment, and evaluate resin performance. Furthermore, radioactive testing is expensive, and expenses could be minimized with effective simulant testing.

From a previous SRS test (Herman et al., 2009), a portion of Tank 2F simulant remained that could be utilized for this work, which was made to the Tank $2 \mathrm{~F}$ specifications listed in a report on a SCIX computational modeling (Smith, 2006; Table 2-1). Of those five tanks in Table 1, Tank 2F concentration of potassium was $0.007 \mathrm{M}$. This was important because potassium is a competitor with cesium for sites on the RF resin under study. Because of the low K concentration, the separation of cesium from the treated waste was expected to be more efficient than wastes with higher concentrations of potassium, such as tanks stored at the Hanford Site. Table 2 compares the make-up of the target waste to that of the 10 liters of prepared simulant. The simulant was analyzed for this test to verify its contents. The concentrations compare well especially for the species (e.g., $\mathrm{Na}$, Cs, and K) which readily load on the RF resin. All measured values are accurate to $\pm 10 \%$ with the exception of ICPMS, which is estimated at $\pm 20 \%$. Despite the high uncertainty, the ICP-MS value for cesium was an exact match with the target. Sodium, potassium, cesium and free hydroxide are the primary components affecting ion exchange modeling. These constituents were found to be well matched compared to the Tank $2 \mathrm{~F}$ target. Note, the cesium in the non-radioactive simulant is all ${ }^{133} \mathrm{Cs}$. In real waste approximately $25 \%$ of the cesium content is made of 
${ }^{137} \mathrm{Cs}$, as was mentioned in the Introduction; however, the RF resin does not distinguish between the different isotopes.

Table 2. Waste simulant used for the SCIX test

\begin{tabular}{|c|c|c|c|c|}
\hline Species & Unit & $\begin{array}{c}\text { Tank 2F } \\
\text { Target (1) } \\
\end{array}$ & $\begin{array}{c}\text { Tank 2F } \\
\text { Simulant (2) } \\
\end{array}$ & $\begin{array}{c}\text { Percentage } \\
\text { Difference }\end{array}$ \\
\hline $\mathrm{Na}^{+1}$ & $M$ & 6.0 & 6.26 & $4 \%$ \\
\hline $\mathrm{NO}_{3}^{-1}$ & $M$ & 4.19 & 4.94 & $18 \%$ \\
\hline $\mathrm{NO}_{2}^{-1}$ & $M$ & 0.149 & 0.171 & $15 \%$ \\
\hline $\mathrm{OH}^{-1}$ & $M$ & 0.76 & 0.80 & $5 \%$ \\
\hline Total $\mathrm{OH}$ & $\mathrm{M}$ & 1.31 & 1.39 & $6 \%$ \\
\hline $\mathrm{SO}_{4}^{-2}$ & $\mathrm{M}$ & 0.032 & 0.033 & $3 \%$ \\
\hline $\mathrm{PO}_{4}^{-3}$ & $\mathrm{M}$ & 0.005 & $<0.01$ & $<100 \%$ \\
\hline $\mathrm{Al}$ & $\mathrm{M}$ & 0.26 & 0.32 & $23 \%$ \\
\hline $\mathrm{F}^{-1}$ & $\mathrm{M}$ & 0.0029 & $<0.013$ & $<348 \%$ \\
\hline $\mathrm{K}^{+1}$ & $M$ & 0.007 & 0.0076 & $8 \%$ \\
\hline $\mathrm{Cs}^{+1}$ & $M$ & 1.70E-05 & 1.69E-05 & $-0.4 \%$ \\
\hline $\mathrm{P}$ & $\mathrm{M}$ & 0.0050 & 0.0053 & $6 \%$ \\
\hline $\mathrm{S}$ & $\mathrm{M}$ & 0.032 & 0.037 & $14 \%$ \\
\hline $\mathrm{pH}$ & - & 14 & 14 & $0 \%$ \\
\hline density $\left(25^{\circ} \mathrm{C}\right)$ & $\mathrm{g} / \mathrm{mL}$ & 1.246 & 1.306 & $5 \%$ \\
\hline
\end{tabular}

\subsection{RADIOACTIVE DISSOLVED SALT SOLUTION}

Two batches of dissolved radioactive salt solution, from Tanks 25 and 41, were prepared in the course of this work. The first mixture was made and all radioactive batch contact work drew from it. This is referred to as "Old Feed" and its composition is shown the Tables 3 and 4. Subsequently, a greater volume of solution was needed for the upcoming radioactive column campaign. A "New Feed” was prepared using "Old Feed” and additional stored liquid wastes from Tank 22 and more of Tank 41. The compositions of the Tanks 22 and 41 materials come from another characterization report (Peters et al., 2008). Radioactive column work used only "New Feed" and its composition is shown in Table 5 and 6. As can be seen in Table 5, the resulting mixture, called "New Feed," is relatively close to the concentration of Tank $2 \mathrm{~F}$ especially for $\mathrm{Na}, \mathrm{Cs}, \mathrm{K}$, and $\mathrm{OH}$. Dissolved saltcake can be expected to be high in nitrate and aluminum and low in fluoride and phosphate. 
Table 3. Chemical Components for "Old Feed"

\begin{tabular}{|c|c|c|c|c|}
\hline Species & Unit & $\begin{array}{c}\text { Tank 2F Target } \\
\text { (1) }\end{array}$ & $\begin{array}{c}\text { SRS Tanks } \\
\text { Real waste (2) }\end{array}$ & $\begin{array}{c}\text { Percentage } \\
\text { Difference }\end{array}$ \\
\hline $\mathrm{Na}^{+1}$ & $\mathrm{M}$ & 6.0 & 6.18 & $3 \%$ \\
\hline $\mathrm{NO}_{3}^{-1}$ & $\mathrm{M}$ & 4.19 & 3.42 & $-18 \%$ \\
\hline $\mathrm{NO}_{2}^{-1}$ & $\mathrm{M}$ & 0.149 & 0.187 & $26 \%$ \\
\hline $\mathrm{OH}^{-1}$ & $M$ & 0.76 & 0.714 & $-6 \%$ \\
\hline Total $\mathrm{OH}$ & $\mathrm{M}$ & 1.31 & 1.53 & $17 \%$ \\
\hline $\mathrm{SO}_{4}^{-2}$ & $\mathrm{M}$ & 0.032 & 0.131 & $310 \%$ \\
\hline $\mathrm{Al}$ & $\mathrm{M}$ & 0.26 & 0.382 & $47 \%$ \\
\hline $\mathrm{F}^{-1}$ & $\mathrm{M}$ & 0.0029 & $<0.13$ & - \\
\hline $\mathrm{K}^{+1}$ & $M$ & 0.007 & 0.0078 & $11 \%$ \\
\hline $\mathrm{Cs}^{+1}$ & $\mathrm{M}$ & $1.70 \mathrm{E}-05$ & $2.71 \mathrm{E}-05$ & $60 \%$ \\
\hline $\mathrm{P}$ & $\mathrm{M}$ & 0.005 & 0.0097 & $94 \%$ \\
\hline $\mathrm{S}$ & $\mathrm{M}$ & 0.032 & 0.164 & $412 \%$ \\
\hline $\mathrm{pH}$ & $\mathrm{M}$ & 14 & 14 & $0 \%$ \\
\hline \multicolumn{5}{|c|}{$\begin{array}{l}\text { (1) Obtained from Smith, 2007, Tables } 2-1 \text { and } 6-3 \\
\text { (2) SRNL Measurements on radioactive dissolved saltcake. Cesium } \\
\text { molarity is the sum of } 133,135 \text {, and } 137 \text { isotopes. }\end{array}$} \\
\hline
\end{tabular}

Table 4. Radiochemistry for "Old Feed"

\begin{tabular}{|c|c|c|c|}
\hline Isotope & Unit & $\begin{array}{l}\text { SRS Tanks } \\
\text { Real waste }\end{array}$ & Major Isotope \\
\hline Cs-137 & $\mathrm{dpm} / \mathrm{mL}$ & $1.41 E+08$ & \\
\hline Sr-90 & $\mathrm{dpm} / \mathrm{mL}$ & $1.03 \mathrm{E}+04$ & \\
\hline Pu-238 & $\mathrm{dpm} / \mathrm{mL}$ & $2.90 \mathrm{E}+04$ & \\
\hline Pu-239/240 & $\mathrm{dpm} / \mathrm{mL}$ & $2.50 \mathrm{E}+02$ & \\
\hline Pu-241 & $\mathrm{dpm} / \mathrm{mL}$ & $<1.95 \mathrm{E}+04$ & \\
\hline Mass 95 & $\mu \mathrm{g} / \mathrm{L}$ & 2290 & Mo \\
\hline Mass 99 & $\mu \mathrm{g} / \mathrm{L}$ & 2330 & Tc-99 (1) \\
\hline Mass 133 & $\mu \mathrm{g} / \mathrm{L}$ & 2550 & Stable Cs \\
\hline Mass 137 & $\mu \mathrm{g} / \mathrm{L}$ & 799 & Cs-137(2) \\
\hline Mass 235 & $\mu \mathrm{g} / \mathrm{L}$ & $<150$ & U-235 \\
\hline Mass 237 & $\mu \mathrm{g} / \mathrm{L}$ & $<100$ & $\mathrm{~Np}-237$ \\
\hline Mass 238 & $\mu \mathrm{g} / \mathrm{L}$ & $<1350$ & U-238 \\
\hline \multicolumn{4}{|c|}{$\begin{array}{l}\text { (1) This mass would be } 8.77 \mathrm{E}+04 \mathrm{dpm} / \mathrm{mL} \text { Tc-99 } \\
\text { (2) Cs-137 gamma activity implies } 699 \mathrm{ug} / \mathrm{L}\end{array}$} \\
\hline
\end{tabular}


Table 5. Chemical Components for "New Feed"

\begin{tabular}{|c|c|c|c|c|}
\hline Species & Unit & $\begin{array}{l}\text { Tank 2F } \\
\text { Target (1) }\end{array}$ & $\begin{array}{c}\text { SRS Tanks } \\
\text { Real waste (2) }\end{array}$ & $\begin{array}{l}\text { Percentage } \\
\text { Difference }\end{array}$ \\
\hline $\mathrm{Na}^{+1}$ & $\mathrm{M}$ & 6.0 & 6.05 & $1 \%$ \\
\hline $\mathrm{NO}_{3}{ }^{-1}$ & $M$ & 4.19 & 3.53 & $-16 \%$ \\
\hline $\mathrm{NO}_{2}^{-1}$ & $\mathrm{M}$ & 0.149 & 0.174 & $17 \%$ \\
\hline $\mathrm{OH}^{-1}$ & $M$ & 0.76 & 0.81 & $7 \%$ \\
\hline Total $\mathrm{OH}$ & $\mathrm{M}$ & 1.31 & 1.47 & $12 \%$ \\
\hline $\mathrm{SO}_{4}^{-2}$ & $M$ & 0.032 & 0.119 & $271 \%$ \\
\hline $\mathrm{PO}_{4}^{-3}$ & $\mathrm{M}$ & 0.005 & 0.007 & $45 \%$ \\
\hline $\mathrm{Al}$ & $M$ & 0.26 & 0.32 & $23 \%$ \\
\hline $\mathrm{F}^{-1}$ & $M$ & 0.0029 & $<0.013$ & - \\
\hline $\mathrm{K}^{+1}$ & $\mathrm{M}$ & 0.007 & 0.0083 & $19 \%$ \\
\hline $\mathrm{Cs}^{+1}$ & $\mathrm{M}$ & 1.70E-05 & 2.51E-05 & $37 \%$ \\
\hline$P$ & $M$ & 0.005 & 0.011 & $118 \%$ \\
\hline $\mathrm{S}$ & $\mathrm{M}$ & 0.032 & 0.129 & $303 \%$ \\
\hline $\mathrm{Hg}$ & $\mathrm{M}$ & & 3.24E-05 & \\
\hline $\mathrm{pH}$ & - & 14 & 14 & $0.0 \%$ \\
\hline density $\left(25^{\circ} \mathrm{C}\right)$ & $\mathrm{g} / \mathrm{mL}$ & 1.246 & 1.300 & $4 \%$ \\
\hline \multicolumn{5}{|c|}{$\begin{array}{l}\text { (1) Obtained from Smith, 2007; Tables } 2-1,6-3 \\
\text { (2) Obtained from analyses of a 9.1-liter sample made of "Old Feed" plus } \\
\text { Tanks } 22 \text { and } 41 \text { liquids. Cesium molarity is the sum of } 133,135 \text {, and } \\
137 \text { isotopes. }\end{array}$} \\
\hline
\end{tabular}

Table 6. Radiochemistry for "New Feed"

\begin{tabular}{|c|c|c|c|}
\hline Isotope & Unit & SRS Real waste & Major Isotope \\
\hline Cs-137 & $\mathrm{dpm} / \mathrm{mL}$ & $1.31 \mathrm{E}+08$ & \\
\hline Sr-90 & $\mathrm{dpm} / \mathrm{mL}$ & No meas & \\
\hline Pu-238 & $\mathrm{dpm} / \mathrm{mL}$ & $2.79 \mathrm{E}+04$ & \\
\hline Pu-239/240 & $\mathrm{dpm} / \mathrm{mL}$ & $5.82 \mathrm{E}+02$ & \\
\hline Pu-241 & $\mathrm{dpm} / \mathrm{mL}$ & $<1.62 \mathrm{E}+03$ & \\
\hline Mass 59 & $\mu \mathrm{g} / \mathrm{L}$ & 246 & Stable Co \\
\hline Mass 95 & $\mu \mathrm{g} / \mathrm{L}$ & 1690 & Mo \\
\hline Mass 99 & $\mu \mathrm{g} / \mathrm{L}$ & 1820 & Tc-99 (1) \\
\hline Mass 133 & $\mu \mathrm{g} / \mathrm{L}$ & 2410 & Stable Cs \\
\hline Mass 137 & $\mu \mathrm{g} / \mathrm{L}$ & 718 & Cs-137(2) \\
\hline Mass 235 & $\mu \mathrm{g} / \mathrm{L}$ & 72.5 & U-235 \\
\hline Mass 237 & $\mu \mathrm{g} / \mathrm{L}$ & 13.8 & Np-237 \\
\hline Mass 238 & $\mu \mathrm{g} / \mathrm{L}$ & 4590 & U-238 \\
\hline \multicolumn{4}{|c|}{$\begin{array}{l}\text { (1) This mass would be } 6.85 \mathrm{E}+04 \mathrm{dpm} / \mathrm{mL} \text { Tc-99 } \\
\text { (2) Cs-137 gamma activity implies } 678 \mathrm{ug} / \mathrm{L}\end{array}$} \\
\hline
\end{tabular}




\subsection{BATCH CONTACT WORK}

Batch contact work was performed in the SRNL Shielded Cells and the batch bottles had 20 $\mathrm{mL}$ of radioactive liquid. The shaker oven used, which rotated the bottles at $175 \mathrm{rpm}$, maintained a temperature of $25 \pm 2^{\circ} \mathrm{C}$, but the actual temperature varied less than $25 \pm 0.5^{\circ} \mathrm{C}$. This was important to measure cesium isotopes of masses 133, 135, and 137 so that total cesium could be obtained because it was needed to evaluated cesium isotherms.

Following a SRNL protocol (Walker, 2004), F-factors, which is the ratio of the mass of moist resin to dry resin, were determined for every batch set and column fill at the time resin was drawn and its bulk water was removed. For example, Batch Set 1 would have eight damp resin aliquots drawn: three would be used to determine the F-factor and five were placed in $20 \mathrm{~mL}$ bottles to perform the batch contacts. Damp resin in the filter cup was mixed well whenever aliquots were scooped out, and all aliquots were taken within a period of a few minutes. Batch bottles were sealed after the solution was measured in and purged with argon. The three F-factor aliquots were weighed into tared beakers, then dried to constant weight over several days at $50^{\circ} \mathrm{C}$. The drying oven was evacuated to less than 90 torr absolute during drying times.

The batch contacts were done in three sets:

Set 1 - dissolved saltcake at a phase ratio of $99 \mathrm{~mL} / \mathrm{g}$

Set 2 - simulant and dissolved saltcake at phase ratios of 23 and $64 \mathrm{~mL} / \mathrm{g}$

Set 3 - non-radioactive simulant at a phase ratio of $110 \mathrm{~mL} / \mathrm{g}$

Where phase ratio is the volume of liquid to the mass of resin in a batch contact bottle.

Note, special precautions were found to be necessary to obtain accurate F-factor measurements. Beakers of 50-mL were used because static electricity on glass Petri dishes, which were of larger diameter, affected the operation of the analytical balance. Static charge generally caused an attraction between large-diameter glassware and the upper part of the balance chamber. Weight appeared to increase in an erratic fashion as static decayed. Handling the glassware with metal tongs and aluminum foil greatly reduced any problem with static. Resin containers had to be handled slowly and carefully to reduce the generation of static electricity between glassware and resin beads. Resin beads could be launched from containers if static repulsion between the beads was too strong.

\subsection{SIMULANT AND REAL-WASTE WITH SMALL SCALE IX COLUMNS}

The three principal parts of the experiment were the IX resin, the feed ${ }^{\dagger}$ solutions, and the test apparatus. Each will be described below.

\footnotetext{
${ }^{\dagger}$ IX feeds include the wastes to be treated for cesium separation and solutions used to regenerate sRF resin. Only the regeneration solutions are discussed in this section because the simulant and real waste feeds were previously discussed in Sections 3.2 and 3.3.)
} 


\subsubsection{Spherical Resorcinol Formaldehyde (sRF)}

During the development of the Ion Exchange (IX) facility for the DOE River Protection Project - Waste Treatement and Immobilization Plant (RPP-WTP), the SRNL assisted in finding a replacement for the facility's baseline resin. A candidate that was developed at SRNL in the 1980s (Ebra and Wallace, 1983) to separate cesium was the IX resin resorcinol formaldehyde (RF). To elaborate on what was mentioned in the Introduction, besides being a good adsorber of cesium the resin needed to be hydraulically robust. That is, an efficient resin is useless if it cannot be handled properly and exhibit good hydraulic characteristics. Past resins were shown to work well in a test tube; however, as the scale increased to plantsize operational mechanical problems became evident. Moreover, past resins tended to break apart easily, creating many fines which led to plugging and unacceptable resistances to the flow of liquid waste needing treatment. Even when they did not break down, irregularlyshaped and sharp-edged resin particles created prohibitive pressure drops, slurrying problems, and non-uniform bed structures that caused resin plugs, and fissures that caused liquid channeling leading to less efficient operation. In 2002, the RF polymer matrix was deposited onto spherical plastic beads by the Norwegian company Microbeads AS. The spherical shape not only provides a large exposure surface area, but it was mechanically robust to minimize bead damage and be hydraulically favorable. Figure 1 shows a microphotograph of new spherical RF (sRF) resin beads in acid form. Note how the beads are almost perfect spheres.

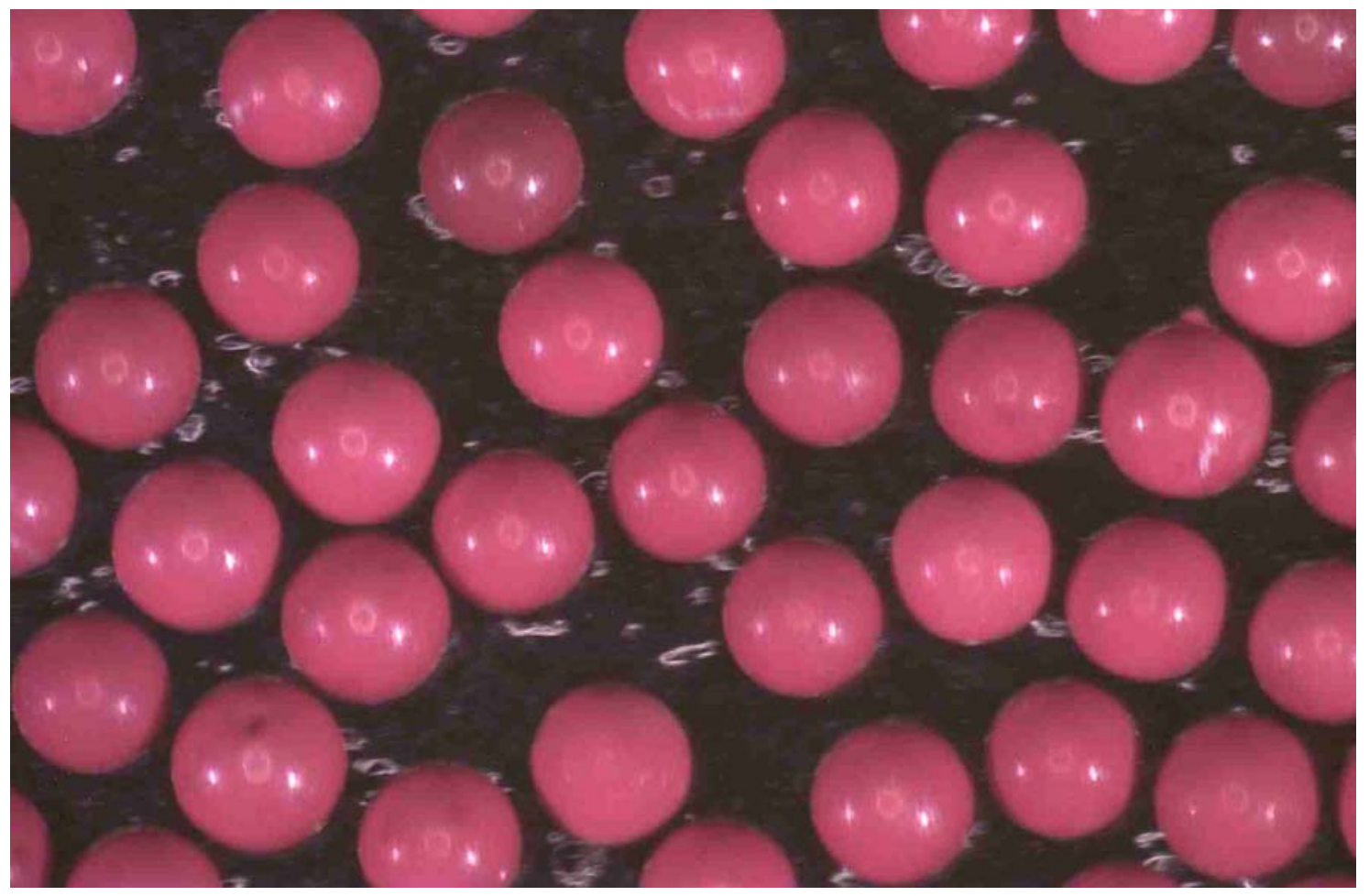

Figure 1. New Spherical Resorcinol Formaldehyde resin beads in H-form 
New beads come in acid form (H-form), ready to be regenerated to sodium form (Na-form) in preparation to remove cesium from a waste. The new beads in $\mathrm{H}$-form have a diameter of approximately 388 microns. While in sodium form the beads expand to approximately 450 microns. At these sizes, individual beads can be readily seen by the naked eye.

For the current study, two IX columns were employed in series and the target resin bed height in each column was $6.5^{\dagger} \mathrm{cm}$ (2.6 in.) to compare to tests that used similar bed heights (e.g., Fiskum et al., 2006a, 2006b). Because the columns had an inside diameter of $1.435 \mathrm{~cm}$ ( $0.565 \mathrm{in}$.), leading to a flow area of $1.617 \mathrm{~cm}^{2}$, then the target bed volume was $10.5 \mathrm{~mL}$. As will be seen in the Results section of this report, the column heights turned out to be an average of $10.6 \mathrm{~mL}$ for the test phase with simulant and $11.2 \mathrm{~mL}$ with real waste because of the volume changes that occur during regeneration.

A batch of sRF resin (specifically, Batch No. 5E-370-641, Drum \#3) was made available for this task from its storage in the Engineering Development Laboratory (EDL) at SRNL, see Fig. 2. This was a small sample from the same batch used in past IX tests for RPP-WTP (Adamson et al., 2006). Before the new resin was used for this test it was pretreated using a RPP-WTP protocol (Nash, 2004). That pretreatment was documented in the task notebook (Nash, 2008, pp. 14-16).

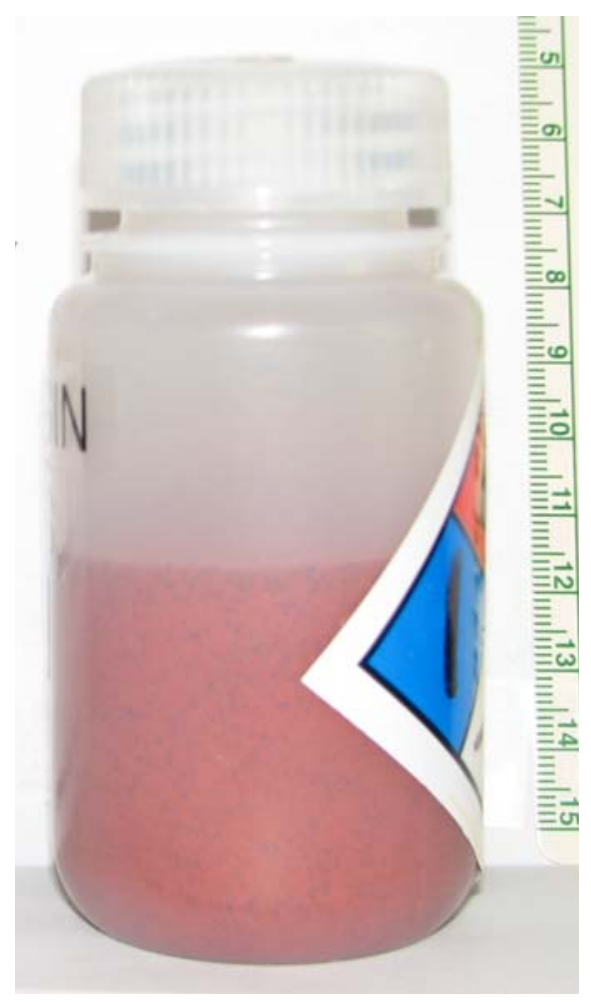

Figure 2. Sample of sRF resin before pretreatment of approximately $80 \mathrm{~mL}$. It is shown in $\mathrm{H}$-form and stored in deionized water

\footnotetext{
${ }^{\dagger}$ This height is given for the Na-form of resin, which it has while treating waste. Once the resin is saturated with Cs ions it undergoes elution in acid to remove those ions so it can be regenerated. The acid shrinks the resin by about $20 \%$ reducing the column height correspondingly. Once the eluted resin is regenerated with sodium it returns to close to its original height.
} 


\subsubsection{Feed solutions for regeneration}

The sRF resin is being considered for SCIX for its ability to separate cesium from liquid waste and because it can be reused after regeneration. Resorcinol Formaldehyde can be regenerated in situ by stripping (elution) it of cesium with acid, so that it can be reused. The process of cesium separation and then resin regeneration is a six-step process that was developed for RPP-WTP (e.g., Adamson et al., 2006). These steps are collectively called a cycle and are as follows:

\begin{tabular}{|c|c|c|}
\hline IX Cycle Step & $\underline{\text { Solution }}$ & Reason \\
\hline 1. Waste Treatment & Alkaline-based waste & $\overline{\text { Remove Cs }}$ \\
\hline 2. Waste Displacement & 0.1 M Sodium Hydroxide & Prevent Al precipitation \\
\hline Caustic Displacement & Deionized Water & Prepare for elution \\
\hline 4. Elution & 0.5 M Nitric Acid & Strip resin of Cs \\
\hline Acid Displacement & Deionized Water & Prevent Al precipitation \\
\hline 6. Regeneration & 0.5 M Sodium Hydroxide & Prepare resin to receive Cs \\
\hline
\end{tabular}

The process of resin regeneration will be discussed in more detail in the Test Matrix section, but the following is a summary of the process with the several solutions used.

After the resin reaches its limit to remove cesium, waste flow is terminated to begin regeneration. The process begins by flushing the resin bed with $5 \mathrm{BV}$ of inhibited water $(0.1 \mathrm{M} \mathrm{NaOH})$ which removes the waste and prepares the bed for neutralization by dropping the $\mathrm{pH}$ from 14 to approximately 12. This protocol is followed by $5 \mathrm{BV}$ for deionized water to further drop the $\mathrm{pH}$ in preparation to receive acid and prevent the precipitation of solids (e.g., aluminum compounds). The resin now receives $30 \mathrm{BV}^{\dagger}$ of $0.5 \mathrm{M} \mathrm{HNO}_{3}$ to remove cesium and prepare it for regeneration. The acid is followed by another $5 \mathrm{BV}$ of deionized water to once again prepare the bed for a change in $\mathrm{pH}$ when it returns to its sodium form. Finally, the resin is regenerated with $6 \mathrm{BV}$ of $0.5 \mathrm{M} \mathrm{NaOH}$.

\subsubsection{Test equipment}

The primary reason for the test with small columns was the demonstration of sRF cesium decontamination on SRS radioactive waste. To reiterate, the test was first done with a nonradioactive simulant and then with real waste. Simulant testing was done to perfect test rig operation and to determine process time to obtain adequate waste treatment, which would lead to refining the radioactive test matrix followed by the real-waste test. For both tests the resin was regenerated and reused and the equipment was the same, except for minor

\footnotetext{
${ }^{\dagger}$ As will be seen in the Results section, only $6 \mathrm{BV}$ was necessary to remove, most or all, of the cesium from the resin, but the current test was to replicate a previous test, (Fiskum, 2006b) that used 30 BV. Volumes of lower amounts, e.g., 15 BV, have been shown to be sufficient (Adamson et al., 2006).
} 
modifications, as well as the process operation. Figure 3 shows the general test setup that highlights the columns and flow logic for each of the two 2-cycle tests.
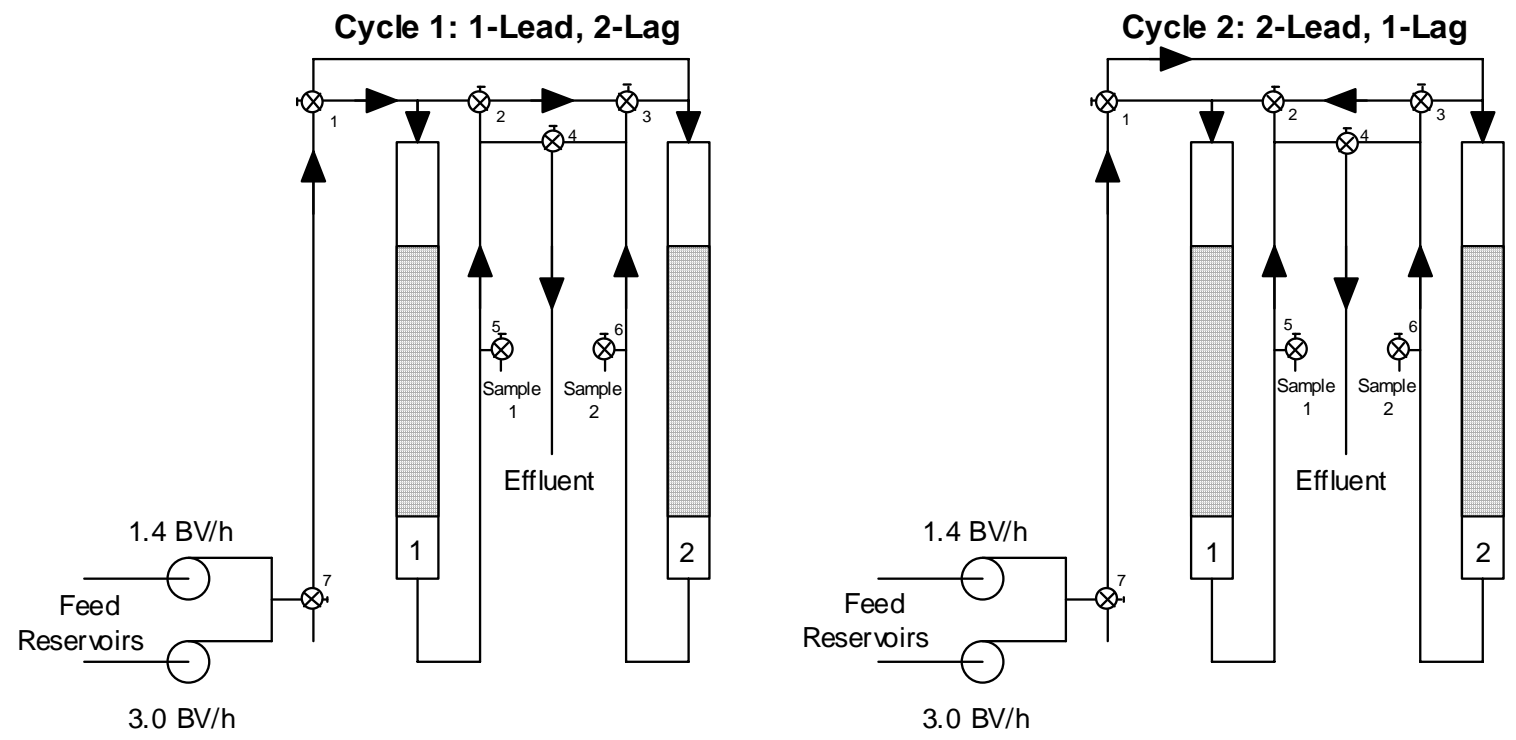

Figure 3. Flow path schematic of two-column test rig in two-column operation

The columns were set up to operate in series with one column as the Lead column and the other as the Lag column. The rationale was to start each phase of the test (i.e., either simulant or real waste) with both columns loaded with freshly regenerated resin ready to separate cesium from waste. Cycle 1 was to operate with Column 1 as the Lead column and its effluent would continue on to the Lag column, Column 2. Once the cesium concentration in the Column 1 effluent attained a set breakthrough point (e.g., 50\%, 75\%, or 100\% of that of the feed stream cesium concentration), then the process was stopped to regenerate the resin in Column 1. Once the Lead column was regenerated, a second cycle would begin by switching the Lag column, Column 2, into the Lead position, while the Lead column, Column 1, would be moved into the Lag position. After the column switch, a complete new cycle, Cycle 2, would be performed, which mimicked Cycle 1 operation. When the Column 2 effluent reached the breakthrough point waste processing stopped so that Column 2 could be regenerated, thus ending one 2-cycle phase of the test. Using the flow logic shown in Fig. 3 , the overall test rig, including all the valves and other equipment, was developed and is shown schematically as Fig. 4.

The test equipment was designed so that all of the steps of each of the two cycles could be performed by only opening and closing 2-Way valves, or redirecting 3-Way valves. This control scheme was important for Shielded Cells processing, which was limited to work with mechanical manipulators. 


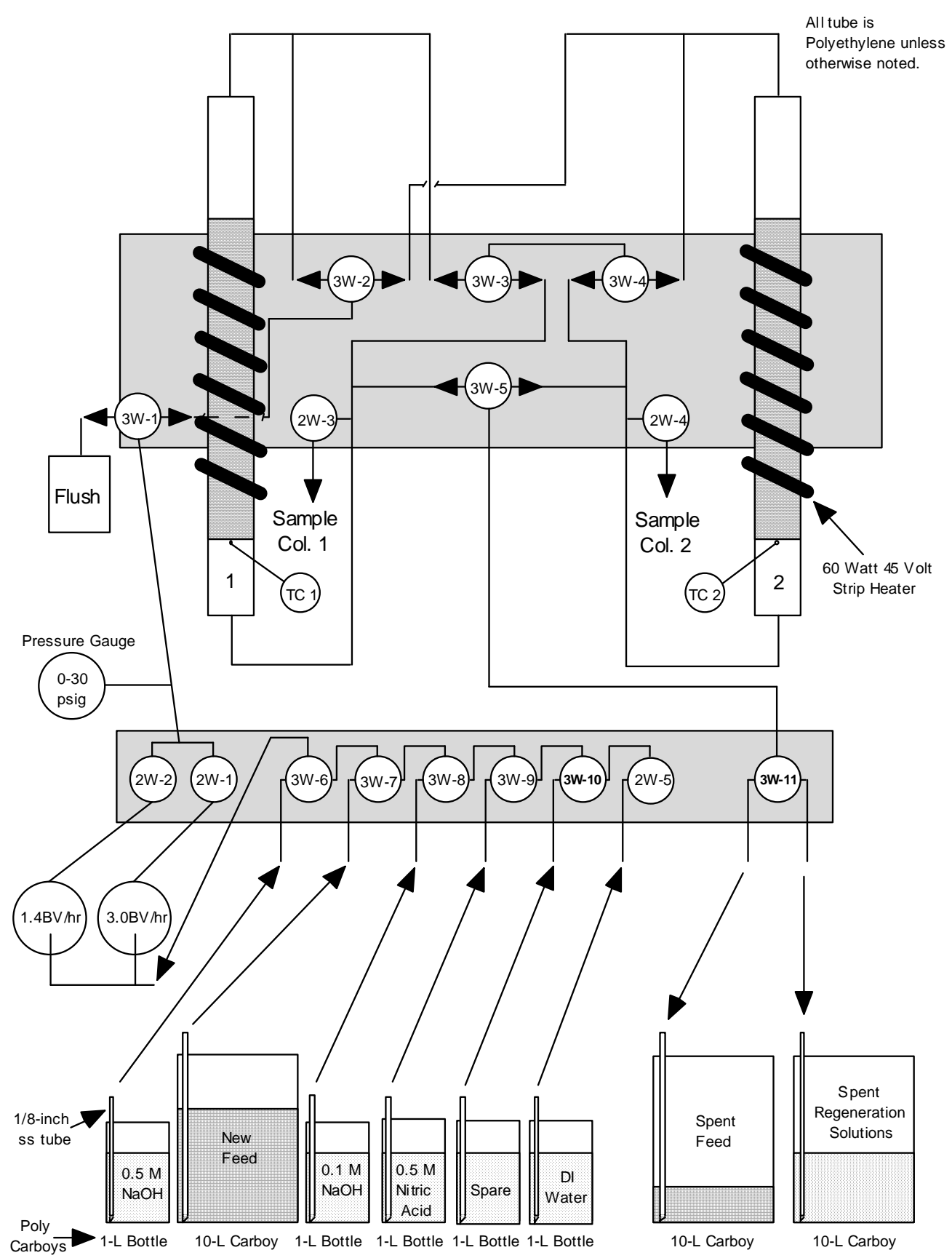

Figure 4. Schematic of test rig with feed reservoirs, effluent reservoirs, tubing runs, valves, strip heater, column thermocouples, and pump discharge pressure gauge

Excluding the two IX columns, all of the flow paths were made of polyethylene tube, with some limited lengths of stainless steel. The polyethylene and steel tubing had an inside diameter of approximately $0.2 \mathrm{~cm}$. The columns were made of borosilicate glass with an inside diameter of $1.435 \mathrm{~cm}$ and approximately $15 \mathrm{~cm}$ tall. To determine throughput times 
for processing and sampling, the volumes of all of the tube runs, with the columns, were estimated and are shown in Table 7. Those volumes consisted of the tubes, the volumes that contained the resin beds, and the volumes of liquid above and below the resin beds. Note, the largest percentage of each of these volumes was due to the tube length, which contained approximately $3 \mathrm{~mL}$ of internal volume per meter.

The target resin Bed Volume was between $10 \mathrm{~mL}$ and $11 \mathrm{~mL}$, which means approximately 6 to $7 \mathrm{~cm}$ of each column was occupied with $\mathrm{Na}$-form ${ }^{\dagger}$ resin. Once the resin screen was placed in the tubes to support the resin, there was approximately $2 \mathrm{~cm}$ of space below the resin. A liquid freeboard of $2 \mathrm{~cm}$ was left above each bed.

Table 7. Internal volumes of flow paths throughout the SCIX test rig

\begin{tabular}{|c|c|c|c|c|}
\hline & \multicolumn{2}{|c|}{ Simulant Phase } & \multicolumn{2}{|c|}{ Real-Waste Phase } \\
\hline & Cycle 1 & Cycle 2 & Cycle 1 & Cycle 2 \\
\hline Two-Column Operation & $\mathrm{mL}$ & $\mathrm{mL}$ & $\mathrm{mL}$ & $\mathrm{mL}$ \\
\hline AV to bottom of Col 2 bed & 54.1 & & 55.0 & \\
\hline AV to bottom of Col 1 bed & & 55.9 & & 56.9 \\
\hline Feed to valve $2 \mathrm{~W}-3$ & 37.0 & 61.1 & 37.9 & 62.0 \\
\hline Feed to valve $2 \mathrm{~W}-4$ & 59.2 & 38.1 & 60.2 & 39.1 \\
\hline \multicolumn{5}{|l|}{ Single-Column Operation } \\
\hline DI Water to valve $2 \mathrm{~W}-3$ & 34.3 & & 36.2 & \\
\hline DI Water to valve $2 \mathrm{~W}-4$ & & 33.6 & & 34.5 \\
\hline $0.5 \mathrm{M} \mathrm{HNO} 3$ to valve $2 \mathrm{~W}-3$ & 33.5 & & 35.4 & \\
\hline $0.5 \mathrm{M}$ HNO3 to valve $2 \mathrm{~W}-4$ & & 34.7 & & 35.6 \\
\hline $0.1 \mathrm{M} \mathrm{NaOH}$ to valve $2 \mathrm{~W}-3$ & 33.1 & & 35.0 & \\
\hline $0.1 \mathrm{M} \mathrm{NaOH}$ to valve $2 \mathrm{~W}-4$ & & 34.3 & & 35.2 \\
\hline $0.5 \mathrm{M} \mathrm{NaOH}$ to valve $2 \mathrm{~W}-3$ & 32.3 & & 34.2 & \\
\hline $0.5 \mathrm{M} \mathrm{NaOH}$ to valve $2 \mathrm{~W}-4$ & & 33.5 & & 34.4 \\
\hline
\end{tabular}

Note that Table 7 is separated into two-column and single-column operation. During the treatment of waste both columns were used and depending on which column was the lead and which was the lag, the overall volumes were slightly different because of the differing flowpaths. The apparatus volume (AV) is defined from the bottom of the feed reservoir suction tube to the bottom of the lag-column resin bed. All other volumes are defined for a specific solution reservoir suction tube to a respective sample valve to determine process volumes captured for each sample. Moreover, the internal volumes of the test rig used during real-waste phase of testing were slightly larger. That is, once the simulant test phase was completed and preparations began for the radioactive test phase, it was necessary to add extra tube to many of the reservoir suction tubes to locate the reservoirs and pumps further apart. The extra distance facilitated the use of robotic manipulators.

\footnotetext{
${ }^{\dagger} \mathrm{H}$-form resin had heights from 5 to $6 \mathrm{~cm}$.
} 
Another equipment feature shown in Fig. 4 was the heating strip wound around each of the columns to maintain the target temperature of $25 \pm 2^{\circ} \mathrm{C}$ when ambient temperature was lower. For the simulant test phase the ambient temperature averaged at approximately $21^{\circ} \mathrm{C}$; therefore, the heater was useful. However, during the radioactive waste test phase, the average ambient temperature was above $25^{\circ} \mathrm{C}$; therefore, the heat was not used, and in fact, cooling air was applied to keep the temperatures of the columns below $27^{\circ} \mathrm{C}$. The temperature of liquid flowing through the columns was measured just under each to the resin bed screens by installed calibrated thermocouples.

Because of the very slow liquid flows through the test rig (i.e., a maximum of $0.55 \mathrm{~mL} / \mathrm{min}$ ), no significant pressure was expected (i.e., $<1$ psig). However, in the event of an accident (e.g., line pluggage, valve left closed, etc.), a pressure gauge was installed in the common discharge line of the two pumps. For safety, the pressure boundaries of the test rig were tested to conform to the leak-test requirements of ASME B31.3, paragraph A324, which requires the flow system to be pressurized to $150 \%$ of the maximum pressure that could possibly occur. According to the manufacturer, the maximum pressure attainable by either of the two pumps used was 20 psig, which meant the required test pressure had to be at least 30 psig. Those pumps were: Model QG20 manufactured by Fluid Metering, Inc., with a 1/8inch diameter piston head made of stainless steel that produces a maximum flowrate of 1.6 $\mathrm{mL} / \mathrm{min}$. The assembled test rig was held for a ten-minute period at 34 psig while an ASME qualified leak inspector verified that the unit was free of leaks. This process was repeated once to confirm the results (Nash, 2008; p. 26). The reason why two pumps were employed, instead of a single pump, was because there were two flowrates, $1.4 \mathrm{BV} / \mathrm{h}(\sim 0.25 \mathrm{~mL} / \mathrm{min})$ and $3.0 \mathrm{BV} / \mathrm{h}(\sim 0.55 \mathrm{~mL} / \mathrm{min})$, and it was much less labor intense and more accurate to have each pump preset with a flowrate. As such, it was a simple matter to just turn on a pump instead of having to set and confirm the flow each time. As a precaution, the flowrates were periodically checked and adjusted when found to be outside acceptable limits.

The last significant feature of the test rig, Fig. 4, is the sixteen 2-way and 3-way valves that controlled the flow. The valves are grouped into two panels described below.

- Pump Feed Panel - To select from which solution reservoir to feed, the effluent container to use, and which pump to use. (Bottom panel)

- Column Control Panel - To select the flow direction during either single or twocolumn operation. (Top panel)

All of the valves are listed in Table 8 and their placement for each of the six cycle steps: Regeneration, (Waste) Feed, Displace (Feed), Pre-Elution Rinse, Elution, and Post-Elution Rinse. There is also a step called "Internal Flush" which sets the valves to remove waste from internal tubes after waste processing is complete. Note that the order of the valves on the pump feed panel to select a specific solution to feed was arbitrary, except the one to select deionized (DI) water, valve $2 \mathrm{~W}-5$. With the water valve upstream of all the other valves then water could rinse all the downstream valves and tubes when necessary.

The next five figures (Figs. 5, 6, 7, 8, and 9) show several aspects of the test equipment as it was used during the processing of the simulated waste phase of the test. 
SRNL-STI-2009-00594, REVISION 0

Table 8. Valve position for each of the 6 cycle steps, plus a "Internal Flush" step to remove waste from internal tubing

\begin{tabular}{|c|c|c|c|c|c|c|c|c|}
\hline \multicolumn{9}{|l|}{ SCIX Valve Positioning } \\
\hline Selection & Valve No. & Regeneration & Feed & Displace & Pre-Elution DIW & Internal Flush & Elution & Post-Elution DIW \\
\hline \multicolumn{9}{|c|}{ Cycle 1: Column 1 as Lead and Column 2 as Lag (or Regenerating Column 1) } \\
\hline From Pump To Columns or Flush & 3W-1 & FROM PUMP & FROM PUMP & FROM PUMP & FROM PUMP & FROM PUMP & FROM PUMP & FROM PUMP \\
\hline From Pump to Column 1 or 2 & $3 \mathrm{~W}-2$ & LEAD 1 & LEAD 1 & LEAD 1 & LEAD 1 & LEAD 1 & LEAD 1 & LEAD 1 \\
\hline From Col. 1 to $3 \mathrm{~W}-4$ or from $3 \mathrm{~W}-4$ to Col. 1 & $3 \mathrm{~W}-3$ & OFF & LEAD 1 & OFF & OFF & LEAD 1 & OFF & OFF \\
\hline From Col. 2 to $3 \mathrm{~W}-3$ or from $3 \mathrm{~W}-3$ to Col. 2 & $3 \mathrm{~W}-4$ & OFF & LEAD 1 & OFF & OFF & LEAD 2 & OFF & OFF \\
\hline Effluent Exit: From Column 1 or 2 & $3 W-5$ & FROM COL 1 & FROM COL 2 & FROM COL 1 & FROM COL 1 & OFF & FROM COL 1 & FROM COL 1 \\
\hline Pump No. $1 @ 3.0$ BV/h & $2 \mathrm{~W}-1$ & $\mathrm{ON}$ & OFF & ON & ON & $\mathrm{ON}$ & OFF & OFF \\
\hline Pump No. $2 @ 1.4$ BV/h & $2 \mathrm{~W}-2$ & OFF & $\mathrm{ON}$ & OFF & OFF & OFF & ON & ON \\
\hline Sample from Column 1 & $2 \mathrm{~W}-3$ & as needed & as needed & as needed & as needed & CLOSED & as needed & as needed \\
\hline Sample from Column 2 & $2 \mathrm{~W}-4$ & not used & as needed & not used & not used & OPEN & not used & not used \\
\hline \multicolumn{9}{|c|}{ Cycle 2: Column 2 as Lead and Column 1 as Lag (or Regenerating Column 2) } \\
\hline From Pump To Columns or Flush & $3 \mathrm{~W}-1$ & FROM PUMP & \begin{tabular}{|l|} 
FROM PUMP \\
\end{tabular} & FROM PUMP & FROM PUMP & FROM PUMP & FROM PUMP & FROM PUMP \\
\hline From Pump to Column 1 or 2 & $3 \mathrm{~W}-2$ & LEAD 2 & LEAD 2 & LEAD 2 & LEAD 2 & LEAD 2 & LEAD 2 & LEAD 2 \\
\hline From Col. 1 to $3 \mathrm{~W}-4$ or from $3 \mathrm{~W}-4$ to Col. 1 & $3 \mathrm{~W}-3$ & OFF & LEAD 2 & OFF & OFF & LEAD 2 & OFF & OFF \\
\hline From Col. 2 to $3 \mathrm{~W}-3$ or from $3 \mathrm{~W}-3$ to Col. 2 & $3 \mathrm{~W}-4$ & OFF & LEAD 2 & OFF & OFF & LEAD 1 & OFF & OFF \\
\hline Effluent Exit: From Column 1 or 2 & $3 \mathrm{~W}-5$ & FROM COL 2 & FROM COL 1 & FROM COL 2 & FROM COL 2 & OFF & FROM COL 2 & FROM COL 2 \\
\hline Pump No.1 @ 3.0 BV/h & $2 \mathrm{~W}-1$ & ON & OFF & ON & ON & ON & OFF & OFF \\
\hline Pump No. 2 @ 1.4 BV/h & $2 \mathrm{~W}-2$ & OFF & ON & OFF & OFF & OFF & ON & ON \\
\hline Sample from Column 1 & $2 \mathrm{~W}-3$ & not used & as needed & not used & not used & OPEN & not used & not used \\
\hline Sample from Column 2 & $2 \mathrm{~W}-4$ & as needed & as needed & as needed & as needed & CLOSED & as needed & as needed \\
\hline \multicolumn{9}{|c|}{ Valve Setting for Five Solutions to Pumps } \\
\hline $0.5 \mathrm{M} \mathrm{NaOH}$ or bypass* & $3 \mathrm{~W}-6$ & $.5 \mathrm{NAOH}$ & TO PUMP & TO PUMP & TO PUMP & TO PUMP & TO PUMP & TO PUMP \\
\hline Feed, bypass, OFF & $3 \mathrm{~W}-7$ & OFF & FEED & bypass & bypass & bypass & bypass & bypass \\
\hline $0.1 \mathrm{M} \mathrm{NaOH}$, bypass, OFF & $3 \mathrm{~W}-8$ & OFF & OFF & $.1 \mathrm{NAOH}$ & bypass & bypass & bypass & bypass \\
\hline $0.5 \mathrm{M} \mathrm{HNO}$, bypass, OFF & $3 W-9$ & OFF & OFF & OFF & bypass & bypass & $.5 \mathrm{ACID}$ & bypass \\
\hline Spare (not used), bypass, OFF & $3 \mathrm{~W}-10$ & OFF & OFF & OFF & bypass & bypass & OFF & bypass \\
\hline DI Water or closed & $2 W-5$ & OFF & OFF & OFF & $\mathrm{H} 2 \mathrm{O}$ & $\mathrm{H} 2 \mathrm{O}$ & OFF & $\mathrm{H} 2 \mathrm{O}$ \\
\hline Effluent - Spent Feed or Solutions & $3 \mathrm{~W}-11$ & SPENT REGEN & SPENT FEED & SPENT REGEN & SPENT REGEN & SPENT REGEN & SPENT REGEN & SPENT REGEN \\
\hline
\end{tabular}

Page 17 of 131 


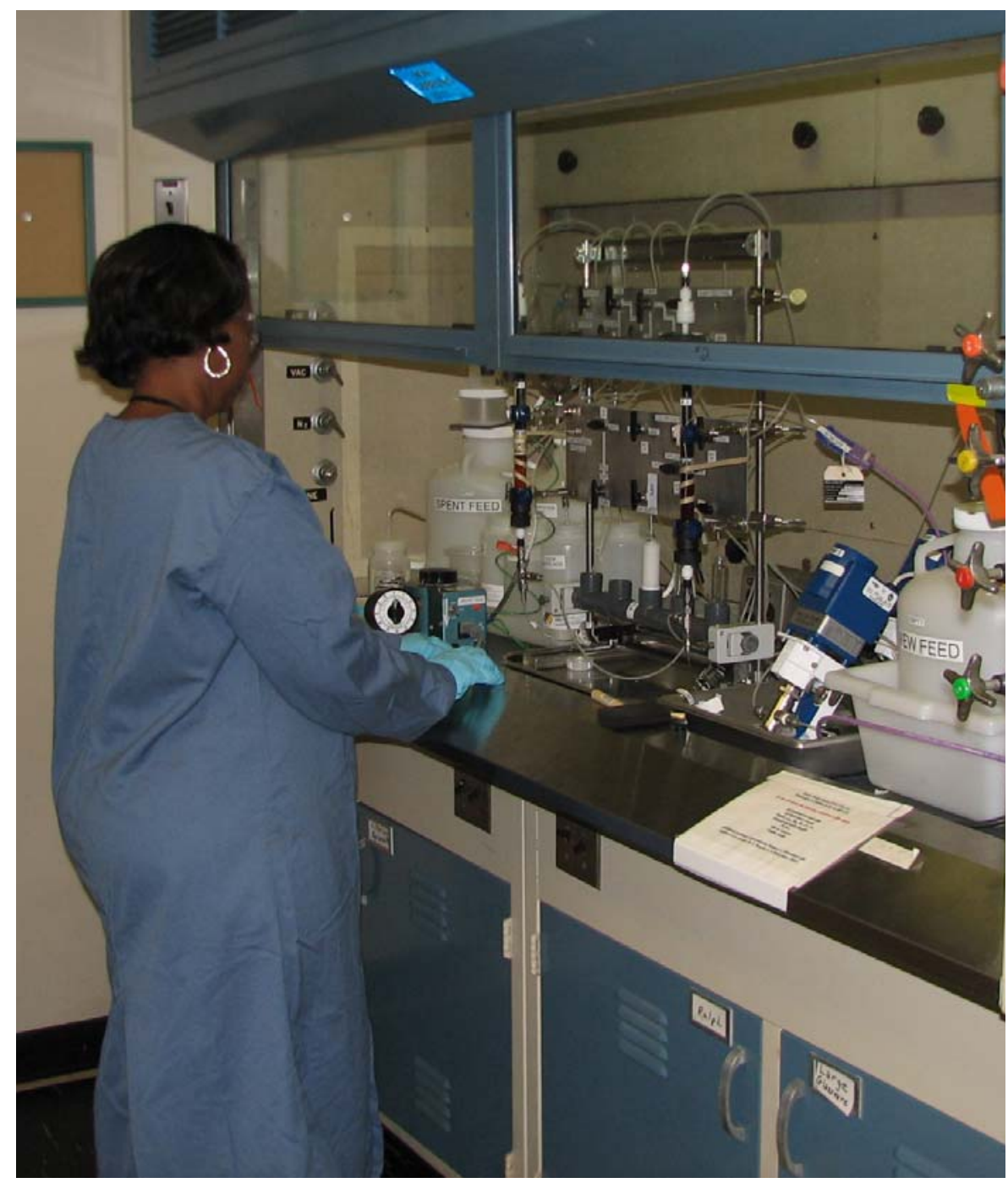

Figure 5. Test rig in ventilation hood demonstrating its size while taking a sample 


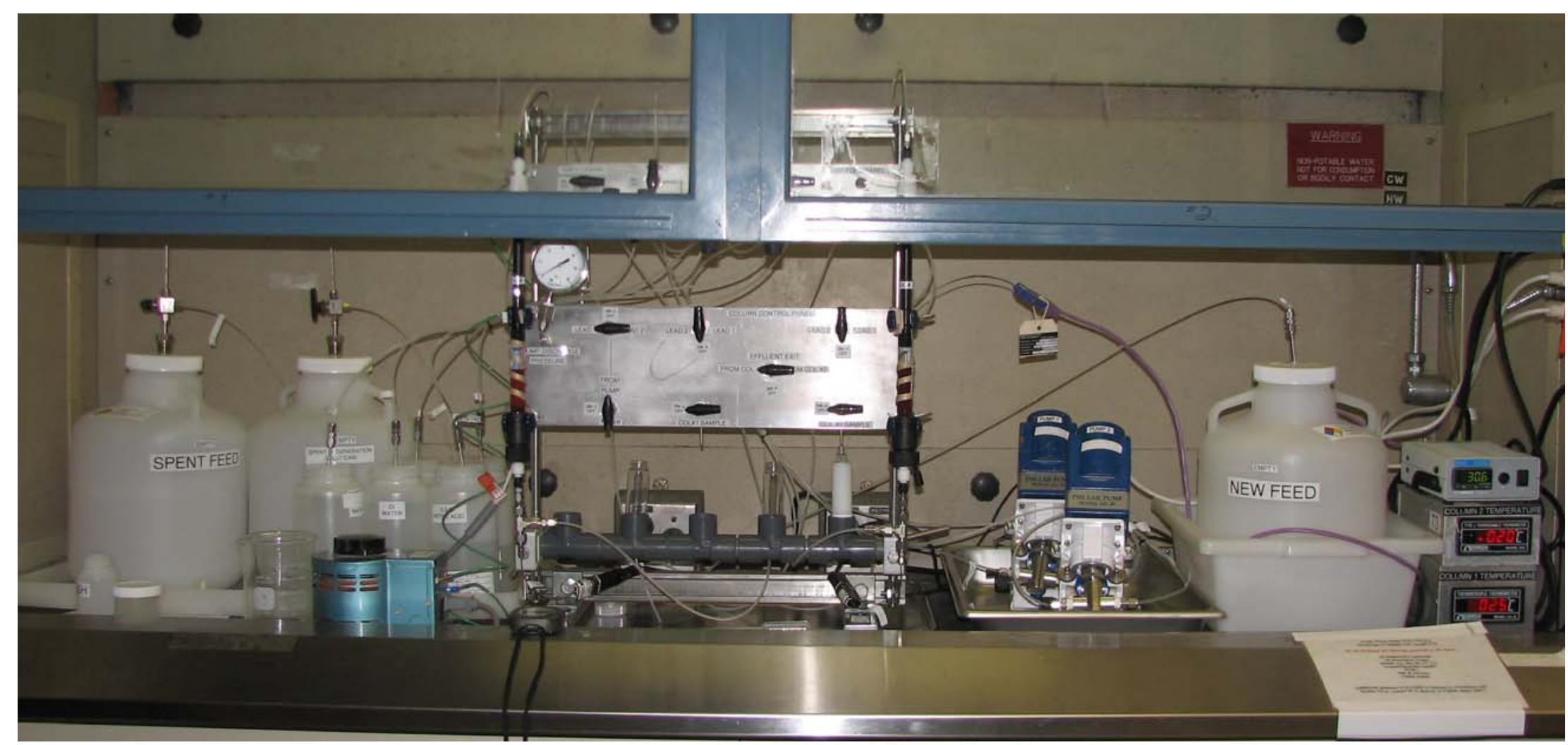

Figure 6. Test rig setup for the simulant test phase. (The real-waste setup was similar.) 


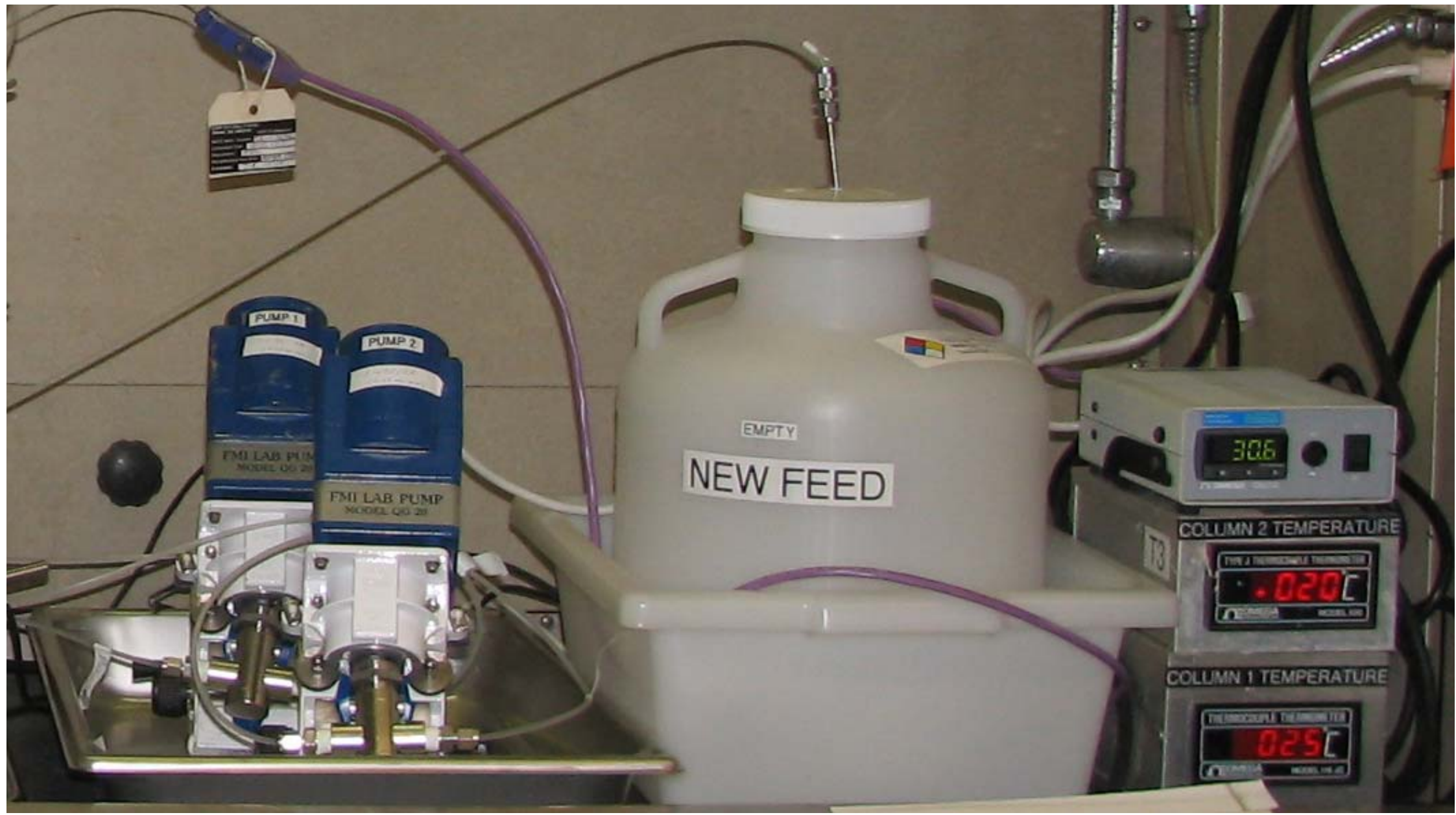

Figure 7. Close-up of pumps, waste feed reservoir, and temperature monitors 


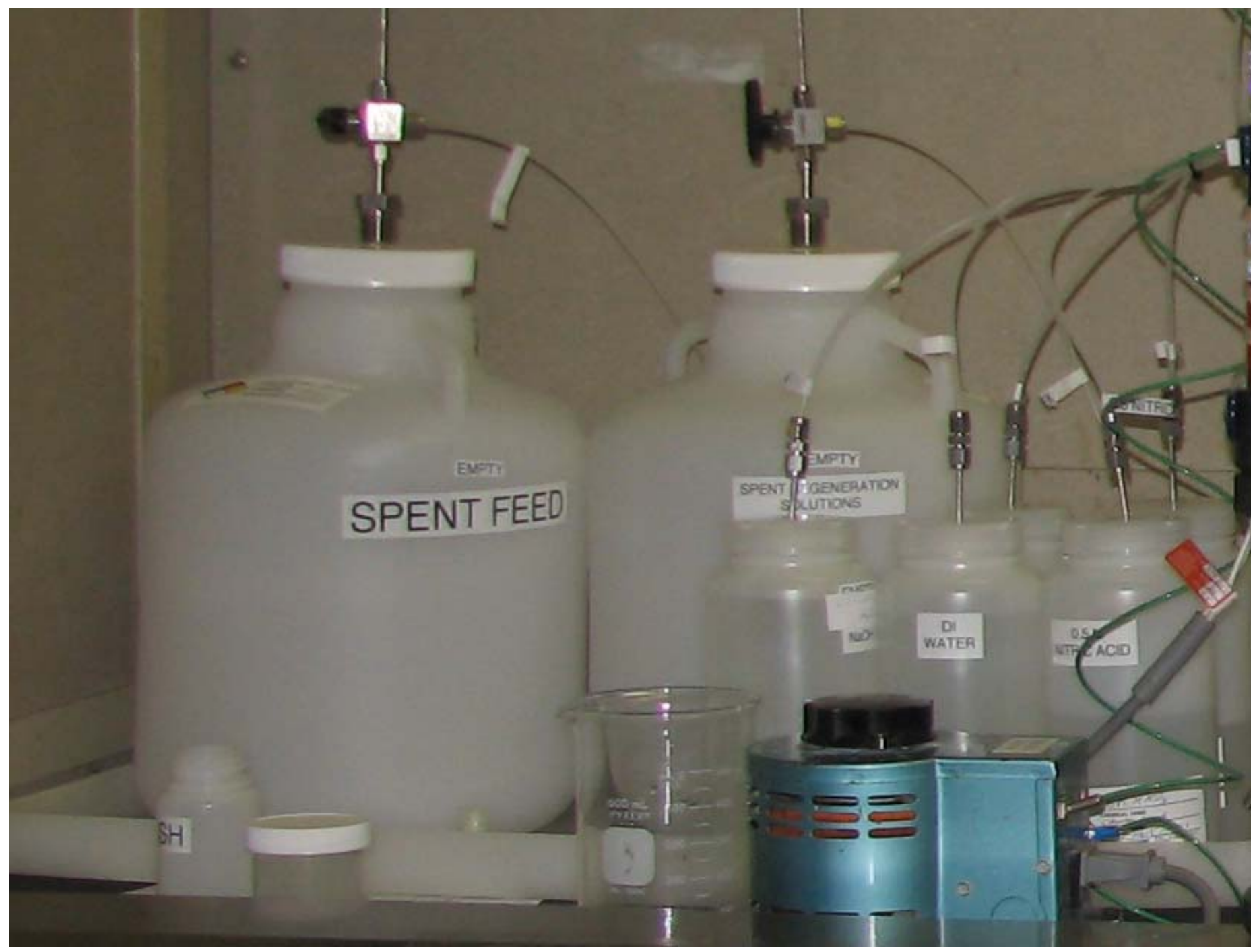

Figure 8. Close-up of the reservoirs for regeneration solutions, the two effluent containers, and the heat strip transformer 


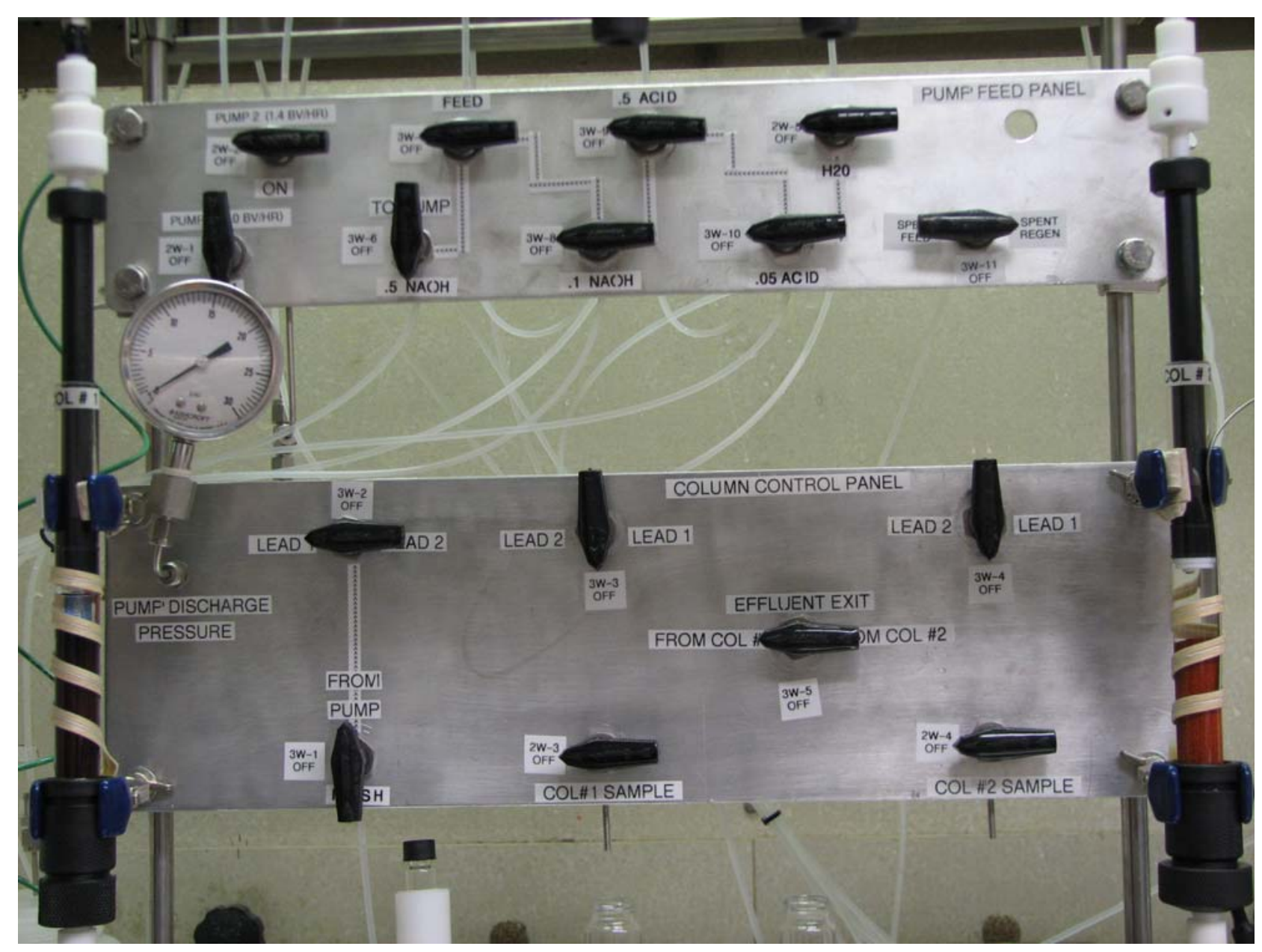

Figure 9. Picture contains the control panels for the feeds and valves, the discharge pump pressure and both IX columns. Note the color difference of the columns. The lighter colored resin to the right had been eluted (i.e., it was in H-form) while the left column was just starting elution (i.e., it was still in Na-form). 
Fig. 5 shows a sample being drawn during Cycle 2 of the test phase with simulant, which clearly shows the small scale of the test equipment. Testing was performed in a chemical hood because of the hazardous nature of the waste simulant. Any released vapors from the chemicals were safely exhausted from the work area. Figure 6 shows the entire layout of the equipment with the feed and effluent containers on both sides, the feed pumps to the right, the Column 1 and Column 2 temperature indicators to the right, and above those indicators was an over-temperature control unit to shut power to the strip heater if temperature became too high; see Figs 7 and 8 . In Fig. 8 the transformer to control the strip heater is the green unit to the left of the test rig.

Figure 9 shows a close-up of the valve panels and note that the panels' orientation is the opposite of what is shown in the Fig. 4 schematic. For operational efficiency the Column Control Panel of the actual test rig was located below the Pump Feed Panel, which contained the sampling ports and therefore would be approximately at waist high for taking samples.

Once simulant testing was completed, the equipment was moved to the SRNL Shielded Cells to begin the radioactive waste processing phase of the test. The test equipment was the same for this second phase of testing; however, its protective location made it much harder to see due to the leaded glass, Fig. 10. While the tube lengths to and from the test rig were increased to facilitate more room among the reservoirs and pumps the operation was the same.

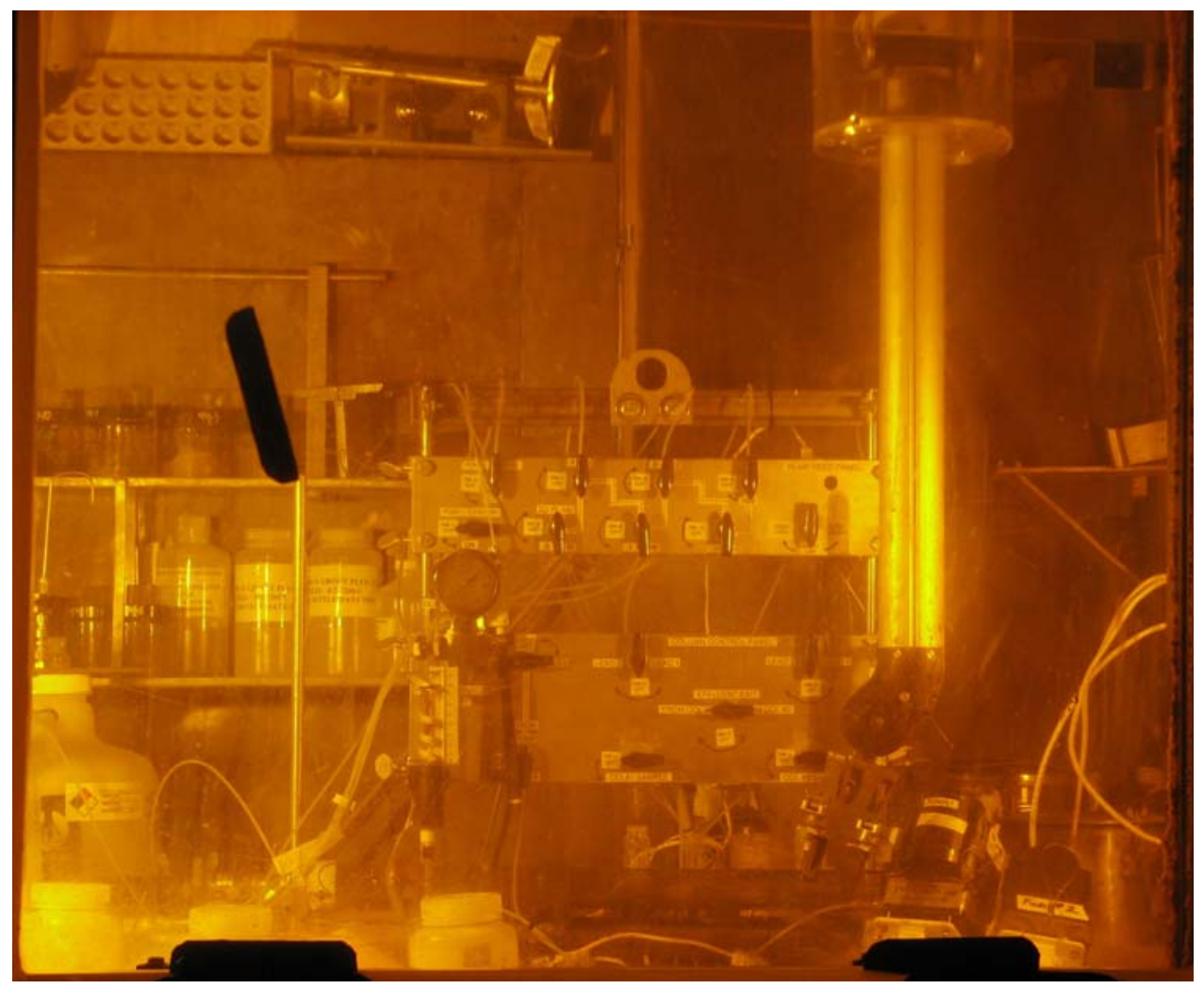

Figure 10. SCIX test equipment during radioactive waste processing 


\subsubsection{Test Matrix}

A matrix was developed that followed those of previous tests (e.g., Fiskum et al., 2006a, 2006b), but in general the matrix was perfected as part of IX process testing for RPP-WTP (e.g., Adamson et al., 2006). For the current work, the baseline parameters used came from Smith (2007) with SRS waste. Those parameters are shown in Table 9 with modifications for the proper scaling. Prototypic aspects were the chemical makeup of the waste, the flowrate in BV/h, and the resin media. The smaller column size necessitated changing the superficial velocities through the columns and the absolute volumes in BV.

Table 9. Target test matrix for 2-Column SCIX test (see following table for X1-X4)

\begin{tabular}{|c|c|c|c|c|c|c|c|c|}
\hline \multirow{3}{*}{$\begin{array}{l}\text { Process Step } \\
\text { Regeneration }(0.5 \mathrm{NaOH})-\text { Column } 1 \\
\text { Regeneration }(0.5 \mathrm{NaOH})-\text { Column } 2\end{array}$} & \multirow{2}{*}{$\begin{array}{c}\begin{array}{c}\text { Vol. } \\
\text { BV (1) }\end{array} \\
6 \\
\end{array}$} & \multirow{2}{*}{$\begin{array}{l}\text { Vol. } \\
\mathrm{mL} \\
64\end{array}$} & \multirow{2}{*}{$\begin{array}{c}\text { Rate } \\
\text { BV / h } \\
3\end{array}$} & \multirow{2}{*}{$\begin{array}{c}\begin{array}{c}\text { Rate } \\
\mathrm{mL} / \mathrm{min}\end{array} \\
0.525\end{array}$} & \multicolumn{2}{|c|}{$\begin{array}{c}\text { Duration } \\
\text { hours days }\end{array}$} & \multirow{2}{*}{\begin{tabular}{|c|}
$\begin{array}{c}\text { Sample } \\
\text { Point }\end{array}$ \\
After Col 1 \\
\end{tabular}} & \multirow{2}{*}{$\begin{array}{c}\begin{array}{c}\text { Sample Time } \\
\text { min. (2) }\end{array} \\
7.5 \\
\end{array}$} \\
\hline & & & & & 2.0 & 0.1 & & \\
\hline & 6 & 64 & 3 & 0.525 & 2.0 & 0.1 & After Col 2 & 7.5 \\
\hline \multicolumn{9}{|c|}{ Cycle 1: Set Column 1 as Lead and Column 2 as Lag } \\
\hline \multirow{7}{*}{$\begin{array}{l}\text { Loading (3) - Column } 1 \\
\text { Loading - Column } 2 \\
\text { Feed Displacement (0.1 M NaOH) - Column } 1 \\
\text { Pre-elution rinse (DI Water) - Column } 1 \\
\text { Elution (0.5 M HNO3) - Column } 1 \\
\text { Post-elution rinse (DI Water) - Column } 1 \\
\text { Regeneration (0.5 NaOH)- Column } 1\end{array}$} & $\mathrm{X} 1$ & $\mathrm{X} 2$ & 1.4 & 0.245 & $\mathrm{X} 3$ & $\mathrm{X} 4$ & After Col 1 & 16.0 \\
\hline & $\mathrm{X} 1$ & $\mathrm{X} 2$ & 1.4 & 0.245 & $\mathrm{X3}$ & $\mathrm{X} 4$ & After Col 2 & 16.0 \\
\hline & 5 & 53 & 3 & 0.525 & 1.7 & 0.1 & After Col 1 & 7.5 \\
\hline & 5 & 53 & 3 & 0.525 & 1.7 & 0.1 & After Col 1 & 7.5 \\
\hline & 30 & 316 & 1.4 & 0.245 & 21.4 & 0.9 & After Col 1 & 16.0 \\
\hline & 5 & 53 & 1.4 & 0.245 & 3.6 & 0.1 & After Col 1 & 16.0 \\
\hline & 6 & 64 & 3 & 0.525 & 2.0 & 0.1 & After Col 1 & 8.1 \\
\hline \multicolumn{9}{|c|}{ Cycle 2: Set Column 2 as Lead and Column 1 as Lag } \\
\hline \multirow{6}{*}{$\begin{array}{l}\text { Loading - Column } 2 \\
\text { Loading - Column } 1 \\
\text { Feed Displacement (0.1 M NaOH) - Column } 2 \\
\text { Pre-elution rinse (DI Water) - Column } 2 \\
\text { Elution (0.5 M HNO3) - Column } 2 \\
\text { Post-elution rinse (DI Water) - Column } 2\end{array}$} & $\mathrm{X} 1$ & $\mathrm{X} 2$ & 1.4 & 0.245 & X3 & $\mathrm{X} 4$ & After Col 1 & 16.0 \\
\hline & $\mathrm{X} 1$ & $\mathrm{X} 2$ & 1.4 & 0.245 & $\mathrm{X} 3$ & $\mathrm{X} 4$ & After Col 2 & 16.0 \\
\hline & 5 & 53 & 3 & 0.525 & 1.7 & 0.1 & After Col 2 & 7.5 \\
\hline & 5 & 53 & 3 & 0.525 & 1.7 & 0.1 & After Col 2 & 7.5 \\
\hline & 30 & 316 & 1.4 & 0.245 & 21.4 & 0.9 & After Col 1 & 16.0 \\
\hline & 5 & 53 & 1.4 & \begin{tabular}{|l}
0.245 \\
\end{tabular} & 3.6 & 0.1 & After Col 2 & 16.0 \\
\hline \multicolumn{9}{|c|}{$\begin{array}{l}\text { 1. BV was assumed to be } 11 \mathrm{~mL} \text { for planning purposes. } \\
\text { 2. Sample size was assumed to be } 4.25 \mathrm{~mL} \text {. } \\
\text { 3. The initial Loading target was } 250 \mathrm{BV} \text { based on modelling, but actual testing extended some cycles to }>500 \mathrm{BV} \text {. } \\
\text { 4. All samples are taken manually. } \\
\text { 5. Resin was pretreated per Protocol RF-P1 (Nash, 2006) before the start of testing. }\end{array}$} \\
\hline
\end{tabular}

Table 10 contains the volume of waste, or simulated waste, processed in each cycle. Ideally each pair of cycles, Cycles 1 and 2 for simulant and Cycles 1 and 2 for real waste, should have treated the same volume of waste but the ability of the resin to load cesium from a target waste was a principal variable under study. Based on computational modeling (Smith, 2007) for waste contained in Tank $2 \mathrm{~F}$ at SRS a volume of $250 \mathrm{BV}$ would be needed for the effluent of the lead column to reach a cesium concentration of $75 \%$ of the untreated waste. As such, Table 10 shows that $250 \mathrm{BV}$ was the initial target volume to process. This target seemed reasonable because of the volumes used in previous tests with sRF, i.e., 240 BV (Nash et al., 2006) and 202 BV (Fiskum et al., 2006a, 2006b), even though those tests used wastes from the Hanford Site and not those at SRS. It seems that those differences in waste streams, (e.g., lower potassium concentration), did have a significant effect because after 
stopping the test to prepare for Cycle 2, the cesium concentration at $250 \mathrm{BV}$ of simulant was found to be slightly less than 5\% of the untreated feed. After it became apparent that cesium concentration in the lead-column, Column 1, effluent did not reach its intended target, the amount of simulant to treat with the Cycle 2 lead column, Column 2, was increased to $580 \mathrm{BV}$. Moreover, the fact that very little cesium would have been loaded onto the resin in Column 2 meant that the resin was starting as basically fresh and unloaded. Subsequently, the $580 \mathrm{BV}$ was found to more than sufficient to fully load the Cycle 2 lead column, Column 2 , and this information was useful to refine the amount of radioactive waste to be treated in the next phase of testing. For the radioactive phase of the test, the amount of waste planned to process in Cycle 2 (315 BV) was considerably less than what was processed in Cycle 1 (483 BV) of same phase. This is due to mimicking the expected SRS SCIX process in which that Lag column is not eluted prior to Cycle 2. Thus, for Cycle 2 the new lead column, Column 2, would have a significant amount of cesium already loaded, leading to a reduced amount of time to become fully loaded.

Table 10. Planned Feed Volumes and Times to Process (see preceding table)

\begin{tabular}{|c|c|c|c|c|c|}
\hline Test & Cycle & Volume & Volume & Process Time & Process Time \\
\hline & No. & $\mathrm{BV}(=10.5 \mathrm{~mL})$ & $\mathrm{mL}$ & hours & days \\
\hline Parameter & & $\mathrm{X} 1$ & $\mathrm{X} 2$ & $\mathrm{X} 3$ & $\mathrm{X} 4$ \\
\hline Simulant & 1 & 250 & 2625 & 179 & 7.4 \\
\hline Simulant & 2 & 580 & 6090 & 414 & 17.3 \\
\hline Real Waste & 1 & 483 & 5072 & 345 & 14.4 \\
\hline Real Waste & 2 & 315 & 3308 & 225 & 9.4 \\
\hline
\end{tabular}

To perform the Test Matrix properly the resin had to be prepared before its introduction into the IX columns. The salient features of those preparation are:

- To minimize sending solids to the resin beds both the simulant and real-waste feeds were filtered using Nalgene dead-end filters with a pore size of 0.45 micrometer.

- Before either the simulant or real-waste phase of the IX column test began the resin was prepared using the pretreatment protocol developed for the resin (Nash, 2006). This was done on March 20, 2009 (Nash, 2008, pp. 14-16).

- After pretreatment the resin F-factor (ratio of the dry mass to moist mass) was determined for the resin and then a quantity of 6.0068 grams of moist resin in $\mathrm{H}$-form was separated for each of the two columns. Since the F-factor for this sample of resin was 0.4838 , each column received 2.9061 grams of resin on a dry hydrogen form basis.

- The two quantities of resin were each soaked in $1 \mathrm{M} \mathrm{NaOH}$ to change them to Naform so the resin would expand to its full volume before filling each of the IX columns. 
- After filling both columns the In-Column pretreatment (Nash, 2006) was performed and the resin was then ready to begin the test. Note, the same sRF resin used in the simulant phase of the test was reused in the real waste phase of the test after being regenerated.

With the resin in place and the Test Matrix in Tables 9 and 10 set, the Cycle 1 of the test could begin. Several steps comprise each cycle. These steps were derived from WTP experience (Adamson et al., 2006) in treating waste with sRF at SRNL and are explained below:

1. At the beginning of a set of two cycles the Lead and Lag column both start with freshly eluted resin in $\mathrm{H}$-form ready to be regenerated.

2. The resin in each column is regenerated with $6 \mathrm{BV}$ of $0.5 \mathrm{M} \mathrm{NaOH}$ at a flowrate of 3.0 BV/h.

3. The columns are now ready to treat waste until the Lead column reaches breakthrough (breakthrough must be defined, but an effluent cesium concentration of $50 \%$ of feed cesium is commonly used). The flowrate is $1.4 \mathrm{BV} / \mathrm{h}$.

4. After Step 3 is complete the Lead column is ready for regeneration while the Lag column is isolated and waits to become the new Lead column in Cycle 2.

5. To begin the regeneration process the waste in the Lead column is displaced with 5 $\mathrm{BV}$ of inhibited waste $(0.1 \mathrm{M} \mathrm{NaOH})$ at $3.0 \mathrm{BV} / \mathrm{h}$.

6. The inhibited water is then rinsed from the column with $5 \mathrm{BV}$ of deionized water at 3.0 BV/h. [Steps 5 and 6 are done to minimize the precipitation of solids in the column when acid is introduced.]

7. To remove the cesium from the resin $30 \mathrm{BV}$ of $0.5 \mathrm{M} \mathrm{HNO}_{3}$ are passed through the column at $1.4 \mathrm{BV} / \mathrm{h}$.

8. The last step to ready the resin to be regenerated with sodium ions is another $5 \mathrm{BV}$ of deionized water at $1.4 \mathrm{BV} / \mathrm{h}$ to minimize solids formation.

9. Step 8 effectively ends a cycle with the next cycle beginning with the regeneration of the resin by repeating Step 2 .

\subsubsection{Test Operation}

The operation is fairly straight forward and assumes all the test equipment is ready for use, the measurement equipment is calibrated, the feed solutions are available and in place, the safety equipment is readily accessible, and the sample containers are labeled and ready for use. The work followed the R\&D Direction, listed in Appendix C, but generally followed the sequence listed below and uses the flow parameters indicated in the test matrix, Tables 9 and 10:

1. Check the flowrate for each of the two pumps.

2. Measure the initial weight of $\mathrm{NaOH}$ reservoir.

3. Set valves to regenerate Column 1

4. Turn on temperature indicators and adjust temperature to $25 \pm 2^{\circ} \mathrm{C}$. 
5. Turn on the Pump $1(3.0 \mathrm{BV} / \mathrm{h})$ to regenerate the resin.

6. Take samples (4 to $4.5 \mathrm{~mL}$ ) from the appropriate column as indicated by the data sheet (Appendix B: Table 20-25 for simulant or Table 26-30 for real waste) and record the time, resin height and temperature of active column.

7. Periodically check the pump flowrate and adjust as necessary.

8. Periodically check the discharge pump pressure to verify it is less that 1 psig to determine that the system remains plug free and all valves are set correctly.

9. Periodically check the column temperature and adjust as necessary.

10. Shut pump and valves.

11. Repeat Steps 3 to 10 once to regenerate Column 2, then measure final weight of $\mathrm{NaOH}$.

12. Set valves to treat waste with both Columns 1 and 2 with Column 1 as the Lead.

13. Measure the initial weight of waste reservoir.

14. Turn on the Pump $2(1.4 \mathrm{BV} / \mathrm{h})$ to treat waste.

15. Take a sample (4 to $4.5 \mathrm{~mL}$ ) from the Lead column and record the time, resin height and temperature of the column. Take a sample ( 4 to $4.5 \mathrm{~mL}$ ) from the Lag column and record the time, resin height and temperature of that column, per the data sheet.

16. Periodically check the pump flowrate and adjust as necessary.

17. Periodically check the discharge pump pressure to verify it is $<1$ psig to determine that the system remains plug free and all appropriate valves are set correctly.

18. Periodically check the column temperature and adjust as necessary.

19. Shut pump, valves, and measure final weight of waste reservoir. Regenerate the Lead column

20. Set valves to regenerate resin in the Lead column and isolate the Lag column which will wait to become the Lead column in Cycle 2.

21. Measure the initial weight of appropriate feed reservoir.

22. Turn on the appropriate pump and open reservoir and effluent valves to process $0.1 \mathrm{M}$ $\mathrm{NaOH}$ through the Lead column.

23. Take samples ( 4 to $4.5 \mathrm{~mL}$ ) from the Lead column as indicated by the data sheet.

24. Periodically check the pump flowrate and adjust as necessary.

25. Periodically check the discharge pump pressure to verify it is less that 1 psig to determine that the system remains plug free and all appropriate valves are set correctly.

26. Periodically check the column temperature and adjust as necessary.

27. Shut pump and measure final weight of appropriate feed reservoir.

28. Repeat Steps 15 to 27 to process DI Water.

29. Repeat Steps 15 to 27 to process $0.5 \mathrm{M} \mathrm{HNO}_{3}$.

30. Repeat Steps 15 to 27 to process DI Water.

One cycle is complete

31. Repeat Steps 15 to 27 to regenerate the resin in the Lead column with $0.5 \mathrm{M} \mathrm{NaOH}$.

32. Begin Cycle 2 by setting valves to treat waste with both Columns 1 and 2 with Column 2 as the Lead.

33. Repeat Steps 13 through 30.

This general operation listed was the same for both the simulant and real-waste test phases; however, it only highlights the major activities performed. 


\subsection{RESULTS AND DISCUSSION}

\subsection{BATCH CONTACT RESULTS}

Batch contacts were performed in three stages to make sure that the experimental techniques and resin performance met expectations. The first stage, Set 1, examined only batch contact time as a variable. Results compared favorably with the SRNL "new isotherm". The second stage, Set 2a, 2b, and 2c, varied phase ratio and initial cesium level to provide additional points for comparison with model isotherms. The last stage, Set 3 , examined the effect of a high concentration of cesium $(27 \mathrm{mg} / \mathrm{L})$.

Note, that in Tables 11, 12, and 13, the letters A and B in the first columns refer to replicates and the resin loading $\mathrm{Q}_{\text {final }}$ was calculated from dry hydrogen-form resin mass and the decrease in cesium concentration in the liquid phase. Post-contact resin was not analyzed because of inability to separate residual solution and un-adsorbed cesium on the beads and in resin pores. The following calculation was used:

$\mathrm{Q}_{\text {final }}=($ Batch liquid volume $) *($ Initial - final Cs batch concentrations $) /$ resin mass

When volume is in $\mathrm{mL}$, cesium concentrations are in molar $(\mathrm{M})$, and resin mass is in grams, the units of $\mathrm{Q}_{\mathrm{final}}$ are $\mathrm{mmol} / \mathrm{g}$. Batch contact result tables also provide resin loadings in units of $\mathrm{mg}$ (Cs)/g (resin). Average cesium atomic weights, accounting for the mix of mass 133, 135, and 137 isotopes, was used for the inter-conversion between mass and moles.

\subsubsection{Batch contact Set 1: Effect of contact time}

All Set 1 batches used the radioactive composite liquid, “Old Feed.” Composition for this liquid is found in Tables 3 and 4.

Table 11. Set 1: Batch Contacts with Real Dissolved Saltcake

\begin{tabular}{|c|c|c|c|c|c|c|}
\hline Batch (1) & Potassium & Phase & Kd & C_final $\mathbf{M}$ & Q final & Q final \\
\hline Bottle & g/L & Ratio, $\mathbf{~ m L / g}$ & $\mathbf{~ m L / g}$ & total Cs, $\mathbf{M}$ & $\mathbf{~ m g / g}$ & $\mathbf{~ m m o l / g}$ \\
\hline feed & 0.309 & N/A & & & & \\
\hline 24 hours & & 99.6 & 2850. & $9.15 \mathrm{E}-07$ & 0.348 & $2.60 \mathrm{E}-03$ \\
\hline 48 hours, A & 0.299 & 99.1 & 3000. & $8.65 \mathrm{E}-07$ & 0.348 & $2.60 \mathrm{E}-03$ \\
\hline 48 hours, B & 0.303 & 99.1 & 3240. & $8.03 \mathrm{E}-07$ & 0.348 & $2.60 \mathrm{E}-03$ \\
\hline 72 hours, A & & 99.2 & 3230. & $8.07 \mathrm{E}-07$ & 0.349 & $2.60 \mathrm{E}-03$ \\
\hline 72 hours, B & & 99.3 & 2650. & $9.76 \mathrm{E}-07$ & 0.347 & $2.59 \mathrm{E}-03$ \\
\hline
\end{tabular}

Note: All initial Cs+ concentrations are $3.62 \mathrm{gm} / \mathrm{L}$ in feed liquid aliquots and the actual liquid and resin masses used for these results can be found in Appendix A, Table 18. 


\subsubsection{Batch contact Set 2: Effect of phase ratio and initial Cs concentration}

Set 2 - (Table 12) used three types of liquid feed:

Set 2a - "Spike simulant” was 25.0243 grams of simulant mixed with 7.154 grams of radioactive composite,

Set $2 \mathrm{~b}$ - "Old Feed” was a radioactive composite, and

Set 2c - "Lo-Cs" was a radioactive composite left in the batch bottles of Set 1 and having approximately one thirtieth of the cesium concentration of unused feed.

Notes:

1. For Set 2b, the "Old Feed" was the same liquid used in Set 1, but the results differ from Set 1 , Table 11, because the Set $2 \mathrm{~b}$ phase ratios were different, as listed in Table 12 . The lower phase ratios mean that there is relatively more resin in the batch bottle and therefore lower resulting cesium in the liquid.

2. For Set 2c, it was fortunate that this material was available to provide the opportunity for batch contact work at very low cesium levels. The liquid material was obtained by filtration of Set 1 material to remove spent resin from those batches.

Table 12. Set 2: Batch contacts with a Mixture of Real waste and Simulant

\begin{tabular}{|c|c|c|c|c|c|c|}
\hline Batch & $\begin{array}{l}\text { Phase } \\
\text { Ratio }\end{array}$ & $\begin{array}{l}\text { C_init, } \\
\text { total Cs }\end{array}$ & Kd & C_final $M$ & Q final & Q final \\
\hline Bottle (1) & $\mathrm{mL} / \mathrm{g}$ & $\mathrm{mg} / \mathrm{L} \mathrm{Cs}$ & $\mathrm{mL} / \mathrm{g}$ & $\begin{array}{c}\text { Total Cs, } \\
\mathbf{M} \\
\end{array}$ & $\mathrm{mg} / \mathrm{g}$ & $\mathrm{mmol} / \mathrm{g}$ \\
\hline \multicolumn{7}{|l|}{$* * *$ Set 2a:*** } \\
\hline Spiked sim. feed (2) & N/A & 2.56 & & & & \\
\hline 48 hours & 23.6 & 2.56 & 3720 & $1.21 \mathrm{E}-07$ & 0.0600 & 4.51E-04 \\
\hline \multicolumn{7}{|l|}{$* * *$ Set $2 \mathrm{~b} * * *$} \\
\hline “Old Feed” & N/A & 3.62 & & & & \\
\hline 48 hours, $\mathrm{A}$ & 23.0 & 3.62 & 4700 & $1.31 \mathrm{E}-07$ & 0.0827 & $6.18 \mathrm{E}-04$ \\
\hline 48 hours, $\mathrm{B}$ & 23.4 & 3.62 & 4810 & $1.31 \mathrm{E}-07$ & 0.0845 & 6.31E-04 \\
\hline 72 hours, & 23.3 & 3.62 & 5110 & $1.23 \mathrm{E}-07$ & 0.0838 & $6.26 \mathrm{E}-04$ \\
\hline \multicolumn{7}{|l|}{$* * *$ Set $2 \mathrm{c} * * *$} \\
\hline Lo-Cs Feed (3) & N/A & 0.1189 & & & & \\
\hline 48 hours, $\mathrm{A}$ & 66.5 & 0.1189 & 5370 & $1.09 \mathrm{E}-08$ & 0.00781 & 5.83E-05 \\
\hline 48 hours, $\mathrm{B}$ & 64.4 & 0.1189 & 5370 & 1.05E-08 & 0.00757 & 5.65E-05 \\
\hline 72 hours & 63.9 & 0.1189 & 6480 & 8.67E-09 & 0.00752 & 5.61E-05 \\
\hline
\end{tabular}

Notes:

(1) Liquid and resin masses used for these results can be found in Appendix A, Table 19

(2) A mixture of simulant with Old Feed.

(3) Lo-Cs feed is the "Old Feed" composite taken from Set 1 


\subsubsection{Batch contact Set 3 - Effect of high initial Cs concentration}

Table 13 shows the results for Set 3 . Tank $2 \mathrm{~F}$ non-radioactive simulant is the composition shown in Table 2, except for the addition of cesium nitrate to obtain a relatively high cesium concentration. The initial cesium level of the simulant was measured to be $26.9 \mathrm{mg} / \mathrm{L}$ for this set. Phase ratio was $110 \mathrm{~mL} / \mathrm{g}$ in all cases.

Table 13. Set 3: Nonradioactive Batch Contacts

\begin{tabular}{|c|c|c|c|c|c|c|}
\hline Batch & $\begin{array}{c}\text { Phase } \\
\text { Ratio }\end{array}$ & Initial Cs & Kd & C_final M & Q final & Q final \\
\hline Bottle & $\mathbf{m L} / \mathbf{g}$ & $\mathbf{m g} / \mathbf{L}$ & $\mathbf{m L} / \mathbf{g}$ & total Cs, M & $\mathbf{~ m g / g}$ & $\mathbf{~ m m o l / g}$ \\
\hline FEED & N/A & 26.9 & & & & \\
\hline $\begin{array}{c}48 \text { hours } \\
\text { (B48) }\end{array}$ & 110 & 26.9 & 1710 & $1.2172 \mathrm{E}-05$ & 2.7872 & $2.10 \mathrm{E}-02$ \\
\hline $\begin{array}{c}72 \text { hours, A } \\
\text { (B72A) }\end{array}$ & 110 & 26.9 & 1679 & $1.2397 \mathrm{E}-05$ & 2.7868 & $2.10 \mathrm{E}-02$ \\
\hline $\begin{array}{c}72 \text { hours, B } \\
\text { (B72B) }\end{array}$ & 110 & 26.9 & 1563 & $1.3218 \mathrm{E}-05$ & 2.7659 & $2.08 \mathrm{E}-02$ \\
\hline & & & & & & \\
\hline STD & N/A & 0.746 & & & & \\
\hline
\end{tabular}

\subsection{ION EXCHANGE COLUMN WORK}

The following sections will first discuss the performance of sRF to treat waste for cesium and the operation of the resin columns during the regeneration process. That discussion will be followed by results on some other key elements.

\subsubsection{Cesium results with Tank 2 F simulant}

Approximately 2.9 liters (275 BV) for Cycle 1 and 5.6 liters (525 BV) for Cycle 2 of simulated Tank $2 \mathrm{~F}$ feed were used to test the sRF resin performance during the nonradioactive phase of testing. Cycle 1 took place over seven days, see Appendix B, during which time the cycle was planned to process $250 \mathrm{BV}$ of feed, achieving significant breakthrough in the lead column. The effluent cesium concentration was expected to be $75 \%$ of the feed concentration. Subsequently, after Cycle 2 began the final Cycle 1 effluent concentration was found to be just under $5 \%$ of the feed concentration. Additionally, the actual volume processed was $275 \mathrm{BV}$ because the actual resin bed volume for Cycle 1 was measured at $10.5 \mathrm{BV}$, instead of the planned $11 \mathrm{BV}$, and because simulant treatment continued to operate a little longer than planned to ensure breakthrough. Figure 11 shows Cycle 1 results. The feed concentration measured was $2.25 \mathrm{mg} / \mathrm{L}$, which was very close to the target waste concentration of $2.26 \mathrm{mg} / \mathrm{L}$, as shown in Table 2 in terms of moles/liter. The 
figure shows two sets of data: one that was obtained from SRNL and one from GEL Laboratories, LLC. On an absolute basis the GEL data were in general 30\% below the SRNL data. That is, when comparing the absolute values of cesium concentrations, those from GEL were on the average $30 \%$ lower then those measured by SRNL. Because the SRNL cesium measurement matched the concentration that was created for the simulant, as explained in Section 3.2, then the SRNL results were more accurate; therefore, the GEL data were increased by $30 \%$ for comparison purposes. GEL was utilized to achieve the low detection limits required in non-radioactive testing.

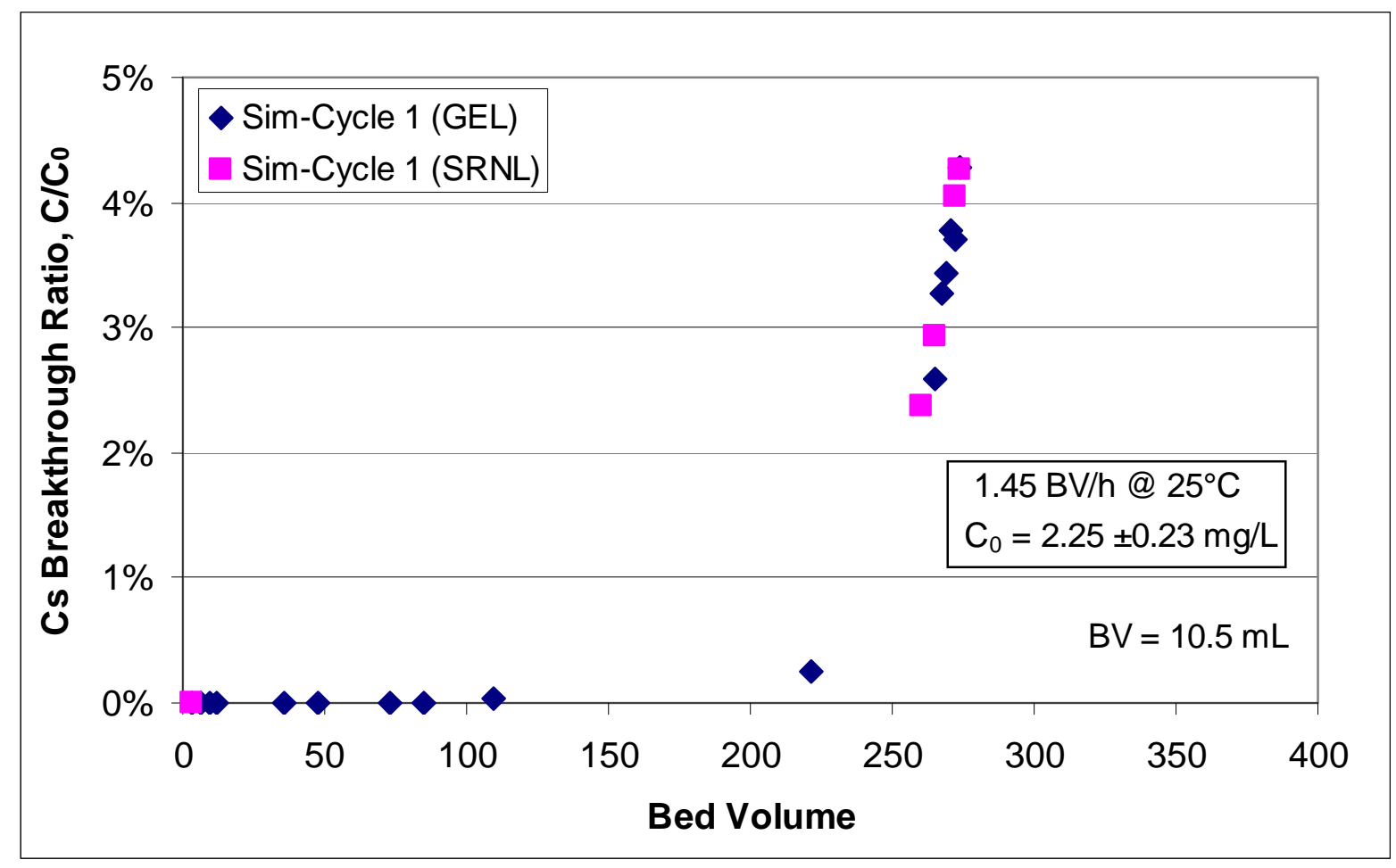

Figure 11. Lead column effluent Cs for Cycle 1 with simulant

Despite Cycle 1 not attaining significant cesium breakthrough, the data in Fig. 11 are useful to determine just when measurable cesium begins to exit the Lead column of newly regenerated sRF resin for a flowrate of $1.4 \mathrm{BV} / \mathrm{h}$ at $25^{\circ} \mathrm{C}$ with a typical SRS feed. It seems at about $200 \mathrm{BV}$ there is enough cesium in the column that it begins to show up in the effluent. From $200 \mathrm{BV}$ to $270 \mathrm{BV}$ the effluent concentration reaches just under $5 \%$ of the feed concentration. At this point absolutely no cesium was detected leaving the Lag column.

To obtain a more complete idea of sRF performance, Fig. 12 shows both Cycles 1 and 2 treatment of SRS Tank 2F simulated waste. The Cycle 2 Lead column, which was the Lag column during Cycle 1, was effectively similar to a column of freshly regenerated sRF because, as seen in Fig. 11, the Lead column effluent cesium concentration only reached $4.4 \%$ of the feed concentration; therefore, the Cycle 1 Lag column had an insignificant 
amount cesium loading. Indeed, the cesium concentration in the effluent of the Cycle 2 Lead column, which was the Cycle 1 Lag column, began showing measurable cesium after treating approximately the same volume of feed (i.e., just before $250 \mathrm{BV}$ ). The transition from no cesium in the Lead column effluent to a concentration equal to the feed was fast and occurred within a span of approximately $150 \mathrm{BV}$. The steep breakthrough slope differed from the modeled behavior using the new isotherm model (Smith, 2007), which indicated that the volume of waste from the onset of cesium in Lead column effluent to when it reaches 100\% breakthrough should have been more than $600 \mathrm{BV}$. The data should be very useful to better benchmark the model, which is currently under revision with data from ORNL.

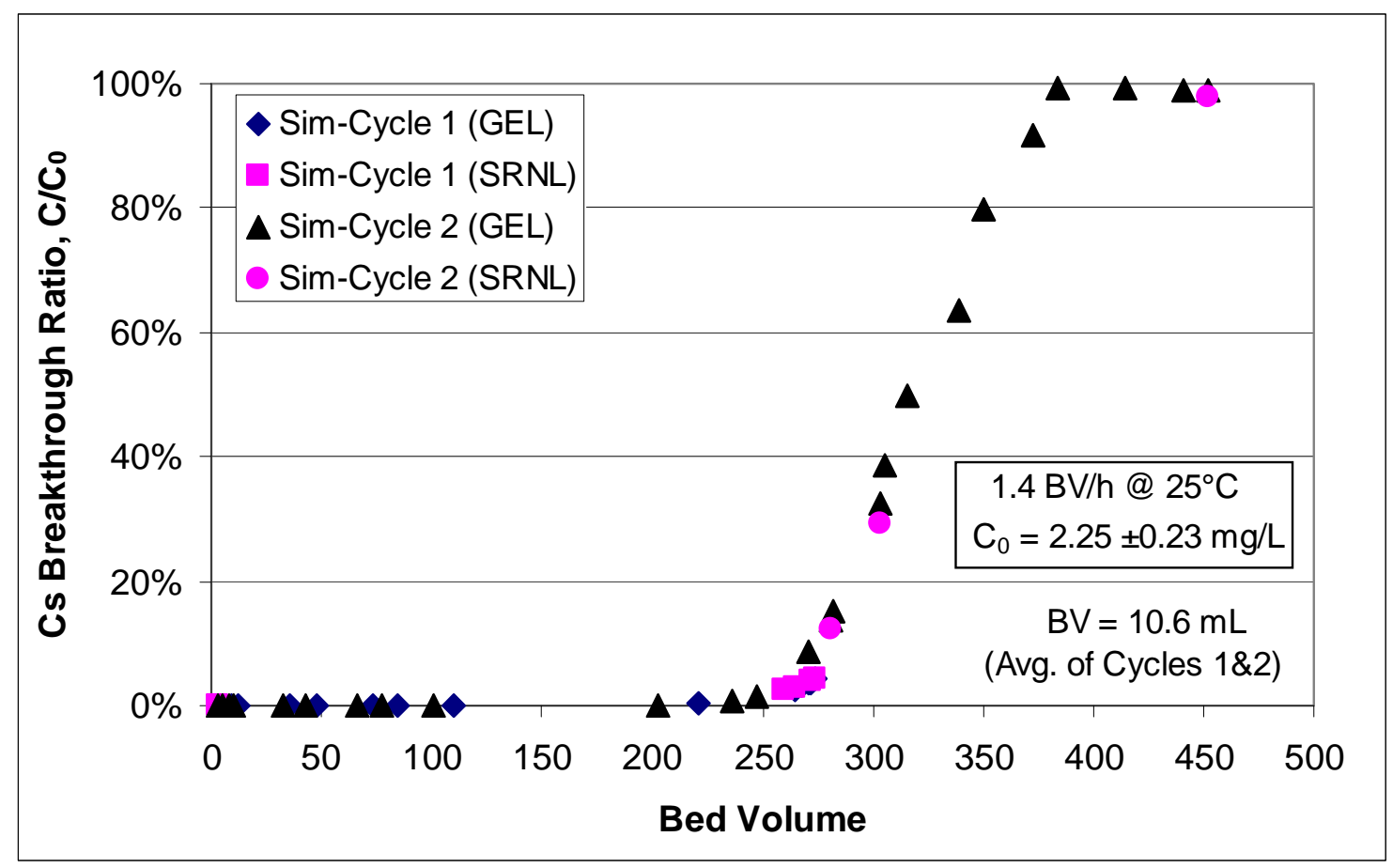

Figure 12. Lead column effluent Cs for Cycles 1 and 2 with simulant

As a sanity check to determine if the column test with simulant ran properly, it is useful to determine if the entire mass of cesium that was adsorbed onto the resin during loading was then removed by eluting the resin, as part of its regeneration. Basically, the data in Fig. 13 show the adsorption as feed moves through the column (i.e., all of the feed concentration of $2.25 \mathrm{mg} / \mathrm{L}$ of cesium was adsorbed until just after $200 \mathrm{BV}$ had traversed the column). After $200 \mathrm{BV}$, the cesium absorption onto the resin began to decline. Cycle 1 was stopped at just under $5 \%$ breakthrough when the Lead column effluent stream had a concentration of approximately $2.15 \mathrm{mg} / \mathrm{L}$. The area under the curve in Fig. 13 gives the adsorbed cesium mass to be $6.2 \pm 0.7 \mathrm{mg}$. However, this is the majority of the adsorption effectiveness for this matrix, as can be seen by comparing it with Cycle 2 Lead column adsorption, Fig. 14. For Cycle 2, the total cesium adsorbed was $7.6 \pm 0.8 \mathrm{mg}$, which is only about $25 \%$ greater than the Cycle 1 value. That is, when cesium begins to show up in the effluent stream of a Lead 
column that started with regenerated resin, approximately $75 \%$ to $80 \%$ of what will be absorbed by the column has already occurred.

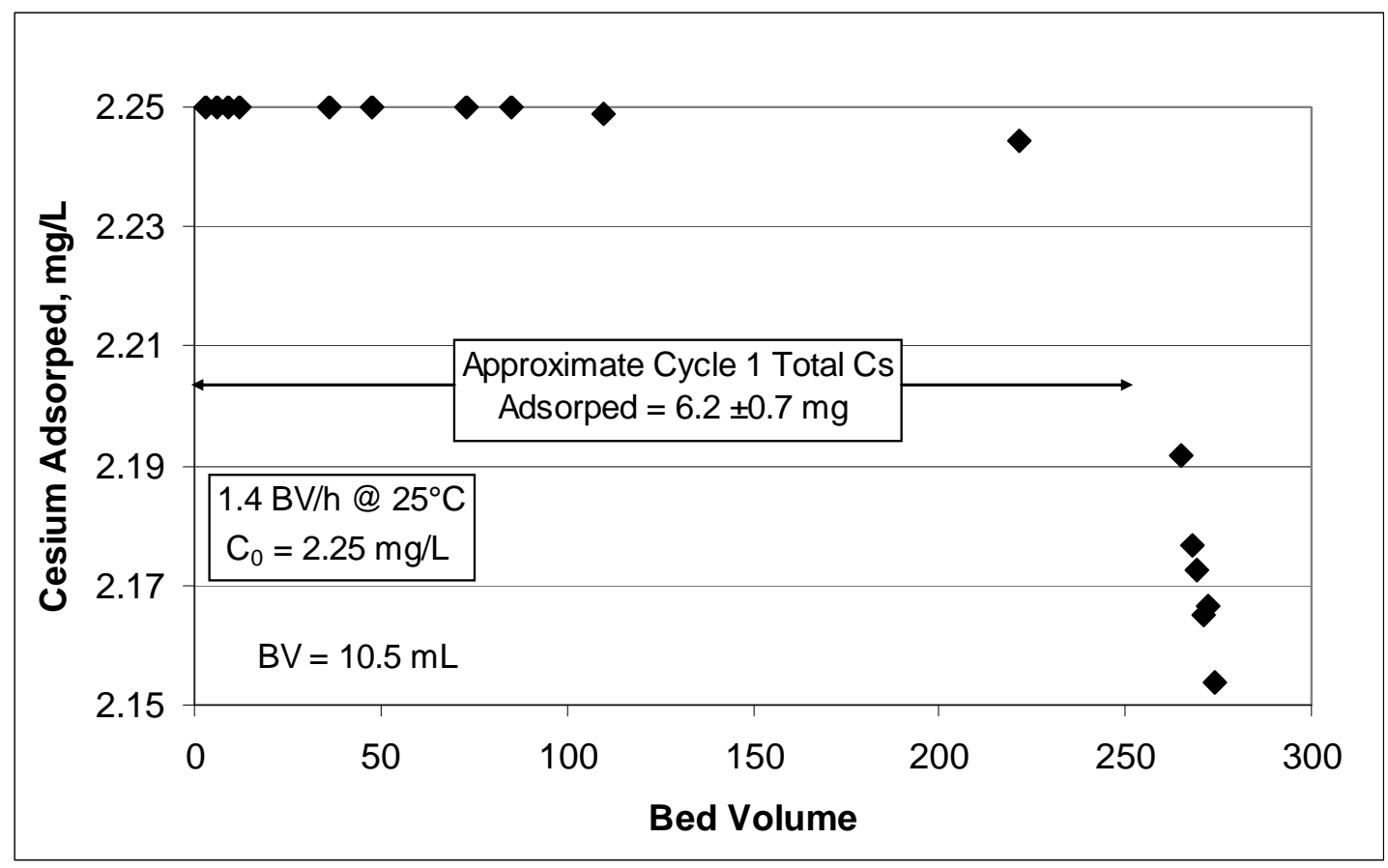

Figure 13. Lead column Cs adsorption for Cycle 1 with simulant [Note, the scale is amplified to show the features near $5 \%$ breakthrough.]

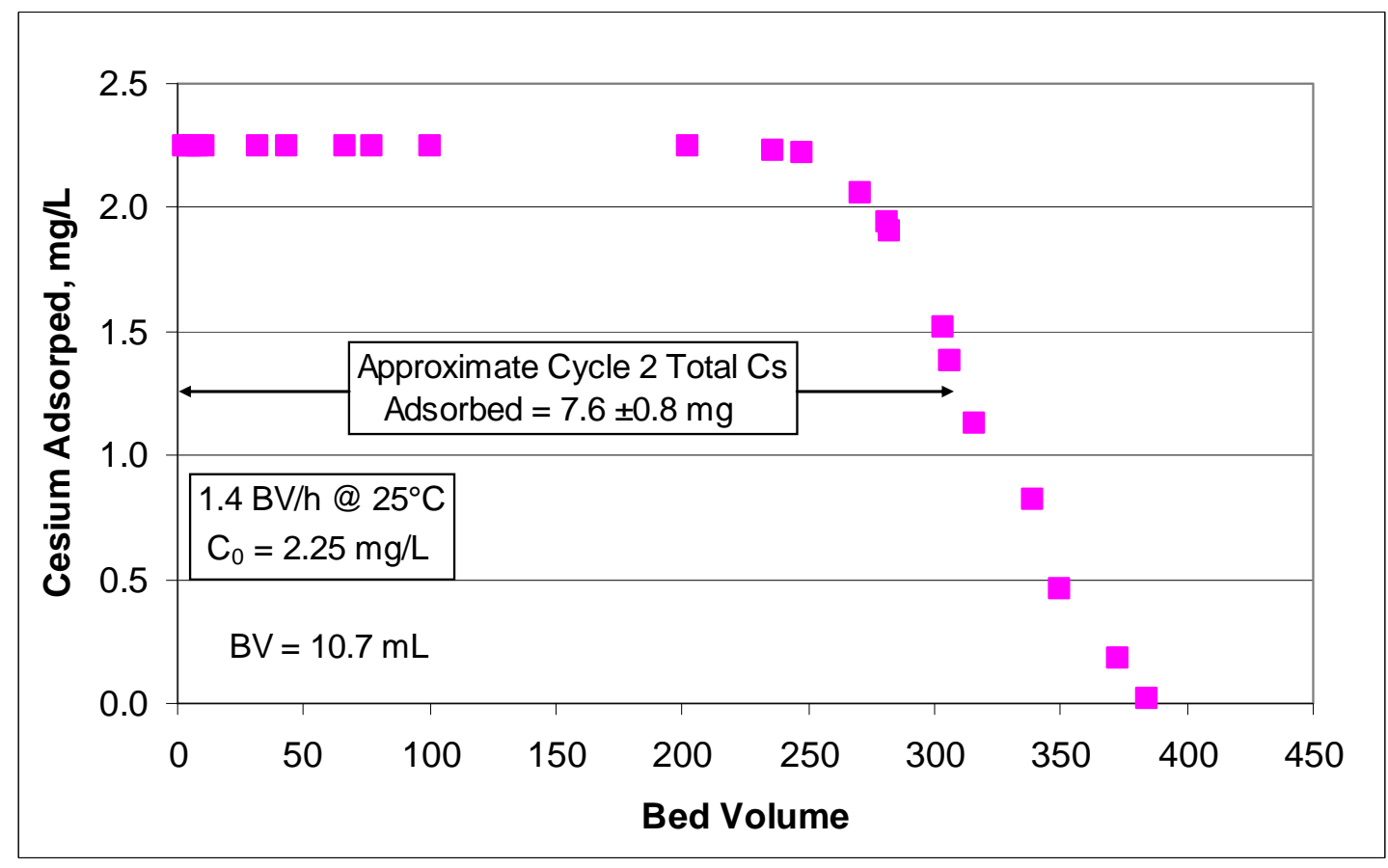

Figure 14. Lead column Cs adsorption for Cycle 2 with simulant 
After both cycles were complete the resin in the respective Lead columns were regenerated. The regeneration process included resin elution by flowing $30 \mathrm{BV}$ of $0.5 \mathrm{M}$ nitric acid at 1.4 BV/h. Figure 15 shows the over all results for both cycles of elution.

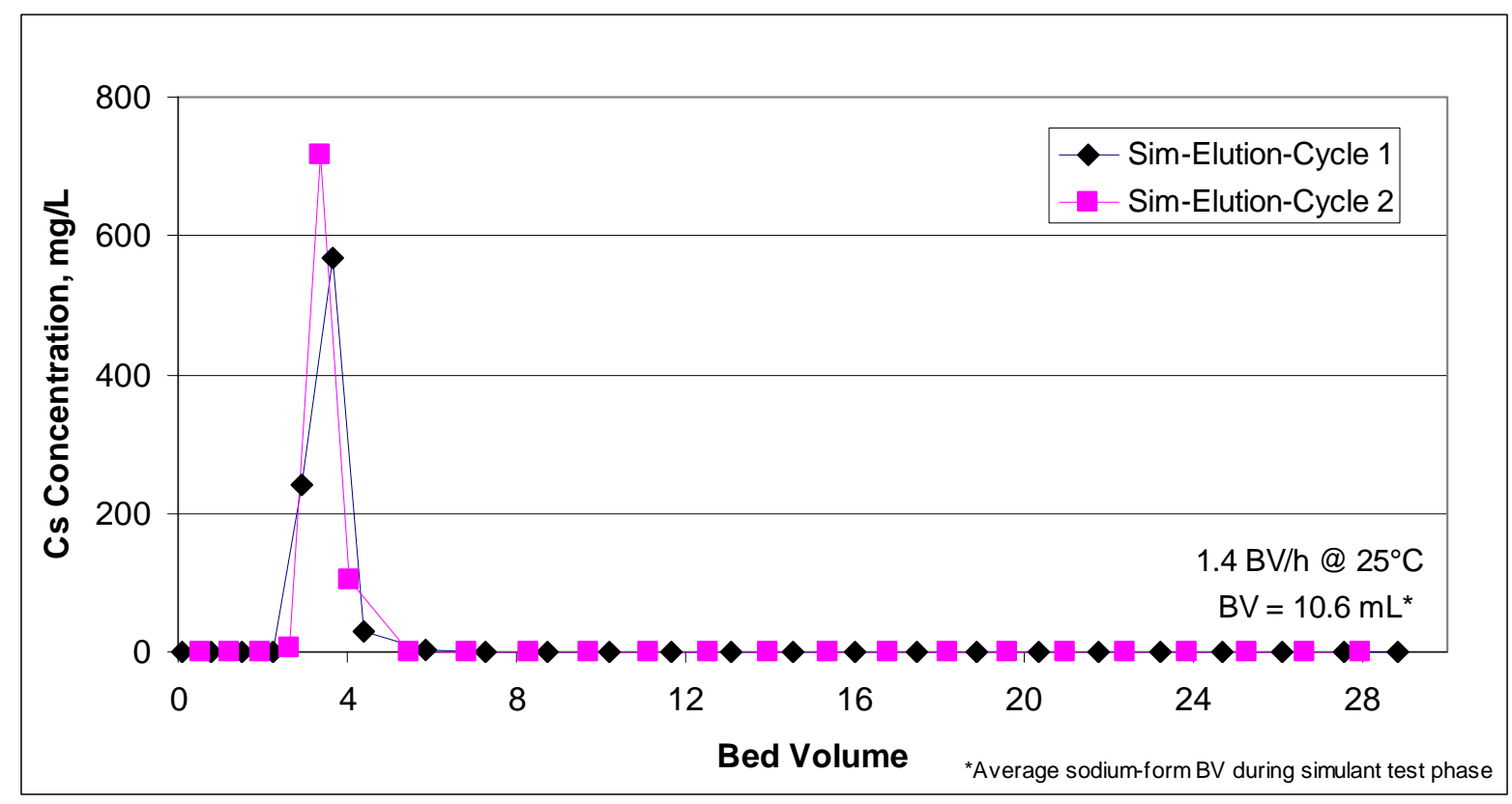

Figure 15. Lead column Cs elution during Cycles 1 \& 2 of the simulant test phase

Based on other work (Fiskum et al., 2006b) the column was eluted to 30 BV expecting a slower and "broader" cesium desorption. It was known that most of the cesium desorption occurs within the first $10 \mathrm{BV}$, of acid elution; therefore, most of the data were taken during that period; however, the elution peak and curve was not expected to be so sharp. It appears that the bulk of desorption starts at around $2 \mathrm{BV}$ and is basically complete at around $6 \mathrm{BV}$. To get a better look at the desorption and to calculate the cesium recovered, the active portions of the elution curves are shown in Figs. 16 and 17. Cycle 1 is shown in Fig. 16. Roughly estimating the area under the curve, the cesium recovered was $6.9 \pm 0.7 \mathrm{mg}$ and this compares well (11\% variance) to the Cycle 1 cesium adsorbed of $6.2 \pm 0.7 \mathrm{mg}$, shown in Fig. 13. The Cycle 2 results depicted in Fig. 17 also show a good comparison (i.e., $6.7 \pm 0.7 \mathrm{mg}$ or $88 \%$ ) of cesium recovered from elution to the $7.6 \pm 0.8 \mathrm{mg}$ adsorbed shown in Fig. 14. Based on these results, eluting the resin past 8 to $10 \mathrm{BV}$ is unnecessary for the removal of cesium. However, some other activities are occurring during elution like size and color changes of the resin. As will be seen in a following section, the resin bed height reduces during elution and continues slightly beyond $10 \mathrm{BV}$ but by this volume of processing the bed height has reached $90 \%$ or more of its final height. 
SRNL-STI-2009-00594, REVISION 0

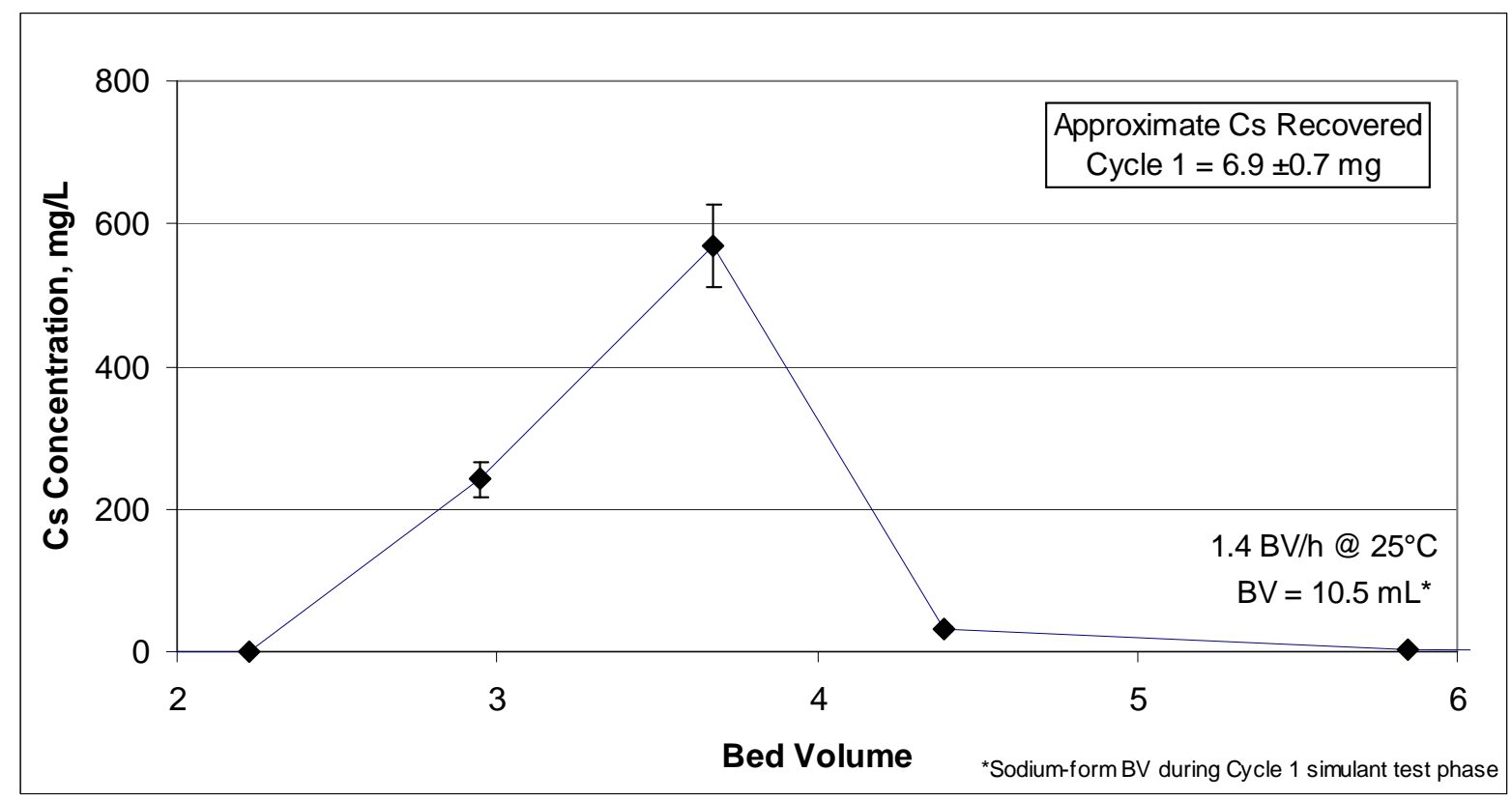

Figure 16. Lead column Cs elution during Cycles 1 of the simulant test phase

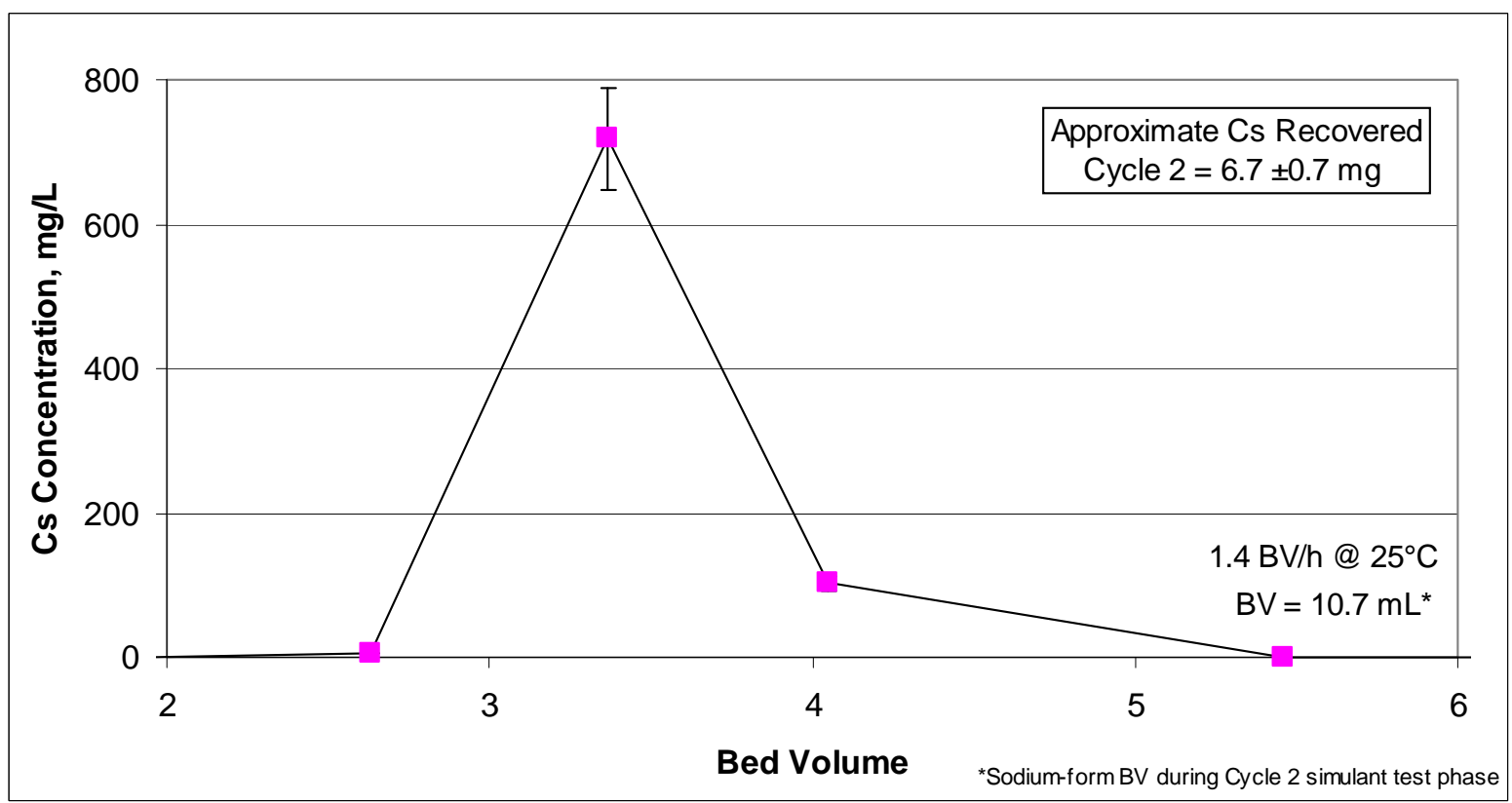

Figure 17. Lead column Cs elution during Cycle 2 of the simulant test phase

\subsubsection{Cesium results with SRS real waste}

Similar to simulant test phase, the real-waste test phase performed two complete IX cycles as currently projected for SRS operations. The intention for both phases was to treat waste with 
Column 1 as the Lead column and Column 2 as the Lag column. Once the Lead column reached a target cesium breakthrough, the treatment would stop to regenerate the resin in the Lead column and then switch columns. The Lag column, now partially loaded with cesium, is moved to the Lead position and the newly regenerated Lead column is moved to the Lag position. As previously explained, significant breakthrough was not realized for Cycle 1 of phase 1; therefore, Cycle 2 began with two columns of resin with little cesium loading. The experience obtained during the simulant phase provided insight for radiological operation. For the radioactive test phase, Cycle 1 began with same two columns of regenerated resin (i.e., reusing resin employed for Phase 1), but for Cycle 2, once the Lead and Lag columns were switched, the new Lead column, Column 2, would begin partial loaded.

Approximately 4.8 L ( 432 BV ${ }^{\dagger}$ ) for Cycle 1 and $3.7 \mathrm{~L}(\sim 329 \mathrm{BV})$ for Cycle 2 of actual SRS waste feed were used to test the SRF resin performance during the radioactive phase of testing. Cycle 1 took place over eighteen days, see Appendix B, during which time the test was operated to attain 100\% breakthrough. Based on the Cycle 2 results of the simulant test phase, which showed 100\% cesium breakthrough at about $380 \mathrm{BV}$, then Cycle 1 of the real waste test was planned to treat at least that volume of feed. As shown in Table 10 the target $\mathrm{BV}$ was 483, but only $432 \mathrm{BV}$ were treated because the average pump flowrate turned out to be slightly lower for Cycle 1 (i.e., $1.3 \mathrm{BV} / \mathrm{h}$ instead of $1.4 \mathrm{BV} / \mathrm{h}$ ), and because the test was stopped sooner than planned once $100 \%$ breakthrough was realized. Figure 18 shows that $100 \%$ breakthrough was reached after $330 \mathrm{BV}$, but most of the data past that point are not shown because they just fluctuate around the feed concentration of $3.36 \mathrm{mg} / \mathrm{L}$ of Cs, i.e., $100 \%$. Note, no significant cesium was measured in the effluent of the Lag column.

The Cycle 1 data shown in Fig. 18 are repeated along side those of Cycle 2 in Fig. 19 to compare the sRF Lead-column performance of the entire radioactive test phase. With the Lead column of Cycle 1 switched to the Lag-Column position in Cycle 2, and without regenerating the resin in the Cycle 2 Lead column, the breakthrough curve initiates earlier (i.e., just after $100 \mathrm{BV}$ ). This breakthrough volume is about $100 \mathrm{BV}$ sooner than newly regenerated resin from Cycle 1. Once cesium is detected in the effluent, the slope of the breakthrough curve is identical to the curve for a freshly regenerated column of resin. In Cycle 2, the cesium began to show up in the effluent at approximately $100 \mathrm{BV}$ and attained $100 \%$ breakthrough at just before 250 BV. For Cycle 1, cesium began at $200 \mathrm{BV}$ and ended at around $340 \mathrm{BV}$, resulting with a similar range of $\sim 140 \mathrm{BV}$ for complete loading.

\footnotetext{
† The actual volume processed was closer to $423 \mathrm{BV}$, but the larger volume that includes the extra 9 BV of feed was due to a pump failure that was found on the $7^{\text {th }}$ day of the radioactive test phase. Unfortunately, the failure was found on a Monday morning so the actual time at failure is not known. However, the volume difference was small and had little impact on the overall data.
} 
SRNL-STI-2009-00594, REVISION 0

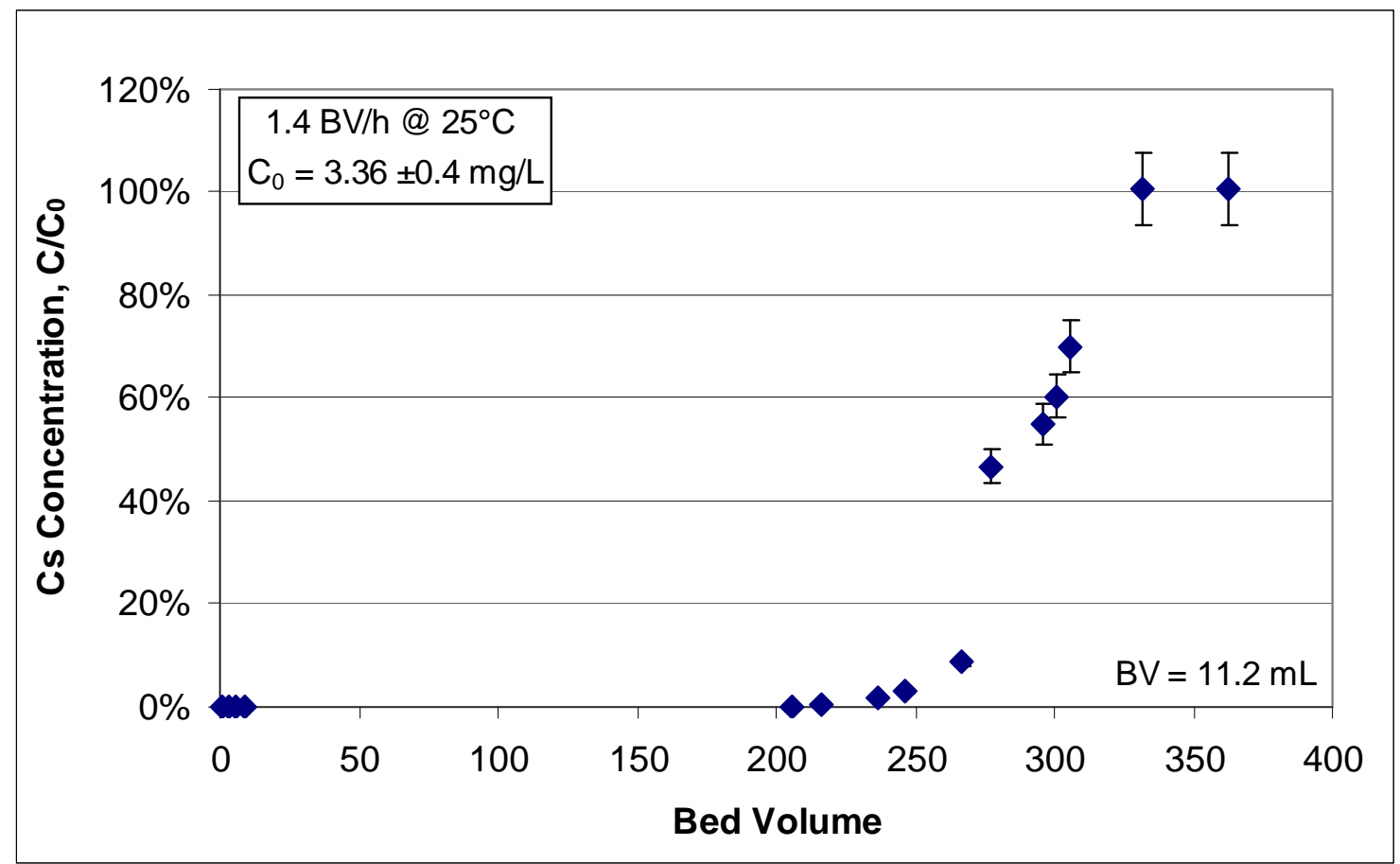

Figure 18. Lead column effluent Cs for Cycle 1 with SRS radioactive waste

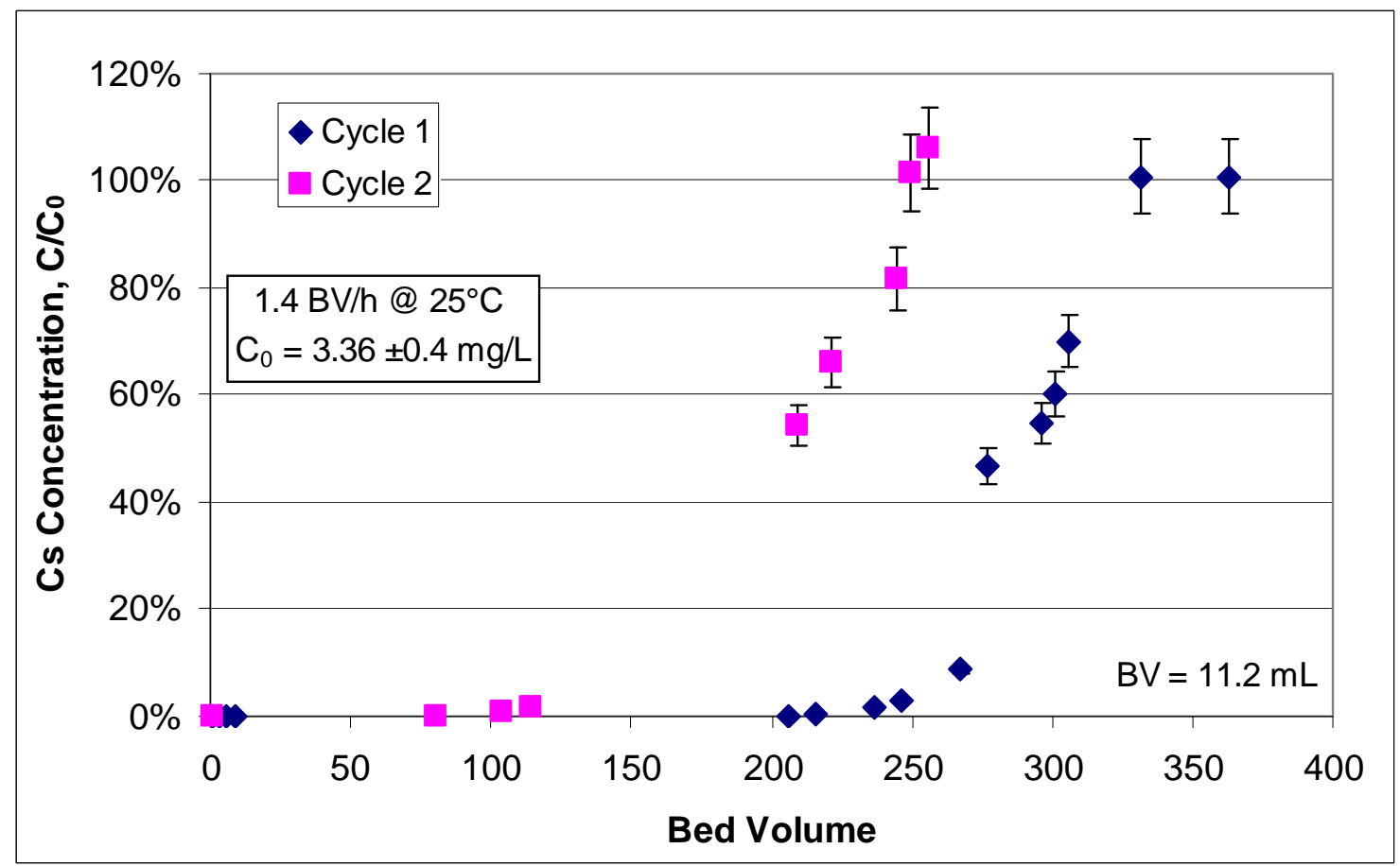

Figure 19. Lead column effluent Cs for Cycle 2 with SRS radioactive waste 
The extent of the cesium loading on the Cycle 1 Lag column resin, which is the same as the amount of cesium in the Lead column at the start of Cycle 2, is shown in Fig. 20. The figure compares the absolute amount of cesium that was absorbed during the Lead column of each cycle. For each of the two curves, the area was roughly estimated. For Cycle 1 it was

$11.3 \pm 1.4 \mathrm{mg}$ and for Cycle 2 it was $8.6 \pm 1.1 \mathrm{mg}$ and it appears that when a resin bed is taken to $100 \%$ breakthrough then approximately $85 \%$ of the cesium is adsorbed before showing up in the column effluent and the remaining $15 \%$ is loaded onto the bed as it reaches saturation. This difference between the cesium absorbed in Cycle 1 and Cycle 2 should be due to the how much cesium was preloaded onto the Cycle 2 Lead column if one can assume that both Columns 1 and 2 have the same capacity of cesium loading when starting from the same state of regeneration. As was seen from Figs. 13 and 14 for the simulant test phase, this assumption should be good. That is, if the Cycle 2 Lead column started with freshly regenerated resin, then it should be able to adsorb approximately $11.3 \mathrm{mg}$ when operated under the same flow conditions. If so, then the Cycle 2 Lead column started with a cesium loading of $11.3-8.6=2.7 \pm 2.5 \mathrm{mg}$ or in other words, that resin bed was $24 \%$ preloaded. Note, that this preloaded value depends on when feed treatment stops after a certain level of breakthrough is realized. For the current test, after the Cycle 1 Lead column effluent reached $100 \%$ breakthrough the feed continued for another approximate $80 \mathrm{BV}$ through the Lag column. This means the Lag column received another $3.36 \mathrm{mg} / \mathrm{L}$ x $80 \mathrm{BV}$ x $11.2 \mathrm{~mL} / \mathrm{BV} /$ $1000 \mathrm{~mL} / \mathrm{L}=3.0 \mathrm{mg}$ of cesium, which, when considering uncertainty, is the entire amount that was shown to be preloaded on the resin bed in the Cycle 1 Lag column (i.e., $2.7 \mathrm{mg}$ ). This implies that if the treatment of feed is stopped at, or slightly before, the point when the Lead column effluent is at $100 \%$ breakthrough then the Lag column still has most of its capacity to adsorb cesium.

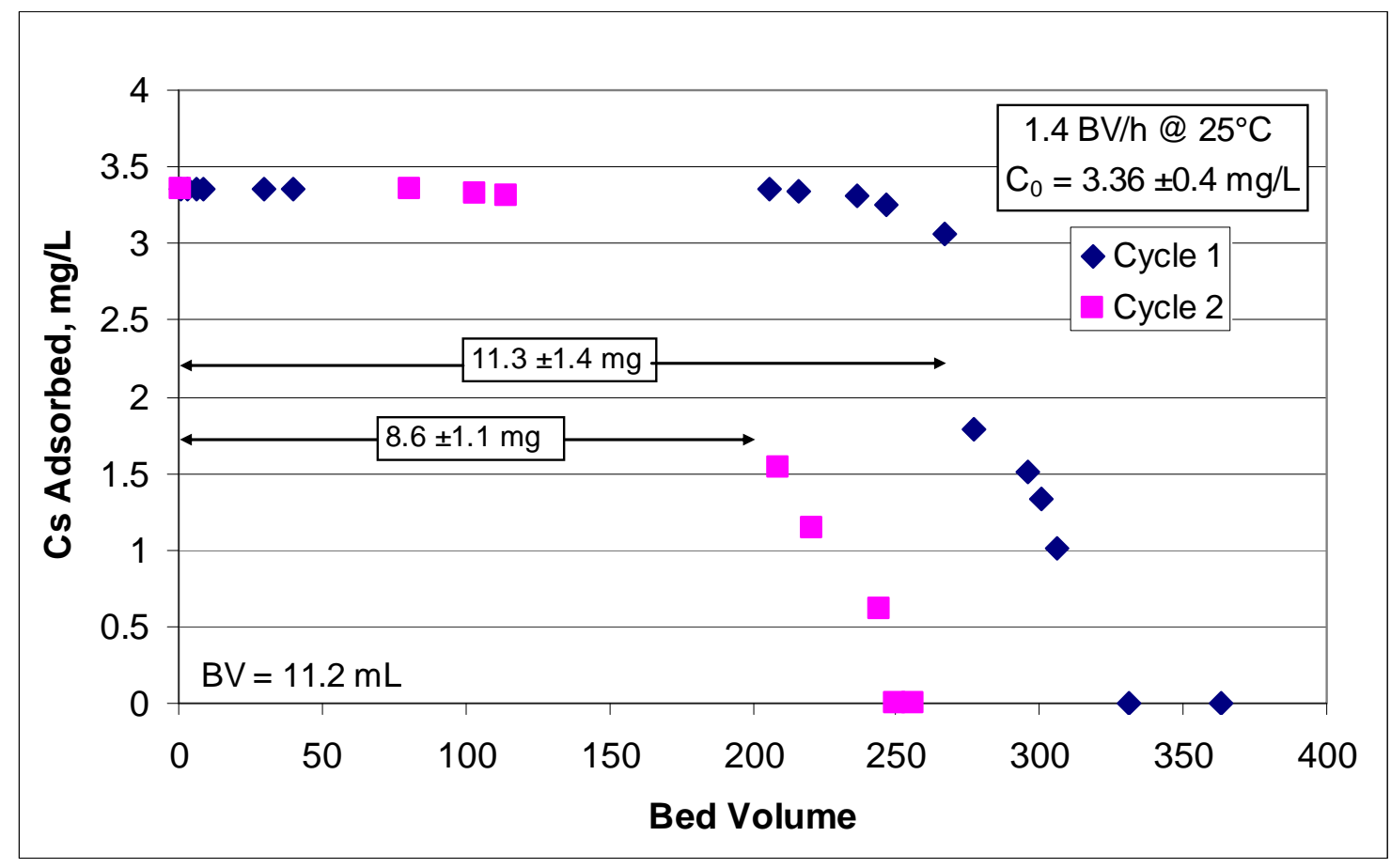

Figure 20. Lead column Cs adsorption for Cycle 1 with SRS radioactive waste 
Once again, a mass balance can be made by determining the amount of cesium that was eluted from the resin during the regeneration process. The results are very similar to those seen in the preceding simulant test phase, that is, the majority, if not all, of the cesium elution occurred between $2 \mathrm{BV}$ and 6 BV, with a sharp peak. For Cycle 1, Fig. 21, that peak of cesium concentration occurred at approximately $3.5 \mathrm{BV}$ and by $5.6 \mathrm{BV}$ the effluent of Column 1, i.e., the Cycle 1 Lead column that was regenerated, no longer had a significant cesium concentration. By roughly estimating the area under the curve the cesium released during Cycle 1 elution was $15.2 \pm 2.3 \mathrm{mg}$. For Cycle 2 the elution curve is shown in Figure 22. Remember that for Cycle 2 the Lead column was not regenerated and started with a certain level of cesium preloading.

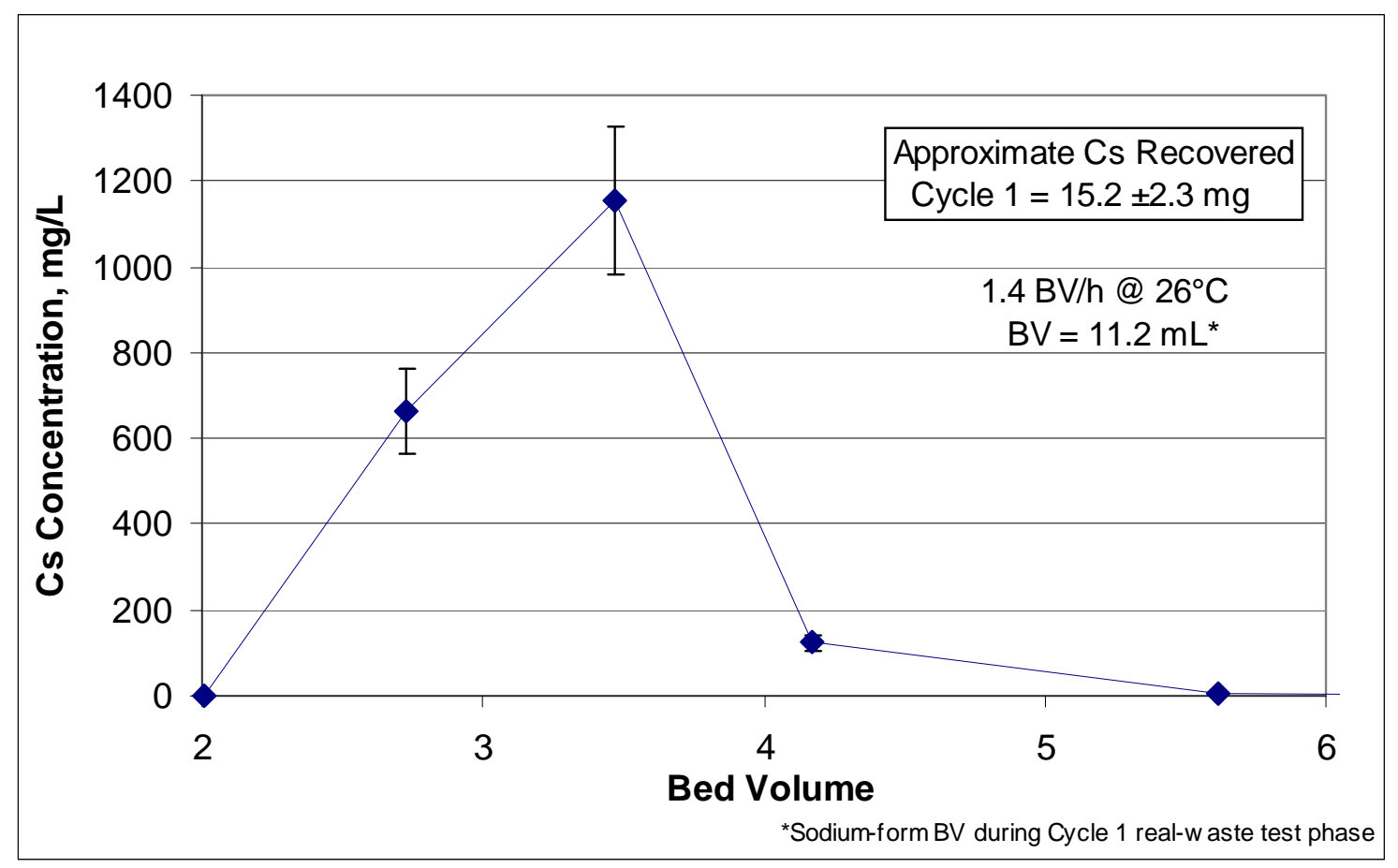

Figure 21. Lead column Cs elution during Cycle 1 of the real waste test phase

However, since that Lead column was also brought to $100 \%$ breakthrough, as was shown in Fig. 19, then the column would be expected to have approximately the same amount of cesium loading and thus elution results should be similar. This is indeed what is seen in Fig. 22. The cesium recovered from Cycle 2 elution was estimated to be $16.1 \pm 2.4 \mathrm{mg}$. Both estimates of the cesium recovered during elution are considerably higher than the Cycle 1 loading of $11.3 \mathrm{mg}$, even when considering the stated uncertainty of $1.4 \mathrm{mg}$. This discrepancy between the mass separated and then recovered indicates the difficulty in accurately estimating the cesium adsorbed during loading, desorbed during elution, or, which is more probable, the estimation of both quantities. Further, the cesium concentration slope shown in Figs. 21 or 22 is steep and over a very small amount of acid processed, which means that even small uncertainties lead to large errors in determining absolute results. 


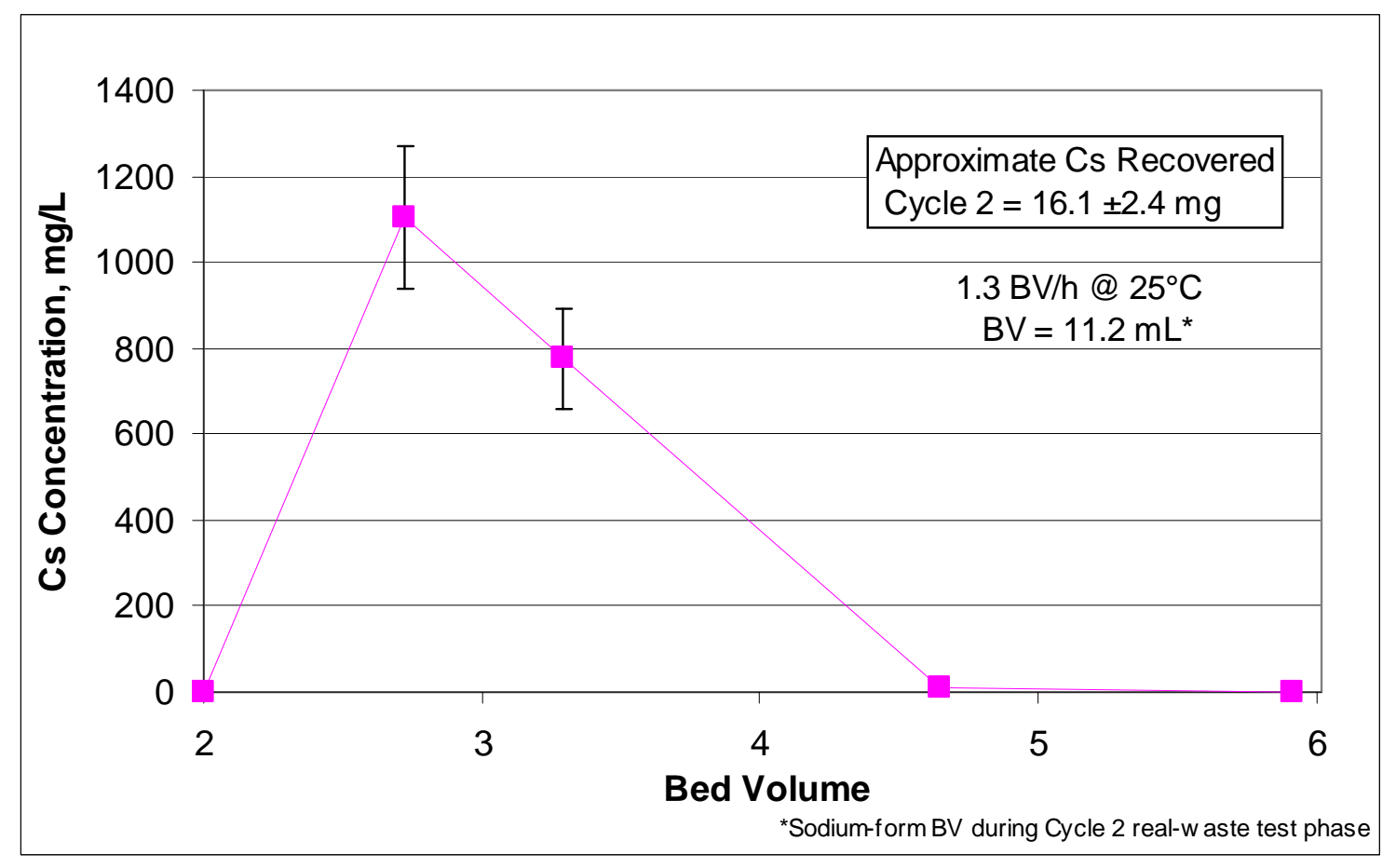

Figure 22. Lead column Cs elution during Cycle 2 of the real waste test phase

Not only was cesium recovered the same from both the Cycle 1 and Cycle 2 elutions, but the overall elution results from both cycles were similar. The data in Figs. 21 and 22 are repeated in Fig. 23, but with the entire data sets to illustrate the similarities. Note, Fig. 23 depicts the data in a semi-log format to illustrate the lower cesium concentrations that could be measured more accurate in the radioactive waste. Once again, as was explained for simulant test phase, the elution volume used of $0.5 \mathrm{M}$ nitric acid was $30 \mathrm{BV}$, which was done to follow the work of a past test (Fiskum et al., 2006b). However, for the SRS waste used the sRF resin stopped releasing significant cesium after $6 \mathrm{BV}$ of acid elution. Both cycles began releasing cesium at $2 \mathrm{BV}$ and beyond $6 \mathrm{BV}$ the cesium concentration drops below $0.1 \mathrm{mg} / \mathrm{L}$. Further, both elutions showed the same peak concentrations (i.e., $1155 \mathrm{mg} / \mathrm{L}$ for Cycle 1 and $1102 \mathrm{mg} / \mathrm{L}$ for Cycle 2), well within the measurement uncertainty of $\pm 15 \%$. Note, the second peaks at low cesium concentrations that can be seen past 8 BV in Fig. 23 may be real because the bed goes through settling as the resin shrinks. This phenomenon has been seen before (Fiskum et al., 2006b), but it was not explained; however, the magnitudes are insignificant for overall elution. 
SRNL-STI-2009-00594, REVISION 0

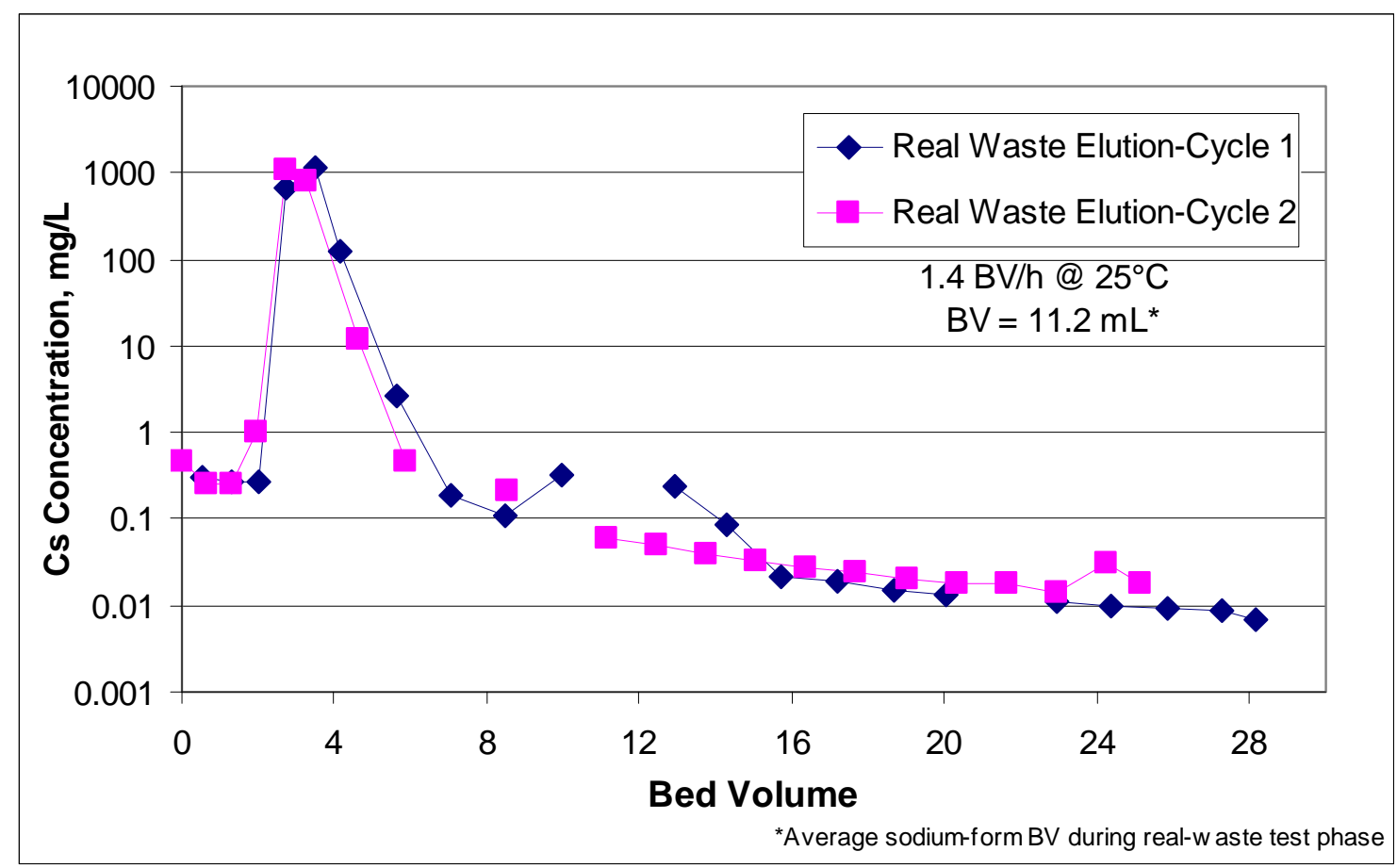

Figure 23. Lead column Cs elution during Cycles $1 \& 2$ of the real waste test phase

\subsubsection{Comparison of cesium results: SRS simulant versus real-waste}

The simulated waste was used to improve the test equipment and the test matrix prior to the radioactive test phase. By utilizing a simulant, strongly representative of the real waste in both its chemical and physical (or hydraulic) properties, useful data were obtained for sRF resin performance. Tables 2 and 5 showed the similarities between the simulant and realwaste streams; therefore, it is important to compare the data sets together. Figure 24 shows the three sets of data where the lead column started with freshly regenerated sRF; the data for Cycle 2 of the real-waste test were not included because the resin was not regenerated before use. The salient cesium loading features depicted in Fig. 24 are:

- Initial breakthrough occurs between 200 and 250 BV.

- At approximately 10\% Cs breakthrough, the slope increases rapidly.

- The transition from initial to $100 \%$ Cs breakthrough takes less than $150 \mathrm{BV}$.

- The simulant well represented the real waste for sRF performance. 
SRNL-STI-2009-00594, REVISION 0

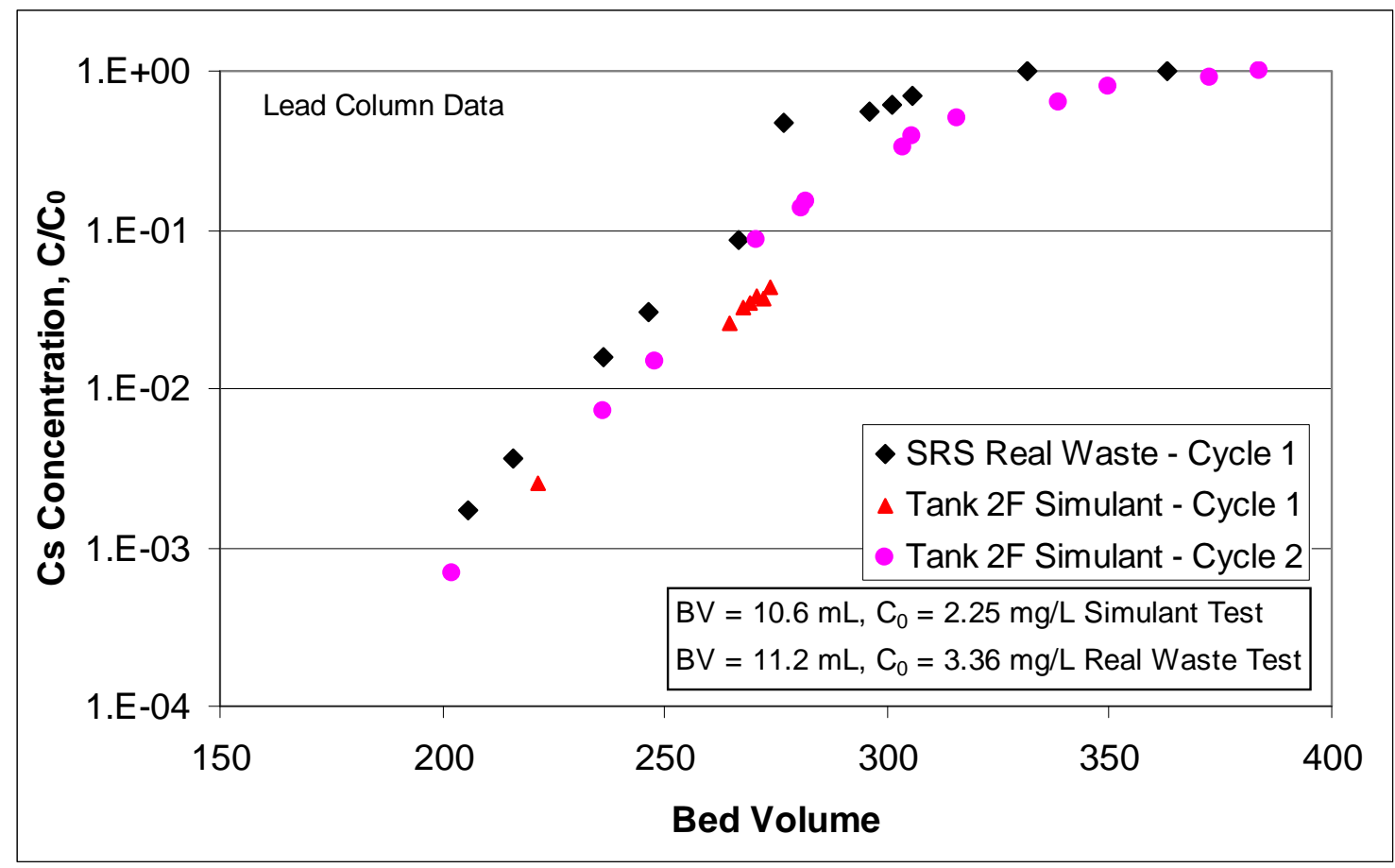

Figure 24. Cs loading of the Lead column for both the simulated waste and real waste

As was mentioned several times, no significant cesium was detected in the effluent streams of the Lag column as evidenced from the random distribution of the data in Fig. 25. That is, all the cesium measured was not significantly different from zero, when considering the uncertainty $^{\ddagger}$ of $\pm 0.03 \mathrm{mg} / \mathrm{L}$, which is $\pm 0.013 \mathrm{C} / \mathrm{C}_{0}$ for the simulated waste or $\pm 0.009 \mathrm{C} / \mathrm{C}_{0}$ for the real waste. This is even true for the Lag column of Cycle 1 of the real-waste test phase, which received more than $80 \mathrm{BV}$ of feed after the Lead column effluent reached 100\% breakthrough at $330 \mathrm{BV}$.

Concerning cesium elution, it was similar for both tests. To see this fact a comparison is shown in Fig. 26. The eluted cesium in the column effluent stream was normalized with the maximum cesium concentration realized by each respective stream. Note, that since waste treatment through the Lead column in Cycle 1 of the simulant test was stopped after only reaching approximately $4 \%$ breakthough, then the sRF resin in the column was not fully saturated $^{\dagger}$ and, therefore, is not shown in Fig. 26.

\footnotetext{
‡ This uncertainty is attributed to cesium measurements with non-radioactive $6 \mathrm{M} \mathrm{Na}+$ waste. Radioactive cesium is easier to measure; however, all of the data show concentrations of $\mathrm{C} / \mathrm{C}_{0}<0.0009$ or $<0.003 \mathrm{mg} / \mathrm{L}$. which is less than three order of magnitude the feed concentration.

${ }^{\dagger}$ Saturation is a function of many variables (e.g., temperature, flow rate of feed, regenerated state of resin, and life of resin). Because this test maintained these parameters constant a comparison can be made.
} 
SRNL-STI-2009-00594, REVISION 0

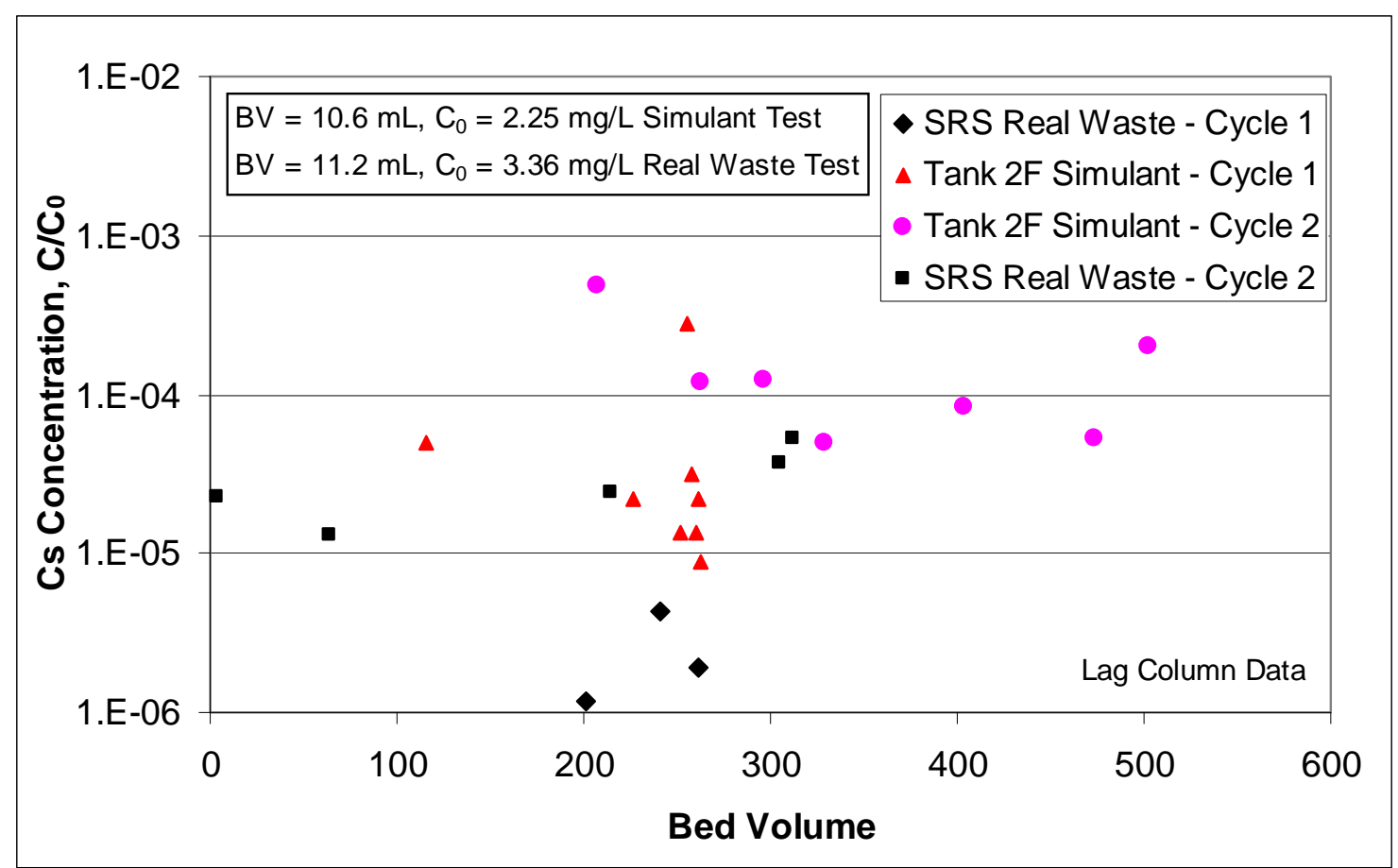

Figure 25. Cs loading of the Lag column for both the simulated waste and real waste

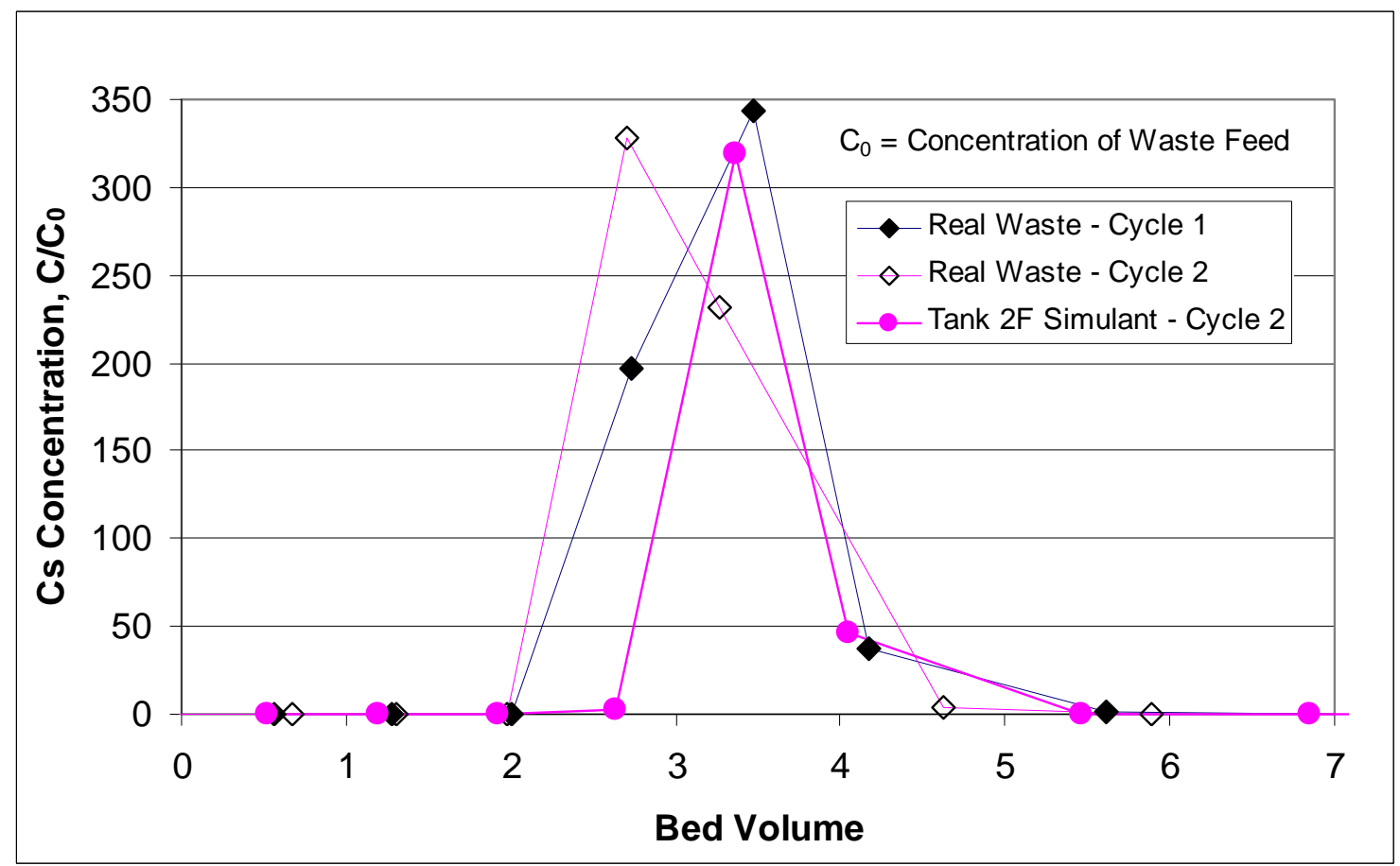

Figure 26. Cs elution for both the simulant and real waste test phases 
The salient cesium elution features depicted in the Fig. 26 are:

- $\quad$ Real waste and simulant tests show initial cesium elution at around 2 BV of acid processing.

- Real waste and simulant tests show final cesium elution at around 6 BV of acid processing.

- The peak cesium concentration during elution is between 300 and 350 times that of the cesium feed concentration, which was loaded onto the sRF resin.

\subsubsection{Bed changes that occur during elution of $\mathrm{sRF}$ resin}

Two of the well known (Duignan et al., 2008) aspects of elutable RF resin is its change in volume and color when undergoing regeneration. When removing cesium with acid, the $\mathrm{pH}$ of the resin drops from 14 to 1 and its volume decreases. When the resin is regenerated with sodium the $\mathrm{pH}$ returns to 14 and the volume returns to its full working size. This volume change has been found to be between 20 to $25 \%$. In the present work, the same results were elicited. At a flowrate of $1.4 \mathrm{BV} / \mathrm{h}$, or, for this small scale, at a superficial velocity through the column of $0.15 \mathrm{~cm} / \mathrm{min}$, the total change in volume from beginning to the end of the elution process was approximately $20 \%$ during the simulant test and $23 \%$ during the realwaste test, Fig. 27.

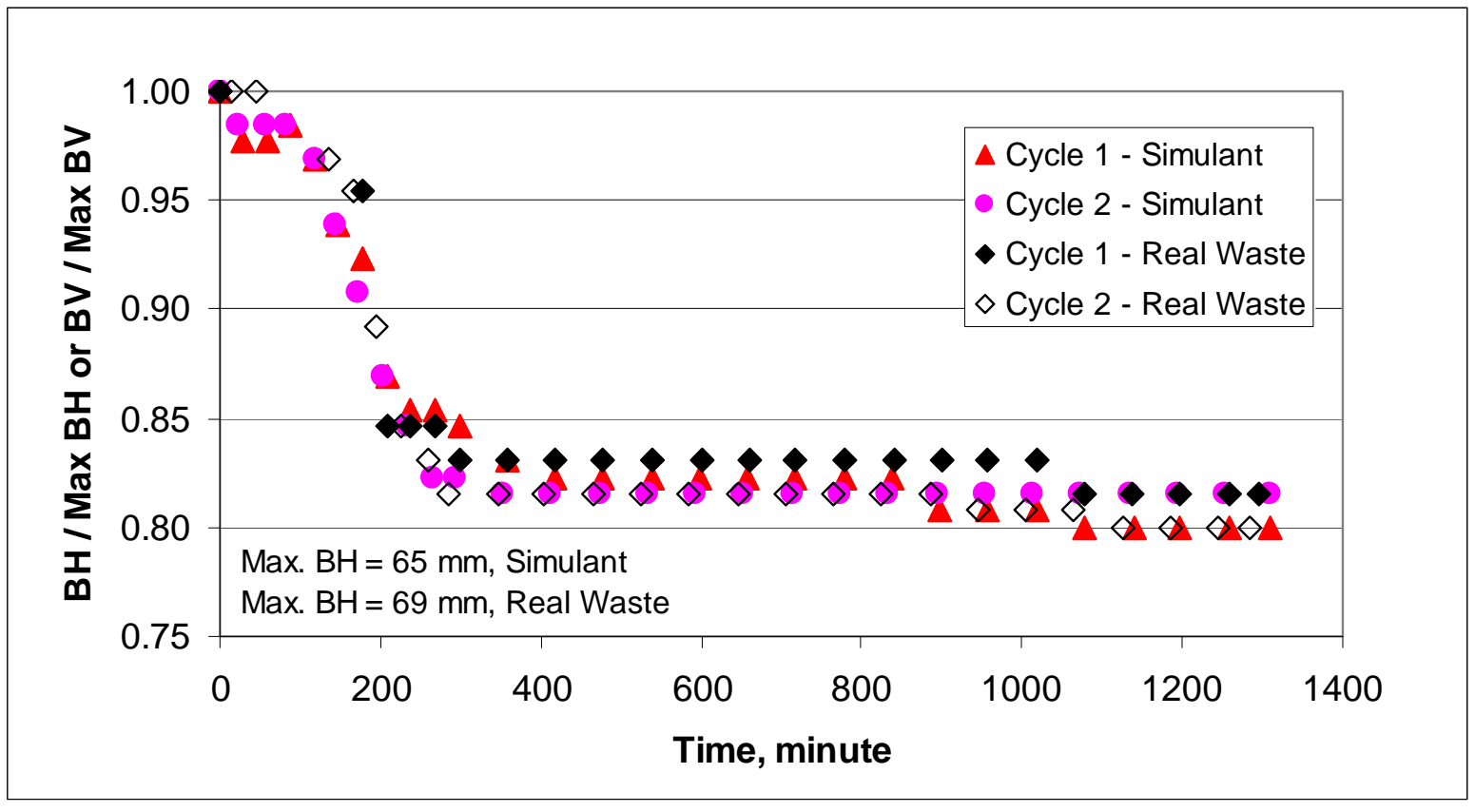

Figure 27. Cs elution for both the simulant and real waste test phases 
The elution time was just over 21 hours, but most of the volume change (i.e., greater than $90 \%$ ), occurred during the first 4 hours, during which about 6 BV of acid passed through the resin bed. This 6-BV volume corresponds with the volume where most of the cesium has been desorbed, see Fig. 15 for simulant, and Fig. 23 for real waste. Only small volume changes occur from $6 \mathrm{BV}$ to $30 \mathrm{BV}$. It appears that all changes end at about $22 \mathrm{BV}$. Figure 28 shows the same data as in Fig.27, but in terms of BV. Note, the "negative" BVs shown in the figure are the volumes processed in the beginning of elution, which is actually showing the tail end of the pre-elution rinse with deionized water. That is, when acid feed is initiated, the tubing leading to the column is still filled with the deionized water that was used to rinse out traces of any waste feed still present to prevent precipitation that would occur. It takes several BVs of acid to clear out the tubing, thus, Fig. 28 is showing the BV of deionized water initially traveling through the resin bed. Even with water, the process of resin shrinkage begins as the $\mathrm{pH}$ drops from its value of 14 . However, once the acid arrives, the bed height takes a precipitous drop.

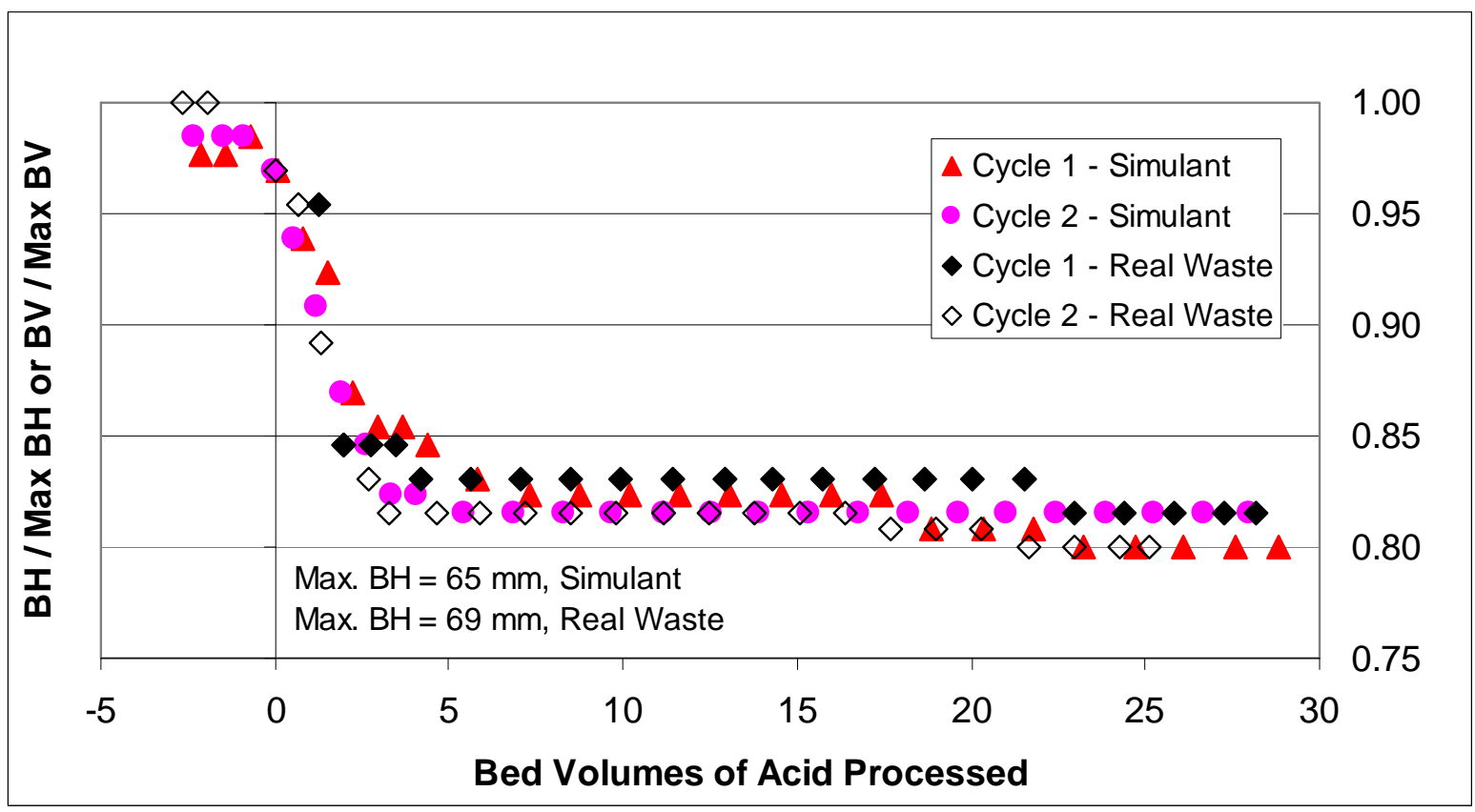

Figure 28. Cs elution for both the simulant and real waste test phases

The other sRF resin feature that changes during elution is its color. In sodium form the sRF resin has a dark burnt orange coloring, which is stable throughout waste treatment, but during elution its color changes. Once acid reaches the resin, not only does it begin to shrink but its stable burnt orange color begins to change to a bright orange. Figure 29 shows the color changing at several stages. Most of this color change occurs sooner than the $6 \mathrm{BV}$ during which time the cesium is removed concurrent with height changes. During the simulant phase of the test, the speed of the color change was measured (Nash, 2008: p. 34). Once the first few resin beads turned to bright orange, the rest of the column only took approximately 70 minutes to completely change. Since the resin bed with simulant started with a height of 
$6.5 \mathrm{~cm}^{\dagger}$, this implies a velocity of $0.09 \mathrm{~cm} / \mathrm{min}$ from the leading edge of the color wave. This velocity was slightly slower than the superficial velocity of the acid traveling through the resin bed, as was mentioned above to be $0.15 \mathrm{~cm} / \mathrm{min}$. This velocity difference is likely impacted by the kinetics of the proton exchange reaction.
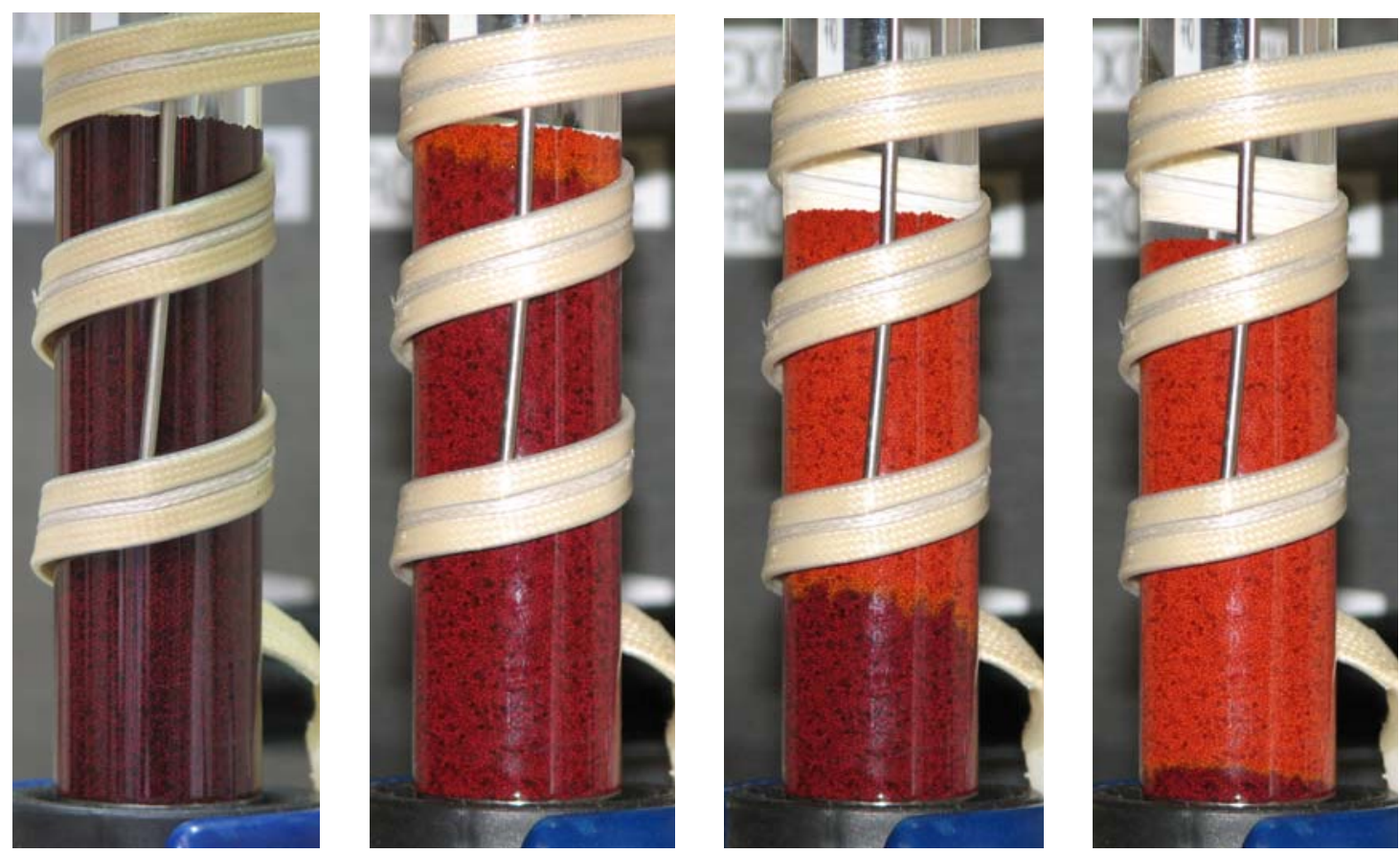

Figure 29. sRF resin color and height shrinkage during elution as it changes from $\mathrm{pH}=14$ to $\mathrm{pH}=1$ [Approximate time progression from left to right: $0,12,45,64 \mathrm{~min}$.]

\subsubsection{Miscellaneous analytes}

\section{Antimony during sRF loading}

The cesium removal of this work allowed the gamma scan method to see the trace antimony $\left({ }^{126} \mathrm{Sb}\right)$ gamma emission in many of the column product samples; thus, Fig. 30 shows that data in the interest of resin chemistry. Antimony probably existed as an oxyanion in the highly alkaline feed solution. There was no measurable interaction between the sRF resin and antimony. The Cycle 1 real-waste data clearly show that the concentration of antimony was not affected as it traveled through both the Lead and Lag columns. This fact was confirmed from the Lag column effluent concentration during Cycle 2. That is, the concentration was the same as it was during Cycle 1 and didn't change after more than 300 BV of processing. Fiskum et al. (2006c) obtained similar results finding that the

\footnotetext{
${ }^{\dagger}$ As can be noted in Fig. 29, not only the color is changing, but the bed volume or bed height is changing, too. As the color interface moves along the resin bed the bed's initial 6.5-cm height concurrently drops to about $80 \%$ of its final height of $5.2 \mathrm{~cm}$ by the time the color is completely changed.
} 
concentration of the "opportunistic analyte" antimony did not change when ICP-ES measurements from AN-102 feed and IX column product were compared.

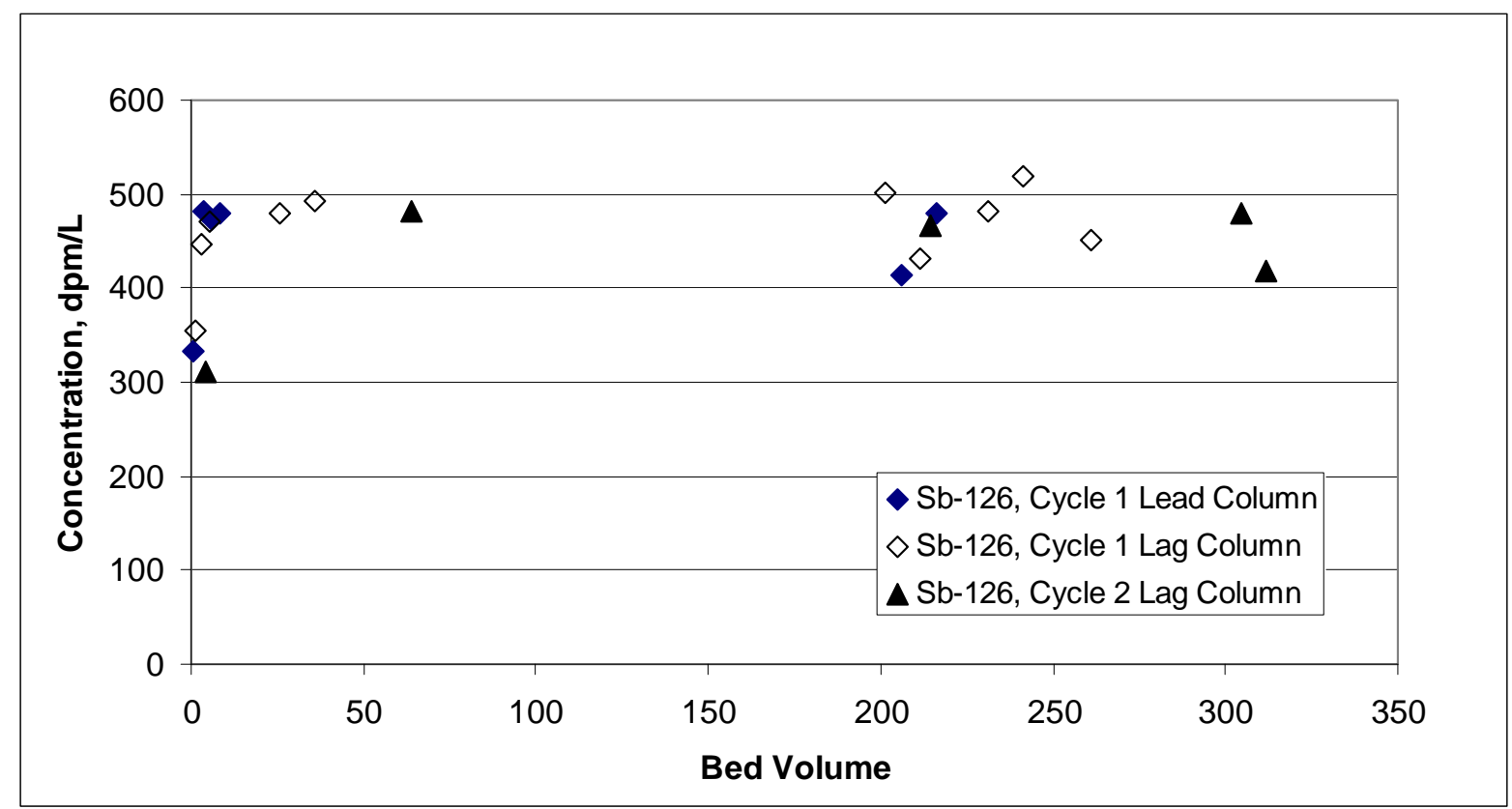

Figure 30. Effect of ${ }^{126} \mathrm{Sb}$ passing through the sRF resin during real-waste loading

Select analytes removal during elution

Three analytes ( $\mathrm{Na}, \mathrm{K}$ and $\mathrm{Al}$ ) were measured in the effluent stream during the Cycle 1 elution of the simulant test phase. In Fig. 31, the analyte concentrations were normalized by the respective analyte concentrations found in the feed simulant. Minimum concentrations of sodium and aluminum were measured in the eluate. Initially, it appears that about $20 \%$ of the feed sodium concentration comes out during elution, but only after approximately $4 \mathrm{BV}$ of acid the effluent concentration of sodium drops to a negligible amount ${ }^{\dagger}$. This is also true for aluminum. However, potassium, which competes for ion sites on the resin like cesium, resists elution for about $2 \mathrm{BV}$ of treatment. Potassium concentration then increases precipitously to almost the concentration that was in the feed stream, indicating that the acid was also removing the potassium at about the same rate as cesium. Cesium removal occurred mainly between 2 and 4 BV of acid processing (Fig. 26).

\footnotetext{
${ }^{\dagger}$ Note, Figure 31 shows that the sodium concentration after 2 BV of acid is approximately 0.6 M, i.e., the feed concentration was $6 \mathrm{M}$. Because the resin bed contains so much sodium it is actually eluted during the waste displacement and pre-elution rinse steps that precede the acid elution, as has been seen in a previous study (King et al., 2005; Fig. 2)
} 
SRNL-STI-2009-00594, REVISION 0

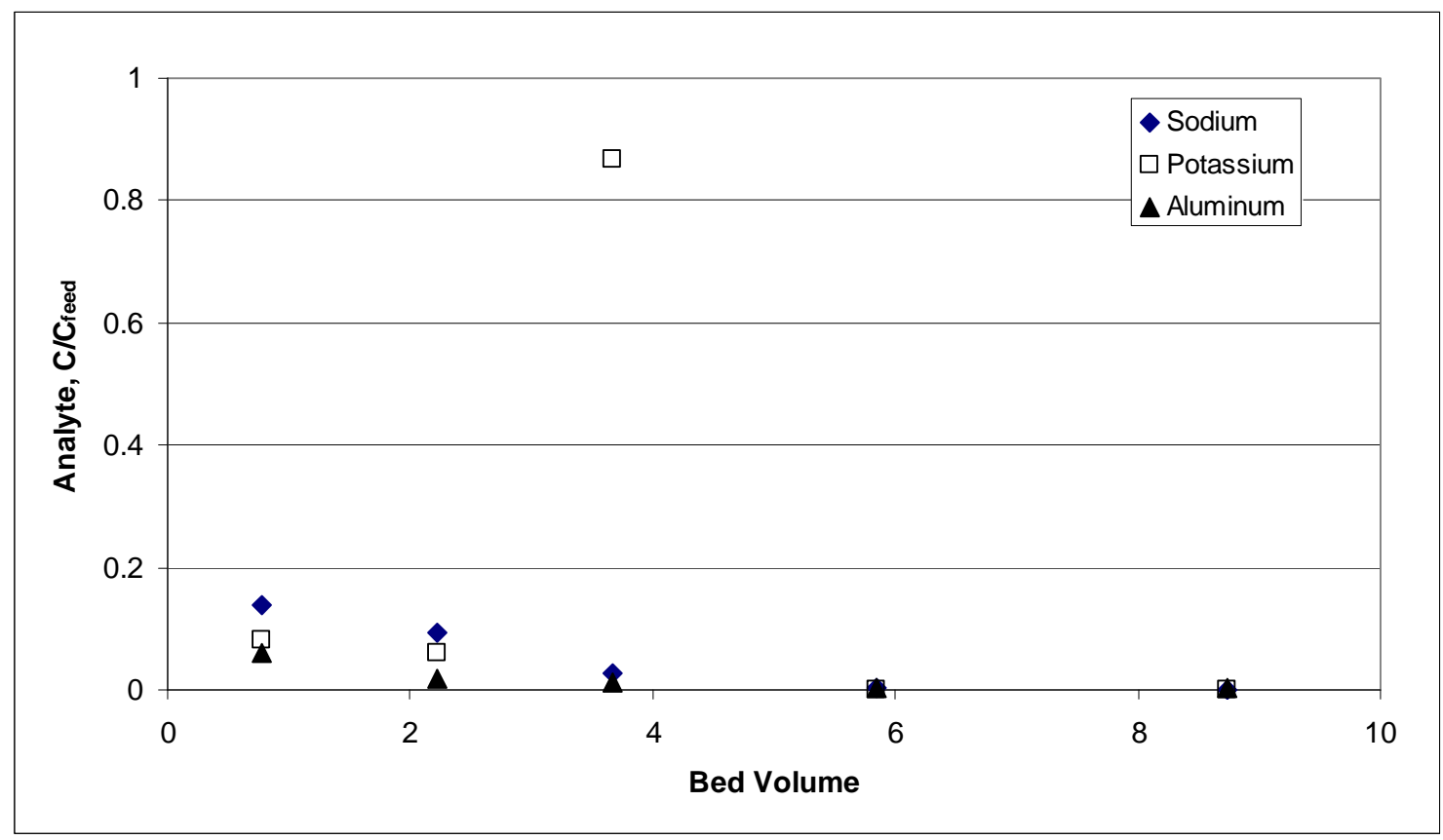

Figure 31. Select analyte concentrations in effluent stream during the elution of the Cycle 1 Lead column for the simulant test phase

\subsubsection{Analyses of composites of eluates during the real-waste test}

Design of an ion exchange plant would likely need information on eluate content outside of acid and cesium components. The acidic effluents from the Cycle- 1 and Cycle- 2 elution campaigns of the real-waste test phase were each collected in separate bottles so that these eluate composites could be characterized. Note that sampling was also done during these collections so while these composites have the bulk of elution volumes, they lack volumes taken in sample vials. They thus give an approximate composition of eluate to be expected from this process. Table 14 shows that aluminum, calcium, chromium, sodium, and zinc were consistently measurable.

For the radionuclides, Table 15 shows that plutonium is concentrated in the process. Its concentration in eluate composites was about 3.5 times that of the "new feed" to ion exchange, Table 6. From previous work Fiskum et al. (2006a) found plutonium concentration in a composite eluate from a Hanford Tank AP-101 feed, but it was only 1 to 2 times the feed level. Fiskum et al (2006b) also found measurable plutonium in a composite eluate from processing a Hanford Tank AN-102 complexant feed, but it was less than one tenth the concentration of the feed. The form of plutonium on the resin is not clear. Fiskum et al. (2006c) found that significant plutonium from real waste was left on sRF resin after elution, strongly suggesting something other than trapping of suspended plutonium solids. The fact that significant plutonium is also found in eluate does not reveal whether solids trapping or ion exchange is also holding plutonium on the resin during loading. Finally, Table 15 shows that technetium was measurable but was about $1 \%$ of the feed concentration. 
Table 14. Stable elements in eluate composites from the real-waste test phase

\begin{tabular}{|c|c|c|c|c|}
\hline Analyte & Cycle 1 & $\%$ RSD & Cycle 2 & $\%$ RSD \\
\hline ICP-ES, mg/L & Eluate & & Eluate & \\
\hline $\mathrm{Ag}$ & $<0.8$ & & $<0.9$ & \\
\hline $\mathrm{Al}$ & 101.0 & 0.9 & 20.4 & 0.9 \\
\hline $\mathrm{B}$ & $<2.5$ & & $<1.5$ & \\
\hline $\mathrm{Ba}$ & $<0.2$ & & $<0.9$ & \\
\hline $\mathrm{Be}$ & $<0.2$ & & $<0.5$ & \\
\hline $\mathrm{Ca}$ & 0.6 & 0.55 & 1.4 & 0.55 \\
\hline $\mathrm{Cd}$ & $<0.3$ & & $<0.4$ & \\
\hline $\mathrm{Ce}$ & $<4.0$ & & $<2.5$ & \\
\hline $\mathrm{Cr}$ & 1.3 & 4.2 & 1.2 & 4.2 \\
\hline $\mathrm{Cu}$ & 0.7 & 11.2 & $<1.1$ & \\
\hline $\mathrm{Fe}$ & 2.3 & 2.3 & $<3.0$ & \\
\hline $\mathrm{Gd}$ & $<0.6$ & & $<0.8$ & \\
\hline $\mathrm{K}$ & $<18.1$ & & $<11.1$ & \\
\hline $\mathrm{La}$ & $<0.5$ & & $<0.7$ & \\
\hline $\mathrm{Li}$ & $<1.3$ & & $<0.8$ & \\
\hline $\mathrm{Mg}$ & $<0.1$ & & $<0.2$ & \\
\hline $\mathrm{Mn}$ & $<0.2$ & & $<0.3$ & \\
\hline Mo & $<1.4$ & & $<0.9$ & \\
\hline $\mathrm{Na}$ & 2155 & 0.1 & 754.4 & 0.1 \\
\hline $\mathrm{Ni}$ & $<0.9$ & & $<1.5$ & \\
\hline$P$ & $<7.5$ & & $<4.6$ & \\
\hline $\mathrm{Pb}$ & $<3.7$ & & $<2.3$ & \\
\hline $\mathrm{S}$ & $<73.4$ & & $<21.6$ & \\
\hline $\mathrm{Sb}$ & $<3.8$ & & $<4.3$ & \\
\hline $\mathrm{Si}$ & $<3.2$ & & $<2.0$ & \\
\hline Sn & $<1.8$ & & $<2.2$ & \\
\hline $\mathrm{Sr}$ & $<0.2$ & & $<0.6$ & \\
\hline $\mathrm{Ti}$ & $<0.1$ & & $<0.4$ & \\
\hline$U$ & $<16.0$ & & $<9.8$ & \\
\hline $\mathrm{V}$ & $<0.3$ & & $<0.4$ & \\
\hline $\mathrm{Zn}$ & 0.6 & 8.9 & 0.5 & 8.9 \\
\hline $\mathrm{Zr}$ & $<0.2$ & & $<0.9$ & \\
\hline As by $A A$ & $<0.38$ & & $<0.46$ & \\
\hline
\end{tabular}


Table 15. Radiochemistry of Eluate Composites

\begin{tabular}{|c|c|c|c|c|}
\hline Isotope & Cycle 1 & \% RSD & Cycle 2 & \% RSD \\
\hline dpm/mL & Eluate & & Eluate & \\
\hline Am-241 & $<194$. & & $<176$. & \\
\hline Am-243 & $<29.0$ & & $<28.4$ & \\
\hline Am-242m & $<3.55$ & & $<3.78$ & \\
\hline Cm-243 & $<106$. & & $<104$. & \\
\hline Cm-245 & $<87.3$ & & $<85.8$ & \\
\hline Cm-247 & $<139$. & & $<143$. & \\
\hline Cf-249 & $<153$. & & $<149$. & \\
\hline Cf-251 & $<95.3$ & & $<99.4$ & \\
\hline Cm-242 & $<2.93$ & & $<3.13$ & \\
\hline Cm-244 & $<11.2$ & & 258 & 23.5 \\
\hline & & & & \\
\hline Sr-90 & $7.66 \mathrm{E}+04$ & & $5.87 \mathrm{E}+04$ & \\
\hline & & & & \\
\hline Tc-99 & 882 & 12.6 & 766 & 18.4 \\
\hline & & & & \\
\hline Pu238 & $1.12 \mathrm{E}+05$ & 6.3 & $9.07 \mathrm{E}+04$ & 6.1 \\
\hline & & & & \\
\hline Pu239-240 & 1940 & 69.4 & 3050 & 24.4 \\
\hline & & & & \\
\hline Pu-241 & 3720 & 16.9 & 4190 & 18.7 \\
\hline
\end{tabular}

\subsection{TCLP RESULTS TO DISPOSE OF SRF RESIN}

At the end of all testing the resin was removed and subjected to the US EPA Toxicity Characteristic Leaching Procedure (TCLP) to provide information for final disposition once a batch of resin is no longer effective in removing cesium. The TCLP test showed that the used sRF resin was negative for organics but for metals mercury was detected at a significantly measurable amount. A separate report will be issued to present the TCLP results along with analyses of the resin itself. 


\subsection{CONCLUSIONS}

\subsubsection{Batch contact tests}

Figure 32 shows that the data appear linear on a log-log plot. An extrapolation of the equation predicts that at a new feed cesium level of 2.51E-05 $\mathrm{M}$ the resin would load to 4.4E-02 $\mathrm{mmol} / \mathrm{g}$ of cesium, or $17 \mathrm{mg}$ vs. the $12.5 \mathrm{mg}$ seen in the Cycle 1 lead column. A similar prediction for simulant Cycle 2 would yield $12 \mathrm{mg}$. versus the $9.4 \mathrm{mg}$ seen.

Curvature of the isotherm up into the $1 . \mathrm{E}-05 \mathrm{M}$ cesium range is likely the reason for the under predictions.

A simple power law fit of the batch contact data provides the following equation.

$$
\mathrm{Q}_{\text {final }}, \mathrm{mmol} / \text { gram }=10^{(2.3862 \pm 0.14)} \cdot\left(\mathrm{Cs}^{+}, \mathrm{M}\right)^{(0.8225 \pm 0.02)}
$$

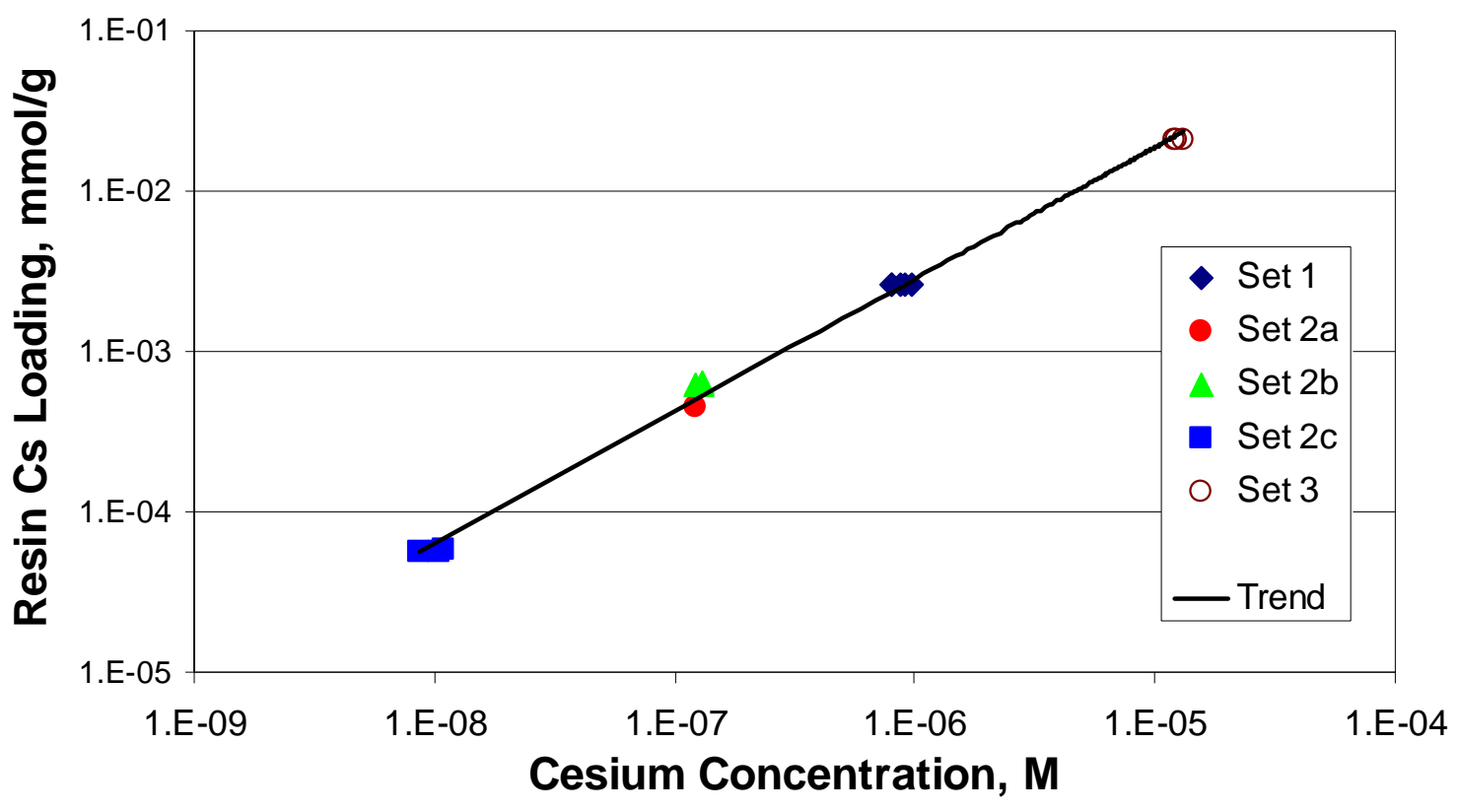

Figure 32. Plot of the Batch Contact Data and a Power Law Fit 


\subsubsection{Ion exchange column tests}

This task is the first to demonstrate the treatment of SRS waste with sRF resin and the tests clearly demonstrated cesium decontamination for actual waste. Moreover, the simulant and actual waste results were equivalent, demonstrating resin performance can be accurately obtained with non-radioactive dissolved salt wastes. The following SCIX conclusions to separate cesium from SRS Waste are presented in the order of testing.

\subsubsection{SRF resin performance to remove cesium from a SRS Tank $2 F$ Simulant}

1. Cesium breakthrough begins after processing between 200 and $250 \mathrm{BV}$ for a treatment flowrate of $1.4 \mathrm{BV} / \mathrm{h}$ at $25^{\circ} \mathrm{C}$.

2. Cesium breakthrough reaches $100 \%$ at around $400 \mathrm{BV}$, or $150 \mathrm{BV}$ after breakthrough begins, for a treatment flowrate of $1.4 \mathrm{BV} / \mathrm{h}$ at $25^{\circ} \mathrm{C}$.

3. The slope of the cesium breakthrough curve from about $5 \%$ to $100 \%$ breakthrough is approximately linear.

4. During elution all significant cesium desorption from the resin using $0.5 \mathrm{M}$ nitric acid at a flowrate of $1.4 \mathrm{BV} / \mathrm{h}$ and at $25^{\circ} \mathrm{C}$ occurs from 2 to $6 \mathrm{BV}$.

5. Most, if not all of the cesium adsorbed onto the resin is released during acid elution.

6. During elution after $2 \mathrm{BV}$ the sRF resin color stops changing from a burnt orange to a bright orange, after $6 \mathrm{BV}$ the cesium stop desorbing from the resin and more than $90 \%$ of the volume changes have occurred with all volume changes ending after 22 $\mathrm{BV}$.

\subsubsection{SRF resin performance to remove cesium from a SRS Real waste}

1. Analogous conclusions for the simulant test phase are true for the real-waste test phase.

2. Loading and elution results for the simulant work follow closely the results from the real-waste work and therefore both tests are useful to determine resin performance.

3. From both cycles it appears that if a resin bed is loaded to saturation then approximately $85 \%$ of the cesium that will be adsorbed occurs before cesium is detected in the bed effluent with the remaining $15 \%$ occurring as the bed reaches saturation.

4. Even when a Lag column that has some level of cesium pre-loading when put in the Lead position, as occurred during Cycle 2 of the real-waste phase of testing, waste treatment results in a breakthrough curve with the same approximate slope and duration, i.e., the rate of increase of the breakthrough curve and the number of BV from $0 \%$ to $100 \%$ breakthrough is the same as for a column of freshly regenerated resin. However, the start of breakthrough depends on the amount of cesium preloading. 


\subsubsection{Physical Changes of sRF resin performance during waste processing}

1. During the sRF resin regeneration process the resin shrinks to about $80 \%$ of its fully working bed volume, or bed height, in sodium form as $0.5 \mathrm{M}$ nitric acid is used to elute cesium that changes the $\mathrm{pH}$ from 14 to 1.

2. Approximately $90 \%$ of the bed height shrinkage occurs during the first $6 \mathrm{BV}$ of acid and bed size changes stop completely at approximately $22 \mathrm{BV}$.

3. During elution the resin change color from the burnt orange color while it is sodium form to a bright orange in hydrogen form.

4. The color change occurs during the first $2 \mathrm{BV}$ of acid processing and the color wave moves along the height of the resin bed at approximately $60 \%$ of the superficial velocity of the acid moving through the column.

\subsubsection{Miscellaneous analytes effects}

1. ${ }^{126} \mathrm{Sb}$ was measured during cesium loading and was found not to change throughout the process, that is, it was unaffected by the resin.

2. Elution with $0.5 \mathrm{M}$ nitric acid elutes some of the sodium and while it does not appear to elute aluminum it probably dissolves some of the Al solids deposited on the resin. Potassium was eluted from the resin with about the same amount acid processing as for the cesium, i.e., 4 to $6 \mathrm{BV}$.

3. Plutonium was the only notable component showing concentration outside of cesium. Other detected analytes such as sodium, aluminum, and technetium were likely present because of their relatively high concentrations in the feed and not because of concentration by ion exchange.

\subsection{FUTURE WORK}

1. More batch contact data are needed at relatively low potassium levels to support an isotherm for SRS-typical wastes. Much of the batch work in the past was at either zero potassium or at concentrations an order of magnitude higher than concentrations found in SRS supernates and dissolved saltcake.

2. The used resin from this work should be analyzed. It is anticipated that a follow-on report to this one will contain such characterizations.

3. The sharpness of the cesium elution curves from this work implies that acid-saving strategies can probably be applied. Strategies involving the use of less acid after the elution peak has passed are likely. For example, a flow rate reduction of acid after the peak has passed may accomplish practical elution in the same time but using much less acid. 
SRNL-STI-2009-00594, REVISION 0

\subsection{REFERENCES}

Adamson, D.J., M.D. Fowley, J.L. Steimke, T.J. Steeper, M.R. Williams, C.E. Duffey, F.Fondeur, 2006. Testing Of Resorcinol Formaldehyde Ion Exchange Resin, WSRC-TR2005-00570, SRNL-RPP-2006-00013, Savannah River National Laboratory.

Arm, S. T., D.L. Blanchard, Jr., K.P. Brooks, W.C. Buchmiller, B.J. Cook, J.M. Cuta, S.K. Fiskum, Z. Hontz, C. Isackson, A.A. Schepmoes, and D.E. Wallace, 2006. Laboratory Scale Hydraulic Testing of Spherical Resorcinol Formaldehyde Ion Exchange Resins, WTP-RPT-142, Rev. 0, Battelle-Pacific Northwest Division.

Duignan, M.R., C.A. Nash, and T.M. Punch, 2008. High Aspect Ratio Ion Exchange Resin Bed - Hydraulic Results for Spherical Resin Beads, Separation Science and Technology, Vol. 43, pp. 2943-2979

Ebra, M.A. and R.M. Wallace, 1983. Phenolic Cation Exchange Resin Material for Recovery of Cesium and Strontium, U.S. Patent No. 4,423,159, December 27.

Fiskum, S.K., S.T. Arm, M.J. Steele, and D.L. Blanchard, Jr., 2006a. Spherical ResorcinolFormaldehyde Resin Testing for ${ }^{137}$ Cs Removal from Simulated and Actual Hanford Waste Tank 241-AP-101 Diluted Feed (Envelope A), WTP-RPT-134, Rev. 0, BattellePacific Northwest Division.

Fiskum, S.K., M.J. Steele, and D.L. Blanchard, Jr., 2006b. Small Column Ion Testing of Spherical Resorcinol-Formaldehyde Resin for ${ }^{137}$ Cs Removal from Pre-Treated Hanford Tank 241-AN-102 Waste (Envelope C), WTP-RPT-135, Rev. 1, Battelle-Pacific Northwest Division.

Fiskum, S.K., I.E. Burgeson, O.T. Farmer, III, L.R. Greenwood, C.Z. Soderquist, M.J. Steele, and M.P. Thomas, 2006c. Spherical Resorcinol-Formaldehyde Resin Analysis Following Actual Hanford Tank Waste Processing, WTP-RPT-144, Rev. 0, Battelle-Pacific Northwest Division.

Herman, D.T., D.B. Stefanko, M.R. Poirier, and S.D. Fink, 2009. Testing of a Full-Scale Rotary Microfilter for the Enhanced Process for Radionuclides Removal, SRNL-STI2009-00183, Rev. 0.

King, W.D., W.A. Spencer, L.L. Hamm, S.E. Aleman, C.E. Duffey, and M.A. Pettis, 2005. Column Performance Testing of SuperLig 639 with Simulated Hanford Waste Supernates: Indentification of the Primary Sorbing Species and Detailed Characterization of Their Desorption Profiles, Separation Science and Technology, Vol. 40, pp. 383-394 
Nash, C. A. 2004. Hanford RPP-WTP Alt Resin Program - Protocol P1-RF: Spherical Resin Sampling from Containers, Resin Pretreatment, F-Factor, and Resin Loading to Column, SRNL-RPP-2004-00058, Savannah River National Laboratory.

Nash, C. A., 2008, Controlled Laboratory Notebook: Ion Exchange Resin Research part II, SRNS-NB-2008-00005, opened 08/14/2008.

Nash, C.A., M.R. Duignan, and C.E. Duffey, 2006. Batch, Kinetic, and Column Data from Spherical Resorcinol-Formaldehyde Resin, WSRC-STI-2006-00071, Rev. 0. [also: SRNL-RPP-2006-00024, Rev. 0]

Nash, C. A., and Duignan, M. R., 2009. Task Technical And Quality Assurance Plan: Small Column Ion Exchange Testing with Tank Waste and Spherical Resorcinol-Formaldehyde Resin, SRNS-RP-2009-00262, rev. 0.

Peters, T. B., Nash, C. A., and Fink, S. D.., 2008. ISDP Salt Batch \#2 Supernate Qualification, SRNL-STI-2008-00446, rev. 1.

Smith, F. G., 2007. Modeling of Ion-Exchange for Cesium Removal from Dissolved Saltcake in SRS Tanks 1-3, 37 and 4, WSRC-STI-2007-00315, August, 2007.

Tran, H.Q., 2007. Tanks 1-3, 37, and 41 Dissolved Salt Solution Projected Compositions, LWO-PIT-00040, Rev. 0.

Walker, D. D. 2004. Hanford RPP-WTP Alt Resin Program - Protocol P2-RF: Ion Exchange Batch Contact Tests, SRNL-RPP-2004-00055, Savannah River National Laboratory.

Welch, T.D., K.K. Anderson, D.A. Bostick, T.A. Dillow, M.W. Geetings, R.D. Hunt, R. Lenarduzzi, A.J. Mattus, P.A. Taylor, and W.R. Wilmarth, 2000. Hydraulic Perfomance and Gas Behavior of a Tall Crystalline Silicotitanate Ion-Exchange Column, ORNL/TM1999/103, Chemical Technology Division of Oak Ridge National Laboratory. 


\subsection{ACKNOWLEDGMENTS}

The authors would like to thank all of the SRNL personnel who made this test a success. For discussions with Duane Adamson, Bill King, Mark Fowley, Dan McCabe, John Steimke, and for the technical review by Bill King. For preparing the test rig equipment the authors thank: Jerry Corbett, Tim Steeper, Andy Foreman, Jimmy Mills, and especially Mike Armstrong for his robust construction. For providing the SRS Tank 2F simulant and the SRS radioactive waste we are indebted to Mike Poirier and Chris Martino, as well as and for the use of Chris's laboratory for the non-radioactive testing.

For the simulant work we greatly appreciate the long hours put in by Shirley Brunson-Brown for running the equipment, to Mrya Pettis and Henry Bolton for providing equipment and preparing solutions, and to Mona Blume for her assistance with both the many nonradioactive and radioactive samples. For the radioactive work, the entire SRNL Shielded Cells Group deserves our thanks, including Jane Howard, Nan Stanley, Monica Jenkins, and others, but a special thanks goes to Dee Wheeler and Phyllis Burkhalter. Moreover, Ron Blessing is the man in the Shielded Cells who solved our equipment problems. Thank you!

For the eHAP we thank all the Subject Matter Experts and to complete that process the assistance of both Elliot Clark and Jake Venzie was very helpful. We would like to thank all of the SRNL management involved from our immediate managers, Bill Giddings, Doug Sumpter, and Sam Fink, to the overall SRNL Ion Exchange project lead, Frank Pennebaker, and to the principal managers in the Shielded Cells, Steven Beard and Babb Attaway for being flexible, understanding, and keeping us safe. Finally, this work could have been realized without the funding and confidence of Bill Wilmarth and support of Sharon Marra. 


\section{APPENDIX A. BATCH CONTACT DATA}

The following data provide the detailed data from batch contact work. Set 1 used "Old Feed" and Set 2 used an "Old Feed" - simulant mixture, "Old Feed" at lower phase ratio, and feed that had already seen cesium removal from Set 1 .

Table 16. F-Factor Data For Batch Contacts

\begin{tabular}{|l|c|c|c|c|c|c|}
\hline & Set 1 & Set 1 & Set 1 & Set 2 & Set 2 & Set 2 \\
\hline & Resin 1 & Resin 2 & Resin 3 & Resin 1 & Resin 2 & Resin 3 \\
\hline & & & & & & \\
\hline Moist & 0.4614 & 0.4687 & 0.5849 & 0.4322 & 0.6193 & 0.5795 \\
\hline Dry & 0.2259 & 0.2317 & 0.2849 & 0.2251 & 0.3218 & 0.303 \\
\hline F-fact & 0.4896 & 0.4943 & 0.4871 & 0.5208 & 0.5196 & 0.5229 \\
\hline & & & & & & \\
\hline Average & & 0.4903 & & & 0.5211 & \\
\hline \% RSD & & 0.75 & & & 0.31 & \\
\hline
\end{tabular}

Table 17. F-Factor Data for Resin used in the Columns

\begin{tabular}{|l|c|c|c|}
\hline & Column & Column & Column \\
\hline & Resin 1 & Resin 2 & Resin 3 \\
\hline & & & \\
\hline Moist & 0.442 & 0.4892 & 0.4745 \\
\hline Dry & 0.2164 & 0.2324 & 0.231 \\
\hline F-fact & 0.4896 & 0.4751 & 0.4868 \\
\hline & & & \\
\hline Average & & 0.4838 & \\
\hline \% RSD & & 1.6 & \\
\hline
\end{tabular}

Table 18. Resin and Liquid Masses for Set 1

\begin{tabular}{|c|c|c|c|c|c|}
\hline Replicate & $\begin{array}{c}\text { Resin } \\
\text { Mass }\end{array}$ & $\begin{array}{c}\text { Std Resin } \\
\text { Mass }\end{array}$ & $\begin{array}{c}\text { Liq. } \\
\text { Mass }\end{array}$ & $\begin{array}{c}\text { Calc. } \\
\text { vol. }\end{array}$ & Phase Ratio \\
\hline & g, moist & H+ form & $\mathrm{g}$ & $\mathrm{mL}$ & $\mathrm{mL} / \mathrm{g}$ \\
\hline feed & 0 & 0 & $\sim 20$ & & \\
\hline 24 hours & 0.4325 & 0.2121 & 27.444 & 21.116 & 99.57 \\
\hline 48 hours & 0.4341 & 0.2129 & 27.417 & 21.095 & 99.10 \\
\hline 48 hours & 0.4330 & 0.2123 & 27.346 & 21.041 & 99.10 \\
\hline 72 hours & 0.4340 & 0.2128 & 27.432 & 21.107 & 99.18 \\
\hline 72 hours & 0.4342 & 0.2129 & 27.480 & 21.144 & 99.31 \\
\hline
\end{tabular}


Table 19. Resin and Liquid Masses for Set 2

\begin{tabular}{|c|c|c|c|c|c|}
\hline Replicate & $\begin{array}{c}\text { Resin } \\
\text { Mass }\end{array}$ & $\begin{array}{c}\text { Std Resin } \\
\text { Mass }\end{array}$ & $\begin{array}{c}\text { Liq. } \\
\text { Mass }\end{array}$ & $\begin{array}{c}\text { Calc. } \\
\text { vol. }\end{array}$ & Phase Ratio \\
\hline g, moist & H+ form & g & $\mathrm{mL}$ & $\mathrm{mL} / \mathrm{g}$ \\
\hline Spike sim feed (1) & 0 & 0 & $\sim 26$ & $\sim 20$ & \\
\hline Sp_sim48 & 1.6505 & 0.8601 & 26.405 & 20.317 & 23.62 \\
\hline & & & & & \\
\hline "Old Feed” & 0 & 0 & $\sim 26$ & $\sim 20$ & \\
\hline 48 hours, A & 1.6110 & 0.8395 & 25.040 & 19.266 & 22.95 \\
\hline 48 hours, B & 1.6500 & 0.8598 & 26.190 & 20.151 & 23.44 \\
\hline 72 hours & 1.6434 & 0.8564 & 25.879 & 19.912 & 23.25 \\
\hline & & & & & \\
\hline Lo-Cs Feed (2) & 0 & 0 & $\sim 26$ & $\sim 20$ & \\
\hline 48 hours A & 0.5848 & 0.3047 & 26.339 & 20.266 & 66.50 \\
\hline 48 hours B & 0.5855 & 0.3051 & 25.554 & 19.662 & 64.44 \\
\hline 72 hours & 0.5979 & 0.3116 & 25.859 & 19.896 & 63.86 \\
\hline
\end{tabular}

(1) A mixture of simulant with "Old Feed."

(3) Lo-Cs feed is the "Old Feed” composite taken from Set 1 


\section{APPENDIX B. DATA SHEETS: SIMULANT \& REAL-WASTE TESTS}

Tables 20 to 30 list all the data taken during the both the simulant and real-waste phases of testing. Each row that lists a Sample Indentifier is when a sample was taken and the status of the operating columns was noted. At times, the \#'s listed in the tables many seem to be missing, but are missing because data were not taken due to being deemed not necessary at the time. Conversely, at the time the \#'s will be augmented with decimals or letters, e.g., 27, 27.1, 27.2 or $21 \mathrm{a}, 21 \mathrm{~b}$, which only means that extra samples were taken after the test started and the test matrix had been fixed. Finally, some of the Sample-Identifier numbers may not seem to be in order, where endings may change from, e.g., -337 to -209 to -349 , or sometimes they are repeated. All of these items are not errors but changes that occurred while taking data.

Table 20. Part A - Cycle 1 Simulant Data Sheet

\begin{tabular}{|c|c|c|c|c|c|c|c|}
\hline \multicolumn{8}{|c|}{ Cycle 1 Testing with Simulant } \\
\hline Date & \# & Loc. & Time & Col. $1 \mathrm{~T}\left({ }^{\circ} \mathrm{C}\right)$ & Col. $2 \mathrm{~T}\left({ }^{\circ} \mathrm{C}\right)$ & $\mathrm{Col} \mathrm{H}(\mathrm{mm})$ & Sample Indentifier \\
\hline \multicolumn{8}{|c|}{ Regen. with $0.5 \mathrm{M} \mathrm{NaOH}$} \\
\hline $4 / 27 / 2009$ & reserv & ir at start & $12: 00$ & & 614.8 & $<$ grams & \\
\hline $4 / 27 / 2009$ & 1 & col1 & $12: 58$ & 27 & 23 & 60.0 & sim-1-c1-preTre-col1-3 \\
\hline $4 / 27 / 2009$ & 2 & col1 & $13: 58$ & 25 & 23 & 64.0 & sim-2-c1-preTre-col1-6 \\
\hline $4 / 27 / 2009$ & & col1>col2 & $14: 05$ & \multicolumn{4}{|c|}{ Switched from Column 1 to Column 1 Processing } \\
\hline $4 / 27 / 2009$ & 3 & $\mathrm{col} 2$ & $14: 58$ & 23 & 25 & 63.0 & sim-3-c1-preTre-col2-3 \\
\hline $4 / 27 / 2009$ & 4 & $\mathrm{col} 2$ & $16: 05$ & 23 & 26 & 64.0 & sim-4-c1-preTre-col2-6 \\
\hline $4 / 27 / 2009$ & reserv & ir at end & $16: 13$ & & 468.5 & $<$ grams & \\
\hline \multicolumn{8}{|c|}{ Simulant thru Lead Col. } \\
\hline $4 / 28 / 2009$ & reserv & ir at start & $7: 00$ & & 5917.5 & $<$ grams & \\
\hline $4 / 28 / 2009$ & 5 & lead-col1 & $11: 00$ & 25 & 26 & 63.0 & sim-5-c1-load-lead-6 \\
\hline $4 / 28 / 2009$ & 6 & lead-col1 & $13: 00$ & 27 & 27 & 63.0 & sim-6-c1-load-lead-8 \\
\hline $4 / 28 / 2009$ & 7 & lead-col1 & $15: 00$ & 26 & 26 & 64.0 & sim-7-c1-load-lead-11 \\
\hline $4 / 28 / 2009$ & 8 & lead-col1 & $16: 53$ & 26 & 26 & 64.0 & sim-8-c1-load-lead-14 \\
\hline $4 / 29 / 2009$ & 9 & lead-col1 & $8: 15$ & 24 & 25 & 64.0 & sim-9-c1-load-lead-35 \\
\hline $4 / 29 / 2009$ & 10 & lead-col1 & $15: 50$ & 27 & 26 & 64.0 & sim-10-c1-load-lead-46 \\
\hline $4 / 30 / 2009$ & 11 & lead-col1 & $8: 10$ & 23 & 24 & 64.0 & sim-11-c1-load-lead-69 \\
\hline $4 / 30 / 2009$ & 12 & lead-col1 & $15: 50$ & 25 & 25 & 64.5 & sim-12-c1-load-lead-80 \\
\hline $5 / 1 / 2009$ & 13 & lead-col1 & $8: 00$ & 24 & 24 & 64.5 & sim-13-c1-load-lead-102 \\
\hline $5 / 1 / 2009$ & 14 & lead-col1 & $15: 30$ & 26 & 26 & 64.5 & sim-14-c1-load-lead-113 \\
\hline $5 / 3 / 2009$ & 14.5 & lead-col1 & $12: 54$ & 25 & 26 & 65.0 & sim-14.5-c1-load-lead-176 \\
\hline $5 / 4 / 2009$ & 15 & lead-col1 & $7: 59$ & 24 & 25 & 65.0 & sim-15-c1-load-lead-203 \\
\hline $5 / 4 / 2009$ & 16 & lead-col1 & $16: 00$ & 26 & 26 & 65.0 & sim-16-c1-load-lead-214 \\
\hline $5 / 5 / 2009$ & 17 & lead-col1 & $7: 58$ & 25 & 25 & 65.0 & sim-17-c1-load-lead-237 \\
\hline $5 / 5 / 2009$ & 18 & lead-col1 & $8: 58$ & 25 & 24 & 65.0 & sim-18-c1-load-lead-238 \\
\hline $5 / 5 / 2009$ & 19 & lead-col1 & 9:58 & 25 & 26 & 65.0 & sim-19-c1-load-lead-239 \\
\hline $5 / 5 / 2009$ & 20 & lead-col1 & $10: 58$ & 25 & 25 & 65.0 & sim-20-c1-load-lead-241 \\
\hline $5 / 5 / 2009$ & 21 & lead-col1 & $11: 59$ & 25 & 25 & 65.0 & sim-21-c1-load-lead-242 \\
\hline $5 / 5 / 2009$ & 22 & lead-col1 & $12: 58$ & 25 & 25 & 65.0 & sim-22-c1-load-lead-244 \\
\hline $5 / 5 / 2009$ & 23 & lead-col1 & $14: 00$ & 25 & 25 & 65.0 & sim-23-c1-load-lead-245 \\
\hline $5 / 5 / 2009$ & 24 & lead-col1 & $14: 54$ & 25 & 25 & 65.0 & sim-24-c1-load-lead-246 \\
\hline $5 / 5 / 2009$ & 25 & lead-col1 & $15: 55$ & 25 & 25 & 65.0 & sim-25-c1-load-lead-248 \\
\hline $5 / 5 / 2009$ & 26 & lead-col1 & $16: 55$ & 25 & 25 & 65.0 & sim-26-c1-load-lead-249 \\
\hline $5 / 5 / 2009$ & 27 & lead-col1 & $17: 55$ & 24 & 25 & 65.0 & sim-27-c1-load-lead-251 \\
\hline
\end{tabular}


Table 21. Part B - Cycle 1 Simulant Data Sheet

\begin{tabular}{|c|c|c|c|c|c|c|c|}
\hline \multicolumn{8}{|c|}{ Simulant thru Lag Col. } \\
\hline $4 / 28 / 2009$ & 28 & lag-col2 & $11: 19$ & 25 & 25 & 63.0 & sim-28-c1-load-lag-6 \\
\hline $4 / 28 / 2009$ & 29 & lag-col2 & $13: 20$ & 26 & 25 & 63.0 & sim-29-c1-load-lag-8 \\
\hline $4 / 28 / 2009$ & 30 & lag-col2 & $15: 18$ & 26 & 25 & 63.0 & sim-30-c1-load-lag-11 \\
\hline $4 / 28 / 2009$ & 31 & lag-col2 & $17: 10$ & 26 & 26 & 64.0 & sim-31-c1-load-lag-14 \\
\hline $4 / 29 / 2009$ & 32 & lag-col2 & $8: 31$ & 24 & 23 & 65.0 & sim-32-c1-load-lag-35 \\
\hline $4 / 29 / 2009$ & 33 & lag-col2 & $16: 07$ & 27 & 26 & 65.0 & sim-33-c1-load-lag-46 \\
\hline 4/30/2009 & 34 & lag-col2 & $8: 30$ & 25 & 25 & 65.0 & sim-34-c1-load-lag-69 \\
\hline $4 / 30 / 2009$ & 35 & lag-col2 & $16: 08$ & 25 & 25 & 65.5 & sim-35-c1-load-lag-80 \\
\hline $5 / 1 / 2009$ & 36 & lag-col2 & $8: 18$ & 25 & 24 & 65.5 & sim-36-c1-load-lag-102 \\
\hline $5 / 1 / 2009$ & 37 & lag-col2 & $15: 47$ & 26 & 25 & 65.5 & sim-37-c1-load-lag-113 \\
\hline $5 / 3 / 2009$ & 37.5 & lag-col2 & $13: 10$ & 24 & 24 & 65.5 & sim-37.5-c1-load-lag-176 \\
\hline $5 / 4 / 2009$ & 38 & lag-col2 & $8: 17$ & 25 & 24 & 65.5 & sim-38-c1-load-lag-203 \\
\hline $5 / 4 / 2009$ & 39 & lag-col2 & $16: 17$ & 26 & 25 & 65.5 & sim-39-c1-load-lag-214 \\
\hline $5 / 5 / 2009$ & 40 & lag-col2 & $8: 16$ & 24 & 24 & 65.5 & sim-40-c1-load-lag-237 \\
\hline $5 / 5 / 2009$ & 41 & lag-col2 & 9:17 & 24 & 25 & 65.5 & sim-41-c1-load-lag-238 \\
\hline $5 / 5 / 2009$ & 42 & lag-col2 & $10: 21$ & 24 & 25 & 65.5 & sim-42-c1-load-lag-239 \\
\hline $5 / 5 / 2009$ & 43 & lag-col2 & $11: 17$ & 25 & 24 & 65.5 & sim-43-c1-load-lag-241 \\
\hline $5 / 5 / 2009$ & 44 & lag-col2 & $12: 18$ & 25 & 24 & 65.5 & sim-44-c1-load-lag-242 \\
\hline $5 / 5 / 2009$ & 45 & lag-col2 & $13: 19$ & 25 & 24 & 65.5 & sim-45-c1-load-lag-244 \\
\hline $5 / 5 / 2009$ & 46 & lag-col2 & $14: 18$ & 25 & 25 & 65.5 & sim-46-c1-load-lag-245 \\
\hline $5 / 5 / 2009$ & 47 & lag-col2 & $15: 14$ & 25 & 24 & 65.5 & sim-47-c1-load-lag-246 \\
\hline $5 / 5 / 2009$ & 48 & lag-col2 & $16: 15$ & 25 & 24 & 65.5 & sim-48-c1-load-lag-248 \\
\hline $5 / 5 / 2009$ & 49 & lag-col2 & $17: 15$ & 24 & 24 & 65.5 & sim-49-c1-load-lag-249 \\
\hline $5 / 5 / 2009$ & 50 & lag-col2 & 18:15 & 24 & 24 & 65.5 & sim-50-c1-load-lag-251 \\
\hline $5 / 5 / 2009$ & \multicolumn{2}{|c|}{ reservoir at end } & $18: 32$ & & 2107.17 & $<$ grams & \\
\hline \multicolumn{8}{|c|}{ Displacemt $0.1 \mathrm{M} \mathrm{NaOH}$} \\
\hline $5 / 5 / 2009$ & \multicolumn{2}{|c|}{ reservoir at start } & 19:35 & & 335.97 & $<$ grams & \\
\hline $5 / 5 / 2009$ & 51 & col1 & $19: 49$ & 27 & na & 66.5 & sim-51-c1-disp-col1-2 \\
\hline $5 / 5 / 2009$ & 52 & col1 & $20: 20$ & 26 & na & 66.5 & sim-52-c1-disp-col1-4 \\
\hline $5 / 5 / 2009$ & 53 & col1 & $20: 40$ & 25 & na & 66.5 & sim-53-c1-disp-col1-5 \\
\hline $5 / 5 / 2009$ & & col1 & $20: 49$ & & 297.1 & <grams & ended for night \\
\hline $5 / 6 / 2009$ & & col1 & $7: 23$ & & 297.1 & & restarted to complete BVs \\
\hline $5 / 6 / 2009$ & 53.5 & col1 & $7: 49$ & 26 & na & 66.0 & sim-53.5-c1-disp-col1-5 \\
\hline $5 / 6 / 2009$ & \multicolumn{2}{|c|}{ reservoir at end } & $7: 56$ & & 278.86 & $<$ grams & \\
\hline \multicolumn{3}{|c|}{ Pre-Elution DIW } & & & & & \\
\hline $5 / 6 / 2009$ & \multicolumn{2}{|c|}{ reservoir at start } & $8: 30$ & & 902.72 & $<$ grams & \\
\hline $5 / 6 / 2009$ & 54 & col1 & 9:00 & 26 & na & 66.0 & sim-54-c1-preElu-col1-3 \\
\hline $5 / 6 / 2009$ & 55 & col1 & 9:30 & 25 & na & 65.0 & sim-55-c1-preElu-col1-4 \\
\hline $5 / 6 / 2009$ & 56 & col1 & $10: 08$ & 26 & na & 64.0 & sim-56-c1-preElu-col1-5 \\
\hline $5 / 6 / 2009$ & \multicolumn{2}{|c|}{ reservoir at end } & $10: 16$ & & 845.04 & & \\
\hline
\end{tabular}


Table 22. Part C - Cycle 1 Simulant Data Sheet

\begin{tabular}{|c|c|c|c|c|c|c|c|}
\hline \multicolumn{8}{|c|}{ Elution with $0.5 \mathrm{M}$ HNO3 } \\
\hline $5 / 6 / 2009$ & \multicolumn{2}{|c|}{ reservoir at start } & $10: 17$ & & 512.83 & $<$ grams & \\
\hline $5 / 6 / 2009$ & 57 & col1 & $10: 45$ & 24 & na & 63.5 & sim-57-c1-elu-col1-1 \\
\hline $5 / 6 / 2009$ & 58 & col1 & $11: 15$ & 24 & na & 63.5 & sim-58-c1-elu-col1-1.5 \\
\hline $5 / 6 / 2009$ & 59 & col1 & $11: 45$ & 24 & na & 64.0 & sim-59-c1-elu-col1-2 \\
\hline $5 / 6 / 2009$ & 60 & col1 & $12: 16$ & 26 & na & 63.0 & sim-60-c1-elu-col1-3 \\
\hline $5 / 6 / 2009$ & 61 & col1 & $12: 45$ & 26 & na & 61.0 & sim-61-c1-elu-col1-3.5 \\
\hline $5 / 6 / 2009$ & 62 & col1 & $13: 15$ & 26 & na & 60.0 & sim-62-c1-elu-col1-4 \\
\hline $5 / 6 / 2009$ & 63 & col1 & $13: 45$ & 26 & na & 56.5 & sim-63-c1-elu-col1-5 \\
\hline $5 / 6 / 2009$ & 64 & col1 & $14: 15$ & 26 & na & 55.5 & sim-64-c1-elu-col1-5.5 \\
\hline $5 / 6 / 2009$ & 65 & col1 & $14: 45$ & 25 & na & 55.5 & sim-65-c1-elu-col1-6 \\
\hline $5 / 6 / 2009$ & 66 & col1 & $15: 15$ & 25 & na & 55.0 & sim-66-c1-elu-col1-7 \\
\hline $5 / 6 / 2009$ & 67 & col1 & $16: 15$ & 26 & na & 54.0 & sim-67-c1-elu-col1-8.5 \\
\hline $5 / 6 / 2009$ & 68 & col1 & $17: 15$ & 26 & na & 53.5 & sim-68-c1-elu-col1-10 \\
\hline $5 / 6 / 2009$ & 69 & col1 & $18: 15$ & 26 & na & 53.5 & sim-69-c1-elu-col1-11 \\
\hline $5 / 6 / 2009$ & 70 & col1 & $19: 15$ & 26 & na & 53.5 & sim-70-c1-elu-col1-13 \\
\hline $5 / 6 / 2009$ & 71 & col1 & $20: 15$ & 26 & na & 53.5 & sim-71-c1-elu-col1-14 \\
\hline $5 / 6 / 2009$ & 72 & col1 & $21: 15$ & 26 & na & 53.5 & sim-72-c1-elu-col1-15 \\
\hline $5 / 6 / 2009$ & 73 & col1 & $22: 15$ & 26 & na & 53.5 & sim-73-c1-elu-col1-17 \\
\hline $5 / 6 / 2009$ & 74 & col1 & $23: 15$ & 26 & na & 53.5 & sim-74-c1-elu-col1-18 \\
\hline $5 / 7 / 2009$ & 75 & col1 & $0: 16$ & 25 & na & 53.5 & sim-75-c1-elu-col1-20 \\
\hline $5 / 7 / 2009$ & 76 & col1 & $1: 15$ & 25 & na & 52.5 & sim-76-c1-elu-col1-21 \\
\hline $5 / 7 / 2009$ & 77 & col1 & $2: 15$ & 25 & na & 52.5 & sim-77-c1-elu-col1-22 \\
\hline $5 / 7 / 2009$ & 78 & col1 & $3: 15$ & 25 & na & 52.5 & sim-78-c1-elu-col1-24 \\
\hline $5 / 7 / 2009$ & 79 & col1 & $4: 16$ & 25 & na & 52.0 & sim-79-c1-elu-col1-26 \\
\hline $5 / 7 / 2009$ & 80 & col1 & $5: 16$ & 25 & na & 52.0 & sim-80-c1-elu-col1-27 \\
\hline $5 / 7 / 2009$ & 81 & col1 & $6: 15$ & 25 & na & 52.0 & sim-81-c1-elu-col1-28 \\
\hline $5 / 7 / 2009$ & 82 & col1 & $7: 15$ & 25 & na & 52.0 & sim-82-c1-elu-col1-29 \\
\hline $5 / 7 / 2009$ & 83 & col1 & $8: 08$ & 24 & na & 52.0 & sim-83-c1-elu-col1-31 \\
\hline $5 / 7 / 2009$ & resen & at end & $8: 24$ & & 171.54 & $<$ grams & \\
\hline \multicolumn{8}{|c|}{ Post-Elution DIW } \\
\hline $5 / 7 / 2009$ & \multicolumn{2}{|c|}{ reservoir at start } & $8: 24$ & & 844.95 & $<$ grams & \\
\hline $5 / 7 / 2009$ & 84 & col1 & $9: 30$ & 25 & na & 52.0 & sim-84-c1-postElu-col1-1 \\
\hline $5 / 7 / 2009$ & 85 & col1 & $10: 48$ & 26 & na & 52.0 & sim-85-c1-postElu-col1-3 \\
\hline $5 / 7 / 2009$ & 86 & col1 & $12: 00$ & 26 & na & 52.0 & sim-86-c1-postElu-col1-4 \\
\hline $5 / 7 / 2009$ & \multicolumn{2}{|c|}{ reservoir at end } & $12: 18$ & & 785.88 & $<$ grams & \\
\hline
\end{tabular}

Cycle 1 Facts:

\begin{tabular}{|c|c|c|c|c|c|}
\hline \multirow[t]{5}{*}{ Waste $\gg$} & \multicolumn{2}{|c|}{ Averages $=$} & Height (mm) & $\mathrm{BV}(\mathrm{mL})$ & Temp. $\left({ }^{\circ} \mathrm{C}\right)$ \\
\hline & Lead & Column 1 & 64.6 & 10.44 & 25.0 \\
\hline & Lag & Column 2 & 65.1 & 10.52 & 24.9 \\
\hline & & & Averages = & 10.48 & 25.0 \\
\hline & & & Std Dev = & 0.13 & 0.8 \\
\hline Elution $\gg>$ & & & dHeight (mm) & dHeight $\%$ & Temp. $\left({ }^{\circ} \mathrm{C}\right)$ \\
\hline & Lead & Column 1 & 12.6 & $19.5 \%$ & 25.3 \\
\hline
\end{tabular}


SRNL-STI-2009-00594, REVISION 0

Table 23. Part A - Cycle 2 Simulant Data Sheet

\begin{tabular}{|c|c|c|c|c|c|c|c|}
\hline \multicolumn{8}{|c|}{ Cycle 2 Testing with Simulant } \\
\hline Date & \# & LOC. & Time & Col. $1 \mathrm{~T}\left({ }^{\circ} \mathrm{C}\right)$ & Col. 2 T $\left({ }^{\circ} \mathrm{C}\right)$ & $\mathrm{Col} \mathrm{H}(\mathrm{mm})$ & Sample Indentifier \\
\hline \multicolumn{8}{|c|}{ Regen. with $0.5 \mathrm{M} \mathrm{NaOH}$} \\
\hline $5 / 11 / 2009$ & \multicolumn{2}{|c|}{ reservoir at start } & $13: 30$ & & 468.32 & $<$ grams & \\
\hline $5 / 11 / 2009$ & 1 & col1 & $14: 00$ & 26 & na & 54.0 & sim-1-c2-gen-col1-2 \\
\hline $5 / 11 / 2009$ & 2 & col1 & $14: 30$ & 27 & na & 62.5 & sim-2-c2-gen-col1-3 \\
\hline $5 / 11 / 2009$ & 3 & col1 & $15: 00$ & 25 & na & 67.0 & sim-3-c2-gen-col1-5 \\
\hline $5 / 11 / 2009$ & 4 & col1 & $15: 30$ & 25 & na & 67.5 & sim-4-c2-gen-col1-6 \\
\hline $5 / 11 / 2009$ & \multicolumn{2}{|c|}{ reservoir at end } & $15: 39$ & & 395.24 & $<$ grams & \\
\hline \multicolumn{8}{|c|}{ Simulant thru Lead Col. } \\
\hline $5 / 12 / 2009$ & \multicolumn{2}{|c|}{ reservoir at start } & $7: 00$ & & 10898.17 & $<$ grams & \\
\hline $5 / 12 / 2009$ & 5 & lead-col2 & $11: 20$ & 25 & 25 & 64.5 & sim-5-c2-load-lead-6 \\
\hline $5 / 12 / 2009$ & 6 & lead-col2 & $13: 01$ & 26 & 27 & 64.5 & sim-6-c2-load-lead-8 \\
\hline $5 / 12 / 2009$ & 7 & lead-col2 & $14: 59$ & 27 & 26 & 64.5 & sim-7-c2-load-lead-11 \\
\hline $5 / 12 / 2009$ & 8 & lead-col2 & $16: 32$ & 26 & 26 & 64.5 & sim-8-c2-load-lead-14 \\
\hline $5 / 13 / 2009$ & 9 & lead-col2 & $8: 01$ & 26 & 26 & 64.5 & sim-9-c2-load-lead-35 \\
\hline $5 / 13 / 2009$ & 10 & lead-col2 & $15: 42$ & 26 & 26 & 64.5 & sim-10-c2-load-lead-46 \\
\hline $5 / 14 / 2009$ & 11 & lead-col2 & $8: 00$ & 24 & 24 & 65.0 & sim-11-c2-load-lead-69 \\
\hline $5 / 14 / 2009$ & 12 & lead-col2 & $15: 48$ & 25 & 24 & 65.0 & sim-12-c2-load-lead-80 \\
\hline $5 / 15 / 2009$ & 13 & lead-col2 & $8: 01$ & 26 & 26 & 65.0 & sim-13-c2-load-lead-102 \\
\hline $5 / 15 / 2009$ & 14 & lead-col2 & $15: 11$ & 26 & 26 & 65.0 & sim-14-c2-load-lead-113 \\
\hline $5 / 18 / 2009$ & 15 & lead-col2 & $7: 58$ & 27 & 25 & 65.0 & sim-15-c2-load-lead-203 \\
\hline $5 / 18 / 2009$ & 16 & lead-col2 & $15: 52$ & 26 & 26 & 65.0 & sim-16-c2-load-lead-214 \\
\hline $5 / 19 / 2009$ & 17 & lead-col2 & $7: 53$ & 27 & 26 & 65.0 & sim-17-c2-load-lead-237 \\
\hline $5 / 19 / 2009$ & 18 & lead-col2 & $15: 49$ & 26 & 26 & 65.5 & sim-18-c2-load-lead-248 \\
\hline $5 / 20 / 2009$ & 19 & lead-col2 & $8: 03$ & 24 & 24 & 65.5 & sim-19-c2-load-lead-270 \\
\hline $5 / 20 / 2009$ & $20 a$ & lead-col2 & $15: 23$ & 27 & 26 & 65.5 & sim-20a-c2-load-lead-281 \\
\hline $5 / 20 / 2009$ & $20 \mathrm{~b}$ & lead-col2 & $15: 59$ & 27 & 27 & 65.5 & sim-20b-c2-load-lead-281 \\
\hline $5 / 21 / 2009$ & $21 a$ & lead-col2 & $7: 21$ & 25 & 24 & 65.5 & sim-21a-c2-load-lead-304 \\
\hline $5 / 21 / 2009$ & $21 b$ & lead-col2 & $8: 51$ & 27 & 26 & 65.5 & sim-21b-c2-load-lead-304 \\
\hline $5 / 21 / 2009$ & 22 & lead-col2 & $15: 57$ & 27 & 26 & 65.5 & sim-22-c2-load-lead-315 \\
\hline $5 / 22 / 2009$ & 23 & lead-col2 & $8: 00$ & 24 & 25 & 65.5 & sim-23-c2-load-lead-337 \\
\hline $5 / 22 / 2009$ & 24 & lead-col2 & $15: 55$ & 25 & 26 & 65.5 & sim-24-c2-load-lead-349 \\
\hline $5 / 23 / 2009$ & 25 & lead-col2 & $7: 56$ & 26 & 25 & 65.5 & sim-25-c2-load-lead-371 \\
\hline $5 / 23 / 2009$ & 26 & lead-col2 & $15: 58$ & 27 & 27 & 65.5 & sim-26-c2-load-lead-382 \\
\hline $5 / 24 / 2009$ & 27 & lead-col2 & $13: 43$ & 27 & 27 & 65.5 & sim-27-c2-load-lead-410 \\
\hline $5 / 25 / 2009$ & 27.1 & lead-col2 & $7: 59$ & 24 & 24 & 65.5 & sim-27.1-c2-load-lead-438 \\
\hline $5 / 25 / 2009$ & 27.2 & lead-col2 & $15: 59$ & 28 & 28 & & sim-27.2-c2-load-lead-449 \\
\hline $5 / 26 / 2009$ & 27.3 & lead-col2 & $8: 20$ & 24 & 25 & 66.0 & sim-27.3-c2-load-lead-472 \\
\hline $5 / 26 / 2009$ & 27.4 & lead-col2 & $16: 02$ & 25 & 25 & 66.0 & sim-27.4-c2-load-lead-483 \\
\hline $5 / 27 / 2009$ & 27.5 & lead-col2 & $8: 20$ & 26 & 25 & 66.0 & sim-27.5-c2-load-lead-505 \\
\hline $5 / 27 / 2009$ & 27.6 & lead-col2 & $10: 42$ & 26 & 25 & 66.0 & sim-27.6-c2-load-lead-517 \\
\hline $5 / 27 / 2009$ & 27.7 & lead-col2 & $12: 23$ & 26 & 25 & 66.0 & sim-27.7-c2-load-lead-539 \\
\hline $5 / 27 / 2009$ & 27.8 & lead-col2 & $13: 54$ & 25 & 25 & 66.0 & sim-27.8-c2-load-lead-550 \\
\hline
\end{tabular}


Table 24. Part B - Cycle 2 Simulant Data Sheet

\begin{tabular}{|c|c|c|c|c|c|c|c|}
\hline \multicolumn{8}{|c|}{ Simulant thru Lag Col. } \\
\hline $5 / 12 / 2009$ & 28 & lag-col1 & $11: 00$ & 25 & 25 & 66.5 & sim-5-c2-load-lag-6 \\
\hline $5 / 12 / 2009$ & 29 & lag-col1 & $13: 20$ & 25 & 27 & 66.0 & sim-6-c2-load-lag-8 \\
\hline $5 / 12 / 2009$ & 30 & lag-col1 & $15: 18$ & 24 & 26 & 66.0 & sim-7-c2-load-lag-11 \\
\hline $5 / 12 / 2009$ & 31 & lag-col1 & $16: 47$ & 26 & 26 & 66.0 & sim-8-c2-load-lag-14 \\
\hline $5 / 13 / 2009$ & 32 & lag-col1 & $8: 21$ & 24 & 25 & 66.0 & sim-9-c2-load-lag-35 \\
\hline $5 / 13 / 2009$ & 33 & lag-col1 & $16: 00$ & 25 & 26 & 66.5 & sim-10-c2-load-lag-46 \\
\hline $5 / 14 / 2009$ & 34 & lag-col1 & $8: 18$ & 24 & 25 & 66.5 & sim-11-c2-load-lag-69 \\
\hline $5 / 14 / 2009$ & 35 & lag-col1 & $16: 06$ & 24 & 25 & 66.5 & sim-12-c2-load-lag-80 \\
\hline $5 / 15 / 2009$ & 36 & lag-col1 & $8: 21$ & 25 & 26 & 66.5 & sim-13-c2-load-lag-102 \\
\hline $5 / 15 / 2009$ & 37 & lag-col1 & $15: 30$ & 26 & 25 & 66.5 & sim-14-c2-load-lag-113 \\
\hline $5 / 18 / 2009$ & 38 & lag-col1 & $8: 24$ & 24 & 25 & 66.5 & sim-15-c2-load-lag-203 \\
\hline $5 / 18 / 2009$ & 39 & lag-col1 & $16: 13$ & 25 & 26 & 66.5 & sim-16-c2-load-lag-214 \\
\hline $5 / 19 / 2009$ & 40 & lag-col1 & $8: 13$ & 25 & 27 & 66.5 & sim-17-c2-load-lag-237 \\
\hline $5 / 19 / 2009$ & 41 & lag-col1 & $16: 08$ & 25 & 25 & 67.0 & sim-18-c2-load-lag-248 \\
\hline $5 / 20 / 2009$ & 42 & lag-col1 & $8: 23$ & 24 & 24 & 66.5 & sim-19-c2-load-lag-270 \\
\hline $5 / 20 / 2009$ & $43 a$ & lag-col1 & $15: 41$ & 26 & 27 & 66.5 & sim-20a-c2-load-lag-281 \\
\hline $5 / 20 / 2009$ & $43 b$ & lag-col1 & $16: 17$ & 26 & 27 & 66.5 & sim-20b-c2-load-lag-281 \\
\hline $5 / 21 / 2009$ & $44 a$ & lag-col1 & $7: 39$ & 24 & 25 & 66.5 & sim-21a-c2-load-lag-304 \\
\hline $5 / 21 / 2009$ & $44 \mathrm{~b}$ & lag-col1 & $9: 16$ & 25 & 26 & 66.5 & sim-21b-c2-load-lag-304 \\
\hline $5 / 21 / 2009$ & 45 & lag-col1 & $16: 16$ & 25 & 26 & 66.5 & sim-22-c2-load-lag-315 \\
\hline $5 / 22 / 2009$ & 46 & lag-col1 & $8: 18$ & 24 & 25 & 66.5 & sim-23-c2-load-lag-337 \\
\hline $5 / 22 / 2009$ & 47 & lag-col1 & $16: 14$ & 25 & 26 & 66.5 & sim-24-c2-load-lag-349 \\
\hline $5 / 23 / 2009$ & 48 & lag-col1 & $8: 18$ & 25 & 26 & 66.5 & sim-25-c2-load-lag-371 \\
\hline $5 / 23 / 2009$ & 49 & lag-col1 & $16: 18$ & 27 & 26 & 66.5 & sim-26-c2-load-lag-382 \\
\hline $5 / 24 / 2009$ & 50 & lag-col1 & $14: 01$ & 26 & 27 & 66.5 & sim-27-c2-load-lag-410 \\
\hline $5 / 25 / 2009$ & 50.1 & lag-col1 & $8: 17$ & 25 & 26 & 66.5 & sim-27.1-c2-load-lag-438 \\
\hline $5 / 25 / 2009$ & 50.2 & lag-col1 & $16: 17$ & 27 & 28 & 66.5 & sim-27.2-c2-load-lag-449 \\
\hline $5 / 26 / 2009$ & 50.3 & lag-col1 & $8: 42$ & 24 & 25 & 67.0 & sim-27.3-c2-load-lag-472 \\
\hline $5 / 26 / 2009$ & 50.4 & lag-col1 & $16: 21$ & 24 & 25 & 67.0 & sim-27.4-c2-load-lag-483 \\
\hline $5 / 27 / 2009$ & 50.5 & lag-col1 & $8: 46$ & 24 & 24 & 67.0 & sim-27.5-c2-load-lag-505 \\
\hline $5 / 27 / 2009$ & 50.6 & lag-col1 & $11: 02$ & 24 & 25 & 67.0 & sim-27.6-c2-load-lag-517 \\
\hline $5 / 27 / 2009$ & 50.7 & lag-col1 & $12: 43$ & 24 & 25 & 67.0 & sim-27.7-c2-load-lag-539 \\
\hline $5 / 27 / 2009$ & 50.8 & lag-col1 & $14: 17$ & 25 & 25 & 67.0 & sim-27.8-c2-load-lag-550 \\
\hline $5 / 27 / 2009$ & \multicolumn{2}{|c|}{ reservoir at end } & $14: 51$ & & 3622.95 & $<$ grams & \\
\hline \multicolumn{8}{|c|}{ Displacemt $0.1 \mathrm{M} \mathrm{NaOH}$} \\
\hline $5 / 27 / 2009$ & \multicolumn{2}{|c|}{ reservoir at start } & $14: 52$ & & 278.386 & $<$ grams & \\
\hline $5 / 27 / 2009$ & 51 & $\mathrm{col} 2$ & $15: 50$ & na & 25 & 67.0 & sim-51-c2-disp-col2-2 \\
\hline $5 / 27 / 2009$ & 52 & col2 & $16: 10$ & na & 25 & 66.5 & sim-52-c2-disp-col2-3 \\
\hline $5 / 27 / 2009$ & 53 & $\mathrm{col} 2$ & $16: 40$ & na & 25 & 66.5 & sim-53-c2-disp-col2-5 \\
\hline $5 / 27 / 2009$ & \multicolumn{2}{|c|}{ reservoir at end } & \multicolumn{2}{|l|}{$16: 52$} & \multirow{2}{*}{\multicolumn{2}{|c|}{215.058}} & \\
\hline \multirow{2}{*}{\multicolumn{3}{|c|}{\begin{tabular}{|l|l|} 
Pre-Elution DIW & \\
$5 / 28 / 2009$ & reservoir at start
\end{tabular}}} & & & & & \\
\hline $5 / 28 / 2009$ & & reservoir at start & $8: 00$ & & 785.55 & $<$ grams & \\
\hline $5 / 28 / 2009$ & 54 & col2 & $8: 30$ & na & 27 & 66.0 & sim-54-c2-preElu-col2-3 \\
\hline $5 / 28 / 2009$ & 55 & col2 & 9:01 & na & 23 & 65.5 & sim-55-c2-preElu-col2-5 \\
\hline $5 / 28 / 2009$ & 56 & $\mathrm{col} 2$ & $9: 44$ & na & 25 & 64.0 & sim-56-c2-preElu-col2-5 \\
\hline $5 / 28 / 2009$ & \multicolumn{2}{|c|}{ reservoir at end } & \multicolumn{2}{|l|}{$9: 51$} & 725.35 & \multicolumn{2}{|r|}{ 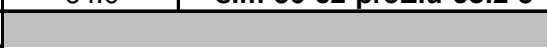 } \\
\hline
\end{tabular}


SRNL-STI-2009-00594, REVISION 0

Table 25. Part C - Cycle 2 Simulant Data Sheet

\begin{tabular}{|c|c|c|c|c|c|c|c|}
\hline \multicolumn{8}{|c|}{ Elution with $0.5 \mathrm{M} \mathrm{HNO3}$} \\
\hline $5 / 28 / 2009$ & \multicolumn{2}{|c|}{ reservoir at start } & $9: 52$ & & 567.48 & $<$ grams & \\
\hline $5 / 28 / 2009$ & 57 & col2 & $10: 15$ & na & 24 & 64.0 & sim-57-c2-elu-col2-1 \\
\hline $5 / 28 / 2009$ & 58 & $\mathrm{col} 2$ & $10: 49$ & na & 24 & 64.0 & sim-58-c2-elu-col2-1.5 \\
\hline $5 / 28 / 2009$ & 59 & $\mathrm{col} 2$ & $11: 14$ & na & 25 & 64.0 & sim-59-c2-elu-col2-2 \\
\hline $5 / 28 / 2009$ & 60 & col2 & $11: 51$ & na & 26 & 63.0 & sim-60-c2-elu-col2-3 \\
\hline $5 / 28 / 2009$ & 61 & $\mathrm{col} 2$ & $12: 15$ & na & 26 & 61.0 & sim-61-c2-elu-col2-3.5 \\
\hline $5 / 28 / 2009$ & 62 & col2 & $12: 44$ & na & 26 & 59.0 & sim-62-c2-elu-col2-4 \\
\hline $5 / 28 / 2009$ & 63 & col2 & $13: 15$ & na & 25 & 56.5 & sim-63-c2-elu-col2-5 \\
\hline $5 / 28 / 2009$ & 64 & $\mathrm{col} 2$ & $13: 45$ & na & 25 & 55.0 & sim-64-c2-elu-col2-5.5 \\
\hline $5 / 28 / 2009$ & 65 & $\mathrm{col} 2$ & $14: 16$ & na & 25 & 53.5 & sim-65-c2-elu-col2-6 \\
\hline $5 / 28 / 2009$ & 66 & $\mathrm{col} 2$ & $14: 45$ & na & 25 & 53.5 & sim-66-c2-elu-col2-7 \\
\hline $5 / 28 / 2009$ & 67 & $\mathrm{col} 2$ & $15: 45$ & na & 25 & 53.0 & sim-67-c2-elu-col2-8.5 \\
\hline $5 / 28 / 2009$ & 68 & col2 & $16: 44$ & na & 25 & 53.0 & sim-68-c2-elu-col2-10 \\
\hline $5 / 28 / 2009$ & 69 & $\mathrm{col} 2$ & $17: 45$ & na & 25 & 53.0 & sim-69-c2-elu-col2-11 \\
\hline $5 / 28 / 2009$ & 70 & col2 & $18: 45$ & na & 25 & 53.0 & sim-70-c2-elu-col2-13 \\
\hline $5 / 28 / 2009$ & 71 & $\mathrm{col} 2$ & $19: 46$ & na & 25 & 53.0 & sim-71-c2-elu-col2-14 \\
\hline $5 / 28 / 2009$ & 72 & col2 & $20: 45$ & na & 25 & 53.0 & sim-72-c2-elu-col2-15 \\
\hline $5 / 28 / 2009$ & 73 & $\mathrm{col} 2$ & $21: 45$ & na & 25 & 53.0 & sim-73-c2-elu-col2-17 \\
\hline $5 / 28 / 2009$ & 74 & col2 & $22: 45$ & na & 25 & 53.0 & sim-74-c2-elu-col2-18 \\
\hline $5 / 28 / 2009$ & 75 & $\mathrm{col} 2$ & $23: 45$ & na & 24 & 53.0 & sim-75-c2-elu-col2-20 \\
\hline $5 / 29 / 2009$ & 76 & col2 & $0: 46$ & na & 25 & 53.0 & sim-76-c2-elu-col2-21 \\
\hline $5 / 29 / 2009$ & 77 & col2 & $1: 46$ & na & 25 & 53.0 & sim-77-c2-elu-col2-22 \\
\hline $5 / 29 / 2009$ & 78 & col2 & $2: 45$ & na & 25 & 53.0 & sim-78-c2-elu-col2-24 \\
\hline $5 / 29 / 2009$ & 79 & col2 & $3: 45$ & na & 24 & 53.0 & sim-79-c2-elu-col2-26 \\
\hline $5 / 29 / 2009$ & 80 & $\mathrm{col} 2$ & $4: 46$ & na & 25 & 53.0 & sim-80-c2-elu-col2-27 \\
\hline $5 / 29 / 2009$ & 81 & $\mathrm{col} 2$ & $5: 46$ & na & 25 & 53.0 & sim-81-c2-elu-col2-28 \\
\hline $5 / 29 / 2009$ & 82 & col2 & $6: 45$ & na & 25 & 53.0 & sim-82-c2-elu-col2-29 \\
\hline $5 / 29 / 2009$ & 83 & $\operatorname{col}^{*}$ & $8: 16$ & na & 24 & 53.0 & sim-83-c2-elu-col2-31 \\
\hline $5 / 29 / 2009$ & reserv & at end* & $8: 33$ & na & 229.068 & $<$ grams & *minus $35 \mathrm{~min}$ (see p. 67) \\
\hline \multicolumn{8}{|c|}{ Post-Elution DIW } \\
\hline $5 / 29 / 2009$ & \multicolumn{2}{|c|}{ reservoir at start } & $8: 33$ & & 725.34 & $<$ grams & \\
\hline $5 / 29 / 2009$ & 84 & col2 & 9:29 & na & 25 & 53.0 & sim-84-c2-postElu-col2-1 \\
\hline $5 / 29 / 2009$ & 85 & $\mathrm{col} 2$ & $10: 32$ & na & 25 & 52.5 & sim-85-c2-postElu-col2-3 \\
\hline $5 / 29 / 2009$ & 86 & col2 & $11: 37$ & na & 25 & 52.5 & sim-86-c2-postElu-col2-4 \\
\hline $5 / 29 / 2009$ & \multicolumn{2}{|c|}{ reservoir at end } & $12: 00$ & na & 672.17 & $<$ grams & \\
\hline
\end{tabular}

Cycle 2 Facts:

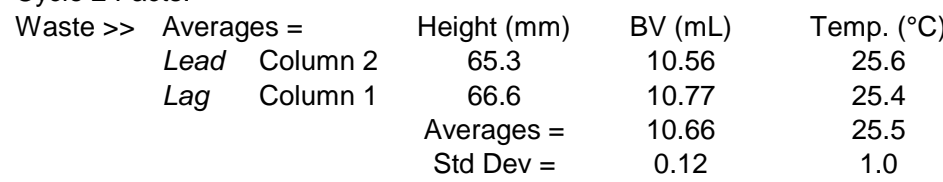

Elution $>>$ dHeight (mm) dHeight\% $\quad$ Temp. $\left({ }^{\circ} \mathrm{C}\right)$
Lead Column 2
12.3
$18.8 \%$
24.9

\begin{tabular}{|c|c|c|c|c|c|c|c|}
\hline \multicolumn{8}{|c|}{ Cycle 2a Testing with Simulant } \\
\hline Date & $\#$ & Loc. & Time & Col. 1 T $\left({ }^{\circ} \mathrm{C}\right)$ & Col. $2 \mathrm{~T}\left({ }^{\circ} \mathrm{C}\right)$ & $\mathrm{Col} \mathrm{H}(\mathrm{mm})$ & Sample Indentifier \\
\hline \multicolumn{8}{|c|}{ Regen. with $0.5 \mathrm{M} \mathrm{NaOH}$} \\
\hline $6 / 2 / 2009$ & \multicolumn{2}{|c|}{ reservoir at start } & $8: 00$ & & 634 & $<$ grams & \\
\hline $6 / 2 / 2009$ & 1 & col1 & $9: 01$ & 25 & na & 66.0 & sim-1-c2a-elu-col1-1 \\
\hline $6 / 2 / 2009$ & 2 & col1 & $10: 01$ & 23 & na & 61.5 & sim-2-c2a-elu-col1-3 \\
\hline $6 / 2 / 2009$ & 3 & col1 & $11: 00$ & 27 & na & 57.0 & sim-3-c2a-elu-col1-4 \\
\hline $6 / 2 / 2009$ & 4 & col1 & $12: 00$ & 26 & na & 54.5 & sim-4-c2a-elu-col1-6 \\
\hline $6 / 2 / 2009$ & 5 & col1 & $13: 00$ & 26 & na & 54.0 & sim-5-c2a-elu-col1-7 \\
\hline $6 / 2 / 2009$ & 6 & col1 & $14: 41$ & 25 & na & 53.5 & sim-6-c2a-elu-col1-8 \\
\hline $6 / 2 / 2009$ & 7 & col1 & $15: 42$ & 25 & na & 53.5 & sim-7-c2a-elu-col1-10 \\
\hline $6 / 2 / 2009$ & 8 & col1 & $16: 26$ & 25 & na & 53.5 & sim-8-c2a-elu-col1-11 \\
\hline $6 / 3 / 2009$ & 9 & col1 & $8: 41$ & 25 & na & 53.0 & sim-9-c2a-elu-col1-34 \\
\hline $6 / 3 / 2009$ & 10 & col1 & $9: 44$ & 26 & na & 53.0 & sim-10-c2a-elu-col1-35 \\
\hline $6 / 3 / 2009$ & \multicolumn{2}{|c|}{ reservoir at end } & $10: 02$ & & 230.83 & $<$ grams & \\
\hline
\end{tabular}


SRNL-STI-2009-00594, REVISION 0

Table 26. Part A - Cycle 1 Real-waste Data Sheet

\begin{tabular}{|c|c|c|c|c|c|c|c|}
\hline \multicolumn{8}{|c|}{ Cycle 1 Testing with Real Waste } \\
\hline Date & \# & Loc. & Time & Col. $1 \mathrm{~T}\left({ }^{\circ} \mathrm{C}\right)$ & Col. $2 \mathrm{~T}\left({ }^{\circ} \mathrm{C}\right)$ & $\mathrm{Col} \mathrm{H}(\mathrm{mm})$ & Sample Indentifier \\
\hline \multicolumn{8}{|c|}{ Regen. with $0.5 \mathrm{M} \mathrm{NaOH}$} \\
\hline $6 / 29 / 2009$ & resert & Dir at start & $8: 30$ & & 528.14 & $<$ grams & \\
\hline $6 / 29 / 2009$ & 1 & col1 & $9: 32$ & 29.3 & 29.2 & 62.5 & rad-1-c1-regen-col1-3 \\
\hline $6 / 29 / 2009$ & 2 & col1 & $10: 00$ & 29.6 & 29.3 & 68.0 & rad-2-c1-regen-col1-5 \\
\hline $6 / 29 / 2009$ & 3 & col1 & $10: 30$ & 29.4 & 28.8 & 70.5 & rad-3-c1-regen-col1-6 \\
\hline $6 / 29 / 2009$ & & col1 $>\mathrm{col} 2$ & $10: 41$ & \multicolumn{4}{|c|}{ Switched from Column 1 to Column 1 Processing } \\
\hline $6 / 29 / 2009$ & 4 & col2 & $11: 41$ & 28.4 & 30 & 66.0 & rad-4-c1-regen-col2-3 \\
\hline $6 / 29 / 2009$ & 5 & col2 & $12: 11$ & 29.1 & 30.1 & 67.5 & rad-5-c1-regen-col2-5 \\
\hline $6 / 29 / 2009$ & 6 & $\mathrm{col} 2$ & $12: 41$ & 29.4 & 29.8 & 68.0 & rad-6-c1-regen-col2-6 \\
\hline $6 / 29 / 2009$ & \multicolumn{2}{|c|}{ reservoir at end } & $12: 50$ & & \multicolumn{2}{|l|}{377.49} & \\
\hline \multicolumn{8}{|c|}{ Real Waste thru Lead Col. } \\
\hline $6 / 30 / 2009$ & \multicolumn{2}{|c|}{ reservoir at start } & $7: 00$ & & 7922.14 & $<$ grams & \\
\hline $6 / 30 / 2009$ & 7 & lead-col1 & $10: 00$ & 26.5 & na & 69.0 & rad-7-c1-load-lead(col1)-4 \\
\hline $6 / 30 / 2009$ & 8 & lead-col1 & $12: 02$ & 26 & na & 69.0 & rad-8-c1-load-lead(col1)-7 \\
\hline $6 / 30 / 2009$ & 9 & lead-col1 & $14: 05$ & 26.4 & na & 69.0 & rad-9-c1-load-lead(col1)-10 \\
\hline $6 / 30 / 2009$ & 10 & lead-col1 & $16: 02$ & 28.3 & na & 69.0 & rad-10-c1-load-lead(col1)-13 \\
\hline $7 / 1 / 2009$ & 11 & lead-col1 & $8: 02$ & 26.2 & na & 69.0 & rad-11-c1-load-lead(col1)-35 \\
\hline $7 / 1 / 2009$ & 12 & lead-col1 & $16: 02$ & 28.6 & na & 69.0 & rad-12-c1-load-lead(col1)-46 \\
\hline $7 / 6 / 2009$ & \multicolumn{2}{|c|}{ Pump 2 failed $>$} & $7: 30$ & & 5168.28 & $<$ grams & \\
\hline $7 / 6 / 2009$ & \multicolumn{7}{|c|}{ Unfortunately, actual failure time is unknown however remaining waste indicates a flowrate of $0.243 \mathrm{~mL} / \mathrm{min}$. } \\
\hline $7 / 6 / 2009$ & \multicolumn{7}{|c|}{ This $1 \%$ difference in flowrate means the pump failed minutes before it was found, i.e., an insignificant loss. } \\
\hline $7 / 6 / 2009$ & \multicolumn{2}{|c|}{ reservoir at start } & $16: 40$ & & 5168.28 & $<$ grams & \\
\hline $7 / 7 / 2009$ & 15 & lead-col1 & $8: 04$ & 24.3 & na & 69.0 & rad-15-c1-load-lead(col1)-237 \\
\hline $7 / 7 / 2009$ & 16 & lead-col1 & $16: 03$ & 24.2 & na & 69.0 & rad-16-c1-load-lead(col1)-248 \\
\hline $7 / 8 / 2009$ & 17 & lead-col1 & $8: 05$ & 22.9 & na & 69.0 & rad-17-c1-load-lead(col1)-270 \\
\hline $7 / 8 / 2009$ & 18 & lead-col1 & $15: 58$ & 25.9 & na & 69.0 & rad-18-c1-load-lead(col1)-281 \\
\hline $7 / 9 / 2009$ & 19 & lead-col1 & $8: 00$ & 22.5 & na & 69.0 & rad-19-c1-load-lead(col1)-304 \\
\hline $7 / 9 / 2009$ & 20 & lead-col1 & $15: 56$ & 25.5 & na & 70.5 & rad-20-c1-load-lead(col1)-315 \\
\hline $7 / 10 / 2009$ & 21 & lead-col1 & $6: 47$ & 23.2 & na & 70.5 & rad-21-c1-load-lead(col1)-337 \\
\hline $7 / 10 / 2009$ & 13 & lead-col1 & $10: 43$ & 24.2 & na & 70.0 & rad-13-c1-load-lead(col1)-203 \\
\hline $7 / 10 / 2009$ & 22 & lead-col1 & $14: 32$ & 25.2 & na & 70.5 & rad-22-c1-load-lead(col1)-349 \\
\hline $7 / 11 / 2009$ & 23 & lead-col1 & $8: 25$ & 24 & na & 70.5 & rad-23-c1-load-lead(col1)-372 \\
\hline $7 / 11 / 2009$ & \multicolumn{7}{|c|}{ Five (5) of flushing was performed causing flow through columns to be stopped for that period $\gg>$} \\
\hline $7 / 11 / 2009$ & 14 & lead-col1 & $10: 44$ & 24.5 & na & 70.5 & rad-14-c1-load-lead(col1)-214 \\
\hline $7 / 11 / 2009$ & 24 & lead-col1 & $11: 38$ & 25.2 & na & 70.5 & rad-24-c1-load-lead(col1)-376 \\
\hline $7 / 12 / 2009$ & 25 & lead-col1 & $8: 40$ & 23.8 & na & 70.5 & rad-25-c1-load-lead(col1)-405 \\
\hline $7 / 12 / 2009$ & 26 & lead-col1 & $11: 31$ & 25.6 & na & 70.5 & rad-26-c1-load-lead(col1)-410 \\
\hline $7 / 13 / 2009$ & 27 & lead-col1 & $7: 05$ & 26.1 & na & 70.5 & rad-27-c1-load-lead(col1)-438 \\
\hline $7 / 13 / 2009$ & 28 & lead-col1 & $16: 10$ & 27 & na & 70.5 & rad-28-c1-load-lead(col1)-449 \\
\hline $7 / 14 / 2009$ & 29 & lead-col1 & $8: 01$ & 25.2 & na & 70.5 & rad-30-c1-load-lead(col1)-472 \\
\hline $7 / 14 / 2009$ & 32 & lead-col1 & $10: 00$ & 24.9 & na & 70.5 & rad-33-c3-load-lead(col1)-476 \\
\hline $7 / 14 / 2009$ & 35 & lead-col1 & $12: 56$ & 25.2 & na & 70.5 & rad-35-c5-load-lead(col1)-479 \\
\hline & & & & & & & \\
\hline
\end{tabular}


Table 27. Part B - Cycle 1 Real-waste Data Sheet

\begin{tabular}{|c|c|c|c|c|c|c|c|}
\hline \multicolumn{8}{|c|}{ Real Waste thru Lag Col. } \\
\hline $6 / 30 / 2009$ & 39 & lag-col2 & $10: 20$ & na & 26.7 & 67.5 & rad-39-c1-load-lag(col2)-4 \\
\hline $6 / 30 / 2009$ & 40 & lag-col2 & $12: 22$ & na & 26.2 & 67.0 & rad-40-c1-load-lag(col2)-7 \\
\hline $6 / 30 / 2009$ & 41 & lag-col2 & $14: 26$ & na & 26.4 & 67.0 & rad-41-c1-load-lag(col2)-10 \\
\hline $6 / 30 / 2009$ & 42 & lag-col2 & $16: 23$ & na & 25 & 67.0 & rad-42-c1-load-lag(col2)-13 \\
\hline $7 / 1 / 2009$ & 43 & lag-col2 & $8: 21$ & na & 26.3 & 67.0 & rad-43-c1-load-lag(col2)-35 \\
\hline $7 / 1 / 2009$ & 44 & lag-col2 & $16: 23$ & na & 27.1 & 67.0 & rad-44-c1-load-lag(col2)-46 \\
\hline $7 / 6 / 2009$ & \multicolumn{2}{|c|}{ Pump 2 failed $>$} & $7: 30$ & \multicolumn{4}{|c|}{ New pump and time restarted at 16:40 hours to determined overall flowrate } \\
\hline $7 / 7 / 2009$ & 47 & lag-col2 & $8: 26$ & na & 24.6 & 67.5 & rad-47-c1-load-lag(col2)-237 \\
\hline $7 / 7 / 2009$ & 48 & lag-col2 & $16: 23$ & na & 25.4 & 68.0 & rad-48-c1-load-lag(col2)-248 \\
\hline $7 / 8 / 2009$ & 49 & lag-col2 & $8: 26$ & na & 23.7 & 67.5 & rad-49-c1-load-lag(col2)-270 \\
\hline $7 / 8 / 2009$ & 50 & lag-col2 & $16: 21$ & na & 26.3 & 67.5 & rad-50-c1-load-lag(col2)-281 \\
\hline $7 / 9 / 2009$ & 51 & lag-col2 & $8: 22$ & na & 22.7 & 67.5 & rad-51-c1-load-lag(col2)-304 \\
\hline $7 / 9 / 2009$ & 52 & lag-col2 & $16: 16$ & na & 25.9 & 70.0 & rad-52-c1-load-lag(col2)-315 \\
\hline $7 / 10 / 2009$ & 53 & lag-col2 & $7: 11$ & na & 23.4 & 70.0 & rad-53-c1-load-lag(col2)-337 \\
\hline $7 / 10 / 2009$ & 45 & lag-col2 & $11: 02$ & na & 24.6 & 70.0 & rad-45-c1-load-lag(col2)-203 \\
\hline $7 / 10 / 2009$ & 54 & lag-col2 & $14: 49$ & na & 25.2 & 70.0 & rad-54-c1-load-lag(col2)-349 \\
\hline $7 / 11 / 2009$ & 55 & lag-col2 & $8: 45$ & na & 24.5 & 70.0 & rad-55-c1-load-lag(col2)-372 \\
\hline $7 / 11 / 2009$ & \multicolumn{7}{|c|}{ Five (5) of flushing was performed causing flow through columns to be stopped for that period $>>$} \\
\hline $7 / 11 / 2009$ & 56 & lag-col2 & $11: 58$ & na & 25.6 & 70.0 & rad-56-c1-load-lag(col2)-376 \\
\hline $7 / 12 / 2009$ & 57 & lag-col2 & $9: 00$ & na & 24.5 & 70.0 & rad-57-c1-load-lag(col2)-405 \\
\hline $7 / 12 / 2009$ & 58 & lag-col2 & $11: 50$ & na & 25.9 & 70.0 & rad-58-c1-load-lag(col2)-410 \\
\hline $7 / 13 / 2009$ & 59 & lag-col2 & $7: 22$ & na & 26.8 & 69.0 & rad-59-c1-load-lag(col2)-438 \\
\hline $7 / 13 / 2009$ & 60 & lag-col2 & $16: 31$ & na & 27.2 & 68.5 & rad-60-c1-load-lag(col2)-449 \\
\hline $7 / 14 / 2009$ & 62 & lag-col2 & $8: 23$ & na & 26.4 & 68.5 & rad-62-c1-load-lag(col2)-472 \\
\hline $7 / 14 / 2009$ & 64 & lag-col2 & $10: 22$ & na & 25.8 & 68.5 & rad-64-c2-load-lag(col2)-475 \\
\hline $7 / 14 / 2009$ & 67 & lag-col2 & $13: 15$ & na & 25.2 & 68.5 & rad-67-c5-load-lag(col2)-479 \\
\hline $7 / 14 / 2009$ & reserve & ir at end & $16: 00$ & & 1628.05 & $<$ grams & \\
\hline \multicolumn{8}{|c|}{ Displacemt 0.1 M NaOH } \\
\hline $7 / 14 / 2009$ & reservo & ir at start & $16: 30$ & & 404.63 & $<$ grams & \\
\hline $7 / 14 / 2009$ & 71 & col1 & $17: 01$ & 26.8 & na & 70.0 & rad-71-c3-disp-col1-2 \\
\hline $7 / 14 / 2009$ & 72 & col1 & $17: 30$ & 25.8 & na & 70.0 & rad-72-c2-disp-col1-3 \\
\hline $7 / 14 / 2009$ & 73.0 & col1 & $18: 15$ & 26.1 & na & $\begin{array}{l}70.5 \\
\end{array}$ & rad-73-c1-disp-col1-5 \\
\hline $7 / 14 / 2009$ & reservc & ir at end & $18: 35$ & & 338.33 & $<$ grams & \\
\hline \multicolumn{8}{|c|}{\begin{tabular}{|l|l|} 
Pre-Elution DIW & \\
\end{tabular}} \\
\hline $7 / 15 / 2009$ & reservc & ir at start & $8: 30$ & & 892.65 & $<$ grams & \\
\hline $7 / 15 / 2009$ & 74 & col1 & $9: 01$ & 25.2 & na & 70.0 & rad-74-c0-preElu-col1-2 \\
\hline $7 / 15 / 2009$ & 75 & col1 & $9: 30$ & 25.4 & na & 70.0 & rad-75-c1-preElu-col1-3 \\
\hline $7 / 15 / 2009$ & 76 & col1 & $10: 00$ & 25.6 & na & 69.0 & rad-76-c1-preElu-col1-5 \\
\hline $7 / 15 / 2009$ & reservo & ir at end & 10:08 & & 834.92 & & \\
\hline
\end{tabular}


SRNL-STI-2009-00594, REVISION 0

Table 28. Part C - Cycle 1 Real-waste Data Sheet

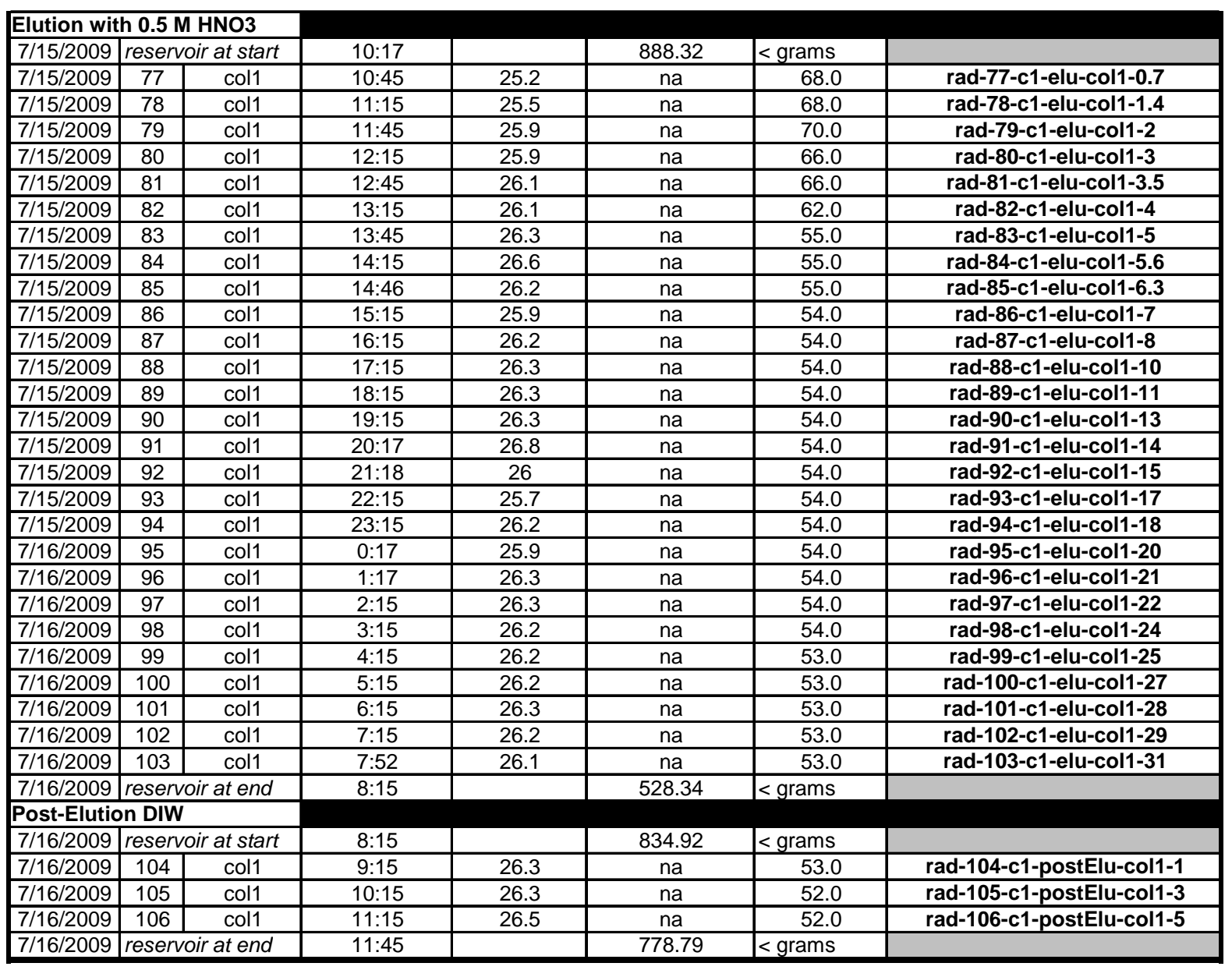

Cycle 1 Facts:

\begin{tabular}{|c|c|c|c|c|c|}
\hline \multirow[t]{5}{*}{ Waste $\gg$} & \multicolumn{2}{|c|}{ Averages = } & Height (mm) & $\mathrm{BV}(\mathrm{mL})$ & Temp. $\left({ }^{\circ} \mathrm{C}\right)$ \\
\hline & Lead & Column 1 & 69.8 & 11.29 & 25.3 \\
\hline & Lag & Column 2 & 68.5 & 11.08 & 25.5 \\
\hline & & & Averages = & 11.18 & 25.4 \\
\hline & & & Std Dev = & 0.20 & 1.3 \\
\hline Elution $>>$ & & & dHeight (mm) & dHeight $\%$ & Temp. $\left({ }^{\circ} \mathrm{C}\right)$ \\
\hline & Lead & Column 1 & 16.8 & $24.1 \%$ & 26.1 \\
\hline
\end{tabular}


Table 29. Part A - Cycle 2 Real-waste Data Sheet

\begin{tabular}{|c|c|c|c|c|c|c|c|}
\hline \multicolumn{8}{|c|}{ Cycle 2 Testing with Real Waste } \\
\hline Date & \# & Loc. & Time & Col. 1 T $\left({ }^{\circ} \mathrm{C}\right)$ & Col. $2 \mathrm{~T}\left({ }^{\circ} \mathrm{C}\right)$ & $\mathrm{Col} \mathrm{H}(\mathrm{mm})$ & Sample Indentifier \\
\hline \multicolumn{8}{|c|}{ Regen. with $0.5 \mathrm{M} \mathrm{NaOH}$} \\
\hline $7 / 20 / 2009$ & resert & ir at start & $8: 00$ & & 375.607 & $<$ grams & \\
\hline $7 / 20 / 2009$ & 1 & col1 & 9:00 & 26.3 & na & 63.0 & rad-1-c2-regen-col1-3 \\
\hline $7 / 20 / 2009$ & 2 & col1 & $9: 30$ & 25.4 & na & 70.0 & rad-2-c2-regen-col1-5 \\
\hline $7 / 20 / 2009$ & 3 & col1 & $10: 00$ & 24.2 & na & 71.0 & rad-3-c2-regen-col1-6 \\
\hline $7 / 20 / 2009$ & resert & ir at end & $10: 15$ & & 297.064 & $<$ grams & \\
\hline \multicolumn{8}{|c|}{ Real Waste thru Lead Col. } \\
\hline $7 / 21 / 2009$ & resert & ir at start & $7: 00$ & & 6491.83 & $<$ grams & \\
\hline $7 / 21 / 2009$ & 4 & lead-col2 & $10: 00$ & na & 24.8 & 68.0 & rad-4-c2-load-lead(col2)-4 \\
\hline $7 / 21 / 2009$ & 5 & lead-col2 & $12: 00$ & na & 25.1 & 68.0 & rad-5-c2-load-lead(col2)-7 \\
\hline $7 / 21 / 2009$ & 6 & lead-col2 & $14: 00$ & na & 25.8 & 67.5 & rad-6-c2-load-lead(col2)-10 \\
\hline $7 / 21 / 2009$ & 7 & lead-col2 & $16: 00$ & na & 26.7 & 67.5 & rad-7-c2-load-lead(col2)-13 \\
\hline $7 / 22 / 2009$ & 8 & lead-col2 & $8: 00$ & na & 24.8 & 67.5 & rad-8-c2-load-lead(col2)-35 \\
\hline $7 / 22 / 2009$ & 9 & lead-col2 & $16: 00$ & na & 26.3 & 68.0 & rad-9-c2-load-lead(col2)-46 \\
\hline $7 / 23 / 2009$ & 10 & lead-col2 & $8: 00$ & na & 25.3 & 68.5 & rad-10-c2-load-lead(col2)-69 \\
\hline $7 / 23 / 2009$ & 11 & lead-col2 & $16: 05$ & na & 26.6 & 68.0 & rad-11-c2-load-lead(col2)-80 \\
\hline $7 / 24 / 2009$ & 12 & lead-col2 & $8: 00$ & na & 24.8 & 68.5 & rad-12-c2-load-lead(col2)-102 \\
\hline $7 / 24 / 2009$ & 13 & lead-col2 & $15: 02$ & na & 26.9 & 68.5 & rad-13-c2-load-lead(col2)-113 \\
\hline $7 / 27 / 2009$ & 14 & lead-col2 & $8: 02$ & na & 26.9 & 67.5 & rad-14-c2-load-lead(col2)-203 \\
\hline $7 / 27 / 2009$ & 15 & lead-col2 & $16: 00$ & na & 26.9 & 67.5 & rad-15-c2-load-lead(col2)-214 \\
\hline $7 / 28 / 2009$ & 16 & lead-col2 & $8: 00$ & na & 24.6 & 67.5 & rad-16-c2-load-lead(col2)-237 \\
\hline $7 / 28 / 2009$ & 21 & lead-col2 & $11: 30$ & na & 25.9 & 67.5 & rad-21-c2-load-lead(col2)-304 \\
\hline $7 / 28 / 2009$ & 17 & lead-col2 & $16: 00$ & na & 26.4 & 67.5 & rad-17-c2-load-lead(col2)-248 \\
\hline $7 / 29 / 2009$ & 18 & lead-col2 & $8: 00$ & na & 25.1 & 67.5 & rad-18-c2-load-lead(col2)-270 \\
\hline $7 / 29 / 2009$ & 23 & lead-col2 & $12: 04$ & na & 26.0 & 67.5 & rad-23-c2-load-lead(col2)-307 \\
\hline $7 / 29 / 2009$ & 19 & lead-col2 & $15: 59$ & na & 26.4 & 67.5 & rad-19-c2-load-lead(col2)-281 \\
\hline $7 / 30 / 2009$ & 20 & lead-col2 & $7: 02$ & na & 24.4 & 67.5 & rad-20-c2-load-lead(col2)-302 \\
\hline $7 / 30 / 2009$ & 22 & lead-col2 & 9:01 & na & 24.9 & 67.5 & rad-22-c2-load-lead(col2)-305 \\
\hline $7 / 30 / 2009$ & 24 & lead-col2 & $10: 59$ & na & 25.3 & 67.5 & rad-24-c2-load-lead(col2)-308 \\
\hline $7 / 30 / 2009$ & 26 & lead-col2 & $13: 00$ & na & 25.8 & 67.5 & rad-26-c2-load-lead(col2)-311 \\
\hline $7 / 30 / 2009$ & 28 & lead-col2 & $15: 05$ & na & 25.8 & 67.5 & rad-28-c2-load-lead(col2)-314 \\
\hline \multicolumn{8}{|c|}{ Real Waste thru Lag Col. } \\
\hline $7 / 21 / 2009$ & 30 & lag-col1 & $10: 16$ & 24.5 & na & 70.0 & rad-30-c2-load-lag(col1)-4 \\
\hline $7 / 21 / 2009$ & 31 & lag-col1 & $12: 20$ & 25.0 & na & 69.0 & rad-31-c2-load-lag(col1)-7 \\
\hline $7 / 21 / 2009$ & 32 & lag-col1 & $14: 17$ & 25.7 & na & 71.0 & rad-32-c2-load-lag(col1)-10 \\
\hline $7 / 21 / 2009$ & 33 & lag-col1 & $16: 16$ & 26.9 & na & 71.0 & rad-33-c2-load-lag(col1)-13 \\
\hline $7 / 22 / 2009$ & 34 & lag-col1 & $8: 17$ & 24.3 & na & 71.0 & rad-34-c2-load-lag(col1)-35 \\
\hline $7 / 22 / 2009$ & 35 & lag-col1 & $16: 19$ & 26.1 & na & 70.0 & rad-35-c2-load-lag(col1)-46 \\
\hline $7 / 23 / 2009$ & 36 & lag-col1 & $8: 17$ & 24.8 & na & 70.0 & rad-36-c2-load-lag(col1)-69 \\
\hline $7 / 23 / 2009$ & 37 & lag-col1 & $16: 25$ & 26.3 & na & 70.0 & rad-37-c2-load-lag(col1)-80 \\
\hline $7 / 24 / 2009$ & 38 & lag-col1 & $8: 17$ & 24.7 & na & 70.0 & rad-38-c2-load-lag(col1)-102 \\
\hline $7 / 24 / 2009$ & 39 & lag-col1 & $15: 18$ & 26.5 & na & 70.0 & rad-39-c2-load-lag(col1)-113 \\
\hline $7 / 27 / 2009$ & 40 & lag-col1 & $8: 21$ & 25.3 & na & 71.0 & rad-40-c2-load-lag(col1)-203 \\
\hline $7 / 27 / 2009$ & 41 & lag-col1 & $16: 17$ & 26.4 & na & 71.0 & rad-41-c2-load-lag(col1)-214 \\
\hline $7 / 28 / 2009$ & 42 & lag-col1 & $8: 19$ & 24.9 & na & 70.5 & rad-42-c2-load-lag(col1)-237 \\
\hline $7 / 28 / 2009$ & 47 & lag-col1 & $11: 49$ & 26.3 & na & 70.5 & rad-47-c2-load-lag(col1)-304 \\
\hline $7 / 28 / 2009$ & 43 & lag-col1 & $16: 16$ & 26.5 & na & 70.5 & rad-43-c2-load-lag(col1)-248 \\
\hline $7 / 29 / 2009$ & 44 & lag-col1 & $8: 17$ & 25.2 & na & 70.5 & rad-44-c2-load-lag(col1)-270 \\
\hline $7 / 29 / 2009$ & 49 & lag-col1 & $12: 20$ & 26.1 & na & 70.5 & rad-49-c2-load-lag(col1)-307 \\
\hline $7 / 29 / 2009$ & 45 & lag-col1 & $16: 19$ & 26.4 & na & 70.5 & rad-45-c2-load-lag(col1)-281 \\
\hline $7 / 30 / 2009$ & 46 & lag-col1 & $7: 19$ & 23.4 & na & 70.5 & rad-46-c2-load-lag(col1)-302 \\
\hline $7 / 30 / 2009$ & 48 & lag-col1 & $9: 19$ & 24.2 & na & 70.5 & rad-48-c2-load-lag(col1)-305 \\
\hline $7 / 30 / 2009$ & 50 & lag-col1 & $11: 20$ & 24.6 & na & 70.5 & rad-50-c2-load-lag(col1)-308 \\
\hline $7 / 30 / 2009$ & 52 & lag-col1 & $13: 20$ & 25.0 & na & 70.5 & rad-52-c2-load-lag(col1)-311 \\
\hline $7 / 30 / 2009$ & 54 & lag-col1 & $15: 26$ & 25.1 & na & 70.5 & rad-54-c2-load-lag(col1)-314 \\
\hline $7 / 30 / 2009$ & resert & ir at end & $15: 52$ & & 1706.77 & $<$ grams & \\
\hline
\end{tabular}


SRNL-STI-2009-00594, REVISION 0

Table 30. Part B - Cycle 2 Real-waste Data Sheet

\begin{tabular}{|c|c|c|c|c|c|c|c|}
\hline \multicolumn{8}{|c|}{ Displacemt 0.1 M NaOH } \\
\hline 7/30/2009 & \multicolumn{2}{|c|}{ reservoir at start } & $16: 00$ & & 337.428 & $<$ grams & \\
\hline $7 / 30 / 2009$ & 56 & col2 & $16: 30$ & na & 25.8 & \begin{tabular}{|l|}
68.0 \\
\end{tabular} & rad-56-c2-disp-col2-2 \\
\hline $7 / 30 / 2009$ & 57 & $\mathrm{col} 2$ & $17: 00$ & na & 25.4 & 68.5 & rad-57-c2-disp-col2-3 \\
\hline $7 / 30 / 2009$ & 58 & $\mathrm{col} 2$ & $17: 48$ & na & 26.1 & 68.5 & rad-58-c2-disp-col2-5 \\
\hline \multirow{2}{*}{\multicolumn{2}{|c|}{\begin{tabular}{|l|}
$7 / 30 / 2009$ \\
Pre-Elution DIW
\end{tabular}}} & & 18:00 & & 270.53 & $<$ grams & \\
\hline & & & & & & & \\
\hline $8 / 3 / 2009$ & \multicolumn{2}{|c|}{ reservoir at start } & $8: 30$ & & 774.23 & $<$ grams & \\
\hline $8 / 3 / 2009$ & 59 & col2 & 9:00 & na & 25.2 & 68.0 & rad-59-c2-preElu-col2-2 \\
\hline $8 / 3 / 2009$ & 60 & $\mathrm{col} 2$ & $9: 29$ & na & 25.2 & 68.0 & rad-60-c2-preElu-col2-3 \\
\hline $8 / 3 / 2009$ & 61 & col2 & $10: 12$ & na & 24.6 & 65.0 & rad-61-c2-preElu-col2-5 \\
\hline $8 / 3 / 2009$ & \multicolumn{2}{|c|}{ reservoir at end } & $10: 20$ & & 709.46 & $<$ grams & \\
\hline \multicolumn{8}{|c|}{ Elution with $0.5 \mathrm{M}$ HNO3 } \\
\hline $8 / 3 / 2009$ & \multicolumn{2}{|c|}{ reservoir at start } & $10: 30$ & & 527.29 & $<$ grams & \\
\hline $8 / 3 / 2009$ & 62 & col2 & $10: 45$ & na & 24.6 & 65.0 & rad-62-c2-elu-col2-0.7 \\
\hline $8 / 3 / 2009$ & 63 & $\mathrm{col} 2$ & $11: 16$ & na & 25.4 & 65.0 & rad-63-c2-elu-col2-1.4 \\
\hline $8 / 3 / 2009$ & 65 & $\mathrm{col} 2$ & $12: 15$ & na & 25.1 & 65.5 & rad-65-c2-elu-col2-3 \\
\hline $8 / 3 / 2009$ & 66 & col2 & $12: 45$ & na & 24.9 & 63.0 & rad-66-c2-elu-col2-3.5 \\
\hline $8 / 3 / 2009$ & 67 & $\mathrm{col} 2$ & $13: 16$ & na & 25.1 & 62.0 & rad-67-c2-elu-col2-4 \\
\hline $8 / 3 / 2009$ & 68 & $\mathrm{col} 2$ & $13: 45$ & na & 25.4 & 58.0 & rad-68-c2-elu-col2-5 \\
\hline $8 / 3 / 2009$ & 69 & $\mathrm{col} 2$ & $14: 16$ & na & 26.0 & 55.0 & rad-69-c2-elu-col2-5.6 \\
\hline $8 / 3 / 2009$ & 70 & $\mathrm{col} 2$ & $14: 49$ & na & 25.8 & 54.0 & rad-70-c2-elu-col2-6.3 \\
\hline $8 / 3 / 2009$ & 71 & $\mathrm{col} 2$ & $15: 15$ & na & 25.8 & 53.0 & rad-71-c2-elu-col2-7 \\
\hline $8 / 3 / 2009$ & 72 & $\mathrm{col} 2$ & $16: 17$ & na & 25.9 & 53.0 & rad-72-c2-elu-col2-8 \\
\hline $8 / 3 / 2009$ & 73 & $\mathrm{col} 2$ & $17: 15$ & na & 25.9 & 53.0 & rad-73-c2-elu-col2-10 \\
\hline $8 / 3 / 2009$ & 74 & $\mathrm{col} 2$ & $18: 15$ & na & 25.9 & 53.0 & rad-74-c2-elu-col2-11 \\
\hline $8 / 3 / 2009$ & 75 & $\mathrm{col} 2$ & $19: 15$ & na & 25.9 & 53.0 & rad-75-c2-elu-col2-13 \\
\hline $8 / 3 / 2009$ & 76 & $\mathrm{col} 2$ & $20: 15$ & na & 26.2 & 53.0 & rad-76-c2-elu-col2-14 \\
\hline $8 / 3 / 2009$ & 77 & $\mathrm{col} 2$ & $21: 15$ & na & 26.6 & 53.0 & rad-77-c2-elu-col2-15 \\
\hline $8 / 3 / 2009$ & 78 & $\mathrm{col} 2$ & $22: 15$ & na & 25.0 & 53.0 & rad-78-c2-elu-col2-17 \\
\hline $8 / 3 / 2009$ & 79 & $\mathrm{col} 2$ & $23: 15$ & na & 25.2 & 53.0 & rad-79-c2-elu-col2-18 \\
\hline $8 / 4 / 2009$ & 80 & $\mathrm{col} 2$ & $0: 15$ & na & 25.1 & 53.0 & rad-80-c2-elu-col2-20 \\
\hline $8 / 4 / 2009$ & 81 & $\mathrm{col} 2$ & $1: 15$ & na & 25.0 & 53.0 & rad-81-c2-elu-col2-21 \\
\hline $8 / 4 / 2009$ & 82 & $\mathrm{col} 2$ & $2: 15$ & na & 25.0 & 52.5 & rad-82-c2-elu-col2-22 \\
\hline $8 / 4 / 2009$ & 83 & $\mathrm{col} 2$ & $3: 15$ & na & 24.9 & 52.5 & rad-83-c2-elu-col2-24 \\
\hline $8 / 4 / 2009$ & 84 & $\mathrm{col} 2$ & $4: 15$ & na & 24.8 & 52.5 & rad-84-c2-elu-col2-25 \\
\hline $8 / 4 / 2009$ & 85 & $\mathrm{col} 2$ & $5: 15$ & na & 25.0 & 52.0 & rad-85-c2-elu-col2-27 \\
\hline $8 / 4 / 2009$ & 86 & $\mathrm{col} 2$ & $6: 15$ & na & 24.9 & 52.0 & rad-86-c2-elu-col2-28 \\
\hline $8 / 4 / 2009$ & 87 & $\mathrm{col} 2$ & $7: 15$ & na & 24.8 & 52.0 & rad-87-c2-elu-col2-29 \\
\hline $8 / 4 / 2009$ & 88 & $\mathrm{col} 2$ & $7: 55$ & na & 24.9 & 52.0 & rad-88-c2-elu-col2-31 \\
\hline $8 / 4 / 2009$ & reserv & at end & $8: 16$ & & 203.6 & $<$ grams & \\
\hline \multicolumn{8}{|c|}{ Post-Elution DIW } \\
\hline $8 / 4 / 2009$ & \multicolumn{2}{|c|}{ reservoir at start } & $8: 16$ & & 709.46 & $<$ grams & \\
\hline $8 / 4 / 2009$ & 89 & col2 & $9: 16$ & na & 26.0 & 52.0 & rad-89-c2-postElu-col2-1 \\
\hline $8 / 4 / 2009$ & 90 & $\mathrm{col} 2$ & $10: 15$ & na & 25.5 & 52.0 & rad-90-c2-postElu-col2-3 \\
\hline $8 / 4 / 2009$ & 91 & $\mathrm{col} 2$ & $11: 15$ & na & 25.5 & 52.0 & rad-91-c2-postElu-col2-5 \\
\hline $8 / 4 / 2009$ & \multicolumn{2}{|c|}{ reservoir at end } & $11: 45$ & na & 660.7 & $<$ grams & \\
\hline
\end{tabular}

Cycle 2 Facts:

$\begin{array}{ccccc}\text { Waste } \gg \text { Averages }= & \text { Height }(\mathrm{mm}) & \text { BV }(\mathrm{mL}) & \text { Temp. }\left({ }^{\circ} \mathrm{C}\right) \\ & \text { Lead Column 2 } & 67.7 & 10.95 & 25.7 \\ \text { Lag } & \text { Column 1 } & 70.4 & 11.39 & 25.4 \\ & & \text { Averages }= & 11.17 & 25.6 \\ & & \text { Std Dev }= & 0.23 & 0.9\end{array}$

Elution $>>\quad$ dHeight $(\mathrm{mm}) \quad$ dHeight\% $\quad$ Temp. $\left({ }^{\circ} \mathrm{C}\right)$

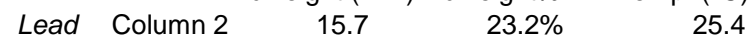




\title{
APPENDIX C. R\&D DIRECTION FOR REAL-WASTE TEST
}

\section{R\&D Direction: Small Column IX with sRF for SRS Waste}

\author{
Date: $\quad$ 06/20/2009 Customer: $\quad$ W.R. Wilmarth, 773-A, A-261 \\ Activity: $\quad$ LFWWIX001 Researchers: M. R. Duignan, 786-5A, 11 \\ C.A. Nash, 773-42A, 182 \\ Technicians: P. U. Burkhalter, 773-A, E-004 \\ D. J. Wheeler, 773-A, E-002 \\ Managers: $\quad$ B. J. Giddings, 786-5A, 2 / D.J. Adamson, 786-5A, 8 \\ S. D. Fink, 773-A, B-112 \\ F. M. Pennebaker, 773-42A, 121
}

\section{Table of Contents}

[Note: This R\&D Direction is for operation and not assembly. It assumes that the test rig is fully assembled, the feed and 10-liter bottles are in place and both columns are eluted, in $\mathrm{H}$-form, and filled with deionized water, as well as the rest of the test rig.]

\section{Pre-requisites}

1. General operation of the test rig.

2. Overall test matrix

3. Initial filling and handling of feed reservoirs (bottles) and effluent vessels.

4. Check flowrates for the two feed pumps.

\section{Cycle 1 Test}

5. Pre-Cycle 1 regeneration of Columns 1 and 2

6. Cycle 1 loading (of cesium) - Column 1 Lead and Column 2 Lag

7. Cycle 1 waste displacement from Column 1

8. Cycle 1 initial rinse of Column 1

9. Cycle 1 elution of Column 1 - need around-the-clock coverage

10. Cycle 1 final rinse of Column 1

\section{Cycle 2 Test}

11. Pre-Cycle 2 regeneration of column 1

12. Cycle 2 loading (of cesium) - Column 2 Lead and Column 1 Lag

13. Cycle 2 waste displacement from Column 2

14. Cycle 2 initial rinse of Column 2

15. Cycle 2 elution of Column 2 - need around-the-clock coverage

16. Cycle 2 final rinse of Column 2

Cycle 2a Post-Test Elution of Column1

17. Cycle 2a waste displacement from Column 1 
18. Cycle 2a initial rinse of Column 1

19. Cycle 2a elution of Column 1

20. Cycle 2a final rinse of Column 1

End of SCIX test

\section{Appendices}

A. Sketch of test system

B. Picture of test system control panels

C. Table of valve settings

D. Test and Sampling Matrix

E. Data Sheets

F. Direction on taking Cycle 1 two-column samples

G. Direction on taking Cycle 2 two-column samples

H. Direction on taking single-column samples from Column 1

I. Direction on taking single-column samples from Column 2

\section{End of the table of contents}




\section{General operation of the test rig}

Look over the sketch of the test rig in Appendix A.

1. The apparatus is divided into two basic parts:

a. The Ion Exchange (IX) columns and the flow direction controls for the columns.

b. Feed and 10-liter effluent bottles and the flow selection for each.

2. The columns can be operated so that both are working together in series and either Column 1 can be first and Column 2 second (This will be Cycle 1 of testing.) or Column 2 can be first with Column 1 being second (This will be Cycle 2 of testing.).

3. Each of the columns can operate individually so the test rig can operate with only Column 1 or Column 2. (This is important when only the IX resin in one column will be refreshed (regenerated) after use. Specifically, Columns 1 and 2 will be individually regenerated to start the overall test campaign and then Column 1 is regenerated after Cycle 1 testing and Column 2 is regenerated after Cycle 2 testing. Note. Column 1 is regenerated for a second time after the test is over.)

4. Flow of liquids is always DOWN through the IX resin beds.

5. There is a 30 psig pressure gauge to show the pressure at the discharge of the pumps and at all times the pressure should be less than 1 psig. If pressure exceeds 1 psig this commonly means that a valve is incorrectly closed, which prevents the liquid to flow. Make sure all valves are correctly set. A high pressure could also mean a pluggage in the system but this is not expected since the liquid was filtered and does not have solids. The presences of solids would indicated precipitation due to the mix of acid and basic and will indicate a problem that will need PI assistance to resolve.

6. The flow rates of the two pumps are indicated as $1.4 \mathrm{BV} / \mathrm{HR}$ (Pump 2) or 3.0 BV/HR (Pump 1) [Note, BV = (resin) Bed Volume $=10.51 \mathrm{~mL}$, therefore 1.4 $\mathrm{BV} / \mathrm{HR}=0.25 \mathrm{~mL} / \mathrm{minute}$ or $3.0 \mathrm{BV} / \mathrm{HR}=0.53 \mathrm{~mL} /$ minutes.]

7. The sketch shows 6 feed bottles, however only 5 will be used because the $0.05 \mathrm{M}$ Nitric Acid feed in no longer in the test.

8. The wands in the bottles are designed to touch the bottom of the containers.

9. The exit port of the wands in the two effluent receipt vessels are designed to end near the top of the containers to allow the effluent to fall into the vessels and not build up pressure if they were submerged.

10. The strip heater shown on each column only provides very mild heating (around $28^{\circ} \mathrm{C}$ ) because the goal is to maintain the liquid in the IX columns at $25^{\circ} \mathrm{C} \pm 2^{\circ} \mathrm{C}$. The heater will not be used if the temperature in the cell is above $23^{\circ} \mathrm{C}$.

11. The flush container shown probably will not be used and is present only in the event that the pumps need to be flushed.

12. Not shown on the sketch are the 3-way valves on the top of each of the two effluent vessels. These valves exist to locally stop the effluent to the tanks and collect local samples of liquid in order to check a pump's flowrate. 
Look over the picture (Fig. B1) of the test system control panels in Appendix B.

13. Note that the panels shown in the sketch are the same but reversed in the picture with the panel containing valves to control feed from the bottles at the top and the panel to control flow direction through the columns at the bottom. Further, the valve positions for each test phase are listed in Appendix C.

14. The Pump Feed Panel at top contains three groups of valves:

a. To the left there are two 2-way valves: 2W-1 (for Pump 1) and 2W-2 (for Pump 2) to isolate the pumps when not in use. The pumps are shown in Fig. B3 in Appendix B.

a. To the right there is one 3-way valve $3 \mathrm{~W}-11$ to direct column effluent to the appropriate receipt vessel. Pointing to the left for Spent Waste Feed. Point to the right for Spent Regen (which means all other effluents). Point down shuts to valve.

b. The 6 valves in the center (3W-6, 3W-7, 3W-8, 3W-9, 3W-10, and finally $2 \mathrm{~W}-5$ ) are to choose which feed to draw from. Point a valve towards a labeled feed to choose that feed. Once a feed is chosen then all other valves to the right of the feed valve are in the off position and all valves to the left of the feed valve are in the bypass position (this position is when the valve stem is pointing along the line of arrows, except the last valve, 3W-6, which will always point to the TO PUMP position EXCEPT when the chosen feed just happens to be $0.5 \mathrm{M} \mathrm{NaOH}$. As an example the Fig. B1 in Appendix B shows this situation, that is, valve 3W-6 points towards the label $.5 \mathrm{NAOH}$ to choose that feed while all the other 5 valves to the right are pointing to the OFF positions.).

15. The Column Control Panel at the bottom contains the valves to choose how to operate the columns:

a. Two-Columns Operation - Column 1 is Lead - To operate with two columns in series with Column 1 (at left) being first and Column 2 second, then set: The three valves at top $3 \mathrm{~W}-2,3 \mathrm{~W}-3$, and $3 \mathrm{~W}-4$ pointing to the LEAD 1 position, the EFFLUENT EXIT valve, 3W-5, to FROM COL \#2, the valve at the bottom at left, $3 \mathrm{~W}-1$, points to FROM PUMP position, and the two sampling valves $2 \mathrm{~W}-3$ and $2 \mathrm{~W}-4$ are in the OFF position.

b. Two-Column Operation - Column 2 is Lead- To operate with two columns in series with Column 2 (at right) being first and Column 1 second, then set: The three valves at top 3W-2, 3W-3, and 3W-4 pointing to the LEAD 2 position, the EFFLUENT EXIT valve, 3W-5, to FROM COL \#1, the valve at the bottom at left, $3 \mathrm{~W}-1$, points to FROM PUMP position, and the two sampling valves $2 \mathrm{~W}-3$ and $2 \mathrm{~W}-4$ are in the OFF position.

c. Single-Column Operation - Column 1 - To operate with a single column with Column 1, then set: The three valves at top $3 \mathrm{~W}-2$ is in the LEAD 1 position, but $3 \mathrm{~W}-3$ and $3 \mathrm{~W}-4$ pointing to the OFF position, the EFFLUENT EXIT valve, 3W-5, to FROM COL \#1, the valve at the bottom at left, 3W-1, points to FROM PUMP position, and the two sampling valves $2 \mathrm{~W}-3$ and $2 \mathrm{~W}-4$ are in the OFF position. 
d. Single-Column Operation - Column 2 - To operate with single column with Column 2, then set: The three valves at top 3W-2 is in the LEAD 2 position, but $3 \mathrm{~W}-3$ and $3 \mathrm{~W}-4$ pointing to the OFF position, the EFFLUENT EXIT valve, 3W-5, to FROM COL \#1, the valve at the bottom at left, $3 \mathrm{~W}-1$, points to FROM PUMP position, and the two sampling valves $2 \mathrm{~W}-3$ and $2 \mathrm{~W}-4$ are in the OFF position.

e. Flush Internal Tubes - It is advisable to flush the small amount of waste trapped in the internal tubes after any Two-Column Operation between valves 2W-3 and 3W-3 (after Cycle 1) or between valves 2W-4 and 3W-4 (after Cycle 2) with water just before treating the IX resin with nitric acid. This can be done during single column operation.

i. After Cycle 1 Pre-Elution Rinse then set: The three valves at top $3 \mathrm{~W}-2$ and $3 \mathrm{~W}-3$ are in the LEAD 1 position and $3 \mathrm{~W}-4$ is in the LEAD 2 position, the EFFLUENT EXIT valve, $3 W-5$ is in the OFF position, the valve at the bottom at left, $3 \mathrm{~W}-1$, points to FROM PUMP position, and the two sampling valve $2 \mathrm{~W}-3$ is in the OFF position, but sampling valve $2 \mathrm{~W}-4$ is in the pointing down in the COL \#2 SAMPLE position. Allow the pump to push the trapped waste through the sample port for about 5 minutes to flush the line.

ii. After Cycle 2 Pre-Elution Rinse then set: The three valves at top $3 \mathrm{~W}-2$ and $3 \mathrm{~W}-3$ are in the LEAD 2 position and 3W-4 is in the LEAD 1 position, the EFFLUENT EXIT valve, $3 W-5$ is in the OFF position, the valve at the bottom at left, $3 \mathrm{~W}-1$, points to FROM PUMP position, and the two sampling valve $2 \mathrm{~W}-3$ is in the COL \#1 SAMPLE position, and sampling valve $2 \mathrm{~W}-4$ is in the OFF position. Allow the pump to push out the trapped waste through the sample port for about 5 minutes to flush the line.

16. As partially shown in Fig. B1 and shown in Fig. B2 of Appendix B, at the very bottom of the test rig is a rack to hold sample bottles and catch bottles. That is, under the two sample ports, valves $2 \mathrm{~W}-3$ and $2 \mathrm{~W}-4$, there are places in the rack to hold the sample bottles directly under the sample ports. There is a specially made sample bottle holder of white plastic into which a 1-dram sample bottle can be placed and then that holder can be placed in the rack. With using this holder the distance between the bottom of a sample port tube and the top a sample bottle is approximately $1 / 4$ inch, therefore the sample bottle rack is loosely held to allow it to be rotated outwards that will allow the sample bottle and its holder to be placed and removed easily. This also goes for the two catch bottles that are usually in place under the sample ports when samples are not being drawn.

\section{End of general operation}


SRNL-STI-2009-00594, REVISION 0

\section{Becoming familiar with the overall test matrix (Appendix D)}

1. In general this task is to process approximately 8 liters of SRS tank waste to remove cesium with Ion Exchange (IX) resin that is contained in two IX columns. Those columns will be used together in series and are referred to Column 1 (on the left side of the test apparatus) and Column 2 (on the right side of the test apparatus).

2. Look over the test matrix table in Appendix D and the black horizontal line that splits the table into two cycles. Cycle 1 uses Column 1 as the Lead column and Column 2 as the Lag column. Cycle 2 will then reverse the direction and Column 2 will be the Lead column and Column 1 will be the Lag.

3. At the beginning of each cycle the resin is prepared to remove cesium by regenerating the resin with 6 Bed Volumes $(\mathrm{BV}=10.51 \mathrm{~mL})$ of $0.5 \mathrm{M} \mathrm{NaOH}$ at a flowrate of $3.0 \mathrm{BV} / \mathrm{HR}(0.53 \mathrm{~mL} /$ minute $)$. At the beginning of Cycle 1 both columns of resin need to be regenerated and each column is regenerated separately so they have the same starting point. The purpose of Cycle 2 will simply switch the Cycle-1 Lag column (Column 2) to the Lead position and Cycle-1 Lead column (Column 1) to the Lag position. However the new Lag column (Column 1) needs to be regenerated first since it will be saturated with cesium from Cycle 1, while the new Lead column (Column 2) is only partially loaded with cesium and will be used without regeneration.

4. After regeneration for both cycles that the columns are ready to be loaded with cesium and will process the indicated volume of waste at a flowrate of $1.4 \mathrm{BV} / \mathrm{HR}$ (0.245 mL/minute)

5. When waste processing is complete the resin in the Lead column needs to be regenerated because it is loaded with cesium.

6. The regeneration process begins by removing the waste from the Lead column by pushing it out with $5 \mathrm{BV}$ of $0.1 \mathrm{M} \mathrm{NaOH}$ at a flowrate of $3.0 \mathrm{BV} / \mathrm{HR}$.

7. The resin in the Lead column is then rinsed with $5 \mathrm{BV}$ of deionized water (DIW or $\mathrm{H} 2 \mathrm{O}$ ) at a flowrate of $3.0 \mathrm{BV} / \mathrm{HR}$.

8. To remove the cesium from the Lead column resin $30 \mathrm{BV}$ of $0.5 \mathrm{M}$ Nitric Acid is passed though the resin at a flowrate of $1.4 \mathrm{BV} / \mathrm{FR}$. A process called elution.

9. Finally, the nitric acid in Lead column is removed with $5 \mathrm{BV}$ of $\mathrm{H} 2 \mathrm{O}$ at a flowrate of $1.4 \mathrm{BV} / \mathrm{HR}$.

10. Cycle 2 then begins by regenerating the Cycle 1 Lead column with 6 BV of 0.5 $\mathrm{NaOH}$ at a flowrate of $3.0 \mathrm{BV} / \mathrm{HR}$

11. The lead and lag columns are reversed and the entire process repeats once.

12. The acceptable operational range for temperature is $23^{\circ} \mathrm{C}$ to $27^{\circ} \mathrm{C}$ but small variations outside this range for short periods (an hour or two) can be tolerated.

13. Throughout all the process steps periodic samples are taken as indicated on the Test and Sample Matrix (App. D) and on the Data Sheets (App. E), however, note that the most intensive sampling will be during elution (processing with nitric acid) because of the fast changes occurring during cesium removal. Sampling starts at a frequency of every 30 minutes for 5 hours, then hourly for 17 hours.

\section{End of becoming familiar with the test matrix}




\section{Initial filling and handling of feed reservoirs (bottles) and effluent vessels}

1. There are 5 feed vessels used for this test, as shown on the sketch in App. A and on the PUMP FEED PANEL in Fig. B1 of App. B:
a. $0.5 \mathrm{M} \mathrm{NaOH}$ (or just . $5 \mathrm{NAOH}$ )
b. New Feed (or just FEED)
c. $0.1 \mathrm{M} \mathrm{NaOH}$ (or just $01 \mathrm{NAOH}$ )
d. $0.5 \mathrm{M}$ Nitric Acid (or just .5 ACID)
e. DI Water (or just H2O)

[Note the 0.05 M Nitric Acid (or just .05 ACID) will not be used.]

2. Before the test begins in will be necessary to have the feed solutions ready. The amount of each liquid to be used throughout the test is shown on the Test and Sample Matrix (App. D) and is summarized here:

Cycle 1

a. $0.5 \mathrm{M} \mathrm{NaOH}=126 \mathrm{~mL}$ or $126 \mathrm{~g}$

b. $\quad$ New Feed $=5.1$ liters or $3.9 \mathrm{~g}$

c. $0.1 \mathrm{M} \mathrm{NaOH}=53 \mathrm{~mL}$ or $53 \mathrm{~g}$

d. $0.5 \mathrm{M}$ Nitric Acid $=316 \mathrm{~mL}$ or $313 \mathrm{~g}$

e. $\quad$ DI Water $=111 \mathrm{~mL}$ or $111 \mathrm{~g}$

Cycle 2

a. $0.5 \mathrm{M} \mathrm{NaOH}=63 \mathrm{~mL}$ or $63 \mathrm{~g}$

b. New Feed $=5.1$ liters or $3.9 \mathrm{~g}$

c. $0.1 \mathrm{M} \mathrm{NaOH}=53 \mathrm{~mL}$ or $53 \mathrm{~g}$

d. $0.5 \mathrm{M}$ Nitric Acid $=316 \mathrm{~mL}$ or $313 \mathrm{~g}$

e. $\quad$ DI Water $=111 \mathrm{~mL}$ or $111 \mathrm{~g}$

Post Cycle 2 Elution of Column 1

a. $0.1 \mathrm{M} \mathrm{NaOH}=53 \mathrm{~mL}$ or $53 \mathrm{~g}$

b. $\quad 0.5 \mathrm{M}$ Nitric Acid $=316 \mathrm{~mL}$ or $313 \mathrm{~g}$

c. DI Water $=106 \mathrm{~mL}$ or $106 \mathrm{~g}$

Total Quantities Needed

a. $0.5 \mathrm{M} \mathrm{NaOH}=378 \mathrm{~mL}$ or $378 \mathrm{~g}$

b. $\quad$ New Feed $=8.4$ liters or $6.4 \mathrm{~g}$

c. $0.1 \mathrm{M} \mathrm{NaOH}=159 \mathrm{~mL}$ or $159 \mathrm{~g}$

d. $0.5 \mathrm{M}$ Nitric Acid $=948 \mathrm{~mL}$ or $939 \mathrm{~g}$

e. $\quad$ DI Water $=328 \mathrm{~mL}$ or $329 \mathrm{~g}$

Fill Reservoirs to the following quanties:

f. $\quad 0.5 \mathrm{M} \mathrm{NaOH}>>$ at least 0.5 liter (500 g)

g. New Feed $>>$ Use total available

h. $0.1 \mathrm{M} \mathrm{NaOH}>>$ at least 0.25 liter $(250 \mathrm{~g})$

i. $\quad 0.5 \mathrm{M}$ Nitric Acid $>>$ at least 1.0 liter (990 g)

j. $\quad$ DI Water $>>$ at least 0.5 liter (500 g)

Fill each feed bottle to the indicated amount, measure the weight and document the results in the task notebook. While the initial weights are to be 
noted here before and after each process step each bottle is shall be weighted because with time the solutions can evaporate and cause errors in the measurements.

3. There are 2 effluent receipt vessels used for this test, as shown on the sketch in App. A and on the PUMP FEED PANEL in Fig. B1 of App. B:

a. 10-L carboy labed SPENT FEED

b. 10-L carboy labled SPENT REGENERATION SOLUTIONS (or just SPENT REGEN)

4. These effluent vessels have three basic functions;

a. To receive the spent solutions as they process through the IX columns which occurs when the 3-way effluent valve on the top of each vessel is pointing down towards the vessel.

b. To show that a solution is flowing by turning up the 3-way effluent valve on the top of each vessel so the effluent is directed to the pour spout into a catch bottle.

c. To collect small samples of a solution while the test rig operates in order to check the flowrate of each pump if necessary.

5. To reiterate, the overall flowrate of each of the solutions as it is processed through the test rig will be measured by the initial and final weights of each feed solution.

\section{End of handling of feed and 10-liter effluent bottles}




\section{Check flowrates for the two feed pumps (Fig. B3 of Appendix B)}

[Note: This direction is to be used before testing begins, when the test rig is filled with with deionized water or when sample times change from what is listed in the direction (which indicates an unexpected flowrate change). Make sure the $25 \mathrm{~mL}$ graduated cylinder is available before use. If this chapter is to be used while the test is in progress due to a change in sample times informed the PI to determine if he will want to assist in the check]

1. Note, on Pump 1 the flowrate is indicated as 3.0 BV/HR and on Pump 2 the flowrate is indicated as $1.4 \mathrm{BV} / \mathrm{HR}$.

2. Note, on the left hand side of the PUMP FEED PANEL that valve $2 \mathrm{~W}-1$ is related to Pump 1 and valve $2 \mathrm{~W}-2$ is related to Pump 2.

3. Fill the DI WATER bottle with deionized water (DIW or H2O) about half full.

4. Have ready and available an empty $25 \mathrm{~mL}$ graduated cylinder, either two calibrated stop watches (timers) or one with two internal timers, and a calibrated scale to weigh a one-liter bottle of water (A more sensitive scale, at least $0.01 \mathrm{~g}$, can be used by using less water in the l-liter $\mathrm{H} 2 \mathrm{O}$ feed bottle.)

\section{Pre-test check of the flow rate of Pump 2 by using both mass and volume:}

5. Set Pump 2 indicator (the pointer below the pump head) midway between the numbers 1 and 2 to the right of the central 0 . [Note, turning the black handle on the left hand side counter-clockwise moves the pump head to the right. If the pointer is already between 1 and 2 the flowrate may already be set from previous testing, therefore, do not move the pointer yet, but check the flowrate at the current setting.]

6. Adjust the valves for 2-column operation (ex. Column 1 is Lead, Column 2 is Lag):

7. Valve $3 \mathrm{~W}-1$ points to FROM PUMP

8. Valves 3W-2, 3W-3, 3W-4 point to LEAD 1

9. Valve $3 \mathrm{~W}-5$ point to FROM COL \#2

10. Valves $2 \mathrm{~W}-3$ and $2 \mathrm{~W}-4$ are $\mathrm{OFF}$

11. Adjust the valves on the PUMP FEED PANEL to feed water:

12. Valve 3W-6 points to TO PUMP

13. Valves 3W-7, 3W-8, 3W-9, 3W-10 point to flow line (bypass)

14. Valve $2 \mathrm{~W}-5$ points to down, to $\mathrm{H} 2 \mathrm{O}$

15. Valve 3W-11 to SPENT REGENERATION SOLUTIONS

16. Take the wand out of the $\mathrm{H} 2 \mathrm{O}$ bottle and measure its weight and note the amount in the notebook. Then return the bottle and replace the wand until it hits the bottom of the container.

17. Empty the $25 \mathrm{~mL}$ graduated cylinder, place it under the spigot on top of the 10 liter SPENT REGENERATION SOLUTIONS bottle and turn the valve UP.

18. Turn on Pump 2, immediately start Timer 1, and wait until water is dripping into the graduated cylinder at a steady pace.

19. At the same time, note the initial liquid level in the graduated cylinder and start Timer 2, then collect about 20 minutes of water. [This should give about $4.9 \mathrm{~mL}$ ] 
20. After the 20 minutes note the final liquid level in the cylinder and at the same time stop Timer 2.

21. Turn off Pump 2 and immediately stop Timer 1.

22. Reweigh the $\mathrm{H} 2 \mathrm{O}$ bottle.

23. Calculate the flowrate using mass:

Flowrate $=($ final-initial $)$ mass $($ grams $) / 0.998 \mathrm{~g} / \mathrm{mL} /$ collection time (minutes)

24. Now calculate the flowrate using volume from the graduated cylinder:

Flowrate $=($ final-initial) liquid level (milliters) $/$ collection time (minutes)

25. Write the results in the notebook.

26. If the measurement by MASS is $0.245 \mathrm{~mL} / \mathrm{min} \pm 0.010 \mathrm{~mL} / \mathrm{min}$ it is OK then go to Step 28.

27. If the flowrate is too high turn the pump handle clockwise $1 / 8^{\text {th }}$ turn OR if the flowrate is too low turn the pump handle counter-clockwise $1 / 8^{\text {th }}$ turn (AFTER THE POINTER BEGINS TO MOVE - reversing the direction causes slack in the treads) then repeat Steps 16 to 26.

28. Close the valve on the 10-liter SPENT REGENERATION SOLUTIONS bottle by turning it horizontal.

Pre-test check of the flow rate of Pump 1 using by mass and volume:

29. Set Pump 1 indicator (the pointer below the pump head) at numbers 3 to the left of the central 0 . [Note, turning the black handle on the left hand side clockwise moves the pump head to the left. If the pointer is already near 3 the flowrate may already be set from previous testing, therefore, do not move the pointer yet, but check the flowrate at the current setting]

30. Use the H2O bottle weight measured in the Pump 2 check for initial water weight.

31. Valve 3W-1 points to FROM PUMP

32. Valves $3 W-2$ to LEAD 1

33. 3W-3, 3W-4 point to OFF

34. Valve $3 \mathrm{~W}-5$ point to FROM COL \#1

35. Valves $2 \mathrm{~W}-3$ and $2 \mathrm{~W}-4$ are OFF

36. Adjust the valves on the PUMP FEED PANEL to feed water:

37. Valve $3 \mathrm{~W}-6$ points to TO PUMP

38. Valves 3W-7, 3W-8, 3W-9, 3W-10 point to flow line (bypass)

39. Valve $2 \mathrm{~W}-5$ points to down, to $\mathrm{H} 2 \mathrm{O}$

40. Valve 3W-11 to SPENT REGENERATION SOLUTIONS

41. Take the wand out of the $\mathrm{H} 2 \mathrm{O}$ bottle and measure its weight and note the amount in the notebook. Then return the bottle and replace the wand until it hits the bottom of the container.

42. Empty the $25 \mathrm{~mL}$ graduated cylinder, place it under the spigot on top of the 10 liter SPENT REGENERATION SOLUTIONS bottle and turn the valve UP.

43. Turn on Pump 1, immediately start Timer 1, and wait until water is dripping into the graduated cylinder at a steady pace. 
44. At the same time, note the initial liquid level in the graduated cylinder and start Timer 2, then collect about 10 minutes of water. [This should give about $5.3 \mathrm{~mL}$ ]

45. After the 10 minutes note the final liquid level in the cylinder and at the same time stop Timer 2.

46. Turn off Pump 1 and immediately stop Timer 1.

47. Reweigh the $\mathrm{H} 2 \mathrm{O}$ bottle.

48. Calculate the flowrate using mass:

Flowrate $=($ final-initial $)$ mass $($ grams $) / 0.998 \mathrm{~g} / \mathrm{mL} /$ collection time (minutes $)$

49. Now calculate the flowrate by volume from the graduated cylinder:

Flowrate $=$ (final-initial) liquid level (milliters) / collection time (minutes)

50. Write the results in the notebook.

51. If the measurement by MASS is $0.525 \mathrm{~mL} / \mathrm{min} \pm 0.020 \mathrm{~mL} / \mathrm{min}$ it is OK then go to Step 53.

52. If the flowrate is too high turn the pump handle clockwise $1 / 8^{\text {th }}$ turn OR if the flowrate is too low turn the pump handle counter-clockwise $1 / 8^{\text {th }}$ turn (AFTER THE POINTER BEGINS TO MOVE) then repeat Steps 41 to 51.

53. Close the valve on the 10-liter SPENT REGENERATION SOLUTIONS bottle by turning it horizontal.

\section{During test check of the flow rate of a pump}

[To check a pump's flowrate after testing begins and during a particular phase of testing, then all the valves will already be set and it only involves the checking of the established flow as it exits into one of the effluent vessels by using the $25 \mathrm{~mL}$ graduated cylinder.]

54. Empty the $25 \mathrm{~mL}$ graduated cylinder and place it under the spigot of the effluent vessel currently in use, that is, either the SPENT FEED or the SPENT

REGENERATION SOLUTIONS. On top of that 10-liter bottle turn the valve UP.

55. Wait until liquid is dripping into the cylinder at a steady pace.

56. Note the initial liquid level in the graduated cylinder then start a timer to collect about 10 minutes of liquid if Pump 1 is in use or 20 minutes of liquid if Pump 2 is in use. [In both cases, this should give about $5 \mathrm{~mL}$ ]]

57. At the same time stop the timer and note the final liquid level in the cylinder.

58. Calculate the flowrate:

Flowrate $=$ (final-initial) liquid level (milliters) / collection time (minutes)

59. For Pump 1: If the measurement is $0.525 \mathrm{~mL} / \mathrm{min} \pm 0.020 \mathrm{~mL} / \mathrm{min}$ it is $\mathrm{OK}$ then go to Step 60, or for Pump 2: If the measurement is $0.245 \mathrm{~mL} / \mathrm{min} \pm 0.010$ $\mathrm{mL} / \mathrm{min}$ it is OK then go to Step 60 . 
60. If the flowrate is too high turn the pump handle clockwise $1 / 8^{\text {th }}$ turn OR if the flowrate is too low turn the pump handle counter-clockwise $1 / 8^{\text {th }}$ turn (AFTER THE POINTER BEGINS TO MOVE) then repeat Steps 54 to 59.

61. Document the collected liquid height, the collection time, and the final flowrate in the notebook.

End of direction to check flows for the pumps 


\section{Pre-Cycle 1 regeneration of Columns 1 and 2}

[Note: The resin in the columns is in Hydrogen form and the test rig is filled with deionized water. Regeneration is done with $0.5 \mathrm{M} \mathrm{NaOH}$ ]

1. Start at 7:30 am Monday

2. Have ready the three (3) sample bottles as listed on the data sheet (App. E).

3. Turn on power to the temperature readouts. Document temperatures of Columns 1 and 2 in notebook. If the temperatures of the columns are above $30^{\circ} \mathrm{C}$ inform one of the PIs. The acceptable operational range is $23^{\circ} \mathrm{C}$ to $27^{\circ} \mathrm{C}$ but small variations outside this range for short periods (an hour or two) can be tolerated.

4. Take the wand out of the $0.5 \mathrm{M} \mathrm{NaOH}$ bottle and measure its weight and note the amount on the data sheet and in the notebook. Then return the bottle and replace the wand until it hits the bottom of the container.

5. Set the test rig valves according to Valve Table (App. C):

PUMP FEED PANEL

a. Pump 1: 2W-1(ON), Pump 2: 2W-2(OFF)

b. Feed: 3W-6(.5 NAOH), 3W-7(OFF), 3W-8(OFF), 3W-9(OFF), 3W10(OFF), 2W-5(OFF)

c. Effluent container: 3W-11(SPENT REGEN)

COLUMN CONTROL PANEL

d. 3W-1(FROM PUMP)

e. Single Column 1: 3W-2(LEAD 1), 3W-3(OFF), 3W-4(OFF)

f. Effluent column: 3W-5(FROM COL \#1)

g. Sample ports: $2 \mathrm{~W}-3(\mathrm{OFF}), 2 \mathrm{~W}-4(\mathrm{OFF})$

6. If temperature is below $23^{\circ} \mathrm{C}$ then turn on the power to the temperature overtemperature device and to the heat strip transformer. Turn transformer to $20 \%$. When the temperature of the columns reaches $24^{\circ} \mathrm{C}$ turn transformer down to about $14 \%$, but the actual percentage will need adjusting until a stable $25^{\circ} \mathrm{C}$ is attained. Continually adjusting the transformer to maintain $25^{\circ} \mathrm{C}$.

[Note: If the temperatures of the columns are above $30^{\circ} \mathrm{C}$ informed one of the PIs. The acceptable operational range is $23^{\circ} \mathrm{C}$ to $27^{\circ} \mathrm{C}$ but small variations outside this range for short periods (an hour or two) can be tolerated.]

7. On top of the 10-liter SPENT REGENERATION SOLUTIONS bottle place the $25 \mathrm{~mL}$ graduated cylinder under the spigot and open the valve to point upwards

8. At 8:00 am turn on Pump 1 (3.0 BV/HR) and note on the data sheet the exact time. Also document the time in the notebook. Regeneration of Column 1 will run two hours until the last sample collection is finished at about 10:08 am.

9. Once flow has been established as noted by liquid exiting the spigot then turn the valve can be turned downwards so that effluent enters the bottle.

10. At approximately 8:50 am get ready to take the first sample. Three samples will be taken at approximately 9, 9:30, and $10 \mathrm{am}$.

11. Follow Appendix H to take each sample from COL\#1 SAMPLE port 2W-3.

12. AS SOON AS THE 10-AM SAMPLE IS FINISHED AT ABOUT 10:08 AM COLUMN 2 WILL BE REGENERATED WITHOUT A PAUSE.

13. While the 10 -am sample is being drawn there is about 7 minutes to plan for the change over from Column 1 to Column 2 operation. 
14. At about 10:08 am change Column 1 to Column 2 operation: PUMP FEED PANEL

a. Do not change any of the valves COLUMN CONTROL PANEL

b. Only two valves are changed for single Column 2:operation: 3W-2(LEAD 2) and effluent column: 3W-5(FROM COL \#2). Switch the two valves as fast a possible or simultaneously.

15. .Regeneration of Column 2 will run two hours until the last sample collection is finished at about 12:16 pm

16. In approximately one hour, at 11:08 get ready to take the first sample. Three samples will be taken at approximately 11:08 am, 11:38 am, and 12:08 pm.

17. Follow Appendix $\mathrm{H}$ to take each sample from COL\#2 SAMPLE port 2W-4

18. At about 12:16 pm regeneration of both columns will be finished. Stop Pump 1 and shut the effluent valve on top of the SPENT REGENERATION SOLUTIONS bottle by turning the valve stem to the horizontal position.

19. Document the finish time on the data sheet and in the notebook.

20. Shut power to the heat strip transformer and turn it down to its lowest position. Temperature readouts can be left on or turned off.

21. Repeat step 4 to measure weight of $0.5 \mathrm{M} \mathrm{NaOH}$ processed.

\section{End of pre-Cycle 1 regeneration}


SRNL-STI-2009-00594, REVISION 0

\section{Cycle 1 loading (of cesium) - Columns 1 Lead and Column 2 Lag}

[Note: The resin regenerated and ready to separate cesium from SRS tank waste.] First day of cesium loading $\left(2^{\text {nd }}\right.$ day of test)

1. Start at 6:30 am Tuesday

2. Have ready the eight (8) sample bottles for this first day of loading as listed on the data sheet (App. E).

3. If not on, then turn on power to the temperature readouts. Document temperatures of Columns 1 and 2 in notebook.

4. If not feed waste was not preweighed then take the wand out of the 10-liter NEW FEED bottle and measure its weight and note the amount on the data sheet and in the notebook. Then return the bottle and replace the wand until it hits the bottom of the container. [NOTE: IF THIS RESERVOIR FILLED WITH 8 LITERS OF WASTE IT WILL BE HEAVY - APPROXIMATELY 11 KG OR 24 LBS!]

5. Set the test rig valves according to Valve Table (App. C):

PUMP FEED PANEL

a. Pump 1: 2W-1(OFF), Pump 2: 2W-2(ON)

b. Feed: 3W-6(TO PUMP), 3W-7(FEED), 3W-8(OFF), 3W-9(OFF), 3W10(OFF), 2W-5(OFF)

c. Effluent container: 3W-11(SPENT REGEN) [this will be changed in 4.5 hours to SPENT FEED when only processed feed is the effluent] COLUMN CONTROL PANEL

d. 3W-1(FROM PUMP)

e. Single Column 1: 3W-2(LEAD 1), 3W-3(LEAD 1), 3W-4(LEAD 1)

f. Effluent column: 3W-5(FROM COL \#2)

g. Sample ports: $2 \mathrm{~W}-3(\mathrm{OFF}), 2 \mathrm{~W}-4(\mathrm{OFF})$

6. If temperature is below $23^{\circ} \mathrm{C}$ then turn on the power to the temperature overtemperature device and to the heat strip transformer. Turn transformer to $20 \%$. When the temperature of the columns reaches $24^{\circ} \mathrm{C}$ turn transformer down to about $14 \%$, but the actual percentage will need adjusting until a stable $25^{\circ} \mathrm{C}$ is attained. Continually adjusting the transformer to maintain $25^{\circ} \mathrm{C}$.

[Note: If the temperatures of the columns are above $30^{\circ} \mathrm{C}$ informed one of the PIs. The acceptable operational range is $23^{\circ} \mathrm{C}$ to $27^{\circ} \mathrm{C}$ but small variations outside this range for short periods (an hour or two) can be tolerated.]

7. On top of the SPENT REGENERATION SOLUTIONS bottle place the $25 \mathrm{~mL}$ graduated cylinder under the spigot and open the valve to point upwards

8. At 7 am turn on Pump $2(1.4$ BV/HR) and note on the data sheet the exact time. Also document the time in the notebook. Waste feed processing will run for 345 hours or about 15 days.

9. Once flow has been established as noted by liquid exiting the spigot then turn the valve can be turned downwards so that effluent enters the bottle.

10. At approximately 9:50 am get ready to take the first Lead and the first Lag samples. On this first day of waste processing a total of four sets of LEAD and LAG samples will be taken at approximately $10 \mathrm{am}, 12$, 2, and 4:00 pm.

11. Follow Appendix F to take Column 1 (LEAD) samples from COL\#1 SAMPLE port 2W-3 and Column 2 (LAG) samples from COL\#2 SAMPLE port 2W-4. 
12. At approximately 11:30 am on top of the 10-liter SPENT FEED bottle place the $25 \mathrm{~mL}$ graduated cylinder under the spigot and open the valve to point upwards, then switch valve 3W-11 on the PUMP FEED PANEL to the SPEND FEED position.

13. Document the time in the notebook of the switchover and close the valve on top of the SPENT REGENERATION SOLUTIONS bottle by placing the valve stem in the horizontal position.

14. Once liquid is steadily dripping into the catch bottle then turn the valve stem downwards so that effluent enters the 10-liter SPENT FEED bottle.

15. Repeat steps 10 and 11 at 11:50 am,, $1: 50$ and 3:50 pm

16. After the 4-pm sample the test rig is then left running overnight.

17. Before leaving the test rig for the night make sure:

a. The column temperatures are fairly close to $25^{\circ} \mathrm{C}$ and if temperature drops in the Cell during the night then the column temperatures may be left a little on the high side, that is, 26 for $27^{\circ} \mathrm{C}$. This will be better judged on the next day of the test when first observed.

b. The valve on the top of the 10-liter SPENT FEED bottle is open and point down.

18. Document the time the test rig is left running for the day in the notebook

$2^{\text {nd }}$ to $14^{\text {th }}$ days of cesium loading (days 3 to 15 of test) [Except test days 13 and 14*] [Note: On each of the following days the follow steps are to be followed.]

19. At the start of each day document the temperatures of the columns in the notebook and then make any necessary adjustments to the heat strip transformer to maintain the temperature at $25^{\circ} \mathrm{C}$. Variations from $23^{\circ} \mathrm{C}$ to $27^{\circ} \mathrm{C}$ are acceptable.

20. Have ready the four (4) sample bottles to take the day's samples.

21. Lead and Lag samples are taken each day approximately at 8:00 am and 4:00 pm, however, it is very important to note the exact time samples were taken.

22. At about 15 minutes before sampling times begin to get ready to sample and follow Appendix F to take Column 1 (LEAD) samples from COL\#1 SAMPLE port 2W-3 and Column 2 (LAG) samples from COL\#2 SAMPLE port 2W-4.

23. After the 4-pm sample the test rig is then left running overnight.

24. Before leaving the test rig for the night make sure:

a. The column temperatures are fairly close to $25^{\circ} \mathrm{C}$ and if temperature drops in the Cell during the night then the column temperatures may be left a little on the high side, that is, 26 for $27^{\circ} \mathrm{C}$. This will be better judged on the next day of the test when first observed.

b. The valve on the top of the 10-liter SPENT FEED bottle is open and point down.

25. Document the time the test rig is left running for the day in the notebook.

$*^{*} 2^{\text {th }}$ and $13^{\text {th }}$ days of cesium loading (days 13 to 14 of test- Saturday and Sunday)

[Note: Samples on this last weekend of Cycle 1 are very important.] 
26. As weekdays, have ready the four (4) bottles to take the each day's samples.

27. Lead and Lag samples are taken each day at 8:30 am and 11:30 am.

28. At about 15 minutes before sampling times begin to get ready to sample and follow Appendix F to take Column 1 (LEAD) samples from COL\#1 SAMPLE port 2W-3 and Column 2 (LAG) samples from COL\#2 SAMPLE port 2W-4.

29. After the 4-pm sample the test rig is then left running overnight.

30. Before leaving the test rig for the day make sure:

a. The column temperatures are fairly close to $25^{\circ} \mathrm{C}$ and if temperature drops in the Cell during the night then the column temperatures may be left a little on the high side, that is, 26 for $27^{\circ} \mathrm{C}$. This will be better judged on the next day of the test when first observed.

b. The valve on the top of the 10-liter SPENT FEED bottle is open and point down.

31. Document the time the test rig is left running for the day in the notebook.

$15^{\text {th }}$ (and last) day of cesium loading for Cycle 1 (16 ${ }^{\text {th }}$ day of test)

32. Start at 6:30 am Tuesday

33. Like previous days document the temperatures of the columns in the notebook and then make any necessary adjustments to the heat strip transformer to maintain the temperature at $25^{\circ} \mathrm{C}$. Variations from $23^{\circ} \mathrm{C}$ to $27^{\circ} \mathrm{C}$ are acceptable

34. Have ready the twenty (20) sample bottles for this last day of loading as listed on the data sheet (App. E).

35. A set of LEAD and LAG samples are taken every hour from 7:00 am to 4:00 pm.

36. During this last day before $4 \mathrm{pm}$ measure the weight of the $0.1 \mathrm{M} \mathrm{NaOH}$ bottle and note the weight on the data sheet and notebook.

37. At about 3:15 pm get ready to take the last samples. Begin the LEAD sample at 3:30 pm so that the LAG sample ends around 4:05 pm. Follow Appendix F to take Column 1 (LEAD) samples from COL\#1 SAMPLE port 2W-3 and Column 2 (LAG) samples from COL\#2 SAMPLE port 2W-4.

38. After the 4-pm sample the test rig will run for another 96 minutes to begin the process of regeneration of the LEAD (Column 1), which begins with pushing out (displaced) waste by using $0.1 \mathrm{M} \mathrm{NaOH}$.

39. Cycle 1 Waste processing is complete therefore without turning off Pump 2 go to the next chapter, Chapter 7, to displace waste which should start at 4:30 pm.

40. Repeat Step 4 to obtain the final weight of the feed waste. (Note: Do this after starting waste displacement in Chapter 7.)

\section{End of Cycle 1 cesium loading}


SRNL-STI-2009-00594, REVISION 0

\section{Cycle 1 waste displacement from Column 1}

[Note: Displacement action is done on the last day of waste processing. Displacement is done with $0.1 \mathrm{M} \mathrm{NaOH]}$

1. Perform the next 9 steps so that Pump 1 in Step 9 is turned on at around 4:30 pm.

2. The test rig is still running with waste and now the feed will be changed, on Column 1 will be used, and the pump will be changed to Pump 1.

3. The $0.1 \mathrm{M} \mathrm{NaOH}$ should have been already weighed and is ready for use. If so go to Step 5.

4. Take the wand out of the $0.1 \mathrm{M} \mathrm{NaOH}$ bottle and measure its weight and note the amount on the data sheet and in the notebook. Then return the bottle and replace the wand until it hits the bottom of the container.

5. Turn Pump 2 off.

6. Set the test rig valves according to Valve Table (App. C): PUMP FEED PANEL

a. Pump 1: 2W-1(ON), Pump 2: 2W-2(OFF)

b. Feed: 3W-6(TO PUMP), 3W-7(bypass), 3W-8(.1 NAOH), 3W-9(OFF), 3W-10(OFF), 2W-5(OFF)

c. Effluent container: 3W-11(SPENT FEED) )

COLUMN CONTROL PANEL

d. 3W-1(FROM PUMP)

e. Single Column 1: 3W-2(LEAD 1), 3W-3(OFF), 3W-4(OFF)

f. Effluent column: 3W-5(FROM COL \#1)

g. Sample ports: 2W-3(OFF), 2W-4(OFF)

7. Continue to adjust the transformer to maintain $25^{\circ} \mathrm{C}$.

8. On top of the 10-liter SPENT FEED bottle place the $25 \mathrm{~mL}$ graduated cylinder under the spigot and open the valve to point upwards

9. At around 4:30 pm turn on Pump 1 (3.0 BV/HR) and note on the data sheet the exact time. Also document the time in the notebook.

10. Once flow has been established, as noted by liquid exiting the spigot, then turn the valve downwards so that effluent enters the 10-liter SPENT FEED bottle.

11. Get ready the three (3) sample bottles and at approximately 4:50 am get ready to take the first sample. Three samples will be taken at approximately 5, 5:30, and 6:15 pm.

12. Follow Appendix $\mathrm{H}$ to take each sample from COL\#1 SAMPLE port 2W-3.

13. At about 6:30 pm the waste in Column 1 will b displaced. Stop Pump 1 and shut the effluent valve on top of the 10-liter SPENT FEED bottle by turning the valve stem to the horizontal position.

14. Document the finish time on the data sheet and in the notebook.

15. Shut power to the heat strip transformer and turn it down to its lowest position. Temperature readouts can be left on or turned off.

16. Repeat Step 4.

\section{End of waste displacement from Column 1}




\section{Cycle 1 initial rinse of Column 1}

[Note: Start this rinse at approximately 08:30 am. Rinse is done with deionized H2O.]

1. Start at 8:00 am

2. Have ready the three (3) sample bottles as listed on the data sheet (App. E).

3. Turn on power to the temperature readouts. Document temperature of Columns 1 in notebook.

4. Take the wand out of the $\mathrm{H} 2 \mathrm{O}$ bottle and measure its weight and note the amount on the data sheet and in the notebook. Then return the bottle and replace the wand until it hits the bottom of the container.

5. Set the test rig valves according to Valve Table (App. C): PUMP FEED PANEL

a. Pump 1: 2W-1(ON), Pump 2: 2W-2(OFF)

b. Feed: 3W-6(TO PUMP), 3W-7(bypass), 3W-8(bypass), 3W-9(bypass), 3W10(bypass), 2W-5(H2O) [Note, bypass means that the valve stems points along arrowed line on panel.]

c. Effluent container: 3W-11(SPENT REGEN)

COLUMN CONTROL PANEL

d. 3W-1(FROM PUMP)

e. Single Column 1: 3W-2(LEAD 1), 3W-3(OFF), 3W-4(OFF)

f. Effluent column: 3W-5(FROM COL \#1)

g. Sample ports: $2 \mathrm{~W}-3(\mathrm{OFF}), 2 \mathrm{~W}-4(\mathrm{OFF})$

6. If temperature is below $23^{\circ} \mathrm{C}$ then turn on the power to the temperature overtemperature device and to the heat strip transformer. Turn transformer to $20 \%$. When the temperature of the columns reaches $24^{\circ} \mathrm{C}$ turn transformer down to about $14 \%$, but the actual percentage will need adjusting until a stable $25^{\circ} \mathrm{C}$ is attained. Continually adjusting the transformer to maintain $25^{\circ} \mathrm{C}$.

[Note: If the temperatures of the columns are above $30^{\circ} \mathrm{C}$ informed one of the PIs. The acceptable operational range is $23^{\circ} \mathrm{C}$ to $27^{\circ} \mathrm{C}$ but small variations outside this range for short periods (an hour or two) can be tolerated.]

7. On top of the 10-liter SPENT REGENERATION SOLUTIONS bottle place the $25 \mathrm{~mL}$ graduated cylinder under the spigot and open the valve to point upwards

8. At 8:30 am turn on Pump 1 (3.0 BV/HR) and note on the data sheet the exact time. Also document the time in the notebook. Pre-elution rinse of Column 1 will run about one hour and 45 minutes until the last sample collection is finished at about 10:15 am.

9. Once flow has been established, as noted by liquid exiting the spigot, then turn the valve downwards so that effluent enters the 10-liter SPENT REGENERATION SOLUTIONS bottle.

10. At approximately 8:50 am get ready to take the first sample. Three samples will be taken at approximately 9, 9:30, and 10:15 am.

11. Follow Appendix $\mathrm{H}$ to take each sample from COL\#1 SAMPLE port $2 \mathrm{~W}-3$.

12. Start taking the 10:15 am sample at about 10:00 am so that the flow of $\mathrm{H} 2 \mathrm{O}$ can be stopped at 10:15 and elution can begin immediately.

13. Immediately after taking the last pre-elution sample let the system run another 5 minutes to flush simulant for internal tubes with the following steps: 
a. Place a catch bottle in the sampling rack under COL\#2 SAMPLE port 2W-4.

b. Open valve $2 \mathrm{~W}-4$.

c. Open valve $3 \mathrm{~W}-3$ towards LEAD 1

d. Open valve $3 \mathrm{~W}-4$ towards LEAD 2

e. Liquid will be exiting the opened sample port and allow to drip for approximately 3 to 5 minutes.

f. After the wait period close sampling valve $2 \mathrm{~W}-4$.

g. Set valves $3 W-3$ and $3 W-4$ to OFF.

14. At 10:15 am Cycle 1 pre-elution rinse is complete. Stop Pump 1 and shut the effluent valve on top of the 10-liter SPENT REGENERATION SOLUTIONS bottle by turning the valve stem to the horizontal position.

15. Document the finish time on the data sheet and in the notebook.

16. Repeat step 4 to measure weight of H2O. (Note: Do this after starting elution Chapter 9.)

\section{End of Cycle 1 initial rinse of Column 1}




\section{Cycle 1 elution of Column 1}

[Note: Elution duration is approximately 22 hours using 0.5 M Nitric Acid..]

1. Elution starts at approximately 10:15 am immediately after the pre-elution rinse.

2. Have ready the 27 sample bottles as listed on the data sheet (App. E).

3. Document temperature and resin height of Columns 1 in notebook.

4. Take the wand out of the 0.5 M NITRIC ACID bottle and measure its weight and note the amount on the data sheet and in the notebook. Then return the bottle and replace the wand until it hits the bottom of the container. [Actually, the weighing should be done while the pre-elution rinse is in progress to save time.]

5. Set the test rig valves according to Valve Table (App. C): PUMP FEED PANEL

a. Pump 1: 2W-1(OFF), Pump 2: 2W-2(ON)

b. Feed: 3W-6(TO PUMP), 3W-7(bypass), 3W-8(bypass), 3W-9(.5 ACID), $3 \mathrm{~W}-10(\mathrm{OFF}), 2 \mathrm{~W}-5(\mathrm{OFF})$ [Note, bypass means that the valve stems points along arrowed line on panel.]

c. Effluent container: 3W-11(SPENT REGEN) COLUMN CONTROL PANEL

d. 3W-1(FROM PUMP)

e. Single Column 1: 3W-2(LEAD 1), 3W-3(OFF), 3W-4(OFF)

f. Effluent column: 3W-5(FROM COL \#1)

g. Sample ports: 2W-3(OFF), 2W-4(OFF)

6. Continue adjusting the transformer to maintain $25^{\circ} \mathrm{C}$.

[Note: If the temperatures of the columns are above $30^{\circ} \mathrm{C}$ informed one of the PIs. The acceptable operational range is $23^{\circ} \mathrm{C}$ to $27^{\circ} \mathrm{C}$ but small variations outside this range for short periods (an hour or two) can be tolerated.]

7. On top of the 10-liter SPENT REGENERATION SOLUTIONS bottle place the $25 \mathrm{~mL}$ graduated cylinder under the spigot and open the valve to point upwards

8. At 10:15 am turn on Pump 2 (3.0 BV/HR) and note on the data sheet the exact time. Also document the time in the notebook. Elution of Column 1 will run about 22 hours until the last sample collection is finished at about 8:15 am the next day.

9. Once flow has been established, as noted by liquid exiting the spigot, then turn the valve downwards so that effluent enters the 10-liter SPENT REGENERATION SOLUTIONS bottle.

10. At approximately 10:35 am get ready to take the first sample. A samples will be taken at approximately every 30 minutes until 3:15 pm and then ever hour until 8:15 am the next day.

11. Follow Appendix $\mathrm{H}$ to take each sample from COL\#1 SAMPLE port 2W-3.

12. Start taking the 8:15 am next-day sample at about 7:55 am so that the flow of ACID can be immediately switched to $\mathrm{H} 2 \mathrm{O}$ at 8:15 when post-elution rinse begins.

13. At 8:15 am Cycle 1 elution is complete therefore without turning off Pump 2 go to the next chapter, Chapter 10, to complete the cycle with post-elution rinse.

14. Repeat Step 4. (Note: Do this after starting the post-elution rinse in Chapter 10.)

\section{End of elution of Column 1}




\section{Cycle 1 final rinse of Column 1}

[Note: Start this rinse immediately after elution ends. Rinse is done with deionized H2O]

1. Switch from acid to water at 8:15 am [Do not turn off pump.]

2. Have ready the three (3) sample bottles as listed on the data sheet (App. E).

3. Document temperature and resin height of Columns 1 in notebook.

4. Take the wand out of the $\mathrm{H} 2 \mathrm{O}$ bottle and measure its weight and note the amount on the data sheet and in the notebook. Then return the bottle and replace the wand until it hits the bottom of the container. [Actually, to not hold up the start of the rinse process the weighing should be done while the elution is in progress.]

5. Set the test rig valves according to Valve Table (App. C): PUMP FEED PANEL

a. Pump 1: 2W-1(OFF), Pump 2: 2W-2(ON)

b. Feed: 3W-6(TO PUMP), 3W-7(bypass), 3W-8(bypass), 3W-9(bypass), 3W10(bypass), 2W-5(H2O) [Note, bypass means that the valve stems points along arrowed line on panel.]

c. Effluent container: 3W-11(SPENT REGEN) COLUMN CONTROL PANEL

d. 3W-1(FROM PUMP)

e. Single Column 1: 3W-2(LEAD 1), 3W-3(OFF), 3W-4(OFF)

f. Effluent column: 3W-5(FROM COL \#1)

g. Sample ports: 2W-3(OFF), 2W-4(OFF)

6. Continue adjusting the transformer to maintain $25^{\circ} \mathrm{C}$.

[Note: If the temperatures of the columns are above $30^{\circ} \mathrm{C}$ informed one of the PIs. The acceptable operational range is $23^{\circ} \mathrm{C}$ to $27^{\circ} \mathrm{C}$ but small variations outside this range for short periods (an hour or two) can be tolerated.]

7. On top of the 10-liter SPENT REGENERATION SOLUTIONS bottle place the $25 \mathrm{~mL}$ graduated cylinder under the spigot and open the valve to point upwards

8. Note on the data sheet the exact time. Also document the time in the notebook. Post-elution rinse of Column 1 will run about three hours and 30 minutes until the last sample collection is finished at about 11:45 am.

9. Once flow has been established, as noted by liquid exiting the spigot, then turn the valve downwards so that effluent enters the 10-liter SPENT REGENERATION SOLUTIONS bottle.

10. At approximately 9:05 am get ready to take the first sample. Three samples will be taken at approximately 9:15, 10:15, and 11:45 am.

11. Follow Appendix H to take each sample from COL\#1 SAMPLE port 2W-3.

12. The 11:45 am sample can be taken any time after 11:00 am.

13. At 11:45 am Cycle 1 is complete. Stop Pump 2 and shut the effluent valve on top of the 10-liter SPENT REGENERATION SOLUTIONS bottle by turning the valve stem to the horizontal position.

14. Document the finish time on the data sheet and in the notebook.

15. Repeat step 4 to measure weight of $\mathrm{H} 2 \mathrm{O}$.

\section{End of Cycle 1 final rinse of Column 1 and of Cycle 1}




\section{Pre-Cycle 2 regeneration of Column 1}

[Note: Cycle 1 left the resin in Column 1 in Hydrogen form and will need to be regenerated for Cycle 2. Regeneration is done with $0.5 \mathrm{M} \mathrm{NaOH}$.]

1. Start at 7:30 am Monday

2. Have ready the three (3) sample bottles as listed on the data sheet (App. E).

3. Turn on power to the temperature readouts. Document temperatures of Columns 1 and 2 in notebook.

4. Take the wand out of the $0.5 \mathrm{M} \mathrm{NaOH}$ bottle and measure its weight and note the amount on the data sheet and in the notebook. Then return the bottle and replace the wand until it hits the bottom of the container.

5. Set the test rig valves according to Valve Table (App. C): PUMP FEED PANEL

a. Pump 1: 2W-1(ON), Pump 2: 2W-2(OFF)

b. Feed: 3W-6(.5 NAOH), 3W-7(OFF), 3W-8(OFF), 3W-9(OFF), 3W10(OFF), 2W-5(OFF)

c. Effluent container: 3W-11(SPENT REGEN)

COLUMN CONTROL PANEL

d. 3W-1(FROM PUMP)

e. Single Column 1: 3W-2(LEAD 1), 3W-3(OFF), 3W-4(OFF)

f. Effluent column: 3W-5(FROM COL \#1)

g. Sample ports: $2 \mathrm{~W}-3(\mathrm{OFF}), 2 \mathrm{~W}-4(\mathrm{OFF})$

6. If temperature is below $23^{\circ} \mathrm{C}$ then turn on the power to the temperature overtemperature device and to the heat strip transformer. Turn transformer to $20 \%$. When the temperature of the columns reaches $24^{\circ} \mathrm{C}$ turn transformer down to about $14 \%$, but the actual percentage will need adjusting until a stable $25^{\circ} \mathrm{C}$ is attained. Continually adjusting the transformer to maintain $25^{\circ} \mathrm{C}$.

[Note: If the temperatures of the columns are above $30^{\circ} \mathrm{C}$ informed one of the PIs. The acceptable operational range is $23^{\circ} \mathrm{C}$ to $27^{\circ} \mathrm{C}$ but small variations outside this range for short periods (an hour or two) can be tolerated.]

7. On top of the 10-liter SPENT REGENERATION SOLUTIONS bottle place the $25 \mathrm{~mL}$ graduated cylinder under the spigot and open the valve to point upwards

8. At 8:00 am turn on Pump 1 (3.0 BV/HR) and note on the data sheet the exact time. Also document the time in the notebook. Regeneration of Column 1 will run two hours until the last sample collection is finished at about 10:08 am.

9. Once flow has been established, as noted by liquid exiting the spigot, then turn the valve downwards so that effluent enters the 10-liter SPENT REGENERATION SOLUTIONS bottle.

10. At approximately 8:50 am get ready to take the first sample. Three samples will be taken at approximately 9, 9:30, and $10 \mathrm{am}$.

11. Follow Appendix $\mathrm{H}$ to take each sample from COL\#1 SAMPLE port $2 \mathrm{~W}-3$.

12. At about 10:08 am regeneration of column 1 will be finished. Stop Pump 1 and shut the effluent valve on top of the 10-liter SPENT REGENERATION SOLUTIONS bottle by turning the valve stem to the horizontal position.

13. Document the finish time on the data sheet and in the notebook. 
14. Shut power to the heat strip transformer and turn it down to its lowest position. Temperature readouts can be left on or turned off.

15. Repeat step 4 to measure weight of $0.5 \mathrm{M} \mathrm{NaOH}$ processed.

\section{End of pre-Cycle 2 regeneration}


SRNL-STI-2009-00594, REVISION 0

\section{Cycle 2 loading - Columns 2 Lead and Column 1 Lag}

[Note: The resin regenerated and ready to separate cesium from SRS tank waste.] First day of Cycle 2 cesium loading (20 ${ }^{\text {th }}$ day of test)

1. Start at 6:30 am Tuesday

2. Have ready the eight (8) sample bottles for this first day of loading as listed on the data sheet (App. E).

3. If not on, then turn on power to the temperature readouts. Document temperatures of Columns 1 and 2 in notebook.

4. If not feed waste was not preweighed then take the wand out of the 10-liter NEW FEED bottle and measure its weight and note the amount on the data sheet and in the notebook. Then return the bottle and replace the wand until it hits the bottom of the container. [NOTE: IF THIS RESERVOIR FILLED WITH 4 LITERS OF WASTE IT WILL BE HEAVY - APPROXIMATELY 5.3 KG OR 12 LBS!]

5. Set the test rig valves according to Valve Table (App. C):

PUMP FEED PANEL

a. Pump 1: 2W-1(OFF), Pump 2: 2W-2(ON)

b. Feed: 3W-6(TO PUMP), 3W-7(FEED), 3W-8(OFF), 3W-9(OFF), 3W10(OFF), 2W-5(OFF)

c. Effluent container: 3W-11(SPENT REGEN) [this will be changed in 4.5 hours to SPENT FEED when only processed feed is the effluent] COLUMN CONTROL PANEL

d. 3W-1(FROM PUMP)

e. Single Column 1: 3W-2(LEAD 2), 3W-3(LEAD 2), 3W-4(LEAD 2)

f. Effluent column: 3W-5(FROM COL \#1)

g. Sample ports: $2 \mathrm{~W}-3(\mathrm{OFF}), 2 \mathrm{~W}-4(\mathrm{OFF})$

6. If temperature is below $23^{\circ} \mathrm{C}$ then turn on the power to the temperature overtemperature device and to the heat strip transformer. Turn transformer to $20 \%$. When the temperature of the columns reaches $24^{\circ} \mathrm{C}$ turn transformer down to about $14 \%$, but the actual percentage will need adjusting until a stable $25^{\circ} \mathrm{C}$ is attained. Continually adjusting the transformer to maintain $25^{\circ} \mathrm{C}$.

[Note: If the temperatures of the columns are above $30^{\circ} \mathrm{C}$ informed one of the PIs. The acceptable operational range is $23^{\circ} \mathrm{C}$ to $27^{\circ} \mathrm{C}$ but small variations outside this range for short periods (an hour or two) can be tolerated.]

7. On top of the 10-liter SPENT REGENERATION SOLUTIONS bottle place the $25 \mathrm{~mL}$ graduated cylinder under the spigot and open the valve to point upwards

8. At 7 am turn on Pump $2(1.4 \mathrm{BV} / \mathrm{HR})$ and note on the data sheet the exact time. Also document the time in the notebook. Waste feed processing will run for 225 hours or about 10 days.

9. Once flow has been established, as noted by liquid exiting the spigot, then turn the valve downwards so that effluent enters the 10-liter SPENT REGENERATION SOLUTIONS bottle.

10. At approximately 9:50 am get ready to take the first Lead and the first Lag samples. On this first day of waste processing a total of four sets of LEAD and LAG samples will be taken at approximately $10 \mathrm{am}, 12$, 2, and $4 \mathrm{pm}$. 
11. Follow Appendix $G$ to take Column 2 (LEAD) samples from COL\#2 SAMPLE port 2W-4 and Column 1 (LAG) samples from COL\#1 SAMPLE port 2W-3.

12. At approximately 11:30 am on top of the 10-liter SPENT FEED bottle place a catch bottle under the curved tube and open the valve to point upwards, then switch valve 3W-11 on the PUMP FEED PANEL to the SPEND FEED position.

13. Document the time in the notebook of the switchover and close the valve on top of the 10-liter SPENT REGENERATION SOLUTIONS bottle by placing the valve stem in the horizontal position.

14. Once liquid is steadily dripping into the catch bottle then turn the valve stem downwards so that effluent enters the 10-liter SPENT FEED bottle.

15. Repeat steps 10 and 11 at 11:50 am,, $1: 50$ and 3:50 pm

16. After the 4-pm sample the test rig is then left running overnight.

17. Before leaving the test rig for the night make sure:

a. The column temperatures are fairly close to $25^{\circ} \mathrm{C}$ and if temperature drops in the Cell during the night then the column temperatures may be left a little on the high side, that is, 26 for $27^{\circ} \mathrm{C}$. This will be better judged on the next day of the test when first observed. The acceptable range is $23^{\circ} \mathrm{C}$ to $27^{\circ} \mathrm{C}$.

b. The valve on the top of the 10-liter SPENT FEED bottle is open and point down.

18. Document the time the test rig is left running for the day in the notebook

$2^{\text {nd }}$ to $14^{\text {th }}$ days of Cycle 2 cesium loading (days 21 to 28 of test)

[Note: On each of the following days the follow steps are to be followed, except on the weekend when no samples will be taken.]

19. At the start of each day document the temperatures of the columns in the notebook and then make any necessary adjustments to the heat strip transformer to maintain the temperature at $25^{\circ} \mathrm{C}$. Variations from $23^{\circ} \mathrm{C}$ to $27^{\circ} \mathrm{C}$ are acceptable.

20. Have ready the four (4) sample bottles to take the day's samples.

21. Lead and Lag samples are taken each day approximately at 8:00 am and 4:00 pm, however, it is very important to note the exact time samples were taken.

22. At about 15 minutes before sampling times begin to get ready to sample and follow Appendix F to take Column 2 (LEAD) samples from COL\#2 SAMPLE port 2W-4 and Column 1 (LAG) samples from COL\#1 SAMPLE port 2W-3.

23. After the 4-pm sample the test rig is then left running overnight.

24. Before leaving the test rig for the night make sure:

a. The column temperatures are fairly close to $25^{\circ} \mathrm{C}$ and if temperature drops in the Cell during the night then the column temperatures may be left a little on the high side, that is, 26 for $27^{\circ} \mathrm{C}$. This will be better judged on the next day of the test when first observed.

b. The valve on the top of the 10-liter SPENT FEED bottle is open and point down.

25. Document the time the test rig is left running for the day in the notebook.

$15^{\text {th }}$ (and last) day of Cycle 2 cesium loading $\left(29^{\text {th }}\right.$ day of test)

26. Start at 6:30 am Tuesday 
27. Like previous days document the temperatures of the columns in the notebook and then make any necessary adjustments to the heat strip transformer to maintain the temperature at $25^{\circ} \mathrm{C}$. Variations from $23^{\circ} \mathrm{C}$ to $27^{\circ} \mathrm{C}$ are acceptable

28. Have ready the twenty (20) sample bottles for this last day of loading as listed on the data sheet (App. E).

29. A set of LEAD and LAG samples are taken every hour from 7:00 am to 4:00 pm.

30. During this last day before $4 \mathrm{pm}$ measure the weight of the $0.1 \mathrm{M} \mathrm{NaOH}$ bottle and note the weight on the data sheet and notebook

31. At about 3:15 pm get ready to take the last samples. Begin the LEAD sample at about 3:30 pm so that the LAG sample ends around 4:05 pm. Follow Appendix G to take Column 2 (LEAD) samples from COL\#2 SAMPLE port 2W-4 and Column 1 (LAG) samples from COL\#1 SAMPLE port 2W-3.

32. After the 4-pm sample the test rig will run for another 96 minutes to begin the process of regeneration of the LEAD (Column 2), which begins with pushing out (displaced) waste by using $0.1 \mathrm{M} \mathrm{NaOH}$.

33. Cycle 2 Waste processing is complete therefore without turning off Pump 2 go to the next chapter, Chapter 13, to displace waste which should start at 4:30 pm.

34. Repeat Step 4 to obtain the final weight of the feed waste. (Note: Do this after starting waste displacement in Chapter 13.)

\section{End of Cycle 2 cesium loading}




\section{Cycle 2 waste displacement from Column 2}

[Note: Displacement is done on the last day of waste processing with $0.1 \mathrm{M} \mathrm{NaOH}$.]

1. Perform the next 9 steps so that Pump 1 in Step 9 is turned on at around 4:30 pm.

2. The test rig is still running with waste and now the feed will be changed, on Column 1 will be used, and the pump will be changed to Pump 1 .

3. The $0.1 \mathrm{M} \mathrm{NaOH}$ should have been already weighed and is ready for use. If so go to Step 5.

4. Take the wand out of the $0.1 \mathrm{M} \mathrm{NaOH}$ bottle and measure its weight and note the amount on the data sheet and in the notebook. Then return the bottle and replace the wand until it hits the bottom of the container.

5. Turn Pump 2 off.

6. Set the test rig valves according to Valve Table (App. C): PUMP FEED PANEL
a. Pump 1: 2W-1(ON), Pump 2: 2W-2(OFF)
b. Feed: 3W-6(TO PUMP), 3W-7(bypass), 3W-8(.1 NAOH), 3W-9(OFF), 3W-10(OFF), 2W-5(OFF)
c. Effluent container: 3W-11(SPENT FEED) )
COLUMN CONTROL PANEL
d. 3W-1(FROM PUMP)
e. Single Column 2: 3W-2(LEAD 2), 3W-3(OFF), 3W-4(OFF)
f. Effluent column: 3W-5(FROM COL \#2)
g. Sample ports: $2 \mathrm{~W}-3(\mathrm{OFF}), 2 \mathrm{~W}-4(\mathrm{OFF})$

7. Continue to adjust the transformer to maintain $25^{\circ} \mathrm{C}$.

[Note: If the temperatures of the columns are above $30^{\circ} \mathrm{C}$ informed one of the PIs.

The acceptable operational range is $23^{\circ} \mathrm{C}$ to $27^{\circ} \mathrm{C}$ but small variations outside this range for short periods (an hour or two) can be tolerated.]

8. On top of the 10-liter SPENT FEED bottle place the $25 \mathrm{~mL}$ graduated cylinder under the spigot and open the valve to point upwards

9. At around 4:30 pm turn on Pump 1 (3.0 BV/HR) and note on the data sheet the exact time. Also document the time in the notebook.

10. Once flow has been established, as noted by liquid exiting the spigot, then turn the valve downwards so that effluent enters the 10-liter SPENT FEED bottle.

11. Get ready the three (3) sample bottles and at approximately 4:50 am get ready to take the first sample. Three samples will be taken at approximately 5, 5:30, and 6:15 pm.

12. Follow Appendix $\mathrm{H}$ to take each sample from COL\#2 SAMPLE port $2 \mathrm{~W}-4$.

13. At about 6:30 pm the waste in Column 2 will b displaced. Stop Pump 2 and shut the effluent valve on top of the 10-liter SPENT FEED by turning the valve stem to the horizontal position.

14. Document the finish time on the data sheet and in the notebook.

15. Shut power to the heat strip transformer and turn it down to its lowest position. Temperature readouts can be left on or turned off.

16. Repeat step 4 to measure weight of $0.01 \mathrm{M} \mathrm{NaOH}$ processed.

\section{End of waste displacement from Column 2}


SRNL-STI-2009-00594, REVISION 0

\section{Cycle 2 initial rinse of Column 2}

[Note: On the following Monday start this rinse at approximately 08:30 am. Rinse is done with deionized H2O.]

1. Start at 8:00 am

2. Have ready the three (3) sample bottles as listed on the data sheet (App. E).

3. Turn on power to the temperature readouts. Document temperature of Columns 1 in notebook.

4. Take the wand out of the $\mathrm{H} 2 \mathrm{O}$ bottle and measure its weight and note the amount on the data sheet and in the notebook. Then return the bottle and replace the wand until it hits the bottom of the container.

5. Set the test rig valves according to Valve Table (App. C): PUMP FEED PANEL

a. Pump 1: 2W-1(ON), Pump 2: 2W-2(OFF)

b. Feed: 3W-6(TO PUMP), 3W-7(bypass), 3W-8(bypass), 3W-9(bypass), 3W10(bypass), 2W-5(H2O) [Note, bypass means that the valve stems points along arrowed line on panel.]

c. Effluent container: 3W-11(SPENT REGEN) COLUMN CONTROL PANEL

d. 3W-1(FROM PUMP)

e. Single Column 2: 3W-2(LEAD 2), 3W-3(OFF), 3W-4(OFF)

f. Effluent column: 3W-5(FROM COL \#2)

g. Sample ports: $2 \mathrm{~W}-3(\mathrm{OFF}), 2 \mathrm{~W}-4(\mathrm{OFF})$

6. If temperature is below $23^{\circ} \mathrm{C}$ then turn on the power to the temperature overtemperature device and to the heat strip transformer. Turn transformer to $20 \%$. When the temperature of the columns reaches $24^{\circ} \mathrm{C}$ turn transformer down to about $14 \%$, but the actual percentage will need adjusting until a stable $25^{\circ} \mathrm{C}$ is attained. Continually adjusting the transformer to maintain $25^{\circ} \mathrm{C}$.

[Note: If the temperatures of the columns are above $30^{\circ} \mathrm{C}$ informed one of the PIs. The acceptable operational range is $23^{\circ} \mathrm{C}$ to $27^{\circ} \mathrm{C}$ but small variations outside this range for short periods (an hour or two) can be tolerated.]

7. On top of the 10-liter SPENT REGENERATION SOLUTIONS bottle place the $25 \mathrm{~mL}$ graduated cylinder under the spigot and open the valve to point upwards

8. At 8:30 am turn on Pump $1(3.0 \mathrm{BV} / \mathrm{HR})$ and note on the data sheet the exact time. Also document the time in the notebook. Pre-elution rinse of Column 1 will run about one hour and 45 minutes until the last sample collection is finished at about 10:15 am.

9. Once flow has been established, as noted by liquid exiting the spigot, then turn the valve downwards so that effluent enters the 10-liter SPENT REGENERATION SOLUTIONS bottle.

10. At approximately 8:50 am get ready to take the first sample. Three samples will be taken at approximately 9, 9:30, and 10:15 am.

11. Follow Appendix I to take each sample from COL\#2 SAMPLE port 2W-4.

12. Start taking the 10:15 am sample at about 9:45 am so that the flow of $\mathrm{H} 2 \mathrm{O}$ can be stopped at 10:15 and elution can begin immediately. 
13. Immediately after taking the last pre-elution sample let the system run another 5 minutes to flush simulant for internal tubes with the following steps:

a. Place a catch bottle in the sampling rack under COL\#2 SAMPLE port 2W-3.

b. Open valve $2 \mathrm{~W}-3$.

c. Open valve $3 \mathrm{~W}-3$ towards LEAD 1

d. Open valve $3 W-4$ towards LEAD 2

e. Liquid will be exiting the opened sample port and allow to drip for approximately 3 to 5 minutes.

f. After the wait period close sampling valve $2 \mathrm{~W}-3$.

g. Set valves $3 W-3$ and $3 W-4$ to OFF.

14. At 10:15 am Cycle 2 pre-elution rinse is complete. Stop Pump 1 and shut the effluent valve on top of the 10-liter SPENT REGENERATION SOLUTIONS bottle by turning the valve stem to the horizontal position.

15. Document the finish time on the data sheet and in the notebook.

16. Repeat step 4 to measure weight of H2O. (Note: Do this after starting elution Chapter 15.)

\section{End of Cycle 2 initial rinse of Column 2}




\section{Cycle 2 Elution of Column 2}

[Note: Elution is done for approximately 22 hours with 0.5 M Nitric Acid.]

1. Elution starts at approximately 10:15 am immediately after the pre-elution rinse.

2. Have ready the 27 sample bottles as listed on the data sheet (App. E).

3. Document temperature and resin height of Columns 2 in notebook.

4. Take the wand out of the 0.5 M NITRIC ACID bottle and measure its weight and note the amount on the data sheet and in the notebook. Then return the bottle and replace the wand until it hits the bottom of the container. [Actually, the weighing should be done while the pre-elution rinse is in progress to save time.]

5. Set the test rig valves according to Valve Table (App. C):

PUMP FEED PANEL

a. Pump 1: 2W-1(OFF), Pump 2: 2W-2(ON)

b. Feed: 3W-6(TO PUMP), 3W-7(bypass), 3W-8(bypass), 3W-9(.5 ACID), $3 \mathrm{~W}-10(\mathrm{OFF}), 2 \mathrm{~W}-5(\mathrm{OFF})$ [Note, bypass means that the valve stems points along arrowed line on panel.]

c. Effluent container: 3W-11(SPENT REGEN)

COLUMN CONTROL PANEL

d. 3W-1(FROM PUMP)

e. Single Column 2: 3W-2(LEAD 2), 3W-3(OFF), 3W-4(OFF)

f. Effluent column: 3W-5(FROM COL \#2)

g. Sample ports: 2W-3(OFF), 2W-4(OFF)

6. Continue adjusting the transformer to maintain $25^{\circ} \mathrm{C}$.

[Note: If the temperatures of the columns are above $30^{\circ} \mathrm{C}$ informed one of the PIs. The acceptable operational range is $23^{\circ} \mathrm{C}$ to $27^{\circ} \mathrm{C}$ but small variations outside this range for short periods (an hour or two) can be tolerated.]

7. On top of the 10-liter SPENT REGENERATION SOLUTIONS bottle place the $25 \mathrm{~mL}$ graduated cylinder under the spigot and open the valve to point upwards

8. At 10:15 am turn on Pump $2(1.4 \mathrm{BV} / \mathrm{HR})$ and note on the data sheet the exact time. Also document the time in the notebook. Elution of Column 2 will run about 22 hours until the last sample collection is finished at about 8:15 am the next day.

9. Once flow has been established, as noted by liquid exiting the spigot, then turn the valve downwards so that effluent enters the 10-liter SPENT REGENERATION SOLUTIONS bottle.

10. At approximately 10:35 am get ready to take the first sample. One sample will be taken at approximately every 30 minutes until 3:15 pm and then ever hour until 8:15 am the next day.

11. Follow Appendix I to take each sample from COL\#2 SAMPLE port 2W-4.

12. Start taking the 8:15 am next-day sample at about 7:55 am so that the flow of ACID can be immediately switched to $\mathrm{H} 2 \mathrm{O}$ at 8:15 when the final rinse begins.

13. At 8:15 am Cycle 2 elution is complete therefore without turning off Pump 2 go to the next chapter, Chapter 16, to complete the cycle with post-elution rinse.

14. Repeat Step 4 to obtain the final weight of the Nitric Acid. (Note: Do this after starting the next $\mathrm{H} 2 \mathrm{O}$ rinse in Chapter 16.)

\section{End of elution of Column 2}




\section{Cycle 2 final rinse of Column 2}

[Note: Start this rinse immediately after elution ends.]

1. Switch from acid to water at 8:15 am [Do not turn off pump.]

2. Have ready the three (3) sample bottles as listed on the data sheet (App. E).

3. Document temperature and resin height of Columns 2 in notebook.

4. Take the wand out of the $\mathrm{H} 2 \mathrm{O}$ bottle and measure its weight and note the amount on the data sheet and in the notebook. Then return the bottle and replace the wand until it hits the bottom of the container. [Actually, to not hold up the start of the rinse process the weighing should be done while the elution is in progress.]

5. Set the test rig valves according to Valve Table (App. C): PUMP FEED PANEL

a. Pump 1: 2W-1(OFF), Pump 2: 2W-2(ON)

b. Feed: 3W-6(TO PUMP), 3W-7(bypass), 3W-8(bypass), 3W-9(bypass), 3W10(bypass), 2W-5(H2O) [Note, bypass means that the valve stems points along arrowed line on panel.]

c. Effluent container: 3W-11(SPENT REGEN) COLUMN CONTROL PANEL

d. 3W-1(FROM PUMP)

e. Single Column 2: 3W-2(LEAD 2), 3W-3(OFF), 3W-4(OFF)

f. Effluent column: 3W-5(FROM COL \#2)

g. Sample ports: $2 \mathrm{~W}-3(\mathrm{OFF}), 2 \mathrm{~W}-4(\mathrm{OFF})$

6. Continue adjusting the transformer to maintain $25^{\circ} \mathrm{C}$.

[Note: If the temperatures of the columns are above $30^{\circ} \mathrm{C}$ informed one of the PIs. The acceptable operational range is $23^{\circ} \mathrm{C}$ to $27^{\circ} \mathrm{C}$ but small variations outside this range for short periods (an hour or two) can be tolerated.]

7. On top of the 10-liter SPENT REGENERATION SOLUTIONS bottle place the $25 \mathrm{~mL}$ graduated cylinder under the spigot and open the valve to point upwards

8. Note on the data sheet the exact time. Also document the time in the notebook. Post-elution rinse of Column 2 will run about three hours and 30 minutes until the last sample collection is finished at about 11:45 am.

9. Once flow has been established, as noted by liquid exiting the spigot, then turn the valve downwards so that effluent enters the 10-liter SPENT REGENERATION SOLUTIONS bottle.

10. At approximately 9:05 am get ready to take the first sample. Three samples will be taken at approximately 9:15, 10:15, and 11:45 am.

11. Follow Appendix I to take each sample from COL\#2 SAMPLE port 2W-4.

12. The 11:45 am sample can be taken any time after 11:00 am.

13. At 11:45 am Cycle 2 is complete. Stop Pump 2 and shut the effluent valve on top of the 10-liter SPENT REGENERATION SOLUTIONS bottle by turning the valve stem to the horizontal position.

14. Document the finish time on the data sheet and in the notebook.

15. Repeat step 4 to measure weight of H2O.

End of Cycle 2 final rinse of Column 2 and of Cycle 2 


\section{Cycle 2a waste displacement from Column 1}

[Notes: In order to put both columns in the same state then Column 1, which currently filled with the SRS waste it will be necessary to elute Column 1, however, no after-hours elution samples will be taken nor will displacement or pre-elution samples be taken. No samples are taken during this chapter. Displacement is done with $0.1 \mathrm{M} \mathrm{NaOH}$.]

1. Begin waste displacement on the same day as soon as possible (at approximately noon) after Cycle 2 ends because the process of removing the waste takes 3 hours and 30 minutes.

2. The $0.1 \mathrm{M} \mathrm{NaOH}$ should have been already weighed and is ready for use. If so go to Step 5.

3. Take the wand out of the $0.1 \mathrm{M} \mathrm{NaOH}$ bottle and measure its weight and note the amount on the data sheet and in the notebook. Then return the bottle and replace the wand until it hits the bottom of the container.

4. Set the test rig valves according to Valve Table (App. C): PUMP FEED PANEL

a. Pump 1: 2W-1(ON), Pump 2: 2W-2(OFF)

b. Feed: 3W-6(TO PUMP), 3W-7(bypass), 3W-8(.1 NAOH), 3W-9(OFF), 3W-10(OFF), 2W-5(OFF)

c. Effluent container: 3W-11(SPENT FEED) ) COLUMN CONTROL PANEL

d. 3W-1(FROM PUMP)

e. Single Column 1: 3W-2(LEAD 1), 3W-3(OFF), 3W-4(OFF)

f. Effluent column: 3W-5(FROM COL \#1)

g. Sample ports: 2W-3(OFF), 2W-4(OFF)

5. On top of the 10-liter SPENT FEED bottle place the $25 \mathrm{~mL}$ graduated cylinder under the spigot and open the valve to point upwards

6. At approximately $12 \mathrm{pm}$ turn on Pump 1 (3.0 BV/HR) and note on the data sheet the exact time. Also document the time in the notebook.

7. Once flow has been established, as noted by liquid exiting the spigot, then turn the valve downwards so that effluent enters the 10-liter SPENT FEED bottle.

8. At about 1 hour and 45 minutes of pump operation the feed solution needs to be changed to $\mathrm{H} 2 \mathrm{O}$.

9. Go to immediately to Chapter 18 to process with $\mathrm{H} 2 \mathrm{O}$.

10. Repeat step 3 to measure weight of $0.01 \mathrm{M} \mathrm{NaOH}$ processed AFTER starting process with water in the next chapter.

11. Do not shut off Pump 1.

End of Cycle 2 a waste displacement from Column 1 


\section{Cycle 2a initial rinse of Column 1}

[Note: There are no samples taken during the rinse. Rinse is done with deionized H2O.]

1. Take the wand out of the $\mathrm{H} 2 \mathrm{O}$ bottle and measure its weight and note the amount on the data sheet and in the notebook. Then return the bottle and replace the wand until it hits the bottom of the container. Do this while processing with 0.1 $\mathrm{M} \mathrm{NaOH}$ in Chapter 17 to save time.

2. Set the test rig valves according to Valve Table (App. C):

PUMP FEED PANEL

a. Pump 1: 2W-1(ON), Pump 2: 2W-2(OFF)

b. Feed: 3W-6(TO PUMP), 3W-7(bypass), 3W-8(bypass), 3W-9(bypass), 3W10(bypass), 2W-5(H2O) [Note, bypass means that the valve stems points along arrowed line on panel.]

c. Effluent container: 3W-11(SPENT REGEN)

COLUMN CONTROL PANEL

d. 3W-1(FROM PUMP)

e. Single Column 1: 3W-2(LEAD 1), 3W-3(OFF), 3W-4(OFF)

f. Effluent column: 3W-5(FROM COL \#1)

g. Sample ports: $2 \mathrm{~W}-3(\mathrm{OFF}), 2 \mathrm{~W}-4(\mathrm{OFF})$

3. On top of the 10-liter SPENT REGENERATION SOLUTIONS bottle place the $25 \mathrm{~mL}$ graduated cylinder under the spigot and open the valve to point upwards

4. Run $\mathrm{H} 2 \mathrm{O}$ for 1 hour and 45 minutes.

5. Immediately after step 4 let the system run another 5 minutes to flush simulant for internal tubes with the following steps:

a. Place a catch bottle in the sampling rack under COL\#2 SAMPLE port 2W-4.

b. Open valve $2 \mathrm{~W}-4$.

c. Open valve $3 \mathrm{~W}-3$ towards LEAD 1

d. Open valve $3 \mathrm{~W}-4$ towards LEAD 2

e. Liquid will be exiting the opened sample port and allow to drip for approximately 3 to 5 minutes.

f. After the wait period close sampling valve $2 \mathrm{~W}-4$.

g. Set valves $3 \mathrm{~W}-3$ and $3 \mathrm{~W}-4$ to OFF.

6. Now the pre-elution rinse is complete. Stop Pump 1 and shut the effluent valve on top of the 10-liter SPENT REGENERATION SOLUTIONS bottle by turning the valve stem to the horizontal position.

7. Document the finish time on the data sheet and in the notebook.

8. Repeat step 1.

\section{End of Cycle $2 a$ initial $\mathrm{H} 2 \mathrm{O}$ rinse of Column 1}




\section{Cycle 2a Elution of Column 1}

[Note: Elution is done for approximately 25 hours but samples will only be taken during normal working hours. Elution is done with $0.5 \mathrm{M}$ Nitric Acid]

1. Start at 7:30 am Wednesday.

2. Have ready the Ten (10) sample bottles as listed on the data sheet (App. E). There are Eight (8) today and Two (2) tomorrow.

3. Turn on power to the temperature readouts. Document temperature and resin height of Column 1 in notebook.

4. Take the wand out of the $0.5 \mathrm{M}$ NITRI ACID bottle and measure its weight and note the amount on the data sheet and in the notebook. Then return the bottle and replace the wand until it hits the bottom of the container.

5. Set the test rig valves according to Valve Table (App. C):

PUMP FEED PANEL

a. Pump 1: 2W-1(OFF), Pump 2: 2W-2(ON)

b. Feed: 3W-6(TO PUMP), 3W-7(bypass), 3W-8(bypass), 3W-9(.5 ACID), $3 \mathrm{~W}-10(\mathrm{OFF}), 2 \mathrm{~W}-5(\mathrm{OFF})$ [Note, bypass means that the valve stems points along arrowed line on panel.]

c. Effluent container: 3W-11(SPENT REGEN)

COLUMN CONTROL PANEL

d. 3W-1(FROM PUMP)

e. Single Column 1: 3W-2(LEAD 1), 3W-3(OFF), 3W-4(OFF)

f. Effluent column: 3W-5(FROM COL \#1)

g. Sample ports: 2W-3(OFF), 2W-4(OFF)

6. Continue adjusting the transformer to maintain $25^{\circ} \mathrm{C}$.

[Note: If the temperatures of the columns are above $30^{\circ} \mathrm{C}$ informed one of the PIs.

The acceptable operational range is $23^{\circ} \mathrm{C}$ to $27^{\circ} \mathrm{C}$ but small variations outside this range for short periods (an hour or two) can be tolerated.]

7. On top of the 10-liter SPENT REGENERATION SOLUTIONS bottle place the $25 \mathrm{~mL}$ graduated cylinder under the spigot and open the valve to point upwards

8. At 8:00 am turn on Pump 2 (1.4 BV/HR) and note on the data sheet the exact time. Also document the time in the notebook. Elution of Column 1 will run about 25 hours until the last sample collection is finished at about 9:00 am the next day.

9. Once flow has been established, as noted by liquid exiting the spigot, then turn the valve downwards so that effluent enters the 10-liter SPENT REGENERATION SOLUTIONS bottle.

10. At approximately 08:50 am get ready to take the first sample. Take samples ever hour until 4:00 pm on this day and two final samples on the following day at 8: am and $9 \mathrm{am}$.

11. Follow Appendix $\mathrm{H}$ to take each sample from COL\#1 SAMPLE port $2 \mathrm{~W}-3$.

12. After the 9:00-am sample, on the following day, Cycle 2a elution is complete therefore without turning off Pump 2 go to the next chapter, Chapter 20, to complete the cycle with post-elution rinse.

13. Repeat Step 4. (Note: Do this after starting the post-elution rinse in Chapter 20.)

\section{End of Cycle 2a elution with 0.5 M Nitric Acid of Column 1}




\section{Cycle 2a final rinse of Column 1}

[Notes: Start this rinse immediately after elution ends. Rinse is done with deionized H2O. There are no samples taken during this chapter.]

1. Switch from acid to water at around 9:15 am [Do not turn off pump.]

2. Document temperature and resin height of Columns 1 in notebook.

3. Take the wand out of the $\mathrm{H} 2 \mathrm{O}$ bottle and measure its weight and note the amount on the data sheet and in the notebook. Then return the bottle and replace the wand until it hits the bottom of the container. [Actually, to not hold up the start of the rinse process the weighing should be done while the elution is in progress.]

4. Set the test rig valves according to Valve Table (App. C): PUMP FEED PANEL

a. Pump 1: 2W-1(OFF), Pump 2: 2W-2(ON)

b. Feed: 3W-6(TO PUMP), 3W-7(bypass), 3W-8(bypass), 3W-9(bypass), 3W10(bypass), 2W-5(H2O) [Note, bypass means that the valve stems points along arrowed line on panel.]

c. Effluent container: 3W-11(SPENT REGEN) COLUMN CONTROL PANEL

d. 3W-1(FROM PUMP)

e. Single Column 1: 3W-2(LEAD 1), 3W-3(OFF), 3W-4(OFF)

f. Effluent column: 3W-5(FROM COL \#1)

g. Sample ports: $2 \mathrm{~W}-3(\mathrm{OFF}), 2 \mathrm{~W}-4(\mathrm{OFF})$

5. Continue adjusting the transformer to maintain $25^{\circ} \mathrm{C}$.

[Note: If the temperatures of the columns are above $30^{\circ} \mathrm{C}$ informed one of the PIs. The acceptable operational range is $23^{\circ} \mathrm{C}$ to $27^{\circ} \mathrm{C}$ but small variations outside this range for short periods (an hour or two) can be tolerated.]

6. On top of the 10-liter SPENT REGENERATION SOLUTIONS bottle place the $25 \mathrm{~mL}$ graduated cylinder under the spigot and open the valve to point upwards

7. Note on the data sheet the exact time. Also document the time in the notebook. Post-elution rinse of Column 1 will run about three hours and 30 minutes.

8. Once flow has been established, as noted by liquid exiting the spigot, then turn the valve downwards so that effluent enters the 10-liter SPENT REGENERATION SOLUTIONS bottle.

9. At 11:45 pm Cycle 2a is complete. Stop Pump 2 and shut the effluent valve on top of the 10-liter SPENT REGENERATION SOLUTIONS bottle by turning the valve stem to the horizontal position.

10. Document the finish time on the data sheet and in the notebook.

11. Repeat step 3.

End of Cycle 2a final rinse of Column 1, Cycle 2a, and the SCIX test 


\section{A. Sketch of Test System}

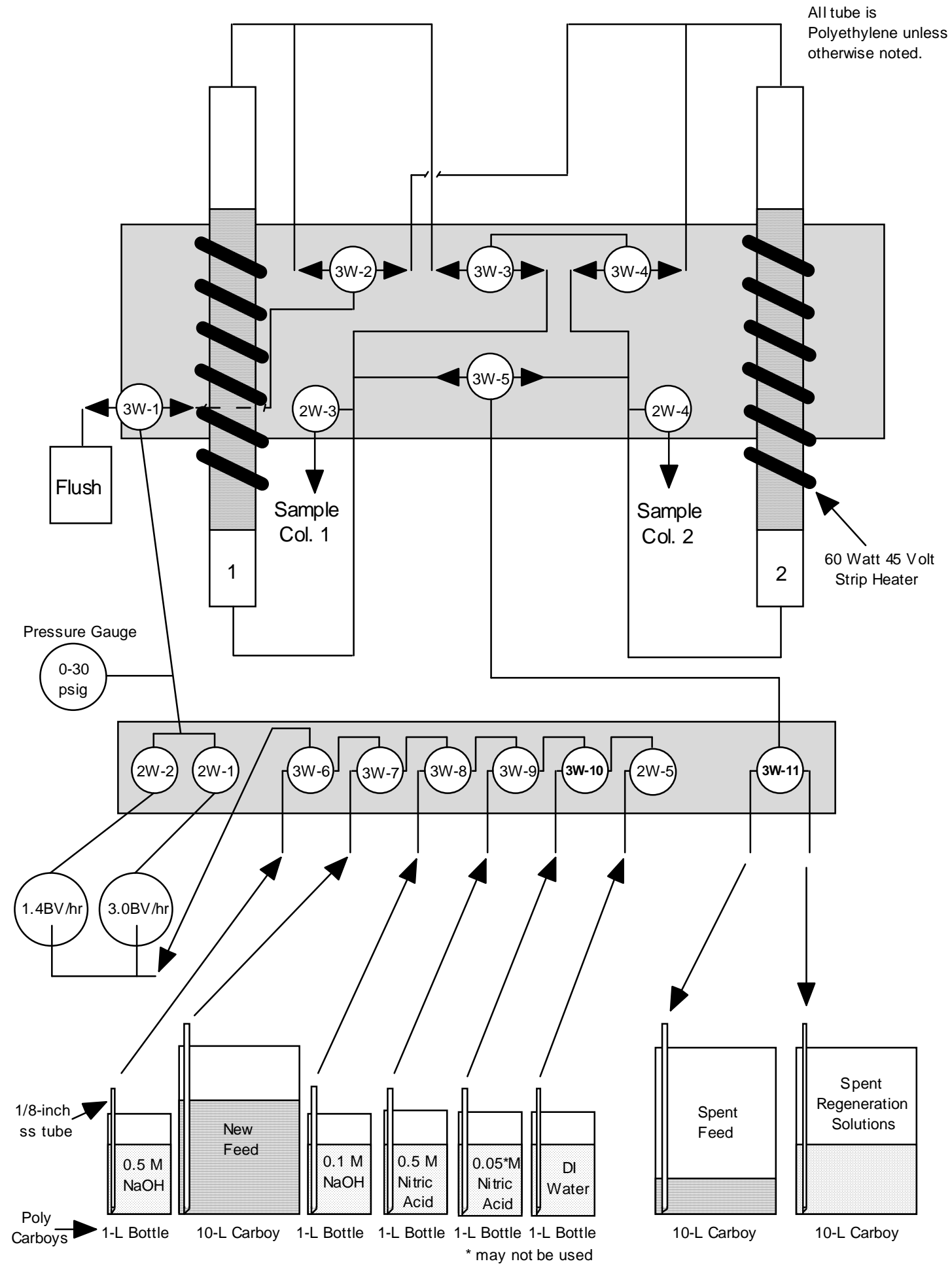




\section{B. Pictures of Test System Control Panels}

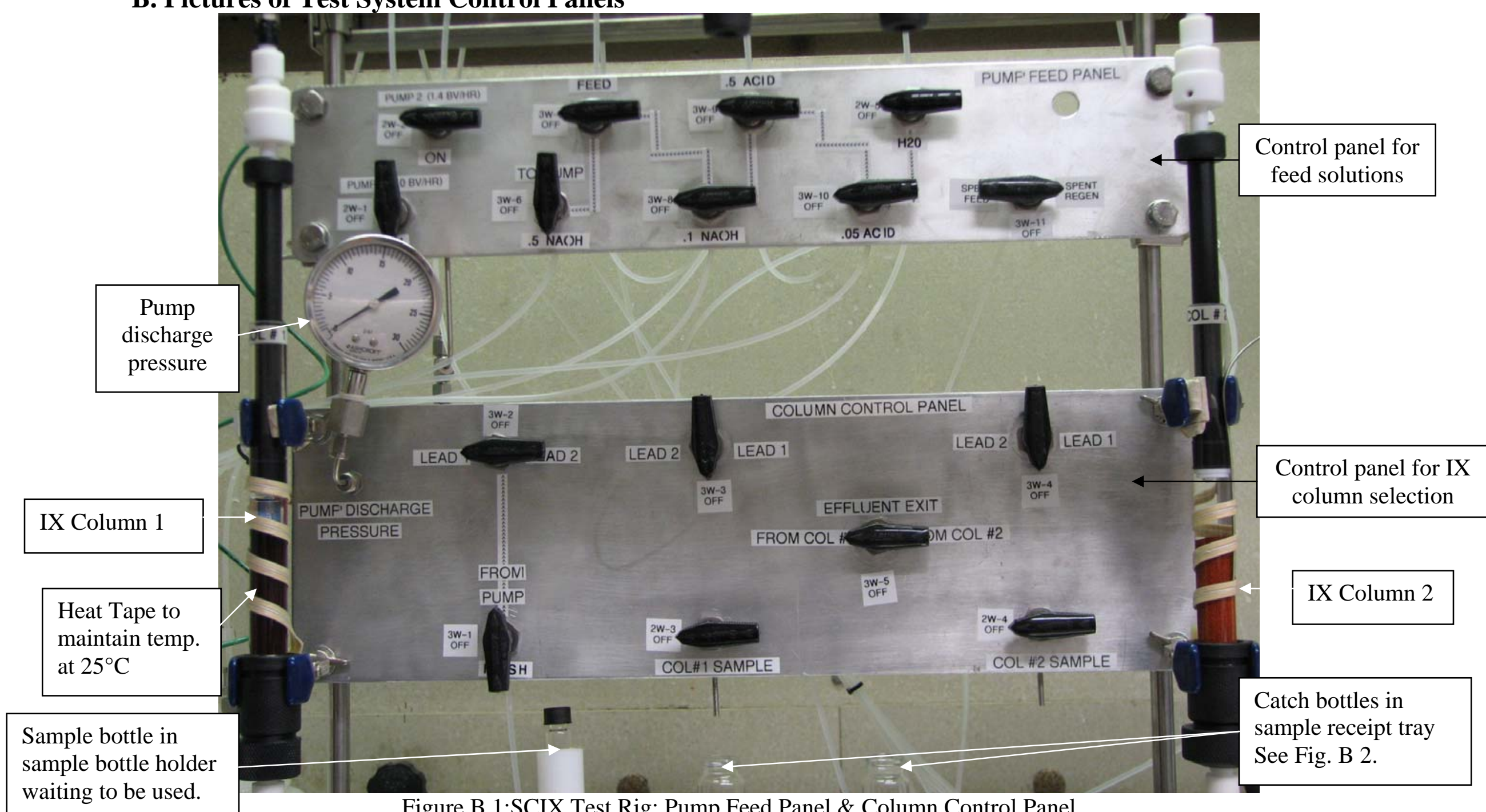

Figure B 1:SCIX Test Rig: Pump Feed Panel \& Column Control Panel 


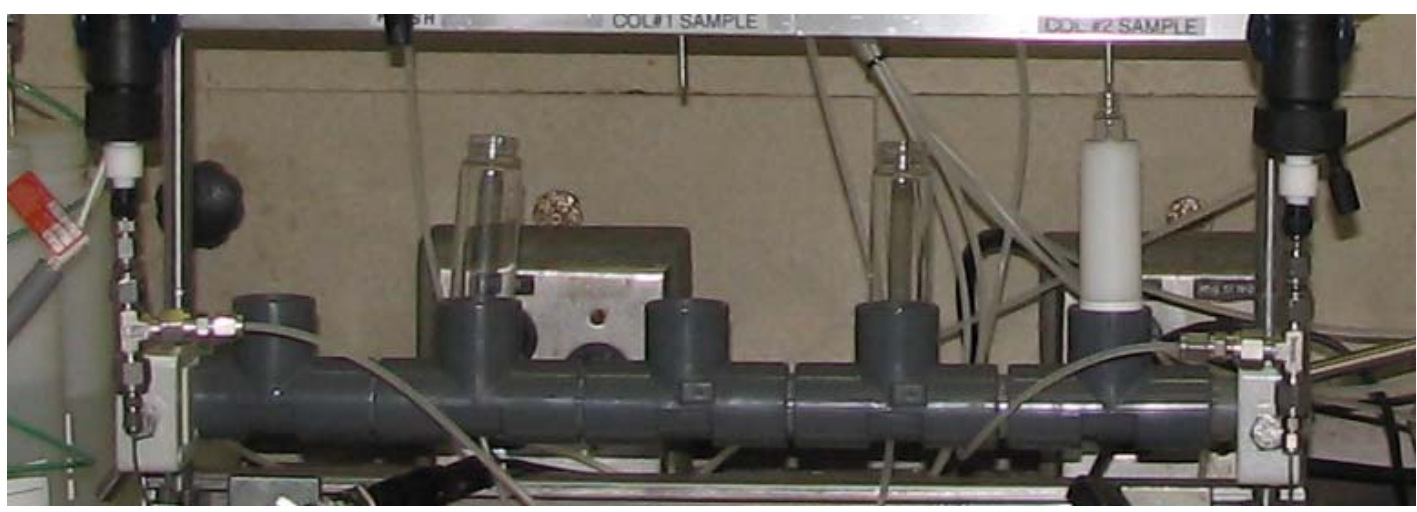

Figure B2. Sample Holding Rack

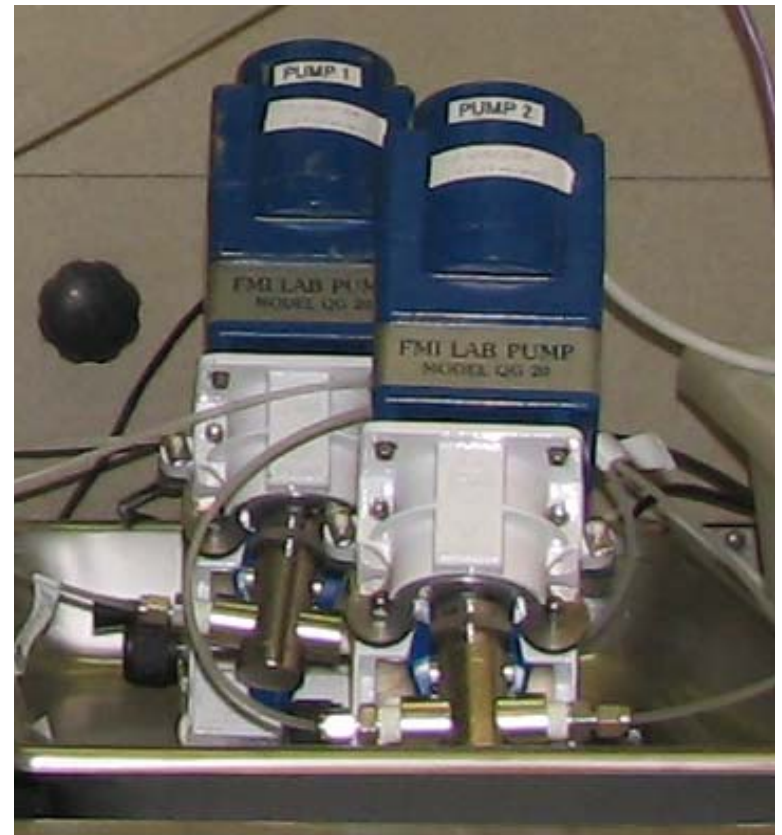

Figure B3. Pump 1 (1.4 BV/HR and Pump 2 (3.0 BV/HR)

Page 107 of 131 
SRNL-STI-2009-00594, REVISION 0

\section{Table of Valve Settings}

\begin{tabular}{|c|c|c|c|c|c|c|c|c|}
\hline \multicolumn{9}{|c|}{ SCIX Valve Positioning (as of 06/20/2009) } \\
\hline Selection & Valve No. & Regeneration & Feed & Displace & Pre-Elution DIW & Flush Simulant & Elution & Post-Elution DIW \\
\hline \multicolumn{9}{|c|}{ Cycle 1: Column 1 as Lead and Column 2 as Lag (or Regenerating Column 1) } \\
\hline From Pump To Columns or Flush & $3 \mathrm{~W}-1$ & FROM PUMP & FROM PUMP & FROM PUMP & FROM PUMP & FROM PUMP & FROM PUMP & FROM PUMP \\
\hline From Pump to Column 1 or 2 & $3 \mathrm{~W}-2$ & LEAD 1 & LEAD 1 & LEAD 1 & LEAD 1 & LEAD 1 & LEAD 1 & LEAD 1 \\
\hline From Col. 1 to $3 \mathrm{~W}-4$ or from $3 \mathrm{~W}-4$ to Col. 1 & $3 \mathrm{~W}-3$ & OFF & LEAD 1 & OFF & OFF & LEAD 1 & OFF & OFF \\
\hline From Col. 2 to $3 \mathrm{~W}-3$ or from $3 \mathrm{~W}-3$ to Col. 2 & $3 \mathrm{~W}-4$ & OFF & LEAD 1 & OFF & OFF & LEAD 2 & OFF & OFF \\
\hline Effluent Exit: From Column 1 or 2 & $3 \mathrm{~W}-5$ & FROM COL 1 & FROM COL 2 & FROM COL 1 & FROM COL 1 & OFF & FROM COL 1 & FROM COL 1 \\
\hline Pump No. $1 @ 3.0$ BV/hr & $2 \mathrm{~W}-1$ & $\mathrm{ON}$ & OFF & $\mathrm{ON}$ & $\mathrm{ON}$ & $\mathrm{ON}$ & OFF & OFF \\
\hline Pump No. $2 @ 1.4$ BV/hr & $2 \mathrm{~W}-2$ & OFF & $\mathrm{ON}$ & OFF & OFF & OFF & ON & $\mathrm{ON}$ \\
\hline Sample from Column 1 & $2 \mathrm{~W}-3$ & as needed & as needed & as needed & as needed & CLOSED & as needed & as needed \\
\hline Sample from Column 2 & $2 W-4$ & not used & as needed & not used & not used & OPEN & not used & not used \\
\hline \multicolumn{9}{|c|}{ Cycle 2: Column 2 as Lead and Column 1 as Lag (or Regenerating Column 2) } \\
\hline From Pump To Columns or Flush & $3 \mathrm{~W}-1$ & FROM PUMP & FROM PUMP & $\overline{F R O M ~ P U M P ~}$ & FROM PUMP & FROM PUMP & $\overline{F R O M ~ P U M P ~}$ & $\overline{\text { FROM PUMP }}$ \\
\hline From Pump to Column 1 or 2 & $3 \mathrm{~W}-2$ & LEAD 2 & LEAD 2 & LEAD 2 & LEAD 2 & LEAD 2 & LEAD 2 & LEAD 2 \\
\hline From Col. 1 to $3 W-4$ or from $3 W-4$ to Col. 1 & $3 \mathrm{~W}-3$ & OFF & LEAD 2 & OFF & OFF & LEAD 2 & OFF & OFF \\
\hline From Col. 2 to $3 \mathrm{~W}-3$ or from $3 \mathrm{~W}-3$ to Col. 2 & $3 \mathrm{~W}-4$ & OFF & LEAD 2 & OFF & OFF & LEAD 1 & OFF & OFF \\
\hline Effluent Exit: From Column 1 or 2 & $3 W-5$ & FROM COL 2 & FROM COL 1 & FROM COL 2 & FROM COL 2 & OFF & FROM COL 2 & FROM COL 2 \\
\hline Pump No. 1 @ 3.0 BV/hr & $2 \mathrm{~W}-1$ & ON & \begin{tabular}{|c|} 
OFF \\
\end{tabular} & $\mathrm{ON}$ & $\mathrm{ON}$ & ON & OFF & OFF \\
\hline Pump No. $2 @ 1.4$ BV/hr & $2 \mathrm{~W}-2$ & OFF & $\mathrm{ON}$ & OFF & OFF & OFF & $\mathrm{ON}$ & ON \\
\hline Sample from Column 1 & $2 \mathrm{~W}-3$ & not used & as needed & not used & not used & OPEN & not used & not used \\
\hline Sample from Column 2 & $2 \mathrm{~W}-4$ & as needed & as needed & as needed & as needed & CLOSED & as needed & as needed \\
\hline \multicolumn{9}{|c|}{ Valve Setting for Five Solutions to Pumps } \\
\hline $0.5 \mathrm{M} \mathrm{NaOH}$ or bypass* & $3 W-6$ & $.5 \mathrm{NAOH}$ & TO PUMP & TO PUMP & TO PUMP & TO PUMP & TO PUMP & TO PUMP \\
\hline Feed, bypass, OFF & $3 \mathrm{~W}-7$ & OFF & FEED & bypass & bypass & bypass & bypass & bypass \\
\hline $0.1 \mathrm{M} \mathrm{NaOH}$, bypass, OFF & $3 \mathrm{~W}-8$ & OFF & OFF & $.1 \mathrm{NAOH}$ & bypass & bypass & bypass & bypass \\
\hline $0.5 \mathrm{M} \mathrm{HNO}$, bypass, OFF & $3 W-9$ & OFF & OFF & OFF & bypass & bypass & $.5 \mathrm{ACID}$ & bypass \\
\hline 0.05 M HNO3, bypass, OFF & $3 \mathrm{~W}-10$ & OFF & OFF & OFF & bypass & bypass & OFF & bypass \\
\hline DI Water or closed & $2 \mathrm{~W}-5$ & OFF & OFF & OFF & $\mathrm{H} 2 \mathrm{O}$ & $\mathrm{H} 2 \mathrm{O}$ & OFF & $\mathrm{H} 2 \mathrm{O}$ \\
\hline Effluent - Spent Feed or Solutions & $3 \mathrm{~W}-11$ & SPENT REGEN & SPENT FEED & SPENT REGEN & SPENT REGEN & SPENT REGEN & SPENT REGEN & SPENT REGEN \\
\hline
\end{tabular}

Page 108 of 131 


\section{Test Matrix}

\begin{tabular}{|c|c|c|c|c|c|c|c|c|c|c|c|c|c|c|}
\hline $\begin{array}{c}\text { (As of 06/13/2009) } \\
\text { Process Cycle Step (Real Waste) }\end{array}$ & $\begin{array}{l}\text { Vol. } \\
\text { BV } \\
\end{array}$ & $\begin{array}{l}\text { Vol. } \\
\mathrm{mL}\end{array}$ & \begin{tabular}{|c|} 
Rate \\
BV $/ \mathrm{hr}$ \\
\end{tabular} & $\begin{array}{r}\text { Rate } \\
\mathrm{mL} / \mathrm{min} \\
\end{array}$ & $\begin{array}{l}\text { Duratio } \\
\text { hours }\end{array}$ & & $\begin{array}{c}\text { Sample } \\
\text { Point }\end{array}$ & \begin{tabular}{|c|} 
Sample \\
Time, $4 \mathrm{~mL}$ \\
min. \\
\end{tabular} & \begin{tabular}{|c|} 
test day 1 \\
Pre-Treat \\
(Start Mon. at 8 am) \\
\end{tabular} & 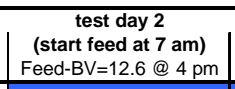 & $\begin{array}{c}\text { test days } 3,8-12,15^{*} \\
\text { Feed-BV }=449.4 @ \text { @ } 4 \text { pm } \\
\text { on test day } 15\end{array}$ & $\begin{array}{c}\text { test day } 16 \text { (Tues.) } \\
\text { Feed-BV=470.4@ } 7 \mathrm{am} \\
\text { Feed-BV=483.0@ } 4 \mathrm{pm} \\
\end{array}$ & \begin{tabular}{|c|} 
test day 17 (Wed.) \\
Pre-Elution \& \\
Elution (start at $8: 30 \mathrm{am}$ ) \\
\end{tabular} & $\begin{array}{l}\text { test day } 18 \text { (Thurs.) } \\
\text { Elution \& } \\
\text { Post-Elution } \\
\end{array}$ \\
\hline Regeneration (0.5 NaOH)-Column 1 & 6 & 63.06 & 3 & 0.53 & 2.0 & 0.1 & After $\mathrm{Col} 1$ & 7.6 & \begin{tabular}{|c|} 
3 samples @ $9,9: 30$, \\
$10 \mathrm{am}$ \\
\end{tabular} & & & & & \\
\hline Regeneration (0.5 NaOH)- Column 2 & 6 & 63.06 & 3 & 0.53 & 2.0 & 0.1 & After Col 2 & 7.6 & $\begin{array}{c}\text { 3 samples @ 11, } \\
\text { 11:30 am, 12:00 pm }\end{array}$ & & & & & \\
\hline $\begin{array}{l}\text { Cycle } 1 \text { - Column } 1 \text { as Lead and Column } 2 \text { as Le } \\
\text { Loading }\end{array}$ & 483 & & & & & & & & & & & & & \\
\hline $\begin{array}{l}\text { Loading } \\
\text { Loading }\end{array}$ & 483 & \begin{tabular}{|l|l}
5006 \\
5076 \\
\end{tabular} & $\frac{1.4}{1.4}$ & 0.25 & $\begin{array}{ll}345.0 \\
345.0 \\
\end{array}$ & $\begin{array}{ll}14.4 \\
14.4 \\
\end{array}$ & \begin{tabular}{|l|l|} 
After Col. 1 \\
After Col. 2 \\
\end{tabular} & $\frac{16.3}{16.3}$ & & \begin{tabular}{|l|}
$4 @ 10 \mathrm{am}, 12,2,4 \mathrm{pm}$ \\
$4 @ 10 \mathrm{am}, 12,2,4 \mathrm{pm}$ \\
\end{tabular} & \begin{tabular}{|l}
18 total, dally@8 a m \& 4 pm \\
18 total, daily $@ 8 \mathrm{am} \& 4 \mathrm{pm}$ \\
\end{tabular} & $\begin{array}{l}10 \text { total, hourly @ } 10 \text { am to } 4 \mathrm{pm} \\
10 \text { total, hourly @ } 7 \mathrm{am} \text { to } 4 \mathrm{pm}\end{array}$ & & \\
\hline $\begin{array}{l}\text { Feed Displacement (0.1 M NaOH) - Column } 1 \\
\text { Pre-elution rinse (DI Water) - Column } 1\end{array}$ & $\begin{array}{l}5 \\
5 \\
\end{array}$ & \begin{tabular}{|l|}
52.55 \\
52.55 \\
\end{tabular} & $\begin{array}{ll}3 \\
3 \\
\end{array}$ & $\begin{array}{ll}0.53 \\
0.53 \\
\end{array}$ & \begin{tabular}{|l|}
1.7 \\
1.7 \\
\end{tabular} & \begin{tabular}{|l|}
0.1 \\
0.1 \\
\end{tabular} & \begin{tabular}{|l|} 
After $\mathrm{Col} 1$ \\
After $\mathrm{Col} 1$ \\
\end{tabular} & $\begin{array}{l}7.6 \\
7.6 \\
\end{array}$ & & & & $3 @ 5,5: 30,6: 15 \mathrm{pm}$ & $3 @ 9,9: 30,10: 15 \mathrm{am}$ & \\
\hline Elution (0.5 M HNO3) - Column 1 & 30 & 315.3 & 1.4 & 0.25 & 21.4 & 0.9 & After Col 1 & 16.3 & & & & & \begin{tabular}{|c|}
$10: 45 \mathrm{pm}$ to $3: 15 \mathrm{pm}:$ \\
$10 @$ Every $1 / 2 \mathrm{hour}$, \\
4:15 pm to $11: 15 \mathrm{pmm}: 8$ \\
$@$ Every 1 hour \\
\end{tabular} & 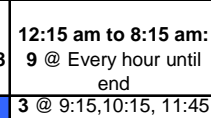 \\
\hline Post-elution rinse (DI Water) - Column 1 & 5 & 52.55 & 1.4 & 0.25 & 3.6 & 0.1 & After Col 1 & 16.3 & & & & & & am -test end \\
\hline & $\begin{aligned} \text { Vol. } \\
\mathrm{BV} \times 1 \\
\end{aligned}$ & $\begin{array}{l}\text { Vol. } \\
\mathrm{mL}\end{array}$ & \begin{tabular}{|c|} 
Rate \\
$\mathrm{BV} / \mathrm{hr}$
\end{tabular} & \begin{tabular}{|c|}
$\begin{array}{c}\text { Rate } \\
\mathrm{mL} / \mathrm{min}\end{array}$ \\
\end{tabular} & \begin{tabular}{|l|l}
$\begin{array}{l}\text { Duratio } \\
\text { hours }\end{array}$ \\
\end{tabular} & $\begin{array}{ll}\text { on in } \\
\text { days }\end{array}$ & $\begin{array}{c}\text { Sample } \\
\text { Point }\end{array}$ & $\begin{array}{c}\text { Sample } \\
\substack{\text { Time, } 4 \mathrm{~mL} \\
\text { min. }} \\
\end{array}$ & \begin{tabular}{|c|} 
Test day 19 \\
Regeneration \\
(Start Mon. at 8 am) \\
\end{tabular} & 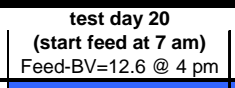 & $\begin{array}{l}\text { test days } 21-23,26-28^{*} \\
\text { Feed-BV }=281.4 @ @ 4 \text { pm } \\
\text { on test day } 28\end{array}$ & $\begin{array}{l}\text { test day } 29 \text { (Thurs.) } \\
\text { Feed-BV=302.4@ } 7 \mathrm{am} \\
\text { Feed-BVV=315@ } 4 \text { pm } \\
\end{array}$ & \begin{tabular}{|c|} 
Test day 30 (Mon.) \\
Pre-Elutiton \& \\
Elution (start at 8:30 am) \\
\end{tabular} & $\begin{array}{l}\text { test day } 31 \text { (Tues.) } \\
\text { Elution \& } \\
\text { Post-Elution }\end{array}$ \\
\hline Regeneration $(0.5 \mathrm{NaOH})$ - Column 1 & 6 & 63.06 & 3 & 0.53 & 2.0 & 0.1 & After Col 1 & 7.6 & $\begin{array}{c}3 \text { samples @ 9, 9:30, } \\
10 \mathrm{am}\end{array}$ & & & & & \\
\hline Cycle 2 - Column 2 as Lead and Column 1 as Le & & & & & & & & & & & & & & \\
\hline $\begin{array}{l}\text { Loading } \\
\text { Loading }\end{array}$ & \begin{tabular}{|l|l}
315 \\
315 \\
\end{tabular} & \begin{tabular}{|l|l|}
3311 \\
3311 \\
\end{tabular} & $\begin{array}{ll}1.4 \\
1.4 \\
\end{array}$ & 0.25 & $\begin{array}{ll}225.0 \\
225.0 \\
\end{array}$ & \begin{tabular}{|l|}
9.4 \\
9.4 \\
\end{tabular} & \begin{tabular}{|l} 
After Col. 2 \\
After Col. 1 \\
\end{tabular} & $\begin{array}{l}16.3 \\
16.3 \\
\end{array}$ & & \begin{tabular}{|l|}
$4 @ 11 a \mathrm{am}, 1,3,5 \mathrm{pm}$ \\
$4 @ 11 \mathrm{am}, 1,3,5 \mathrm{pm}$ \\
\end{tabular} & \begin{tabular}{|l}
12 total, dally@8 a m \& 4 pm \\
12 total, daily@8 am \& pm \\
\end{tabular} & $\begin{array}{l}10 \text { total, hourly@ } 1 \mathrm{am} \text { to } 4 \mathrm{pm} \\
10 \text { total, hourly } 97 \mathrm{am} \text { to } 4 \mathrm{pm}\end{array}$ & & \\
\hline $\begin{array}{l}\text { Feed Displacement (0.1 M NaOH) - Column } 2 \\
\text { Pre-elution rinse (DI Water) - Column } 2\end{array}$ & $\begin{array}{l}5 \\
5 \\
\end{array}$ & \begin{tabular}{|c|c|}
52.55 \\
52.55 \\
\end{tabular} & $\begin{array}{ll}3 \\
3\end{array}$ & $\begin{array}{ll}0.53 \\
0.53 \\
\end{array}$ & $\begin{array}{ll}1.7 \\
1.7 \\
\end{array}$ & \begin{tabular}{|l|}
0.1 \\
0.1 \\
\end{tabular} & \begin{tabular}{|l} 
After $\mathrm{Col} 2$ \\
After $\mathrm{Col} 2$ \\
\end{tabular} & $\begin{array}{l}7.6 \\
7.6 \\
\end{array}$ & & & & $3 @ 5,5: 30,6: 15 \mathrm{pm}$ & $3 @ 9,9: 30,10: 15 \mathrm{am}$ & \\
\hline Elution (0.5 M HNO3) - Column 2 & 30 & 315.3 & 1.4 & 0.25 & 21.4 & 0.9 & After $\mathrm{Col} 2$ & 16.3 & & & & & \begin{tabular}{|c|}
$10: 45 \mathrm{pm}$ to $3: 15 \mathrm{pm}:$ \\
10 @ Every 1/2 hour, \\
4:15 pm to 11:15 pm: 8 \\
$@$ Every 1 hour \\
\end{tabular} & 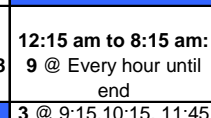 \\
\hline Post-elution rinse (DI Water) - Column 2 & & 52.55 & 1.4 & 0.25 & 3.6 & 0.1 & After $\mathrm{Col} 2$ & 16.3 & & & & & & $\begin{array}{c}3 \text { @ 9:15,10:15, 11:45 } \\
\text { am -test end }\end{array}$ \\
\hline & & & & & & & & & & & & & samples at 08:30 am and & id 11:30 am \\
\hline $\begin{array}{l}\text { 1. BV }=10.51 \mathrm{~mL} \\
\text { 2. Sample size } \sim 4 \mathrm{~mL} \text { (to the shoulder it is closer } \\
\text { 3. For the Cycle } 1 \text { test there are a total of: } 32 \text { lead } \\
\text { also } 6 \text { samples from regeneration before Cycle } \\
\text { 4. Feed samples only taken at start and end of ea } \\
\text { 5. All sample are taken manually. } \\
\text { 5. Loading begins on a Tuesday morning at appro }\end{array}$ & h & & $\begin{array}{l}\text { Cycle 2. T } \\
\text { ast day. F }\end{array}$ & $\begin{array}{l}\text { There a } \\
\text { First da }\end{array}$ & feeds & of 1 & $\begin{array}{l}\text { samples } \\
\text { egins aft }\end{array}$ & 3 hours of & $\begin{array}{l}26 \text { lead and } 26 \mathrm{lag} \\
\text { eration. }\end{array}$ & d samples, as well as & displacement, 3 pre & elution, and 3 post-elution se & for each cycle. Ther & \\
\hline
\end{tabular}

Page 109 of 131 
SRNL-STI-2009-00594, REVISION 0

\section{E. Data Sheets}

\begin{tabular}{|c|c|c|c|c|c|c|c|}
\hline & & & & Cycle 1 & Testing with SF & RS Waste & as of $6 / 13 / 2009$ \\
\hline Date & Sample & Sample Point & Sample Time & Actual Time & Col1 / Col2 T $\left({ }^{\circ} \mathrm{C}\right)$ & Col H (mm) & Sample Indentifier \\
\hline Regenerati & on with c & $.5 \mathrm{M} \mathrm{NaOH}$ & & & & & \\
\hline Weight of re & servoir a & START of proces & s: $\quad$ time $>$ & & & $<$ grams & \\
\hline $6 / 29 / 2009$ & 1 & col1 & 9:00 AM & & & & rad-1-c1-regen-col1-3 \\
\hline $6 / 29 / 2009$ & 2 & col1 & 9:30 AM & & & & rad-2-c1-regen-col1-5 \\
\hline $6 / 29 / 2009$ & 3 & col1 & $10: 00 \mathrm{AM}$ & & & & rad-3-c1-regen-col1-6 \\
\hline $6 / 29 / 2009$ & 4 & col2 & $11: 00 \mathrm{AM}$ & & & & rad-4-c1-regen-col2-3 \\
\hline $6 / 29 / 2009$ & 5 & col2 & $11: 30 \mathrm{AM}$ & & & & rad-5-c1-regen-col2-5 \\
\hline $6 / 29 / 2009$ & 6 & col2 & 12:00 PM & & & & rad-6-c1-regen-col2-6 \\
\hline Weight of re & servoir a & tEND of process: & time $>$ & & & $<$ grams & \\
\hline Waste Feed & ling - Le & ad Column & & & & & \\
\hline Weight of re & servoir a & START of proces & time $>$ & & & $<$ grams & \\
\hline $6 / 30 / 2009$ & 7 & lead - column 1 & $10: 00 \mathrm{AM}$ & & & & rad-7-c1-load-lead(col1)-4 \\
\hline $6 / 30 / 2009$ & 8 & lead - column 1 & 12:00 PM & & & & rad-8-c1-load-lead(col1)-7 \\
\hline $6 / 30 / 2009$ & 9 & lead - column 1 & 2:00 PM & & & & rad-9-c1-load-lead(col1)-10 \\
\hline $6 / 30 / 2009$ & 10 & lead - column 1 & 4:00 PM & & & & rad-10-c1-load-lead(col1)-13 \\
\hline $7 / 1 / 2009$ & 11 & lead - column 1 & 8:00 AM & & & & rad-11-c1-load-lead(col1)-35 \\
\hline $7 / 1 / 2009$ & 12 & lead - column 1 & 4:00 PM & & & & rad-12-c1-load-lead(col1)-46 \\
\hline $7 / 6 / 2009$ & 13 & lead - column 1 & $8: 00 \mathrm{AM}$ & & & & rad-13-c1-load-lead(col1)-203 \\
\hline $7 / 6 / 2009$ & 14 & lead - column 1 & 4:00 PM & & & & rad-14-c1-load-lead(col1)-214 \\
\hline $7 / 7 / 2009$ & 15 & lead - column 1 & 8:00 AM & & & & rad-15-c1-load-lead(col1)-237 \\
\hline $7 / 7 / 2009$ & 16 & lead - column 1 & 4:00 PM & & & & rad-16-c1-load-lead(col1)-248 \\
\hline $7 / 8 / 2009$ & 17 & lead - column 1 & 8:00 AM & & & & rad-17-c1-load-lead(col1)-270 \\
\hline $7 / 8 / 2009$ & 18 & lead - column 1 & 4:00 PM & & & & rad-18-c1-load-lead(col1)-281 \\
\hline $7 / 9 / 2009$ & 19 & lead - column 1 & 8:00 AM & & & & rad-19-c1-load-lead(col1)-304 \\
\hline $7 / 9 / 2009$ & 20 & lead - column 1 & 4:00 PM & & & & rad-20-c1-load-lead(col1)-315 \\
\hline $7 / 10 / 2009$ & 21 & lead - column 1 & 8:00 AM & & & & rad-21-c1-load-lead(col1)-337 \\
\hline $7 / 10 / 2009$ & 22 & lead - column 1 & 4:00 PM & & & & rad-22-c1-load-lead(col1)-349 \\
\hline $7 / 11 / 2009$ & 23 & lead - column 1 & $8: 30 \mathrm{AM}$ & & & & rad-23-c1-load-lead(col1)-372 \\
\hline $7 / 11 / 2009$ & 24 & lead - column 1 & $11: 30$ AM & & & & rad-24-c1-load-lead(col1)-376 \\
\hline $7 / 12 / 2009$ & 25 & lead - column 1 & $8: 30 \mathrm{AM}$ & & & & rad-25-c1-load-lead(col1)-405 \\
\hline $7 / 12 / 2009$ & 26 & lead - column 1 & $11: 30 \mathrm{AM}$ & & & & rad-26-c1-load-lead(col1)-410 \\
\hline $7 / 13 / 2009$ & 27 & lead - column 1 & $8: 00 \mathrm{AM}$ & & & & rad-27-c1-load-lead(col1)-438 \\
\hline $7 / 13 / 2009$ & 28 & lead - column 1 & 4:00 PM & & & & rad-28-c1-load-lead(col1)-449 \\
\hline $7 / 14 / 2009$ & 29 & lead - column 1 & $7: 00 \mathrm{AM}$ & & & & rad-29-c1-load-lead(col1)-470 \\
\hline $7 / 14 / 2009$ & 30 & lead - column 1 & $8: 00 \mathrm{AM}$ & & & & rad-30-c1-load-lead(col1)-472 \\
\hline $7 / 14 / 2009$ & 31 & lead - column 1 & 9:00 AM & & & & rad-31-c1-load-lead(col1)-473 \\
\hline $7 / 14 / 2009$ & 32 & lead - column 1 & $10: 00$ AM & & & & rad-32-c2-load-lead(col1)-475 \\
\hline $7 / 14 / 2009$ & 33 & lead - column 1 & $11: 00$ AM & & & & rad-33-c3-load-lead(col1)-476 \\
\hline $7 / 14 / 2009$ & 34 & lead - column 1 & 12:00 PM & & & & rad-34-c4-load-lead(col1)-477 \\
\hline $7 / 14 / 2009$ & 35 & lead - column 1 & 1:00 PM & & & & rad-35-c5-load-lead(col1)-479 \\
\hline $7 / 14 / 2009$ & 36 & lead - column 1 & $2: 00 \mathrm{PM}$ & & & & rad-36-c6-load-lead(col1)-480 \\
\hline $7 / 14 / 2009$ & 37 & lead - column 1 & 3:00 PM & & & & rad-37-c7-load-lead(col1)-482 \\
\hline $7 / 14 / 2009$ & 38 & lead - column 1 & 4:00 PM & & & & rad-38-c8-load-lead(col1)-483 \\
\hline & & & & & & & \\
\hline
\end{tabular}


SRNL-STI-2009-00594, REVISION 0

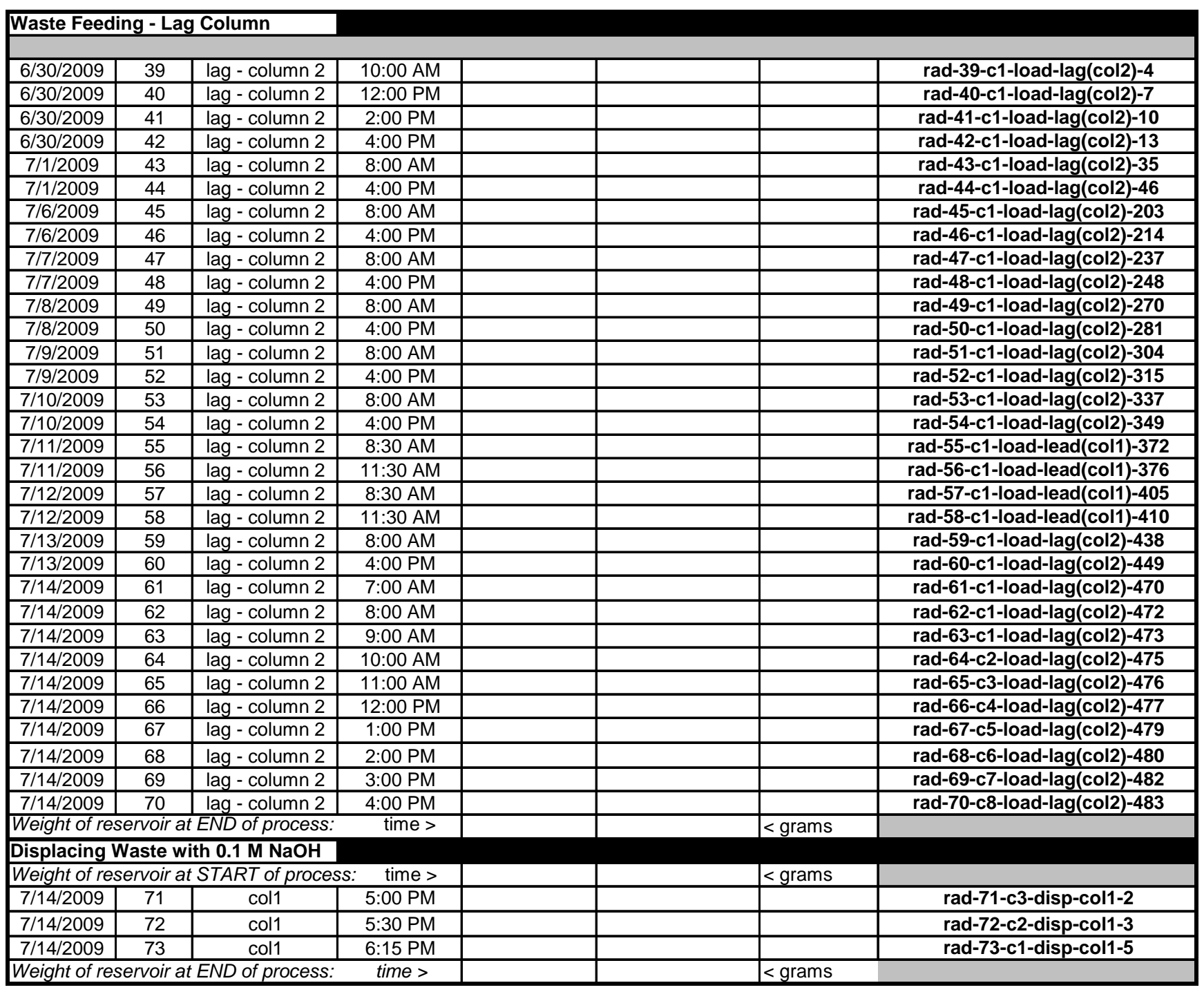


SRNL-STI-2009-00594, REVISION 0

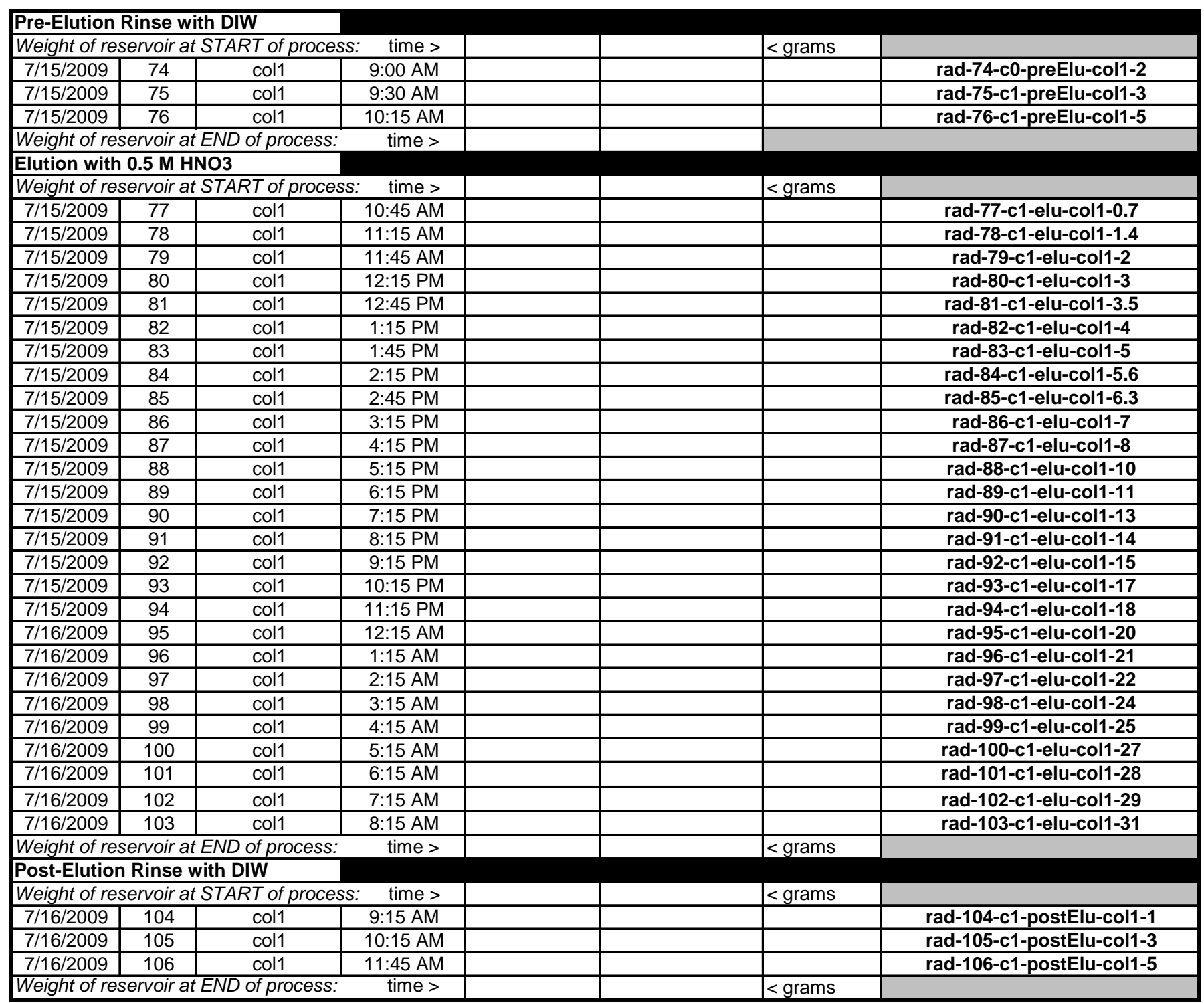


SRNL-STI-2009-00594, REVISION 0

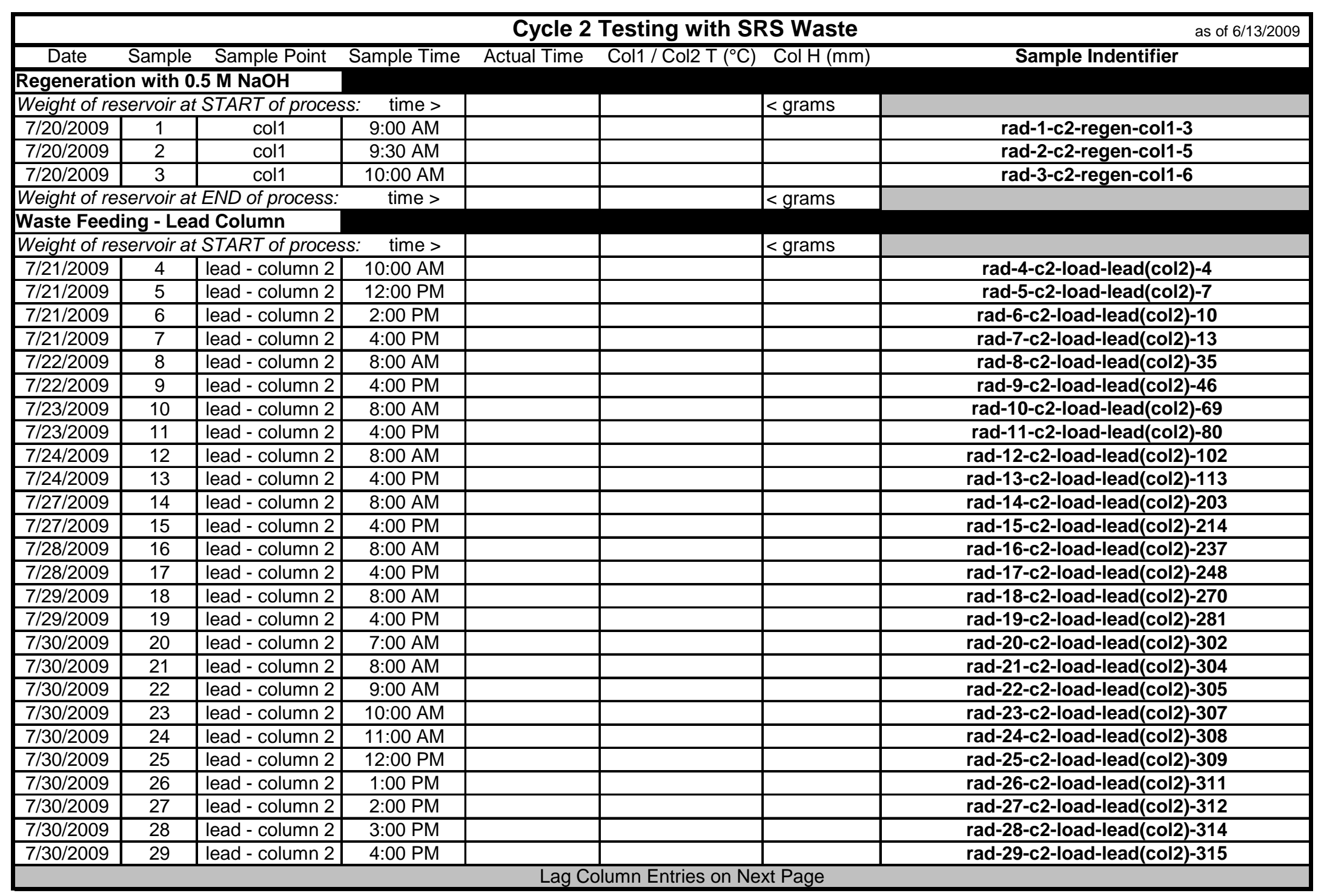

Page 113 of 131 


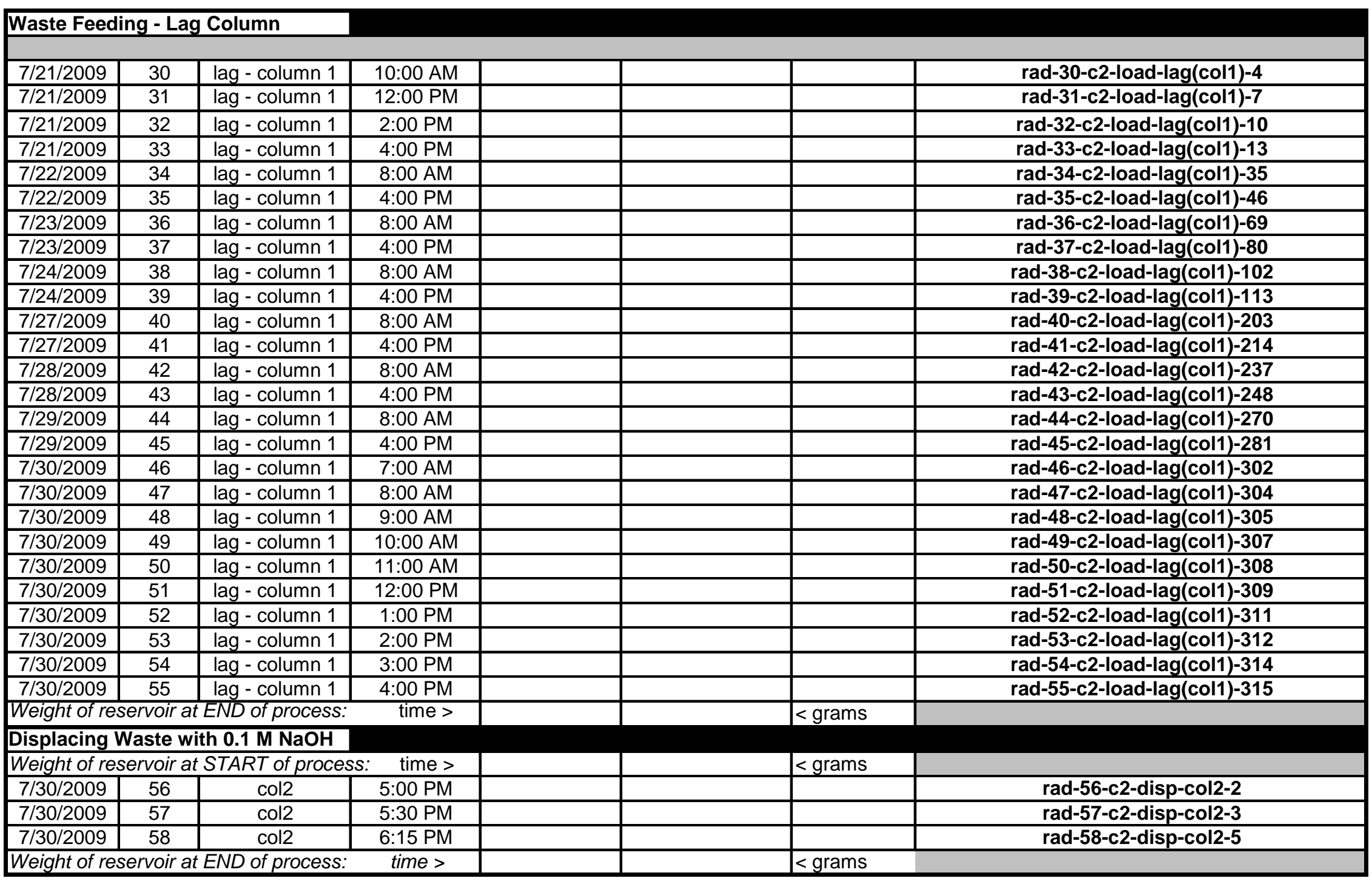

Page 114 of 131 
SRNL-STI-2009-00594, REVISION 0

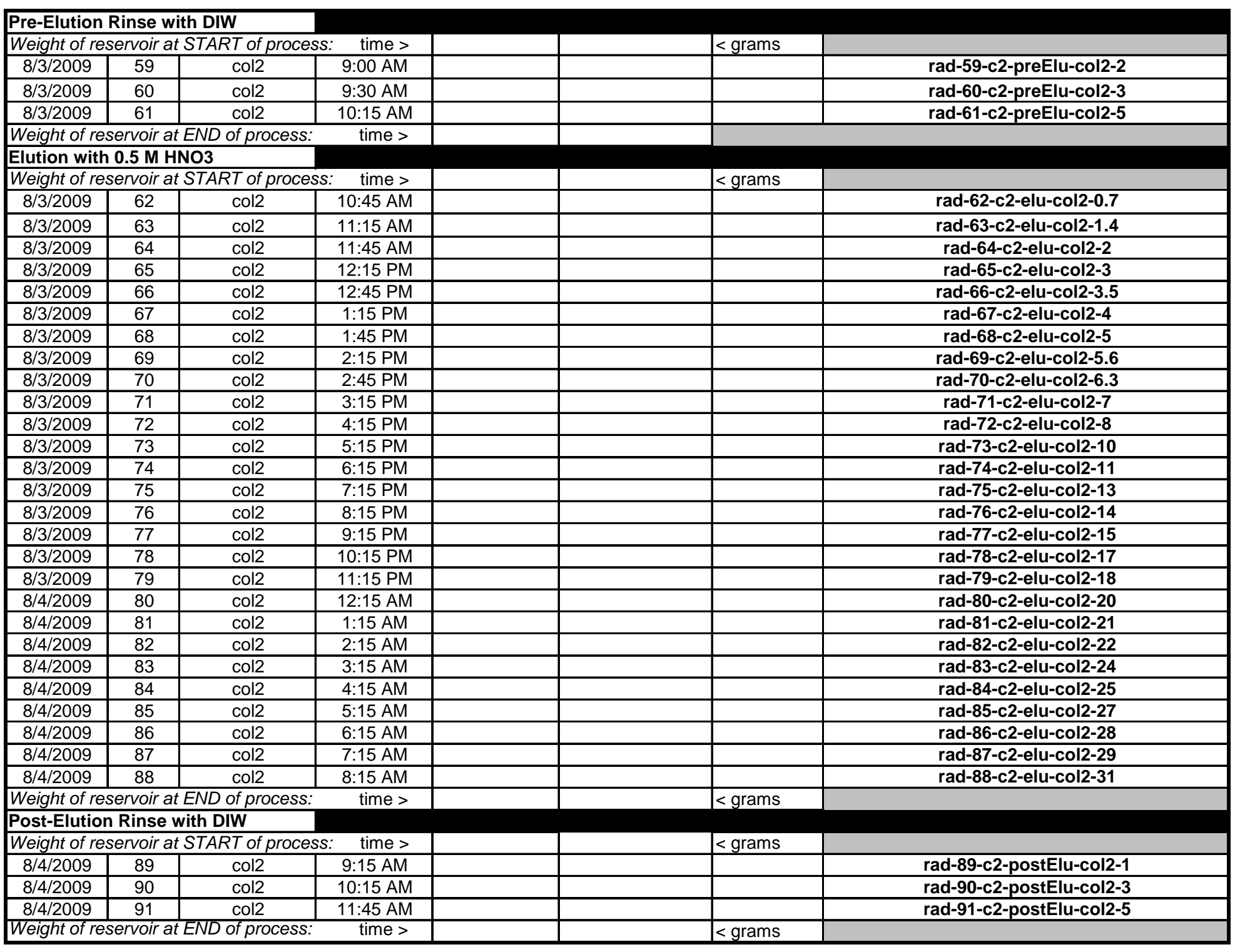

Page 115 of 131 
SRNL-STI-2009-00594, REVISION 0

\begin{tabular}{|c|c|c|c|c|c|c|c|}
\hline \multicolumn{7}{|c|}{ Cycle 2a Eluting Column 1 after Cycle 2} & \multirow{2}{*}{ Sample Indentifier of $6 / 13 / 2009$} \\
\hline Date & Sample & Sample Point & Sample Time & Actual Time & Col1 / Col2 T $\left({ }^{\circ} \mathrm{C}\right)$ & Col H (mm) & \\
\hline \multicolumn{8}{|c|}{ Elution with $0.5 \mathrm{M}$ HNO3 } \\
\hline \multicolumn{7}{|c|}{ Weight of reservoir at START of process: $\quad$ time $>$} & \\
\hline $8 / 5 / 2009$ & 1 & \begin{tabular}{|c|c|} 
col1 & \\
\end{tabular} & 9:00 AM & & & & rad-1-c2a-elu-col1-1 \\
\hline $8 / 5 / 2009$ & 2 & col1 & $10: 00 \mathrm{AM}$ & & & & rad-2-c2a-elu-col1-3 \\
\hline $8 / 5 / 2009$ & 3 & col1 & $11: 00 \mathrm{AM}$ & & & & rad-3-c2a-elu-col1-4 \\
\hline $8 / 5 / 2009$ & 4 & col1 & $12: 00 \mathrm{PM}$ & & & & rad-4-c2a-elu-col1-6 \\
\hline $8 / 5 / 2009$ & 5 & col1 & $1: 00 \mathrm{PM}$ & & & & rad-5-c2a-elu-col1-7 \\
\hline $8 / 5 / 2009$ & 6 & col1 & $2: 00 \mathrm{PM}$ & & & & rad-6-c2a-elu-col1-8 \\
\hline $8 / 5 / 2009$ & 7 & col1 & 3:00 PM & & & & rad-7-c2a-elu-col1-10 \\
\hline $8 / 5 / 2009$ & 8 & col1 & 4:00 PM & & & & rad-8-c2a-elu-col1-11 \\
\hline $8 / 6 / 2009$ & 9 & col1 & 8:00 AM & & & & rad-9-c2a-elu-col1-34 \\
\hline $8 / 6 / 2009$ & 10 & col1 & 9:00 AM & & & & rad-10-c2a-elu-col1-35 \\
\hline \multicolumn{3}{|c|}{ Weight of reservoir at END of process: } & time $>$ & & & $<$ grams & \\
\hline
\end{tabular}




\section{F. Direction on taking Cycle 1 two-column samples}

\section{[Taking a Sample during Two-Column Operation Cycle 1: Column 1 is Lead and Column 2 is Lag}

\section{Perform the following before taking sample:}

1. Check task notebook or data sheet for last Lead \& Lag sample taken. For example: rad-19-c1-load-lead(col1)-304 $<<$ This example is of the $19^{\text {th }}$ sample of Cycle 1 and rad-51-c1-load-lag(col2)-304 $<<$ This example is of the $51^{\text {st }}$ sample of Cycle 1.

2. Find the next Lead \& Lag sample bottles in sample storage rack (e.g., rad-20-... and rad-52-...).

3. Place Lead sample bottle in the sample holder, remove the bottle cap, and place the cap nearby with inside facing up to minimize contamination from the surface.

4. Place the Lag sample bottle near the Column 2 ready to be used.

\section{Perform the following to take Lead sample:}

5. At approximately 30 seconds before taking the Lead sample:

a. Close effluent valve on top of 10 liter carboy marked “Spent Feed,” by turning handle horizontal.

b. Place catch bottle in sample bottle holder below Lead sample port: COL\#1 SAMPLE.

c. Open the sample valve [2W-3] to allow liquid to drip into catch bottle.

6. Allow sample port to drip 6 to 8 drops [about 1 minute].

7. Shut valve sample valve and remove the catch bottle.

8. Place the sample bottle holder with the next sample bottle into rack under the sample port of the column to be sampled.

9. Open the same sample valve $2 \mathrm{~W}-3$ again and make a mental note of time from a nearby clock.

10. Set mechanical timer to approximately 16 minutes (see below*.

11. Note the temperature $\left({ }^{\circ} \mathrm{C}\right)$ and measure the height of resin (millimeters) from the operating column.

12. Enter on the Data Sheet: Starting Time, Column Temperature, AND height of resin.

13. Enter the sample information in the task notebook, including the sample number.

14. When the timer rings get ready to stop sampling by noting the liquid level in the sample bottle.

15. When the liquid reaches the shoulder of the sample bottle shut the sampling valve 2W-3 immediately after a drop has fallen.

16. Remove sample bottle holder with the Lead sample.

\section{Perform the following to take Lag sample:}

17. Place catch bottle in sample bottle holder below Lag sample port: COL\#2 SAMPLE.

18. Open the sample valve $2 \mathrm{~W}-4$ to allow liquid to drip into catch bottle.

Note: The closing of $2 W-3$ and opening of $2 W-4$ in Steps 15 to 18 should be done calmly and safely, but as fast a possible to prevent system pressure to build while flow is stopped because effluent valves are closed. 
19. Allow sample port to drip 6 to 8 drops [about 1 minute].

20. Remove the Lead sample bottle from the sample holder and cap the bottle and place it in the sample storage rack

21. Place the Lag sample bottle in the sample holder.

22. After 8 drops have occurred shut sample valve $2 \mathrm{~W}-4$.

23. Remove catch bottle.

24. Place the sample bottle holder with the Lag sample bottle into rack.

25 . Reopen valve $2 \mathrm{~W}-4$ and make a mental note of time from a nearby clock.

26. Set mechanical timer to approximately 16 minutes (see below*).

27. Note the temperature $\left({ }^{\circ} \mathrm{C}\right.$ ) and measure the height of resin (millimeters) from the operating column.

28. Enter on the Data Sheet: Starting Time, Column Temperature, AND height of resin.

29. Enter the sample information in the task notebook, including the sample number.

30. When the timer rings get ready to stop sampling by noting the liquid level in the sample bottle.

31. When the liquid reaches the shoulder of the sample bottle shut the sampling valve $2 \mathrm{~W}-4$ immediately after a drop has fallen.

32. Immediately open the effluent valve on top of 10-liter Spent Feed bottle by turning handle downwards.

33. Remove sample bottle holder with the Lag sample, cap the sample bottle, and place it in the storage rack.

34. Place the catch bottles back under the sample ports to catch any drips.

\section{End of direction to take Cycle 1 two-column samples}

* If the 16-min. samples taking less than 15 or more that 19 min. perform Chapter 4 \& inform the PI.] 


\section{G. Direction on taking Cycle 2 two-column samples}

\section{[Taking a Sample during Two-Column Operation Cycle 2: Column 2 is Lead and Column 1 is Lag]}

\section{Perform the following before taking sample:}

1. Check task notebook or data sheet for last Lead \& Lag sample taken. For example: rad-19-c1-load-lead(col1)-304 $<<$ This example is of the $19^{\text {th }}$ sample of Cycle 1 and rad-51-c1-load-lag(col2)-304 $<<$ This example is of the $51^{\text {st }}$ sample of Cycle 1.

2. Find the next Lead \& Lag sample bottles in sample storage rack (e.g., rad-20-... and rad-52-...).

3. Place Lead sample bottle in the sample holder, remove the bottle cap, and place the cap nearby with inside facing up to minimize contamination from the surface.

4. Place the Lag sample bottle near the Column 1 ready to be used.

\section{Perform the following to take Lead sample:}

5. At approximately 30 seconds before taking the Lead sample:

a. Close effluent valve on top of 10 liter carboy marked “Spent Feed,” by turning handle horizontal.

b. Place catch bottle in sample bottle holder below Lead sample port: COL\#2 SAMPLE.

c. Open the sample valve [2W-4] to allow liquid to drip into catch bottle.

6. Allow sample port to drip 6 to 8 drops [about 1 minute].

7. Shut valve sample valve remove the catch bottle.

8. Place the sample bottle holder with the next sample bottle into rack under the sample port of the column to be sampled.

9. Open the same sample valve $2 \mathrm{~W}-4$ again and make a mental note of time from a nearby clock.

10. Set mechanical timer to approximately 15 minutes. (see below*)

11. Note the temperature $\left({ }^{\circ} \mathrm{C}\right)$ and measure the height of resin (millimeters) from the operating column.

12. Enter on the Data Sheet: Starting Time, Column Temperature, AND height of resin.

13. Enter the sample information in the task notebook, including the sample number.

14. When the timer rings get ready to stop sampling by noting the liquid level in the sample bottle.

15. When the liquid reaches the shoulder of the sample bottle shut the sampling valve 2W-4 immediately after a drop has fallen.

16. Remove the sample bottle holder with the Lead sample.

\section{Perform the following to take Lag sample:}

17. Place catch bottle in sample bottle holder below Lag sample port:COL\#1 SAMPLE.

18. Open the sample valve $2 \mathrm{~W}-3$ to allow liquid to drip into catch bottle.

Note: The closing of 2W-4 and opening of $2 W-3$ in Steps 15 to 18 should be done calmly and safely, but as fast a possible to prevent system pressure to build while flow is stopped because effluent valves are closed. 
19. Allow sample port to drip 6 to 8 drops [about 1 minute].

20. Remove the Lead sample bottle from the sample holder, cap the bottle, and place it in the sample storage rack.

21. Place the Lag sample bottle in the sample holder.

22. After 8 drops have occurred shut sample valve $2 \mathrm{~W}-3$.

23. Remove catch bottle.

24. Place the sample bottle holder with the Lag sample bottle into rack.

25. Reopen valve $2 \mathrm{~W}-3$ and make a mental note of the time from a nearby clock.

26. Set mechanical timer to approximately 15 minutes (see below*).

27. Note the temperature $\left({ }^{\circ} \mathrm{C}\right)$ and measure the height of resin (millimeters) from the operating column.

28. Enter on the Data Sheet: Starting Time, Column Temperature, AND height of resin.

29. Enter the sample information in the task notebook, including the sample number.

30. When the timer rings get ready to stop sampling by noting the liquid level in the sample bottle

31. When the liquid reaches the shoulder of the sample bottle shut the sampling valve 2W-3 immediately after a drop has fallen.

32. Immediately open the effluent valve on top of 10-liter Spent Feed bottle by turning handle downwards.

33. Remove sample bottle holder with the Lag sample, cap the sample bottle, and place it in the storage rack.

34. Place the catch bottles back under the sample ports to catch any drips.

\section{End of direction to take Cycle 2 two-column samples}

* If the 16-min. samples taking less than 15 or more that 19 min. perform Chapter 4 \& inform the PI.] 
SRNL-STI-2009-00594, REVISION 0

\section{H. Direction on taking single-column samples from Column 1}

\section{Perform the following before taking sample:}

1. Check task notebook or data sheet for last sample taken. For example:

2. rad-80-c2-elu-col2-20 $<<$ This example is of the $80^{\text {th }}$ sample.

3. Find the next sample bottle in sample storage rack (e.g., rad-81-...)

4. Place sample bottle in the sample holder, remove the bottle cap, and place the cap nearby with inside facing up to minimize contamination from the surface.

\section{Perform the following to take sample:}

5. At approximately 30 seconds before taking sample:

a. Close valve on top of 10 liter carboy marked "Spent Regeneration Solutions," by turning handle horizontal.

b. Place catch bottle in sample bottle holder below sample port COL\#1 SAMPLE.

c. Open the sample valve $2 \mathrm{~W}-3$ for Column 1 to allow liquid to drip into catch bottle.

6. Allow sample port to drip 6 to 8 drops [about 1 minute].

7. Shut valve sample valve.

8. Place the sample bottle holder with the next sample bottle into rack under the sample port of valve $2 \mathrm{~W}-3$.

9. Open sample valve $2 \mathrm{~W}-3$ again.

10. Make a mental note of time using nearby clock.

11. Set mechanical timer to approximately the time given below*

12. Note the temperature $\left({ }^{\circ} \mathrm{C}\right)$ and measure the height of resin (millimeters) from the operating column.

13. Enter on the Data Sheet: Starting Time, Column Temperature, AND height of resin.

14. Enter the sample information in the task notebook, including the sample number.

15. When the timer rings get ready to stop sampling by noting the liquid level in the sample bottle.

16. When the liquid reaches the shoulder of the sample bottle shut the sampling valve immediately after a drop has fallen.

17. Open valve on top of 10 liter carboy marked "Spent Regeneration Solutions," by pointing the valve handle DOWN.

18. Remove sample bottle and its holder. Immediate recap the bottle.

19. Place sample bottle back in the storage rack.

20. Place catch bottle in sample holder rack so that it can catch any drips from the port just sampled.

21. Place the catch bottle back under the sample port to catch any drips.

\section{End of direction to take single-column samples from Column 1}

* When Pump 1 is in use (3.0 BV/HR) set the timer at about 7 minutes

When Pump 2 is in use (1.4 BV/HR) set the timer at about 16 minutes.

[7-min. samples taking less than 6 or more that 9 min. perform Chap. 4 \& inform PI]

[16-min. samples taking less than 15 or more that 19 min. perform Chap.4 \& inform PI] 
SRNL-STI-2009-00594, REVISION 0

\section{Direction on taking single-column samples from Column 2}

\section{Perform the following before taking sample:}

1. Check task notebook or data sheet for last sample taken. For example:

2. rad-80-c2-elu-col1-20 $<<$ This example is of the $80^{\text {th }}$ sample.

3. Find the next sample bottle in sample storage rack (e.g., rad-81-...)

4. Place sample bottle in the sample holder, remove the bottle cap, and place the cap nearby with inside facing up to minimize contamination from the surface.

\section{Perform the following to take sample:}

5. At approximately 30 seconds before taking sample:

a. Close valve on top of 10 liter carboy marked "Spent Regeneration Solutions," by turning handle horizontal.

b. Place catch bottle in sample bottle holder below sample port COL\#2 SAMPLE.

c. Open the sample valve $2 \mathrm{~W}-4$ for Column 2 to allow liquid to drip into catch bottle.

6. Allow sample port to drip 6 to 8 drops [about 1 minute].

7. Shut valve sample valve.

8. Place the sample bottle holder with the next sample bottle into rack under the sample port of valve $2 \mathrm{~W}-4$.

9. Open sample valve $2 \mathrm{~W}-4$ again.

10. Make a mental note of time using a nearby clock.

11. Set mechanical timer to approximately the time below*.

12. Note the temperature $\left({ }^{\circ} \mathrm{C}\right)$ and measure the height of resin (millimeters) from the operating column.

13. Enter on the Data Sheet: Starting Time, Column Temperature, AND height of resin.

14. Enter the sample information in the task notebook, including the sample number.

15. When the timer rings get ready to stop sampling by noting the liquid level in the sample bottle.

16. When the liquid reaches the shoulder of the sample bottle shut the sampling valve immediately after a drop has fallen.

17. Open valve on top of 10 liter carboy marked "Spent Regeneration Solutions," by pointing the valve handle DOWN.

18. Remove sample bottle and its holder. Immediate recap the bottle.

19. Place sample bottle back in the storage rack.

20. Place catch bottle under the sample port to catch any drips.

\section{End of direction to take single-column samples from Column2}

* When Pump 1 is in use (3.0 BV/HR) set the timer at about 7 minutes

When Pump 2 is in use (1.4 BV/HR) set the timer at about 16 minutes.

[7-min. samples taking less than 6 or more that 9 min. perform Chap. 4 \& inform PI]

[16-min. samples taking less than 15 or more that 19 min. perform Chap. 4 \& inform PI] 